\title{
IV. Justiz und brauner Terror: das Problem der Verfolgung von Straftaten Angehöriger der Bewegung
}

\section{1. „Nationale Revolution“ und Amnestie \\ a. Sanktionierter Terror und gleichgeschaltete Polizeigewalt}

$\mathrm{Zu}$ den ersten Bekundungen der außernormativen Gewalt, mit der die Justiz auf dem Gebiet der Strafrechtspflege konfrontiert wurde, gehörten die Ausschreitungen der NS-Bewegung bei der Verfolgung ihrer politischen Gegner in der Anfangsphase nach der nationalsozialistischen Machtergreifung. Von entscheidender Bedeutung für die Justiz war hierbei die Haltung der Polizei, auf die sie bei den Ermittlungen ungesetzlicher Handlungen angewiesen war, da sie selbst nicht über eigene Exekutivorgane verfügte. Die Ausübung eines „Terrors von unten“, der mit pseudolegaler „Gleichschaltung von oben“ zur Errichtung und Festigung der Diktatur Hand in Hand ging, hätte sich ohne die Duldung bzw. Förderung durch die anfangs noch den Landesregierungen unterstehenden Polizeiorgane kaum entwickeln können.

Göring, der als kommissarischer Innenminister in Preußen die Verfügung über die Polizei dieses Landes - und damit über den Großteil der deutschen Polizeitruppen gewonnen hatte, setzte ab Februar neue Polizeipräsidenten ein und gab am 17. Februar 1933 den Erlaß zur „Förderung der nationalen Bewegung“1 heraus. Der Erlaß bestimmte, daß „die Polizei auch nur den Anschein einer feindseligen Haltung oder gar den Eindruck einer Verfolgung gegenüber nationalen Verbänden (SA, SS und Stahlhelm) und nationalen Parteien unter allen Umständen zu vermeiden“, vielmehr deren „Betätigung für nationale Zwecke“ zu unterstützen habe. Dagegen sei

„dem Treiben staatsfeindlicher Organisationen mit den schärfsten Mitteln entgegenzutreten ... und, wenn nötig, rücksichtslos von der Waffe Gebrauch zu machen. Polizeibeamte, die in Ausübung dieser Pflichten von der Schußwaffe Gebrauch machen, werden ohne Rücksicht auf die Folgen des Schußwaffengebrauchs von mir gedeckt. Wer hingegen in falscher Rücksichtnahme versagt, hat dienststrafrechtliche Folgen zu gewärtigen ... Jeder Beamte hat sich stets vor Augen zu halten, daß die Unterlassung einer Maßregel schwerer wiegt als begangene Fehler in der Ausübung."

Dieser Erlaß forderte dazu auf, z. B. bei Zusammenstößen - die in dieser Zeit von den nationalsozialistischen Parteitruppen in großer Zahl provoziert wurden - oder bei sonstigen Ungesetzlichkeiten mit zweierlei Maß zu messen; er mußte geradezu polizeiliche Übergriffe gegen Angehörige der nicht-,,nationalen“ Parteien herausfordern, 
da sich der Polizeibeamte dabei von der Führung gedeckt fühlen konnte. Dennoch hätte Görings „Schießerlaß“ bei der Haltung der disziplingewohnten preußischen Polizeibeamtenschaft, bei der die personelle Umbesetzung erst anlief, kaum die erwünschte Wirkung erreicht, wenn er nicht mit einer weit folgenschwereren Maßnahme gekoppelt worden wäre: mit dem "polizeilichen“ Einsatz der SA durch verschiedene der zu Polizeipräsidenten ernannten SA-Führer. Die Verwendung von SA und SS als Hilfspolizei wurde durch Görings Erlaß vom 22. Februar 1933 ausdrücklich sanktioniert. ${ }^{2}$ Danach sollte der Einsatz der Hilfspolizei zwar unter der Führung von Polizeioffizieren erfolgen, er wurde jedoch in der Praxis anders gehandhabt: so wurde z. B. die Hilfspolizei der Berliner SA dem Führer der SA-Gruppe Berlin-Brandenburg unmittelbar unterstellt. Der aufgestaute revolutionäre Elan der SA hatte damit ein Ventil erhalten; die Absicht der Führung, ihn durch die Übertragung staatlich-politischer Verantwortung unter Kontrolle zu bringen ${ }^{3}$, wurde allerdings nur teilweise erreicht. Dem wirkte schon die Verfügung des Stabschefs der SA Ernst Röhm entgegen, „daß der Hilfspolizist in erster Linie SA- und SS-Mann bleibt. Ich ersuche dies allen zur Hilfspolizei abgestellten SA- und SS-Führern ganz nachdrücklich in Erinnerung zu bringen. Bei VerstöBen gegen diesen Befehl ist künftig die sofortige Ablösung der Schuldigen zu verfügen." ${ }^{\text {“4 }}$

Im Gegenteil trat die SA mit ihren neuen Befugnissen meist noch radikaler auf, da jeder Widerstand gegen ihr Vorgehen nun als „Widerstand gegen die Staatsgewalt“ behandelt werden konnte.

Die meisten Länder folgten dem preußischen Vorbild, nachdem in den noch nicht von der NSDAP beherrschten Ländern aufgrund der „Verordnung des Reichspräsidenten zum Schutz von Volk und Staat“ vom 28. Februar 1933 (Reichstagsbrandverordnung) Reichskommissare neben anderen Befugnissen die Polizeigewalt übernommen hatten. ${ }^{5}$ Diese Verordnung schuf vor allem die rechtliche Grundlage für die „Schutzhaft“, d.h. die Verhaftung politischer Gegner durch die Polizei, die sich von den in der Strafprozeßordnung vorgesehenen Haftarten (Haft aufgrund richterlichen

2 Erl. des Preuß. MdI - II C I 59 Nr. 40/33 - an alle RegPräs. pp. mit Durchf.Bestimmungen (Arch. des IfZ, Sign. Fa 152, auch wiedergegeben in der DAZ v. 25.2.33).

3 Vgl. Ber. des Referenten $1 \mathrm{c}$ beim Stab der SA-Gruppe Berlin-Brandenburg v. 18.4.33 über seine Erwiderung gegen die Beschwerden ORRat Diels' von der polit. Polizei: „Der in 12jährigem Kampf gegen Terror und Unterdrückung stehenden SA muß rein menschlich betrachtet ein gewisses Recht eingeräumt werden, Aktionen, die letzten Endes lediglich dem Rechtsempfinden unserer Kameraden entspringen, durchzuführen. “ Da sie durch Befehlsgewalt nicht zu unterdrücken seien, sei es besser, „dadurch, daß die SA zu polizeilichen Charakter tragenden Aktionen als Hilfskräfte zugezogen würde, dem Rechtsempfinden derselben ein Ventil zu schaffen“ (Akten d. preuß. MdI, Geh.StArch. Berlin, Sign. Rep. 77/31). Hitler erklärte in der Reichstagsrede v. 17.5.33 als Zweck der Hilfspolizei, sie sollte, in den kritischen Tagen des Umsturzes dem neuen Regiment zunächst den politisch als unsicher vermuteten Teil der anderen Polizei ersetzen“ (Verhandl. des Reichstags, VIII. Wahlperiode, Stenograph.Ber., Berlin 1934, S.51, Arch. des IfZ, Sign. Da 03.01).

4 Verf. des OSAF Ch.Nr. 1233/33 v. 30.5 .33 (Geh.StArch. München, Sign. Reichsstatthalter 446). Dort heißt es weiter: „Sie sind ebenso wie die Polizeipräsidenten usw. in erster Linie SA-Führer, in zweiter Linie Organe der Staatsverwaltung ... Entscheidend ist nicht, daß täglich ein gleichgeschalteter' Bienenzucht- oder Kegelverein Treueerklärungen beschließt oder daß Straßen der Städte zeitgenössische Namen erhalten; entscheidend ist, daß in den letzten Wochen brave SA-Kameraden von roten und schwarzen Strolchen hingemordet werden konnten. Wir dürfen nicht eher ruhen, bis diese Morde gesühnt und die Voraussetzungen geschaffen sind, daß sie sich nicht wiederholen ... SA und SS haben einen Sieg von kaum erhoffem Ausmaß erkämpft ... Ihre Aufgabe, die nationalsozialistische Revolution zu vollenden und das nationalsozialistische Reich zu schaffen, liegt aber noch vor ihr."

5 RGBI. I, S. 83. § 2 der VO lautete: „Werden in einem Lande die zur Wiederherstellung der öffentlichen Sicherheit und Ordnung nötigen Maßnahmen nicht getroffen, so kann die Reichsregierung insoweit Befugnisse der obersten Landesbehörde vorübergehend wahrnehmen.“ 
Befehls, Untersuchungs- und Strafhaft) sowie von der befristet zulässigen Polizeihaft unterschied und völlig außerhalb der Zuständigkeit der Justiz gehandhabt wurde. ${ }^{6} \mathrm{Ob}-$ wohl in den preußischen Durchführungsbestimmungen ${ }^{7}$ die Befugnis zur Verhängung von Schutzhaft nur den Kreispolizeibehörden zugesprochen wurde, ordneten sowohl in Preußen wie in den anderen Ländern - vor allem in Bayern - SA, SS und örtliche Parteiführer ziemlich selbstherrlich "Schutzhaft" an oder veranlaßten die zuständigen Stellen, Schutzhaftbefehle auszustellen.

In der Atmosphäre des - durch die Reichstagsbrandverordnung geschaffenen Ausnahmezustandes und angeheizt durch aufreizende Reden der Parteiführer ${ }^{8}$, rollte in jenen Wochen und Monaten, während der Wahlkämpfe für die „entscheidende“ Reichstagswahl vom 5. März, vor allem aber danach bei der Gleichschaltung der Länder und der Zerschlagung der Gewerkschaften und der anderen Parteien, eine von SA und SS getragene Terrorwelle9 über Deutschland hinweg. Vor allem in den Großstädten häuften sich Morde und willkürliche Verhaftungen; neben den „staatlich anerkannten“ wurden an mehreren Orten des Reichsgebietes „wilde“ Konzentrationslager errichtet $^{10}$ - in verschiedenen Stadtteilen Berlins „Bunker“ und Prügelstätten der SA in den Kellern ihrer Heime und Sturmlokale sowie das SS-Gefängnis im ColumbiaHaus -, in denen es zu Mißhandlungen und sadistischen Quälereien kam, die vielfach mit dem Tode der Opfer endeten.

Auch die Justizbehörden blieben von derartigen Gewaltakten nicht verschont. So drangen z. B. am 11. März 1933 SA-Trupps in die Gebäude des Breslauer Landgerichts und des Amtsgerichts ein und trieben Richter und Rechtsanwälte jüdischer Abstammung - oder solche, die sie für jüdisch hielten - unter Mißhandlungen auf die Straße, so daß für einige Zeit alle Verhandlungstermine abgesetzt und der „Stillstand der Rechtspflege“ (Justitium) verkündet werden mußte. Nach Berichterstattung durch den Oberlandesgerichtspräsidenten Breslau und den Vorsitzenden der schlesischen Anwaltskammer wandten sich das preußische Justizministerium - noch unter Staatsse-

6 Zur Auseinandersetzung des RJM mit der SS- und Polizeiführung wegen der „Polizeijustiz“ s. Kapitel VI.

7 Preuß. VO betr. die Ergänzung der VO v. 1.Oktober 1931 (GS., S. 213) zur Regelung der Zuständigkeit der Landes- und Kreispolizeibehörden v. 2.3.33 (GS., S.33) und Erl. d. Preuß. MdI v. 3.3.33 (MBliV I, S. 233).

8 Vgl. z. B. Görings Rede in Frankfurt a.M. am 3.3.33: „Volksgenossen, meine Maßnahmen werden nicht angekränkelt sein durch irgendwelche juristischen Bedenken ... Hier habe ich keine Gerechtigkeit zu üben, hier habe ich nur zu vernichten und auszurotten, weiter nichts!... Gewiß, ich werde die staatlichen und die polizeilichen Machtmittel bis zum äußersten auch dazu benutzen, meine Herren Kommunisten ... aber den Todeskampf, in dem ich euch die Faust in den Nacken setze, führe ich mit denen da unten, das sind die Braunhemden!" (Hermann Göring, Reden und Aufsätze, herausg. v. Erich Gritzbach, München 1938, S. 27); auch Frankfurter Zeitung v. 5.3.33, S.4). Ferner Görings Rede in Essen am 10.3.33: „Wenn sie sagen, da und dort sei abgeholt und mißhandelt worden, so kann man nur erwidern: Wo gehobelt wird, fallen Späne. Wir leben in einer außergewöhnlichen Zeit. Wenn wir auch vieles falsch machen, wir werden jedenfalls handeln und die Nerven behalten. Lieber schieße ich ein paarmal zu kurz und zu weit, aber ich schieße wenigstens!“ (Frankfurter Zeitung v. 12.3.33, S.4).

9 Ein geschlossener Úberblick ist kaum möglich, vgl. jedoch K. D. Bracher, W. Sauer, G. Schuiz, Die nationalsozialistische Machtergreifung. Studien zur Errichtung des totalitären Herrschaftssystems in Deutschland 1933/34, Köln u. Opladen 1960, S. 141, 179, 184, 196, 438 ff. u. a. Nach vorsichtiger Schätzung wurden bis Mitte Oktober 1933500 bis 600 Menschen (einschließlich eines geringen Bruchteils von Nationalsozialisten) getötet, a.a.O., S.871; R. Diels, Lucifer ante portas, Stuttgart 1950, S. 222 ff.; symptomatisch der Beschwerdebrief Hugenbergs an Hitler, Frick und Göring v. 12.4.33 wegen des SA-Terrors auch gegen Deutschnationale (Akten d. preuß. MdI, Geh.StArch. Berlin, Sign. Rep. 77/31).

10 Über das frühe Konzentrationslagerwesen vgl. M. Broszat, Nationalsozialistische Konzentrationslager 19331945 (Anatomie des SS-Staates Bd.II, Olten u. Freiburg i. Br. 1965, S.24ff.). In Preußen hatte das preuß. MdI bis Juni 1933 sechs Lager als staatliche Konzentrationslager anerkannt. 
kretär Hölscher"1 - und der Präsident des Deutschen Anwaltvereins Dix an den Reichskommissar für Preußen, Vizekanzler von Papen. Der Vizekanzler unterrichtete telefonisch den in München weilenden Hitler, der daraufhin die Weisung erteilte, diese unmittelbaren Störungen der Rechtspflege zu unterlassen. ${ }^{12}$ Hinsichtlich weiterer Beschwerden von Papens über den wachsenden SA-Terror reagierte Hitler jedoch am 20. März mit einem bezeichnenden Brief, in dem er u. a. ausführte: „Das Urteil der Geschichte wird uns einmal den Vorwurf nicht ersparen, daß wir in einer historischen Stunde, vielleicht selbst schon angekränkelt von der Schwäche und Feigheit unserer bürgerlichen Welt, mit Glacéhandschuhen vorgegangen sind statt mit eiserner Faust.“ Er bat von Papen „auf das eindringlichste, künftighin nicht mehr diese Beschwerden vorbringen $\mathrm{zu}$ wollen. Sie sind nicht berechtigt." ${ }^{13}$

An den zu Bayern gehörenden pfälzischen Gerichten von Kaiserslautern und Zweibrücken kam es am 10. März 1933 zu ganz ähnlichen antisemitisch motivierten Eingriffen in die Rechtspflege. Der Landgerichtspräsident von Kaiserslautern suchte daraufhin mit einem Telegramm bei Reichsstatthalter Ritter von Epp Abhilfe und bat ihn in völliger Verkennung der tatsächlichen Zuständigkeits- und Machtverhältnisse in Bayern „um sofortige entsprechende Weisung an [die] Gauleitung “. ${ }^{14}$ Der Oberlandesgerichtspräsident Zweibrücken protestierte gegenüber den örtlichen NS-Führern, verhandelte mit der pfälzischen Gauleitung und "erreichte nach vielem Hin und Her" den Abzug der uniformierten Trupps aus den Gerichtsgebäuden am Ort und in Kaiserslautern. ${ }^{15}$ In einem Rundschreiben beruhigte der kommissarische bayerische Justizminister Hans Frank die Justizbehörden, daß er , in Úbereinstimmung mit der gesamten kommissarischen Regierung" dieses eigenmächtige Einschreiten der Parteiorgane mißbillige und ersucht habe, „dafür Sorge zu tragen, daß ein solches Vorgehen unterbleibt ${ }^{\text {“ }}{ }^{16} \mathrm{Da}$ aber jene Gesetzlosigkeiten, die nicht unmittelbar den Betrieb der staatlichen Verwaltung und der Justiz störten, von der obersten Führung gedeckt wurden, stand die Justiz den illegalen Terrorhandlungen in dieser ,revolutionären“ Phase - ihr Verhältnis zu der in der gleichen Zeit beginnenden und sich langsam in den

11 Nach dem „Preußenschlag“ v. 20.7.32 hatte Papen den preuß. JM Am Zehnhoff von der Führung der Geschäfte entbunden und den Staatssekretär mit der Geschäftsführung betraut. Der Nationalsozialist Hanns Kerrl wurde erst am 27.3.33 zum Reichskommissar für das preußische JM ernannt.

$12 \mathrm{Zu}$ den Breslauer Vorfällen s. H. Göppinger, Der Nationalsozialismus und die jüdischen Juristen, Villingen 1963, S. 21 f., u. C. Horkenbach, Das Deutsche Reich von 1918 bis heute, Berlin 1935, S. 109. Der Terror hatte seinen Zweck erfüllt: in einem Funkspruch an alle preuß. OLG-Präsidenten u. GStAe (Rundfunkspruch v. 31.3.33, Geh.StArch. Berlin, Rep. 84 a/4542) konnte der neue Justizkommissar Kerrl „die Erregung des Volkes über das anmaßende Auftreten amtierender jüdischer Rechtsanwälte und Richter" zum Anlaß nehmen, anzuordnen, umgehend alle jüdischen Richter und Staatsanwälte zu beurlauben und nur noch eine beschränkte Zahl jüdischer Rechtsanwälte zum Auftreten vor Gericht zuzulassen, die ,im Einvernehmen mit dem Gaurechtsstellenleiter der NSDAP. oder dem Vorsitzenden der Gaugruppe des Bundes n.s.d.J. auszuwählen" waren: ein bezeichnendes Beispiel für das Zusammenwirken des Terrors von unten mit der „Gleichschaltung“ von oben. Zu diesem Vorgriff Kerrls auf die gesetzliche Regelung der Personalpolitik bei der JVerw. s. Kapitel III.1.a., S. $127 \mathrm{f}$.

13 M. Broszat, Der Staat Hitlers, München 1969, S. 110 f., Abschriften des Briefes ließ Hitler an den Reichspräsidenten und an den Reichswehrminister gehen.

14 Akten des bayer. JM (BayHStArch. Abt. II, Sign. MJu 12004).

15 Ber. des OLGPräs. Zweibrücken an das bayer. JM v. 11.3.33 mit Ber. des AGVorst. und LGPräs. Kaiserslautern v. 10.3.33 (a.a.O.). Auch in Bayern wurde der ,in der politischen Neuordnung zum Ausdruck gekommenen Volksmeinung“ durch entsprechende Maßnahmen des kommiss. JM Hans Frank zur Ausschaltung jüdischer Richter, StAe und RAe Rechnung getragen, vgl. Erl. v. 25. u. 31.3.33 (a.a.O.) und Ministerratssitzung v. 7.4.33 (Geh.StArch. München, Sign. MA 99 526).

16 Rdschr. v. 27.3.33, Akten des bayer. JM (BayHStArch. Abt. II, Sign. MJu 12003). 
Vordergrund schiebenden „institutionalisierten“ außergesetzlichen Verfolgung der politischen Gegner durch die Geheime Staatspolizei wird an anderer Stelle behandelt werden ${ }^{17}$ - ziemlich hilflos und unsicher gegenüber. Die unteren Justizbehörden gerieten bei ihrer Absicht, diese politischen Straftaten von Nationalsozialisten pflichtgemäß zu verfolgen, in Schwierigkeiten, weil die örtlichen Parteistellen auf sie Druck ausübten oder die Partei- und SA-Funktionäre, mit denen die Instanzenwege der Polizei und Verwaltung durchsetzt waren, die Anzeigenerstattung an die Staatsanwaltschaft hintertrieben, angelaufene Ermittlungen bald zum Erliegen brachten oder die Verfahrensakten unzulässigerweise einbehielten. Häufig wurde Angehörigen der NSGliederungen von ihren Führern die Aussagegenehmigung verweigert, ihnen das Erscheinen vor Gericht verboten oder Zeugen mit Schutzhaft bedroht. Die Haltung, die der Reichsjustizminister in diesem Dilemma zwischen gesetzlich vorgeschriebener Pflicht und den faktischen politischen Gegebenheiten einnahm, wird in einem Gespräch deutlich, das Gürtner in jener Zeit mit dem Leiter des Geheimen Staatspolizeiamts Diels ${ }^{18}$ führte, der sich über die von den Inhabern der Staatsgewalt gedeckten Gewalttaten seiner „Konkurrenz“ - der SA - besorgt zeigte. Aus diesem Gespräch geht einerseits die Resignation des Juristen Gürtner gegenüber den stärkeren politischen Umständen hervor, andererseits aber auch seine politische Grundeinstellung gegenüber Entwicklungen und Ereignissen, die mit dem Anspruch des "Nationalen“ auftraten. „Revolutionen seien außerrechtliche Ereignisse“, gibt Diels die Ausführungen Gürtners wieder, ,sie verlagern die Gründe des Rechts und suspendieren Gerechtigkeit und Rechtssicherheit.“ Deshalb müsse man „auch in der gegenwärtigen revolutionären Lage den formalen Rechtsstandpunkt hin und wieder verlassen, ohne den Grundsatz aufzugeben. Es gehe allein darum, diesen Zustand sobald als möglich zu beenden." Gürtner berichtete aus seinen Erfahrungen als bayerischer Justizminister, als in der Rheinpfalz

„die Erhebung der nationalen Bevölkerung separatistischen Landesverrätern das Leben gekostet habe. Damals habe sich die Rechtspflege mit Niederschlagungen, Begnadigungen und Amnestien geholfen, ohne den grundsätzlichen Anspruch des Staates auf die Strafverfolgung von Taten aufzugeben, die objektiv Verbrechen gewesen seien, subjektiv aber Handlungen, die den rechtlich [sprich: „national“"] Denkenden eine Bestrafung unbillig erscheinen ließen. ${ }^{.19}$

In der Tat schienen Niederschlagung und Amnestie auch diesmal wieder die einzige Lösung zu sein, um die Justiz aus dem Dilemma zu befreien.

\section{b. Die Straffreibeitsverordnung vom 21.März 1933}

Nachdem es in Königsberg, Breslau und anderen Orten zu Aktionen gekommen war, bei denen die Freilassung von Justizgefangenen gefordert worden war, die sich im

17 S. Anm. 6.

18 Rudolf Diels hatte seit August 1932 die politische Polizeigruppe des preuß. MdI geleitet, wurde von Göring mit der Leitung der politischen Abteilung (IA) im Berliner Polizeiprāsidium betraut, die am 26.4.34 als Gestapa mit der Stellung einer Landespolizeibehörde aus dem Polizeipräsidium ausgegliedert wurde. Diels wurde stellvertretender Leiter des Gestapa unter Göring, der sich die Leitung selbst vorbehielt.

19 R. Diels, Lucifer ante portas, Stuttgart 1950, S. 308 f. Diels legt das Gespräch, in dem er bei Gürtner auch die Bildung einer zentralen Strafverfolgungsbehörde angeregt haben will und dieser ihm daraufhin die in Anm. 39 zu Kapitel IV.2 erwähnte Unterredung mit Kerrl vermittelt haben soll, zeitlich hinter die Tötung des Horst Wessel-Mörders Ali Höhler durch die SA. Höhler wurde aber erst am 20.9.33 ermordet (s. Diensttagebuch des RJM, Bd. 1, Eintr. v. 14.11.34, BA, Sign. R 22/131), als die ZStA längst gegründet worden war. 
Zuge der „nationalen Erhebung“ Straftaten hatten zuschulden kommen lassen ${ }^{20}$, schlug Staatssekretär Hölscher als kommissarischer Leiter des preußischen Justizministeriums am 10. März 1933 im Preußischen Staatsministerium eine Amnestie vor, da „bei der derzeit herrschenden politischen Unruhe eine ruhige Fortführung der Rechtspflege unmöglich sei. Man müsse mit der Störung von Gerichtsverhandlungen und mit der Befreiung von Gefangenen rechnen." Anders als die letzte Amnestie für politische Straftaten vom 20. Dezember $1932^{21}$ müsse die neue Amnestie „auch Verbrechen gegen das Leben und Sprengstoffverbrechen" umfassen. Die Amnestie könne zwar durch eine preußische Notverordnung erlassen werden, besser sei jedoch eine Verordnung des Reichspräsidenten für das ganze Reich. Einen entsprechenden Entwurf hatte Hölscher bereits ausarbeiten lassen. Göring stimmte dem Vorschlag Hölschers zu, und das Kabinett beauftragte ihn, mit dem Reichsjustizministerium deswegen Fühlung zu nehmen. ${ }^{22}$ Noch am selben Tag besprach Hölscher die Frage mit Staatssekretär von Bismarck vom preußischen Innenministerium sowie mit Staatssekretär Schlegelberger und dem Leiter der Strafrechtspflegeabteilung, Ministerialdirektor Schäfer, die zusagten, den Vorschlag im Reichskabinett zur Sprache zu bringen ${ }^{23}$, wo Schlegelberger den seit Anfang März an Mittelohrentzündung erkrankten Gürtner vertrat. Bereits am nächsten Tag wies Göring im Reichskabinett auf die Notwendigkeit einer allgemeinen Amnestie hin; er betonte, daß z.B. auch Leute wie der noch flüchtige Erzberger-Mörder Tillessen in die Amnestie einzubeziehen seien. Reichswehrminister von Blomberg forderte, daß auch schwebende Verfahren niedergeschlagen werden sollten. Das Kabinett beschloß, dem Reichspräsidenten demnächst eine entsprechende Verordnung vorzuschlagen, einen geeigneten Zeitpunkt aber noch abzuwarten. $^{24}$

Da jedoch die Entwicklung in Preußen zu Maßnahmen drängte, wurde Hölscher in der Sitzung des Preußischen Staatsministeriums am 15. März 1933 ermächtigt, von ihm vorgeschlagene Sofortmaßnahmen durchzuführen. Sie fanden ihren Niederschlag in einer Rundverfügung an die preußischen Justizbehörden vom selben Tage und betrafen spezielle Gnadenerweise für Straftaten, die für die „nationale Erhebung“ begangen worden waren: Aufschiebung oder Unterbrechung von Freiheitsstrafen sowie Aufhebung von Untersuchungshaft und anberaumten Terminen. Zur Beruhigung der politischen Szene wurden diese Maßnahmen durch eine Pressenotiz sofort bekanntgemacht. In Sachen von besonderer politischer Bedeutung oder bei besonders schweren

20 In München war es anläßlich der „Machtübernahme“ am 9.3. zu Gefangenenbefreiungen gekommen. Als neu ernannter Justizkommissar verfügte Hans Frank sofort, „daß die in der Nacht vom 9. zum 10. März befreiten Häftlinge der N.S.D.A.P. nicht wieder in die Gefängnisse zurückgebracht werden, da die Würde und der Anstand der deutschen Justiz die Freiheit der Freiheitskämpfer Adolf Hitlers erfordern“ (VB, Süddt. Ausg. v. 11./12.3.33, S.2).

21 Dieses G. über Straffreiheit (RGBl. I, S. 559) betraf Straftaten „aus politischen Beweggründen oder aus Anlaß wirtschaftspolitischer Kämpfe“ sowie „aus wirtschaftlicher Not“, nahm aber gewisse schwere Delikte aus. Auf vor dem Stichtag 1.12.32 begangene Straftaten wurde das G. auch nach der Machtergreifung angewendet: das preuß. JM gab bis Okt. 1934 statist. Zählungen an das RJM (Akten des preuß. JM, Geh.StArch. Berlin, Sign. Rep. 84 a/7909). Insgesamt wurde aufgrund dieses G. im Reich (abgerundet) 76000 Personen wegen Taten aus polit. Beweggrund (Preußen $=52000)$ und 308000 wegen Taten aus wirtschaftlicher Not (Preußen $=204000$ ) eine Vergünstigung zuteil.

22 Sitzung der Kommissare des Reichs v. 10.3.33 (Akten der Reichskanzlei.Die Regierung Hitler, Teil I: 1933/34 [s. Kapitel I, Anm. 3], Band 1, Dok. Nr. 52, S. 187).

23 Verm. v. 3.4.33 (Akten des preuß. JM, Geh.StArch. Berlin, Sign. Rep. 84 a/7908).

24 Niederschr. über die Ministerbesprechung am 11.3.33 nachm. 5 Uhr (Akten der Reichskanzlei, a.a.O., Dok. Nr. 56, S. 196 f.). 
Straftaten wollte das Preußische Staatsministerium allerdings vorher unterrichtet werden. Ferner wurde beschlossen, die Staatsanwaltschaft in Beuthen anzuweisen, bei der Strafkammer die sofortige Freilassung der im Fall Potempa noch nicht abgeurteilten zwei Untersuchungshäftlinge zu beantragen, „nachdem auf Grund der Erklärung des Reichstagsabgeordneten Heines, daß er sich mit seinem Ehrenwort dahin verbürge, daß die Untersuchungsgefangenen sich dem Richter nicht entziehen würden, Fluchtverdacht nicht mehr vorliegt“". Die fünf rechtskräftig verurteilten Mörder von Potempa ${ }^{25}$ sollten zunächst von der Strafvollstreckung beurlaubt werden; das Gericht sollte jedoch veranlaßt werden, „über die Strafumwandlung der lebenslänglichen Zuchthausstrafe in zeitliche Freiheitsstrafen auf Grund der Amnestie alsbald Beschluß zu fassen“. Danach sollte die Frage eines endgültigen Gnadenerweises geprüft werden. $^{26}$

Auch in anderen Ländern wurde das Problem offensichtlich dringend: am 18. März 1933 wandte sich z.B. der Braunschweigische Justizminister mit der Frage an seinen preußischen Kollegen, ob in Preußen eine Amnestie oder Abolition zugunsten von Personen beabsichtigt werde, „die sich in den letzten Wochen aus vaterländischer Begeisterung zu Straftaten haben hinreißen lassen“. Ihm wurde geantwortet, daß man mit einer baldigen Reichsamnestie rechne, daß aber für Preußen ,inzwischen, um beruhigend zu wirken", eine Rundverfügung herausgegeben worden sei, die man ihm vertraulich überlasse. ${ }^{27}$ Unterdessen war im Reichsjustizministerium aufgrund des preuBischen Entwurfs die weitergehende Vorlage einer Amnestieverordnung ausgearbeitet worden. Sie schloß Delikte ein, die „im Kampf für die deutsche Scholle“, d.h. im Interesse der Erhaltung bisherigen Grundbesitzes begangen worden waren: mit dieser Bestimmung sollten die Straftaten anläßlich der Bauernunruhen in Nordwestdeutschland und Ostpreußen von 1929 amnestiert werden können. Am 21. März legte Staatssekretär Schlegelberger in Vertretung des erkrankten Gürtner dem versammelten Reichskabinett den Entwurf der Präsidialverordnung vor, dem die Reichsregierung zustimmte. ${ }^{28}$ Diese von Reichspräsident von Hindenburg noch am selben Tage unterzeichnete Verordnung ${ }^{29}$ gewährte Straffreiheit ,für Straftaten, die im Kampfe für die nationale Erhebung des Deutschen Volkes, zu ihrer Vorbereitung oder im Kampfe für die deutsche Scholle begangen" worden waren. Zeitlich beschränkte sie sich nicht auf Straftaten, die seit dem erwähnten Straffreiheitsgesetz vom Dezember 1932 begangen worden waren, sie schloß vielmehr Taten ein, die um Jahre zurücklagen. Sie erweiterte dieses Reichsgesetz auch sachlich hinsichtlich Verbrechen gegen das Leben ( $\$ \S 211$, 212, $214 \mathrm{StGB}$ ), Verbrechen gegen $\S 1$ der Verordnung gegen politischen Terror vom 9. August 1932, wenn ein Mensch getötet oder verletzt worden war, und wider das Gesetz gegen den verbrecherischen und gemeingefährlichen Gebrauch von Sprengstof-

25 Die fünf SA-Männer waren am 22.8.32 vom SG beim LG Beuthen aufgrund der VO des Reichspräsidenten gegen politischen Terror v. 9.8.32 (RGBl. I, S. 403) zum Tode, ein weiterer zu 2 Jahren Zuchthaus verurteilt worden. Die Todesstrafen wurden unter der Regierung Papen in lebenslängliche Zuchthausstrafen umgewandelt. Vgl. dazu Kapitel I. 5., S.61.

${ }^{26}$ Chefbesprechung der Kommissare des Reichs v. 15.3.33 (Geh.StArch. Berlin, Sitzungsprotokolle, Sign. Rep. 90 A/41).

27 Korrespondenz in den Akten des preuß. JM (Geh.StArch. Berlin, Sign. Rep. 84 a/7908).

${ }^{28}$ Niederschrift über die Ministerbespr. am 21.3.33 nachm. 4 Uhr (Akten der Reichskanzlei, a.a.O., Dok. Nr. 70, S. 244 f.).

29 VO des Reichspräsidenten über die Gewährung von Straffreiheit v. 21.3.33 (RGBl. I, S. 134). 
fen vom 9.Juni $1884 .{ }^{30}$ Wenn die Tat vor dem 21. März 1933 geschehen war, wurden anhängige Verfahren eingestellt und neue Verfahren nicht eröffnet; rechtskräftig erkannte, noch nicht verbüßte Strafen wurden erlassen. Während so die „Träger des nationalsozialistischen Staates“ - wie wir sehen werden, auch für später begangene Taten - von der Strafverfolgung ausgenommen wurden, wurden gleichzeitig oppositionellpolitisch motivierte Taten unter verschärfte Strafen gestellt und für sie Sondergerichte gebildet. ${ }^{31}$ Es war eine der ersten Amtshandlungen Hanns Kerrls am Tage seiner Ernennung zum kommissarischen preußischen Justizminister, den Generalstaatsanwälten nochmals unmißverständlich klarzumachen, daß Straffreiheit keinesfalls für politische Gegner des Nationalsozialismus in Frage komme, insbesondere „auf Straftaten kommunistisch gerichteter Personen niemals Anwendung finden" dürfe. Dagegen sollte sie bei Angehörigen der NS-Verbände möglichst weitherzig und auch auf Präventivtaten angewendet werden, die begangen wurden, „etwa um Angriffe von gegnerischer Seite auf Parteifreunde zu erwidern ..., oder um Gewalttätigkeiten von gegnerischer Seite zuvorzukommen". ${ }^{32}$ Der Referent für Amnestiegesetzgebung im Reichsjustizministerium, der diese Verfügung für „höchst zweckmäßig“" erachtete, forderte vom preußischen Justizministerium die nötige Anzahl Exemplare an, um sie den anderen Landesjustizverwaltungen zu übersenden und bei diesen die Herausgabe gleicher Erlasse anzuregen. ${ }^{33}$ Denn die Durchführung der Straffreiheits-Verordnung oblag zu diesem Zeitpunkt noch nicht dem Reichsjustizministerium, sondern den nunmehr mit nationalsozialistischen Chefs besetzten Landesjustizministerien bzw. obersten Landesjustizbehörden. ${ }^{34}$ Selbst als auf Geheiß Hitlers das Verfahren gegen die noch nicht ergriffenen Erzberger-Mörder Schulz und Tillessen eingestellt werden sollte, konnte das Reichsjustizministerium selbst nichts veranlassen, es mußte sich mit dem kommissarischen badischen Justizminister Rupp in Verbindung setzen. ${ }^{35}$ Es konnte lediglich bitten, daß ihm für eine zentrale Erfassung von den Landesjustizverwaltungen die Zahl der Personen, denen bei der Durchführung der Verordnung Straffreiheit zuteil wurde - getrennt nach Straferlassen und Niederschlagungen -, gemeldet

30 Diese Straftaten waren im $\S 8$ des G. über Straffreiheit v. 2.12.32 (RGBl. I, S. 559) ausdrücklich von den Vergünstigungen ausgeschlossen.

31 Vgl. die in der gleichen Kabinettssitzung (21.3.33) gebilligte VO des Reichspräsidenten zur Abwehr heimtückischer Angriffe gegen die Regierung der nationalen Erhebung v. 21.3.33 (RGBI. I, S. 135) und die VO der Reichsregierung über die Bildung von Sondergerichten vom gleichen Tage (RGBI. I, S.136), später das G. zur Abwehr politischer Gewalttaten v. 4.4 .33 (RGBI. I, S. 162) und das G. zur Gewährleistung des Rechtsfriedens v. 13.10.33 (RGBI. I, S. 723). Die Justiz wollte mit diesen verschärfenden Bestimmungen erreichen und demonstrieren, daß sie in der Lage war, illegalen Widerstand gegen den neuen Staat zu unterdrücken und die Instrumente des Ausnahmezustandes (Schutzhaft und KZ) entbehrlich zu machen, vgl. dazu Kapitel VI. Zu den neuen Strafnormen s. Kapitel VII.3.a.; zur Einrichtung der SGe s. Kapitel VIII.1.b.

32 RV Kerrls v. 27.3.33 zur Straffreiheits-VO v. 21.3.33 (Akten des preuß. JM, Geh.StArch. Berlin, Sign. Rep. $84 \mathrm{a} / 7908)$.

${ }_{33}$ Vgl. Verm. v. 29.3.33 und Begleitschr. (gez. I.V. Schlegelberger) an die außerpreußischen LandesJVerw. (Akten des preuß. JM, Geh.StArch. Berlin, Sign. Rep. 84 a/7908).

34 Vgl. die AV des preuß. JM v. 23.3.33, Justiz-Ministerial-Blatt f. d. preuß. Gesetzgebung u. Rechtspflege (JMBI.), S.97. Danach oblag die Unterbrechung von Freiheitsstrafen den weisungsgebundenen Vollstrekkungsbehörden, die Einstellung der Ermittlungsverfahren den weisungsgebundenen Staatsanwaltschaften (wobei in zweifelhaften Fällen die Entscheidung des Gerichts zu beantragen war) und die Einstellung gerichtlich anhängiger Verfahren den Gerichten, gegen deren Entscheidung Beschwerde zulässig war; bei der Anfechtung einer gerichtlichen Entscheidung sollte jedoch größte Zurückhaltung geübt werden. Ahhnlich die Bekanntmachung des bayer. StMdJ v. 25.3.33, Bayer. Justizministerialblatt (JMBl. n. F. Bd. V, S. 8).

35 Nach Beantragung durch den GStA Karlsruhe setzte das LG Offenburg am 10.4.33 die beiden Mörder aufgrund der StraffreiheitsVO außer Verfolgung (Akten der Reichskanzlei, BA, Sign. R 43 II/1547). 
wurde. ${ }^{36}$ Nach dem Ergebnis der ersten Zählung, das dem Ministerium im April von Preußen zuging, waren allein dort 5 Todesstrafen (Fall Potempa), 33 Zuchthaus- und 101 Gefängnisstrafen, 1 Festungshaft und 179 Geldstrafen erlassen worden und 2896 Niederschlagungen erfolgt, davon 584 im Oberlandesgerichtsbezirk Breslau ${ }^{37}$, wo die SA unter dem berüchtigten Gruppenführer Heines wütete. Insgesamt wurden aufgrund der Straffreiheitsverordnung im Reich 7144 Personen durch Niederschlagung der Verfahren und 1269 durch Straferlasse amnestiert, davon in Preußen 4850 bzw. 642 Personen. $^{38}$

War für die Justiz mit der Straffreiheitsverordnung die rechtliche Grundlage gegeben, die bis zum Stichtag 21. März 1933 begangenen Verbrechen von Partei- und SAAngehörigen im Sinne der Machthaber zu behandeln, so blieb das Problem jedoch bestehen, solange die „revolutionäre“ Phase der NS-Machtergreifung andauerte. Bezeichnende Beispiele dafür bieten drei Anfang Mai in Düsseldorf begangene Morde an „minderwertige[n] Persönlichkeiten, die sich in besonderem Maße an staatsfeindlichen Umtrieben beteiligt und dadurch die Angehörigen der nationalen Verbände auf das schwerste gereizt" hatten, wie der Regierungspräsident von Düsseldorf die Ermordeten in einem vertraulichen Schreiben an Staatssekretär Grauert vom preußischen Innenministerium charakterisierte. Der neue Polizeipräsident, SS-Gruppenführer Weitzel, hatte die mutmaßlichen Täter der Staatsanwaltschaft zunächst gemeldet, dann aber die Einstellung der Verfahren gefordert, da ihnen „wichtige staatspolitische Interessen“ entgegenstünden. Der zuständige Oberstaatsanwalt veranlaßte daraufhin den Generalstaatsanwalt in Düsseldorf, vom preußischen Justizministerium eine Weisung für die Behandlung dieser Fälle einzuholen. Nunmehr begab sich Weitzel selbst nach Berlin, um die Sache durch Rücksprache bei Justizminister Kerrl beizulegen. „Sollte die Sache in Berlin nicht ohne weiteres aus der Welt geschafft werden können“, sekundierte der Regierungspräsident dem Polizeipräsidenten in dem Schreiben an Grauert, „so schlage ich vor, sie mir zur Regelung in persönlicher Verhandlung mit dem Generalstaatsanwalt, den ich langjährig kenne, zu überlassen." Bezeichnenderweise nannte er dabei die anfängliche gesetzmäßige Behandlung der Sache durch Weitzel „sehr un$z$ weckmäßig " ${ }^{39}$ In dieser Lage bedurften die Justizbehörden dringend einer klaren rechtlichen Grundlage für die „zweckmäßige“ Behandlung derartiger, immer wieder auftretender Fälle.

36 Schr. d. RJM an die LandesJVerw. v. 22.3.33 (Akten des preuß. JM, Geh.StArch. Berlin, Sign. Rep. 84 a/ 7908). Dem Wunsche des RJM, bei den Straferlassen zu unterscheiden, ob die im Urteil erkannte Strafe auf Geldstrafe, Festungshaft, Gefängnis bis zu einem Jahr oder über 1 Jahr, Zuchthaus oder Todesstrafe lautete, wurde in den Durchführungsbestimmungen der Länder (s. Anm. 34) entsprochen.

37 Akten des preuß. JM (a.a.O.).

${ }^{38}$ Aufstellung v. 6.3.35 (Akten des RJM, BA, Sign. R 22/1219). Laut AV d. preuß. JM v. 3.5 .34 (DJ, S. 599) wurden die monatl. Zählungen mit Ablauf des 30.4.34 eingestellt. Nach der letzten aufgefundenen preuß. Aufstellung für das RJM v. 20.1.34 (Geh.StArch. Berlin, Sign. Rep. 84 a/7909) waren von diesen 642 Straferlassen: 5 Todesstrafen, 22 Zuchthausstrafen über 2 Jahre, 15 Zuchthausstrafen bis zu 2 Jahren, 26 Gefängnisstrafen über 1 Jahr, 183 Gefängnisstrafen bis zu 1 Jahr, 2 Festungshaftstrafen und 389 Geldstrafen. Maßgebend für die Zählung war die urteilsmäßig erkannte Strafe; die Fälle der Kürzung einer Gesamtstrafe $(\S 4$ der VO v. 21.3.33) wurden mitgezählt.

39 Schr. des Reg.Präs. Düsseldorf an Grauert v. 16.5.33 (Akten des preuß. MdI, Geh.StArch. Berlin, Sign. Rep. 77/31). Der Ausgang der Verhandlungen ist dem Vorgang nicht zu entnehmen. Da seinerzeit im OLGBez. Düsseldorf zahlreiche Verfahren wegen Tötungen niedergeschlagen wurden (vgl. Ber. des OStA Wuppertal v. 18.1.36 über 1933 anhängige Verfahren, Anm. 111 zu Kapitel IV.2.b.), ist auch in diesem Falle eine Niederschlagung höchst wahrscheinlich. 


\section{c. Die Regelung von Straferlaß und Niederschlagung in Preußen und Bayern vom Juli/August 1933}

Eine Wende im Kurs der Machthaber bahnte sich im Juli 1933 an, als mit der Auflösung aller anderen Parteien die letzten organisierten gegnerischen Positionen zerschlagen schienen und Hitler nunmehr ,den freigewordenen Strom der Revolution in das sichere Bett der Evolution hinüberleiten“ wollte. ${ }^{40}$ Reichsinnenminister Frick, der ein besonderes Interesse an einer geordneten, nunmehr in nationalsozialistischen Händen liegenden Staatsverwaltung hatte, gab dem neuen Kurs in mehreren Runderlassen an die Reichsstatthalter und Landesregierungen Ausdruck. Daß demgegenüber die SA den Abschluß der Revolution und die Rückkehr zu geordneten Zuständen noch keineswegs für gekommen ansah, geht z.B. aus der Verfügung ihres Stabschefs Röhm vom 31.Juli 1933 hervor, daß er ,jede Handlung von SA-Männern, die zwar den geltenden gesetzlichen Bestimmungen nicht entspricht, aber dem ausschließlichen Interesse der SA dient“, decke und verantworte, und „daß als Sühne für den Mord an einem SA-Mann durch den zuständigen SA-Führer bis zu 12 Angehörige der feindlichen Organisation, von der der Mord vorbereitet wurde, gerichtet werden dürfen “.41 Es ist deshalb nicht verwunderlich, daß Frick in einem Erlaß vom 6.Oktober 1933 darauf hinweisen mußte, daß SA-Angehörige trotz der wiederholten Kundgebungen Hitlers auch „in den letzten Wochen immer wieder ... selbständig polizeiliche Handlungen vorgenommen“ hätten, „die mit den bestehenden Gesetzen ... nicht vereinbar“ seien. Demgegenüber müsse nunmehr die Staatsautorität rücksichtslos durchgesetzt werden:

„Strafbare Handlungen von Mitgliedern der SA sind nachdrücklich zu verfolgen. Die Beamten dürfen nicht das Gefühl haben, daß ihnen daraus irgendwelche Nachteile entstehen können. Es erscheint mir notwendig, hierauf die Polizei- und Gerichtsbehörden besonders hinzuweisen. Es darf nicht wieder vorkommen, daß in Fällen, in denen Mitglieder der SA unzweifelhaft strafbare Handlungen begangen haben, die Täter angeblich nicht ermittelt werden konnten oder, auch wenn es sich um gewöhnliche Straftaten handelte, die mit dem Kampf um die nationale Erhebung nichts zu tun hatten, außer Verfolgung gesetzt wurden.“42

Die Probleme, die sich aus diesem Gegensatz für die Strafrechtspflege ergaben, mußten zunächst durch die Justizverwaltungen der Länder gelöst werden, deren Erbschaft das Reichsjustizministerium erst bei der „Verreichlichung“ der Justiz antrat. In

40 Amtl. Mitteilung v. 6.7.33 über eine Erklärung Adolf Hitlers vor den Reichsstatthaltern zum Abschluß der Revolution (VB, Süddt. Ausg. v. 8.7.33, S.1). S. im Anschluß daran das Rundschr. Fricks v. 11.7.33 (VB, Süddt. Ausg. v. 12.7.33, S.1) und die Bek. des Stellvertr. d. Führers Heß v. 22.7.33 (VB, Süddt. Ausg. v. 25.7.33, S. 3). Als es zu Verletzung von Ausländern durch SA-Leute kam, ohne daß die Polizei einschritt, und die Reichsregierung dadurch gegenüber ausländischen Missionen ,in starke Verlegenheit“ geriet, kehrte Göring seinen Erl. v. 17.2.33 (s. Anm. 1) in einer Mitteilung an die Ober-, Regierungs- und Polizeipräsidenten v. 16.8.33 geradezu um: „Gegen Polizeibeamte, die offenbar ihrer Pflicht, strafbare Handlungen zu verhindern oder energisch zu verfolgen, nicht nachzukommen gewillt sind, ist unverzüglich einzuschreiten“ (StArch. Düsseldorf, Sign. Best. RW 18, Nr. 2).

41 „Der Oberste SA-Führer Ch Nr. 1415/33 v. 31.7.33, Betreff: Disziplin“ (Akten des RJM, Arch. des IfZ, Sign. MA 108). Auf diese Verf. wurde die Justiz erstmals aufmerksam, als sich ein SA-Angehöriger am 26.8.33 bei seiner Vernehmung durch die StAschaft Dresden darauf berief. In einer persönl. Unterred. arm 8.9.33 mit Gürtner darum gebeten, übersandte Röhm am nächsten Tag eine Abschrift „im Auszug“, bei der die betreffenden Passagen weggelassen waren. Den vollen Wortlaut der Verf. konnte der OStA beim LG Dresden mit Hilfe des Gestapa Sachsen erst im Zusammenhang mit dem Hohnstein-Prozeß (s. Kapitel IV.3, S. 369 f.) beschaffen, nachdem ein Verteidiger auf die Verf. Bezug genommen hatte. So kam der volle Wortlaut dem RJM schließlich am 26.6.35(!) zur Kenntnis.

42 Akten der Reichskanzlei (BA, Sign. R 43 II/1202). 
den beiden größten Ländern Preußen und Bayern, in denen die Entwicklung dieser Probleme im folgenden verfolgt werden soll, wurden im Anschluß an Hitlers Erklärung vom Juli Schritte unternommen, um die Dinge in den Griff zu bekommen. Der preußische Justizminister wies die Staatsanwälte am 12.Juli an, ihm „über jeden Fall der Sabotage des nationalsozialistischen Aufbaus" in der Form unbefugter Eingriffe zu berichten und diese Fälle schnellstens und mit aller Schärfe zu behandeln. ${ }^{43}$ Ergänzend wies er darauf hin, daß wegen Freiheitsberaubung und Amtsanmaßung ( $\S \S 239$, 132 StGB) zur Verantwortung zu ziehen sei, ,wer unbefugt in Anmaßung polizeilicher Befugnisse zu Festnahmen schreitet“, und daß wegen Amtsanmaßung oder Nötigung ( $\S 132,240,114 \mathrm{StGB}$ ) zu verfolgen sei, ,wer ohne Auftrag einer zuständigen Stelle Aufsichtsbefugnisse oder Aufgaben der öffentlichen Verwaltung " übernehme. ${ }^{44}$ Bei der Beratung der nächsten Schritte wurde auch das Reichsjustizministerium eingeschaltet: Staatssekretär Schlegelberger wurde zu einer geheimen Konferenz eingeladen, die Göring am 21. Juli mit Justizminister Kerrl, dem am 1.Juni im preußischen Justizministerium zum Staatssekretär ernannten Freisler, Staatssekretär Grauert und einem Ministerialdirigenten vom preußischen Innenministerium sowie dem Leiter des Geheimen Staatspolizeiamts Diels auf der nordfriesischen Insel Sylt abhielt. ${ }^{45}$ Die Ergebnisse der Beratungen wurden am nächsten Tag auf einer außerordentlichen Sitzung des Preußischen Staatsministeriums in gesetzgeberische Beschlüsse umgemünzt. Das Problem war, wie die seit der Straffreiheits-Verordnung vom 21. März bis zur Beendigung der Revolution - für die nunmehr der Stichtag 15.Juli 1933 festgesetzt wur$\mathrm{de}^{46}$ - für die „nationale Erhebung“ begangenen Straftaten behandelt werden sollten. $\mathrm{Da}$ Hitler eine erneute Reichsamnestie entschieden ablehnte, sich aber mit einem Alleingang Preußens mündlich einverstanden erklärte ${ }^{47}$, ließ Göring, dem als Ministerpräsident die Ausübung des Gnadenrechts in Preußen zustand ${ }^{48}$, durch das Staatsministerium ein Gesetz ${ }^{49}$ beschließen, das Freisler im Justizministerium hatte ausarbeiten lassen und das Artikel 54 Absatz 2 und 3 der preußischen Verfassung aufhob. Die aufgehobenen Bestimmungen hatten u.a. vorgesehen, daß „allgemeine Straferlasse und die Niederschlagung einer bestimmten Art gerichtlich anhängiger Strafsachen oder einer einzelnen gerichtlich anhängigen Strafsache“ nur „auf Grund eines Gesetzes ausgesprochen werden" durften. Gleichfalls am 22.Juli versammelten Göring, Kerrl und Freisler die preußischen Oberlandesgerichtspräsidenten und Generalstaats-

${ }^{43}$ AV des preuß. JM v. 12.7.33 (JMBl., S. 222).

${ }_{44}$ AV des preuß. JM v. 13.7.33 (JMBl., S. 222).

${ }^{45}$ VB, Süddt. Ausg. v. 22.7.33, S. 1; vgl. auch Schulthess' Europäischer Geschichtskalender Bd. 74/1933, herausg. v. U. Thürauf, München 1934, S. 184. Wie im März bei der Amnestiefrage wegen Krankheit, so nahm Gürtner diesmal wegen Urlaubs nicht am Geschehen teil.

46 Das Datum wird genannt in Görings Verf. v. 22.7.33 (s. Anm. 52).

47 Verm. MinRat Döbig v. 25.7.33 über den telefonischen Bericht des bayer. Vertreters in Berlin Min.Dir. Dr. Dürr bez. Unterredung mit Schlegelberger (Akten des Bayer. StMdJ, BayHStArch. Abt. II, Sign. MJu 13598).

48 Aufgrund $\S 1$ Abs. 1 Ziff. 5 des Zweiten G. zur Gleichschaltung der Länder mit dem Reich v. 7.4.33 (RGBi. I, S. 173) i.d. F. des G. v. 25.4.33 (RGBI. I, S. 225) in Verb. mit dem Erl. des Reichskanzlers v. 25.4.33 (GS., S. 133). Göring ermächtigte durch Erl. v. 26.5.33 (enthalten in der AV des preuß. JM v. 13.6.33, DJ 1933, S. 189) den preuß. JM, „das Gnadenrecht hinsichtlich der durch gerichtliche Entscheidungen rechtskräftig erkannten Strafen auszuüben“; lediglich die Entschließung hinsichtlich Todesurteile behielt sich Göring vor.

${ }^{49} \mathrm{G}$. zur Wiederherstellung des uneingeschränkten Begnadigungsrechts des Staatshaupts v. 22.7.33 (GS., S. 270). 
anwälte im preußischen Justizministerium. ${ }^{50}$ Die leitenden Justizbeamten wurden mit einem Erlaß Görings bekannt gemacht, der nunmehr die „unwiderrufliche Festlegung des Grundsatzes“ enthielt, „daß künftig jede strafbare rechtswidrige Handlung, einerlei wer sie begangen hat, verfolgt wird“. Für die vorangegangene Zeit „,bis zur Erklärung der Beendigung der Revolution durch den Führer“ werde Göring jedoch

„in geeigneten Einzelfällen prüfen, ob Handlungen, die für sich allein betrachtet mit den Strafgesetzen in Widerspruch stehen, zur Errichtung des nationalsozialistischen Staates begangen sind, und werde bejahendenfalls durch Niederschlagung oder Begnadigung der Tatsache Rechnung tragen". 51

Diese Prüfung übertrug Göring dem preußischen Justizminister ${ }^{52}$, der die entsprechenden Gnadenerweise, d.h. Erlaß, Herabsetzung oder Umwandlung der Strafe, Aussetzung mit Bewährungsfrist oder Niederschlagung, von' sich aus anordnen konnte. Kerrl ersuchte die Oberstaatsanwälte, ihm über die einschlägigen Fälle unter Beifügung der Akten zu berichten und einen entsprechenden Gnadenerweis vorzuschlagen. Sofern die Betroffenen „zweifelsfrei im Interesse der nationalsozialistischen Revolution gehandelt" hatten, wurden die Oberstaatsanwälte ermächtigt, einstweilen die sofortige Unterlassung bzw. Unterbrechung der Strafvollstreckung anzuordnen, in schwebenden Verfahren die Ermittlungen einzustellen sowie die Aufhebung des Haftbefehls und anberaumter Termine zu erwirken. ${ }^{53}$ Für Niederschlagungsgesuche, die nacb dem 15. Juli begangene Straftaten betrafen und beim Preußischen Ministerpräsidenten eingingen, vereinbarten Kerrl und Göring am 30. November mündlich, daß auch sie vom Justizministerium geprüft würden: nur diejenigen Gesuche, die nach Meinung der Justiz für eine Niederschlagung in Betracht kamen, sollten Göring wieder zugeleitet werden, alle anderen Fälle konnte der Justizminister in Görings Namen

so Bericht des OStA Parey, der i.V. des GStA Naumburg an der Zusammenkunft teilnahm, vor den OStAen dieses Bezirks, s. Niederschrift über Bespr. GStA in Naumburg mit den OStAen seines Bezirks am 8.8.33 (Akten des pr. JM, Geh.StArch. Berlin, Rep. 84 a/4542). Außer dem hier behandelten Problem wurden u.a. noch Maßnahmen zur wirksamen Verfolgung "staatsfeindlicher Bestrebungen“ und der Entw. des späteren ReichsG. zur Gewährleistung des Rechtsfriedens besprochen.

51 Kundgebung des Herrn Preußischen Ministerpräsidenten v. 22.7.33 (JMBl., S. 235). Göring hatte den Stabschef der SA Röhm gebeten, für den Nachmittag des gleichen Tages sämtliche preuß. SA- und SS-Obergruppen- und -Gruppenführer, „soweit sie nicht in ihrer Eigenschaft als Staatsbeamte bereits befohlen sind“, zu einer außerordentlichen Sitzung nach Berlin einzuberufen (VB, Süddt. Ausg. v. 21.7.33). Es ist anzunehmen, daß sie mit dem „neuen Kurs“ der Strafrechtspflege in Preußen gleichfalls vertraut gemacht wurden. Deutlicher Ausdruck der „Beendigung der Revolution“ war die Auflösung der preußischen Hilfspolizei bis Ende September durch Görings Erl. v. 2.8.33 (Schr. des RMdI v. 19.8.33 an alle LänderIM, Geh.StArch. München, Sign. MA 106288 ).

52 Görings Verf. v. 22.7.33 (VB, Süddt. Ausg. v. 24.7.33, S.4). Undatierter Entw. auch in den Akten des preuß. JM (Geh.StArch. Berlin, Sign. Rep. 84 a/7953).

53 Gnadenerweise aus Anlaß der Beendigung der nationalsozialistischen Revolution. AV des preuß. JM v. 25.7.33 (JMBl., S. 236). Eindeutiger als Görings Erl. v. 22.7.33 stellte diese AV hinsichtlich des Gnadenerweises auf Angehörige der SA (einschließlich des Stahlhelms, der sich der Obersten SA-Führung unterstellt hatte) und der SS ab. Über die zahlenmäßige Auswirkung dieser preuß. Amnestie hat der Verf. keine Unterlagen gefunden. Durch eine AV v. 2.8.33 (JMBl., S. 259) verfügte Kerrl ,weitere Gnadenerweise“: Bei „Straftaten, die in der Zeit vom 1.12.1932 bis 17.7.1933 infolge wirtschaftlicher Not des Täters oder seiner Angehörigen, insbesondere Arbeitslosigkeit, begangen sind, ist in eine Nachprüfung einzutreten, ob der Täter eines Gnadenerweises würdig erscheint “. Dieser AV lag ein entspr. Erl. Görings v. 28.7.33 zugrunde (Akten des preuß. JM, Geh.StArch. Berlin, Sign. Rep. 84a/7908). Aufgrund der AV v. 2.8.33 kamen bis Juli 1934 $=6035$ Personen durch Niederschlagung des Verfahrens und 7004 Personen durch gänzliche oder teilweise Straferlasse in den Genuß einer Vergünstigung (lauf. Übersichten in d. Akten des preuß. JM, Geh.StArch. Berlin, Sign. Rep. 84 a/7909). Durch die AV des preuß. JM v. 29.8.34 (DJ, S. 1116) wurden die Zählungen eingestellt. 
ablehnen ${ }^{54}$ Für die Bearbeitung der eingehenden Berichte der Staatsanwaltschaften, vor allem aber für die „mit Fingerspitzengefühl“ zu behandelnden, noch nach dem 15. Juli auftretenden Fälle wurde vom preußischen Justizminister ein neues Instrument geschaffen, von dem noch die Rede sein wird: die Zentralstaatsanwaltschaft.

Das Vorgehen Preußens versetzte die bayerische Regierung in Zugzwang. Der Vertreter des bayerischen Justizministeriums in Berlin, Ministerialdirektor Dürr, wurde angewiesen, sich beim Reichsjustizministerium zu beschweren und vorzubringen, „daß Vorkehrungen erwünscht seien, die ein derartiges, die übrigen Länder verpflichtendes Vorprellen eines Landes in Zukunft unterbinden". ${ }^{55}$ Gleichzeitig sollte er das Ministerium über die daraufhin in Bayern beabsichtigten Maßnahmen unterrichten. Auch in Bayern mußten zunächst verfassungsrechtliche Vorschriften - $\S 69$ Abs. IV der Verfassungsurkunde - außer Kraft gesetzt werden, soweit sie der Niederschlagung eines Ermittlungs- oder Strafverfahrens entgegenstanden. Ein entsprechendes Gesetz wurde auf Antrag Franks in der Ministerratssitzung vom 26. Juli ohne Aussprache angenommen. ${ }^{56}$ Daraufhin ermächtigte Reichsstatthalter v. Epp die Landesregierung, für Straftaten, die seit Inkrafttreten der Verordnung vom 21. März bis einschließlich 25.Juli 1933 „zur Durchsetzung des nationalsozialistischen Staates aus politischer Überzeugung " begangen waren, Straffreiheit zu gewähren; hiervon waren ausdrücklich Straftaten ausgenommen, die „aus Eigennutz oder sonstigen niedrigen Beweggründen begangen" waren. ${ }^{57}$ Die so ermächtigte bayerische Regierung verkündete die Straffreiheit und die Grundsätze für Straferlaß und Niederschlagung in einer entsprechenden Verordnung vom 2. August 1933 und übertrug die Durchführung dem bayerischen Justizminister. ${ }^{58}$ Frank erließ die notwendigen Einzelbestimmungen im amtlichen Veröffentlichungsblatt seines Ministeriums in Form einer „Bekanntmachung“, die im Titel den Zusatz „zur Gewährleistung des Rechtsfriedens“ trug und zugleich die Warnung enthielt, daß nunmehr jede nach dem 25. Juli begangene rechtswidrige Handlung unnachsichtig geahndet werde. Die an sich in einer solchen Durchführungsbestimmung höchst überflüssige und überspannt wirkende Feststellung, daß sich in dieser Frage „die bayerische Landesregierung mit allen maßgebenden Stellen einig“" sei, kam zu diesem Zeitpunkt mehr einem Appell Franks gleich, als daß sie die Realität in Bayern widerspiegelte. In Zukunft sollten

„rechtswidrige Eingriffe in den staatlichen Hoheitsbereich, insbesondere in den gesetzmäßigen Gang der Rechtspflege, und in den Rechtskreis Privater unter keinen Umständen geduldet werden. Jeder Störer der Rechtsordnung wird ohne Ansehen der Person und der Beweggründe seines Handelns unverzüglich und unnachsichtlich nach den bestehenden Gesetzen zur Verantwor-

54 Entw. eines Schr. von Kerrl an Göring v. Dez. 33 (a.a.O., Sign. Rep. 84 a/7953).

ss Verm. v. 25.7.33 (Anm. 47).

56 G. über die Niederschlagung strafrechtlicher Untersuchungen v. 2.8 .33 (GVBl. 1933, S. 210). Dem bayer. Gesamtministerium war als Landesregierung durch das vorläufige G. zur Gleichschaltung der Länder mit dem Reich v. 31.3.33 (RGBl. I, S. 153) die Gesetzgebungsbefugnis übertragen worden; durch das G. zur Behebung der Not des bayer. Volkes und Staates v. 21.5.33 (GVBl. 1933, S. 149) hatte der Landtag ihm das Recht gegeben, dabei von der bayer. Verfassung abzuweichen.

57 Erl. des Reichsstatthalters in Bayern über die Ermächtigung der bayer. Landesregierung zur Gewährung von Straffreiheit v. 2.8.33 (GVBl. 1933, S. 211). Aufgrund §1 des Zweiten G. zur Gleichschaltung der Länder mit dem Reich v. 7.4.33 (RGBl. I, S. 173) stand dem Reichsstatthalter das Begnadigungsrecht zu; er konnte die Ausübung der Landesregierung übertragen, „die zu weiterer Übertragung“ ermächtigt war. Zweites G. zur Änderung des ReichsstatthalterG. v. 26.5.33 (RGBl. I, S. 293).

58 VO über die Gewährung von Straffreiheit v. 2.8.33 (GVBl. 1933, S. 211). Ưber ihre zahlenmäßige Auswirkung hat der Verf. keine Unterlagen gefunden. 
tung gezogen. Den Staatsanwälten und Amtsanwälten mache ich es zur unbedingten Pflicht, diesem Willen der bayerischen Landesregierung bei allen ihren Maßnahmen Rechnung zu tragen. ${ }^{\text {“9 }}$

Wie wir an konkreten Beispielen sehen werden, wurden diese Prinzipien zu diesem Zeitpunkt noch keineswegs „von allen maßgebenden Stellen“ in Bayern anerkannt. ${ }^{60}$

Ein Versuch Franks, das Niederschlagungsrecht für Bayern klar zu regeln, um dadurch auch selbst stärkeren Einfluß nehmen zu können, sollte mißlingen. Da das Gesetz vom 2. August nur das Verbot von Niederschlagungen beseitigt, aber keine Regelung hinsichtlich ihrer Ausübung geschaffen hatte, legte Frank Ministerpräsident Siebert am 5.Oktober den Entwurf eines "Zweiten Gesetzes über die Niederschlagung strafrechtlicher Untersuchungen“ mit der Bitte vor, es in der nächsten Ministerratssitzung beraten zu lassen. Der Entwurf sah vor, (1) daß die Niederschlagung, „die sich auf besondere Gruppen von Personen bezieht, durch Gesetz zu beschließen“ sei, und (2) „strafrechtliche Untersuchungen gegen einzelne Personen ... durch Regierungsakt niedergeschlagen werden, wenn das Gesamtministerium die Niederschlagung aus staatspolitischen Gründen für geboten erklärt hat“. Wie Frank in der Begründung ausführte, wollte er dadurch „den Ausnahmecharakter der Einzelniederschlagung und damit das unerschütterliche Festhalten an der Rechtsstaatlichkeit Bayerns auch der Öffentlichkeit gegenüber“ betonen. ${ }^{61}$ War Frank die Ausübung des „normalen“ Begnadigungsrechts (für Einzelstraferlasse) mit Ausnahme der Fälle von Todesstrafe vom Reichsstatthalter bereits am 2. Mai übertragen worden ${ }^{62}$ und hatte ihn das Kabinett mit der Durchführung der Amnestie vom 2. August betraut, so wollte er auch in $\mathrm{Zu}$ kunft die Zuständigkeit des Kabinetts für Amnestien (Gruppenstraferlasse und Gruppenniederschlagungen) sichern und bei künftigen Einzelniederschlagungen von Fällen - die zeitlich nicht mehr unter die bayerische Straffreiheitsverordnung vom 2. August fielen und zu denen bislang ausschließlich der Reichsstatthalter persönlich befugt war - das Kabinett einschalten, um als dessen Mitglied darauf Einfluß nehmen zu können. Damit wollte er verhindern, daß an von Epp von allen möglichen Seiten unkontrolliert Gesuche um Einzelniederschlagungen herangebracht und von diesem allein entschieden wurden. Franks Entwurf löste in der Ministerratssitzung am 10. Oktober „eine lebhafte Aussprache aus, in der die Auswirkungen der von der Justizverwaltung erbetenen weitgehenden Vollmachten“ und die „staatspolitischen Notwendigkeiten“, die die Vorlage veranlaßt hatten, erörtert wurden. Den Ausschlag dafür, daß der Entwurf abgelehnt wurde und von Frank zurückgezogen werden mußte, gaben die Bedenken von Epps, daß „ihm als Inhaber des Begnadigungsrechts durch Beschlüsse des Ministerrats der Einblick in bestimmte laufende Strafverfahren entzogen werden solle“.

59 Bekanntmachung zur Gewährung des Rechtsfriedens u. zum Vollzuge der VO über die Gewährung von Straffreiheit v. 4.8.33 (Bayer. Justizministerialblatt, S.65). Franks Durchf.Bestimmungen entsprachen im wesentlichen den preußischen. Um auch hinsichtlich der zwei Tage vorher erlassenen weiteren AV Kerrls (vgl. Anm. 53) gleichzuziehen, nahm Frank den Passus auf, daß er ferner die Begnadigung von Personen berücksichtigen werde, „die sich vor dem 26. Juli 1933 aus wirtschaftlicher Not verfehit haben“.

60 Vgl. dazu Kapitel IV.4.

61 Entwurf mit Schr. v. 5.10.33 an Siebert und die anderen StMin, Akten des Bayer.JM (BayHStArch. Abt. II, Sign. MJu 13598).

62 Erl. über die Ausübung des Begnadigungsrechts v. 2.5.33, Bek. über das Verfahren in Begnadigungssachen v. 8.5.33 (beide BayerJMBl., S.22) und Bek. über die Ausübung des Begnadigungsrechts v. 29.5.33 (a.a.O., S. 29). 
Frank konnte indes die erlittene Schlappe insofern wettmachen, als ihn das Kabinett ermächtigte, Einzelfälle von Niederschlagung wenigstens der vorbereitenden Beschlußfassung des Ministerrats zu unterbreiten. ${ }^{63}$

\section{d. Die Regelung auf Reichsebene und das Amnestie-Gesetz vom 7. August 1934}

Während sich mit der Übernahme der Hoheitsrechte der Länder durch das Reich Anfang $1934^{64}$ in der Ausübung des Begnadigungsrechts im engeren Sinne (Recht zum Straferlaß) nur wenig änderte, da der Reichspräsident am 3. Februar 1934 die Ausübung den Reichsstatthaltern - für Preußen dem Reichskanzler - wieder übertrug ${ }^{65}$, gab es hinsichtlich des Niederschlagungsrechts einschneidende Veränderungen. Für das Reich wurde ein Niederschlagungsrecht des Reichspräsidenten überhaupt erst durch das „Erste Gesetz zur Úberleitung der Rechtspflege auf das Reich“ vom 16. Februar $1934^{66}$ begründet. Damit wurden alle früheren Ermächtigungen zur Bewilligung von Niederschlagungen, die den Justizbehörden gegeben worden waren ${ }^{67}$, hinfällig. Zwar übertrug Hindenburg am 21. März die Ausübung dieses Rechts für Straftaten, die zur Zuständigkeit der Gerichte der Länder gehörten, ebenfalls auf die Reichsstatthalter - für Preußen auf den Reichskanzler -, aber nur für jene Straftaten, die vor diesem Stichtag begangen worden waren. ${ }^{68}$ Für Preußen delegierte Hitler diese Ausübung auf den preußischen Ministerpräsidenten ${ }^{69}$, dieser wiederum ermächtigte den preußischen Justizminister, die Entschließung vorzubereiten und unbegründete Niederschlagungsgesuche in seinem Namen abzulehnen. ${ }^{70} \mathrm{Zu}$ seiner Entlastung übertrug der Justizminister die Ablehnung je nach Rechtszug an die Generalstaatsanwälte und Oberstaatsanwälte weiter, jedoch mit der Pflicht zu vorheriger Vorlage, wenn „es sich um eine politische Strafsache“ handelte, „oder um eine Strafsache, die wegen der Person des Beschuldigten oder wegen der verfolgten Tat von besonderer Bedeutung ist" ${ }^{71}$ Dagegen lebten die früheren Ermächtigungen der Oberstaatsanwälte zur Bewilligung von Niederschlagungen nicht wieder auf, da eine Delegation über den Ministerpräsidenten - in außerpreußischen Ländern über den Reichsstatthalter - hinaus nicht zulässig war.

63 Prot. d. MinRatssitzung v. 10.10.33 (GehStArch. München, Sign. MA 107 200).

64 G. über den Neuaufbau des Reichs v. 30.1.34 (RGBl. I, S. 75).

65 Erl. über die Ausübung des auf den Reichspräsidenten übergegangenen Begnadigungsrechts der Länder v. 2.3.34 (RGBI. I, S. 82). Hindenburg behielt sich lediglich das Begnadigungsrecht vor für Straftaten, die Soldaten und Wehrmachtsbeamte während ihrer Zugehörigkeit zur Wehrmacht begangen hatten, sowie für Einzelfälle. Hitler übertrug die Ausübung für Preußen durch Erl. v. 7.2.34 (RGBl. I, S.87) auf den preuß. Ministerpräs. weiter, der die früher erfolgten Úbertragungen (vgl. Anm. 48) an den preuß. JM aufrechterhielt (Erl. v. 16.2.34). Auch in Bayern hielt Reichsstatthalter von Epp die früher an den bayer. JM erteilten Ermächtigungen (vgl. Anm. 62) aufrecht (bayer. GVB1., S. 295).

66 RGBI. I, S.91. Vorher stand dem Reich ein solches Recht nur für erstinstanzliche Hoch- und Landesverratssachen vor dem RG zu; seine Ausübung lag mangels verfassungsrechtlicher Bestimmungen nach herrschender Auffassung beim Gesetzgeber.

67 Vgl. Erl. v. 22. u. 28.7.33 (Anm. 52 u. 53); AV v. 2.8.33 (Anm. 53).

68 Erl. des Reichspräs. über die Ausübung des Niederschlagungsrechts (RGBl. I, S. 211). Hindenburg behielt sich hierbei dieselben Ausnahmen vor wie beim Begnadigungsrecht im engeren Sinn.

69 Erl. über die Ausübung des Niederschlagungsrechts in Preußen v. 16.4.34 (RGBl. I, S. 338).

70 Erl. Görings v. 14.7.34, enthalten in der AV des preuß. JM v. 23.7.34 (DJ 1934, S.959).

71 AV v. 23.7.34 (a.a.O.). Um dabei dem Reichspräs. die Prüfung zu ermöglichen, ob er sich für Ausnahmen die Entschließung vorbehalten wollte, wurde ein kompliziertes Berichtsverfahren eingeführt (nichtveröffentl. Erl. des Reichsprās. v. 21.3.34 u. Hausverf. des preuß. JM v. 23.7.34, Geh.StArch. Berlin, Sign. Rep. 84a/7953). 
Für alle nach dem 20. März 1934 auftretenden Fälle - darin lag die wichtigste Änderung - übte der Reichspräsident, nach Hindenburgs Tod Hitler als Staatsoberhaupt, das Niederschlagungsrecht ohne Ausnahme selbst aus. Diese Regelung blieb auch bestehen, als Hitler mit dem Erlaß vom 1. Februar 1935 das gesamte Gnadenrecht neu und reichseinheitlich ordnete. ${ }^{72}$

Das gleiche Gesetz vom 16. Februar 1934, mit dem das Niederschlagungsrecht für den Reichspräsidenten begründet wurde, legte nochmals fest, daß zukünftig eine Amnestie nur noch durch Reichsgesetz erlassen werden durfte. Die letzte Amnestie, die für die „revolutionären“ Ausschreitungen im Zusammenhang mit der Machtergreifung von Bedeutung gewesen sein dürfte ${ }^{73}$, wurde durch ein solches Gesetz im August 1934 erlassen. In der Sitzung vom 2. August, in der das Reichskabinett nach dem Tod Hindenburgs die bereits am Vortage beschlossene Vereinigung der Ämter des Reichspräsidenten und des Reichskanzlers auf Hitler beriet, schlug von Papen vor, dieses Ereignis zum Anlaß „für eine Amnestie für gewisse politische Vergehen“ zu nehmen. Papen dachte dabei allerdings in erster Linie „an Personen, die deshalb bestraft worden seien, weil sie seine Marburger Rede verbreitet hätten“. Gürtner, dem die Vorgänge bei der „Röhm-Affäre "74 noch in den Knochen steckten, erklärte, „die Amnestie dürfe auf keinen Fall z. B. Personen umfassen, die am 30. Juni lediglich aus Rachsucht persönliche Gegner umgebracht hätten“. Da Frick vorschlug, man solle vielleicht erst das Ergebnis der für den 19. August vorgesehenen Abstimmung über das - bereits in Kraft getretene - Gesetz über das Staatsoberhaupt abwarten, wurde auf dieser Sitzung noch kein endgültiger Beschluß gefaßt. ${ }^{75}$ Offensichtlich wurde es aber für zweckmäßig erachtet, dieses „Wahlgeschenk“ doch noch vor der Abstimmung zu machen: jedenfalls wurde das Straffreiheitsgesetz bereits am 7.August von Hitler, Gürtner und Frick unterzeichnet und trat drei Tage später in Kraft. Anders als die Reichsamnestie im März, die sich auf politische Straftaten beschränkte, umfaßte das Gesetz in der Masse nichtpolitische Straftaten, deren Amnestiewürdigkeit nach der Höhe der erkannten oder zu erwartenden Strafe abgegrenzt wurde. Es gewährte aber auch Straffreiheit - sowohl Straferlaß wie Niederschlagung - „ohne Rücksicht auf die Höhe der verwirkten Strafe“ für „Straftaten, zu denen sich der Täter durch Übereifer im Kampfe für den nationalsozialistischen Gedanken hat hinreißen lassen“. Von der Amnestie ausgenommen waren allerdings Verbrechen gegen das Leben und „Handlungen, bei denen die Art der Ausführung oder die Beweggründe eine gemeine Gesinnung des Täters erkennen lassen “ ${ }^{76}$ Es ist zu vermuten, daß diese einschränkende Bestimmung auf Gürtner zurückgeht, der dabei nicht nur bestimmte Fälle des 30.Juni 1934, sondern auch die gerade laufenden Ermittlungsverfahren wegen der sadistischen Mißhandlungen in den Lagern Hohnstein, Kemna u. a. im Sinn hatte, deren strafrecht-

72 Erl. des Führers und Reichskanzlers über die Ausübung des Gnadenrechts v. 1.2.35 (RGBl. I, S. 74). Unter „Ausübung“ des Niederschlagungsrechts war nur die Bewilligung zu verstehen, das Recht zur Ablehnung wurde von Hitler an den RJM delegiert (vgl. VO des RJM über das Verfahren in Gnadensachen v. 6.2.35 [GnO], DJ 1935, S. 203).

73 Die späteren, noch im Frieden erlassenen Amnestiegesetze v. 23.4.36 (RGBl. I, S. 378), v. 30.4.38 (RGBl. I, S. 433; u. a. betr. "Übereifer-Taten “ in Österreich), Erl. v. 7.6.39 (RGBI. I, S. 1023; Sudetenland und Protektorat) dürften für diese frühen Ausschreitungen kaum mehr von Bedeutung gewesen sein.

74 Siehe dazu Kapitel V.1.

75 Ministerbespr. v. 2.8.34, $8 \mathrm{Uhr}$ abends in der Reichskanzlei (Akten der Reichskanzlei, Die Regierung Hitler, Teil I: 1933/34 [s. Kapitel I, Anm. 3], Band 2, Dok. Nr. 383, S. 1389f.).

76 G. über die Gewährung von Straffreiheit v. 7.8.34 (RGBl. I, S. 769), Stichtag war der 2.8.34. 
liche Verfolgung er durchsetzen wollte. ${ }^{77} \mathrm{Da}$ das Reichsjustizministerium eine beschleunigte Durchführung des Gesetzes anordnete ${ }^{78}$, wurden schon bis Anfang September 1934 allein in Preußen aufgrund des „Übereifer"-Paragraphen die Verfahren gegen 1175 Personen niedergeschlagen und 89 Personen ein Straferlaß gewährt. ${ }^{79} \mathrm{Die}$ entsprechenden Zahlen für Bayern betrugen 166 und 29 Personen, für das Reich insgesamt 1758 und 176 Personen. ${ }^{80}$ Bis März 1935 belief sich die Gesamtzahl der aufgrund dieses Gesetzes Amnestierten im Reich auf 949000 Personen, in der Masse allerdings unpolitische Fälle: der Anteil der Personen mit politischen Straftaten an dieser Zahl betrug rund 12600. Darunter fielen 2736 Personen mit „Übereifertaten“, von denen 2526 mit Niederschlagung und 210 mit Straferlaß bedacht wurden. Den Löwenanteil daran hatte Preußen mit 1785 Niederschlagungen und 117 Straferlassen. ${ }^{81}$ Bis zur Einstellung der Zählung am 10. August $1935^{82}$ stiegen die Zahlen für „Übereifertäter" nicht mehr wesentlich: sie betrugen für das Reich 2717 Niederschlagungen und 227 Straferlasse. ${ }^{83}$

\section{Probleme bei der Strafverfolgung in Preußen}

\section{a. Die Auseinandersetzung mit der SA}

Wegen der Anwendung der Straferlaß- und Niederschlagungsbestimmungen im Einzelfall kam es zwischen den Justizbehörden und den Dienststellen der NS-Bewegung zu ständigen Differenzen. Dabei trat die SA als militanter Stoßtrupp der Bewegung in den Vordergrund, deren Angehörige die politische Gleichschaltung durch „revolutionäre" Aktionen vorantrieben und dabei außerhalb des Gesetzes zu stehen beanspruchten. ${ }^{1}$

Die Auseinandersetzungen, die die Justiz in Preußen mit der SA wegen deren Eingriffe in die Rechtspflege und der Behinderung von Strafverfahren gegen deren Mit-

77 Vgl. dazu Kapitel IV.2.b:, S. 353 ff., und IV.3., S. $368 \mathrm{ff}$.

78 AV des RJM v. 8.8.34 (DJ 1934, S. 1018) mit Durchf.Best. an Gefangenenanstalten, Strafvollstreckungs- u. Strafverfolgungsbehörden. In einer RV v. 9.8.34 wurden die OLGPräs. und GStAe sogar ermächtigt, dafür Hilfskräfte abzuordnen (Akten des preuß. JM, Geh.StArch. Berlin, Sign. Rep. 84 a/7923); die AV des RJM wurde den Justizbehörden in Bayern durch eine Bekanntmachung mit speziellen Zusätzen Franks zur Kenntnis gebracht (Bayer.JMBl., S. 190).

79 1. Zählung (bis Anf. Sept. 34), dem RJM am 3.10.34 übersandt (Akten des preuß. JM, a.a.O.). LGRat Stolzenburg, Die vorläufigen Ergebnisse der letzten Amnestie in Preußen (DJ 1934, S. 1210), unterscheidet bei seinen Zahlenangaben die nationalsozialistischen „Ubereifertaten“ nicht von den amnestierten politischen Straftaten der Gegner des Regimes.

80 Aufstellung v. 28.10.34, in der für Preußen ebenfalls noch die genannten Zahlen angegeben werden (Akten des RJM, BA, Sign. R 22/1219).

81 Aufstellung v. 6.3.35 (a.a.O.).

82 AV des RJM v. 22.6.35 (DJ 1935, S.917).

${ }^{83}$ Gesamtzählung v. 30.9.35 (Akten des RJM, BA, Sign. R 22/1219).

1 Im Mai 1933 waren bei den preuß. VerwBehörden (Oberpräs., Reg.Prās., Landräten nebst kreisunmittelbaren Städten) Sonderkommissare für die Hilfspol. der SA u. SS eingesetzt worden, um im NS-Sinne auf die Behörden einzuwirken (unveröffentl. Erl. des preuß. MdI v. 7.6.33 - II C I 59 Nr.81/33 - Archiv des IfZ, Sign. Fa 115). Auch nach Abschaffung der Hilfspol. wurden die SA-Sonderbevollm. (beim preuß. StMin u. den Oberpräs.) und SA-Sonderbeauftr. (bei den Reg.Präs. u. Landräten) beibehalten, ihre Funktionen allerdings eindeutiger abgegrenzt (RdErl. des preuß. MinPräs. v. 30.10.33, MBliV, S. 1303). Zu diesem Problem in Bayern vgl. Kapitel IV.4.c., S.396 ff.). 
glieder hatte, sollen an einigen typischen Beispielen aus dem Oberlandesgerichtsbezirk Kiel demonstriert werden. Dabei handelte es sich keineswegs um hochpolitische, sondern um Alltagsfälle, die aber den Kleinkrieg der Justiz mit den Vertretern der auBernormativen Gewalt auf der unteren Ebene und die Haltung, die das preußische Justizministerium dabei einnahm, plastisch verdeutlichen.

Am 3. Juli 1933 berichteten Landgerichtspräsident und Oberstaatsanwalt in Flensburg gemeinsam an ihre Dienstvorgesetzten in Kiel, daß ein SA-Sturmbannführer im Amtsgerichtsbezirk Heide die Verhaftung zweier SA-Angehöriger verhinderte, die eine Ersatzgefängnisstrafe zu verbüßen hatten. Die Haftbefehle waren von der Ortspolizeibehörde mit dem Vermerk zurückgekommen, daß die Verhaftungen auf Anweisung des Sturmbannführers „nicht vorzunehmen“ seien und dieser dafür „die Verantwortung“ übernehme. Bei der folgenden Aussprache mit den Justizbeamten des Amtsgerichts forderte der Sturmbannführer, daß das Straffreiheitsgesetz vom 20. Dezember $1932^{2}$ auf die vorliegenden Fälle angewendet werden solle. Als der Aufsichtsrichter antwortete, diese Frage sei bereits „vom Gericht geprüft und in beiden Fällen verneint" worden, stieß der SA-Führer handfeste Drohungen aus und wiederholte, daß er eine Verhaftung der beiden SA-Mitglieder auf jeden Fall verhindern werde. Der Richter erwiderte,

„daß das Amtsgericht derartige Einwirkungen auf keinen Fall hinnehmen, vielmehr im Interesse des neuen Staates und des Ansehens seiner behördlichen Einrichtungen dagegen mit den zur Verfügung stehenden Mitteln einschreiten werde(n), daß allerdings angesichts des Verhaltens der Polizeibehörden dem Gericht im Augenblick nur der Weg der Berichterstattung an den Herrn Justizminister offen bleibe".

Als Antwort darauf untersagte der Sturmbannführer am nächsten Tag zwei der SA angehörenden beschuldigten Viehhändlern, einer Vorladung des Gerichts Folge zu leisten. Als der Oberstaatsanwalt Flensburg gegen den SA-Führer wegen seiner Drohung gegenüber den Justizbeamten ein Verfahren wegen Beamtennötigung einleitete, erschien er zum angesetzten Vernehmungstermin nicht.

Der Bericht der Flensburger Justizbehörden vom 3.Juli enthielt weitere Fälle von Eingriffen in die Rechtspflege, so einen Fall aus dem Amtsgerichtsbezirk Kappeln, wo die Zwangsräumung eines Hausgrundstücks gewaltsam von einer Gruppe SA- und SS-Leute verhindert worden war, die daraufhin wegen Landfriedensbruchs angeklagt wurden. Ferner wurden aus Schleswig, Westerland und Heide drei sogenannte „Prangerfahrten“ gemeldet, bei denen politisch „unliebsame“ Personen - mit entsprechenden Schildern behängt - gewaltsam durch die Straßen geführt wurden, um sie den Anpöbelungen und Tätlichkeiten der Menge auszusetzen. Bezeichnenderweise hatten die Polizeibehörden der Staatsanwaltschaft über die Vorgänge keine Anzeigen erstattet, obwohl sie als strafbare Handlungen wie Landfriedensbruch, Freiheitsberaubung und Nötigung von Amts wegen zu verfolgen waren. Den Justizbehörden waren die Fälle nur durch Anzeigen der Verletzten oder durch Zeitungsberichte bekannt geworden, die ihnen teilweise mit der anonymen Anfrage zugegangen waren, „ob Derartiges jetzt zulässig sei“. Wie die Flensburger Behördenvorstände in ihrem Bericht ausführten, sollten diese Eingriffe unterbunden werden, ,weil sie mit den Grundsätzen einer geordneten Rechtspflege unvereinbar sind und deshalb eine Gefahr für die staatliche

2 Vgl. Kapitel IV.1., Anm. 21. 
Ordnung bedeuten“. Sie ständen auch in offenem Widerspruch zu Hitlers Erklärung vom 10. März $1933^{3}$, daß die Störung des staatlichen Lebens durch Einzelaktionen unterbleiben sollte. Vor allem sei

„nicht abzusehen, welche Folgen schließlich eintreten werden, wenn die Polizei den gesetzmäßig an sie ergehenden Ersuchen der Behörden nicht mehr Folge leistet und ohne einzugreifen Straftaten vor ihren Augen geschehen läßt, weil eine untergeordnete Stelle der SA oder SS es so wünscht ... Die SA und SS sind bestimmt, mit den Behörden zusammen im Sinne der nationalen Regierung zu wirken. Dem widerspricht es, wenn Angehörige dieser Verbände gegen die Behörden tätig werden."

Zum Abschluß ihres Berichts baten die Flensburger Behördenvorstände ihre Kieler Vorgesetzten, „die danach erforderlich scheinenden Schritte zu unternehmen“. ${ }^{4}$

Nach Eingang dieses Berichts ließ der Generalstaatsanwalt Kiel die Oberstaatsanwälte der beiden anderen Landgerichte seines Bezirks am 7.Juli telefonisch auffordern, ihn über beobachtete ähnliche Eingriffe in die Rechtspflege umgehend zu informieren. Die Oberstaatsanwälte von Kiel und Altona berichteten noch am selben Tag, daß drei bzw. zwei Fälle von öffentlichen Anprangerungen stattgefunden hätten, im übrigen aber Eingriffe von SA- oder SS-Angehörigen gegen Strafverfolgungs- oder Strafvollstreckungsmaßnahmen nicht zu verzeichnen seien. ${ }^{5}$

Am nächsten Tag übersandten Oberlandesgerichtspräsident und Generalstaatsanwalt Kiel Abschriften des Flensburger Berichts an den Gauleiter und Oberprāsidenten der Provinz Schleswig-Holstein Lohse und den Führer der SA-Gruppe Nordmark Schoene. Daraufhin kam es am 10.Juli zwischen Lohse, Schoene und den Vertretern des Oberlandesgerichtspräsidenten und des Generalstaatsanwalts zu einer Unterredung, in der der SA-Gruppenführer erklärte:

„Er stehe auf dem Standpunkt, daß eine Verhaftung eines SA-Mannes durch das Gericht, wenn es sich nicht etwa um Kapitalverbrechen handle, nicht wohl geduldet werden könne. Es sei auch bei der Reichenhaller Führertagung eine gesetzliche Regelung in Aussicht gestellt worden ${ }^{6}$, wonach die Strafrechtspflege gegen Mitglieder der SA besonderen Behörden übertragen werden solle ... Es liege auch eine Verfügung des Herrn Regierungspräsidenten vor, wonach die Polizeibehörden von der Verhaftung von SA-Leuten absehen sollten."

Das Verbot des Sturmbannführers in Heide an die beschuldigten SA-Leute, der Vorladung des Gerichts Folge zu leisten, beruhe auf seiner - Schoenes - Anordnung; die „Prangerfahrten“ aber entsprächen lediglich dem Volksbewußtsein. Demgegenüber führten die Justizvertreter aus, „daß eine künftige gesetzliche Regelung für die Gegenwart noch nicht maßgebend sein könne, und daß es eine schwere Erschütterung

3 Als verschiedentlich Ausländer von SA- u. SS-Leuten belāstigt worden waren, warnte Hitler am 10.3.33 in einem zu diesem Zeitpunkt noch bewußt zweideutig gehaltenen Aufruf (VB vom 11./12.3.33) vor „kommunistischen Spitzeln“ in den eigenen Reihen, die „die Partei durch Einzelaktionen zu kompromittieren“ suchten. Einerseits verurteilte er Einzelstörungen, da nach Übernahme der vollziehenden Gewalt "der weitere Vollzug der nationalen Erhebung ein von oben gelenkter, planmäßiger sein“" werde, andererseits aber forderte er auf, jeden „Widerstand sofort und gründlich zu brechen“, und endete mit den Worten: „Im übrigen laßt Euch in keiner Sekunde von unserer Parole wegbringen: Sie heißt: Vernichtung des Marxismus."

4 Gemeinsamer Ber. des LGPräs. u. OStA Flensburg an OLGPräs. u. GStA Kiel v. 3.7.33, Akten des preuß. JM (Geh.StArch. Berlin, Sign. Rep. 84 a/12004); am selben Tage hatten die Kieler Behörden einen Ber. des Gefängnisvorstehers aus Leck (a.a.O.) erhalten, daß die SA unter Gewaltandrohung einen Polizeigefangenen zu einem Prangermarsch aus dem Gerichtsgefängnis geholt habe.

5 Ber. des OStA Altona u. des OStA Kiel an den GStA Kiel v. 7.7.33 (a.a.O.).

6 Vgl. dazu Kapitel IV.5, S. 413. 
der Staatsautorität und des Ansehens der Gerichte bedeute, wenn gewisse Teile der Bevölkerung ohne rechtlichen Grund dem gerichtlichen Zugriff entzogen würden“. Bei den Prangerfahrten handele es sich „um reine Lynchjustiz“, bei der keine Gewähr für eine ordnungsgemäße Untersuchung der Fälle gegeben sei. ${ }^{7}$

In einem Schreiben vom selben Tage, das er an den Oberlandesgerichtspräsidenten von Kiel richtete, vertrat Schoene seinen Standpunkt noch weit schärfer als in der Besprechung. Seine Ausführungen spiegeln die damalige Auffassung der SA-Führerschaft von Recht und Gesetz mit aller Deutlichkeit wider. Auf die erwähnte Anklage gegen SA- und SS-Männer in Kappeln wegen Landfriedensbruchs Bezug nehmend, schrieb er:

„Als Führer der Gruppe Nordmark habe ich den mir unterstellten SA-Männern verboten, bis zur Entscheidung über das Disziplinargesetz der SA und SS vor Gericht zu erscheinen ... Ich möchte aber doch noch bemerken, daß ich unter keinen Umständen dulden kann, daß ein SAMann, der wegen irgendeiner Übertretung in der Zeit des nationalen Umsturzes oder vordem bestraft worden ist, eine Strafe zahlt oder dafür eine Freiheitsstrafe antritt. Wenn auch das Gericht formal im Recht ist, so ist letzten Endes der SA das Gelingen der nationalen Revolution zuzuschreiben und wenn auch Übergriffe vor- und nachdem geschehen sind, so muß man es auch entschuldigen können ...

Ich kann die sogenannte Prangerfahrt nicht als Eingriff in die Rechtsordnung betrachten. Die Nationalsozialistische Revolution ist noch nicht abgeschlossen. Ich habe keine Lust zu dulden, daß Männer, die sich in unerhörter Weise gegen Volk und Nation benommen haben, unbestraft davon kommen. Wenn die SA diese Männer dadurch straft, daß sie sie an den Pranger stellt, so ist dagegen nichts einzuwenden. Die in der Beschwerde erwähnten Äußerungen des Herrn Oberstaatsanwalts und des Herrn Landgerichtspräsidenten, daß strafbare Handlungen ... vorliegen, kann ich mir nicht zu eigen machen, da man wohl nach dem formalen alten Recht urteilt, nicht aber die heutigen Verhältnisse in Betracht zieht. Ich werde mich nach wie vor weigern, gegen irgendeinen SA-Mann vorzugehen, wenn er sich an einer derartigen Tat beteiligt hat, die nach gesundem deutschen Recht richtig war. Eine Entscheidung über meine Maßnahmen und die Maßnahmen der SA gestehe ich nur der Obersten SA-Führung zu. ${ }^{\text {"8 }}$

Dieses Schreiben schickte der SA-Gruppenführer auch an den preußischen Justizminister Kerrl persönlich mit folgendem Kommentar:

„Es scheint so, als ob die Herren weder den Sinn der nationalen Revolution noch die Bedeutung der SA erkannt haben ... Sie werden auch verstehen, daß es heute unmöglich ist, vom SAMann zu verlangen, daß er eine Strafe oder ein kleines Vergehen bezahlt oder gar absitzt ..., wenn er im Kampf um die Freiheit der Nation glaubt zu Recht gehandelt zu haben. Wenn wir so handeln wollen, wie die alten Juristen es verlangen, dann dürfen wir keine Kommunisten, keine Sozialisten, keinen Schweinehund grob anfassen. Wenn wir nach den Buchstaben des Gesetzes vorgehen, dann wird es zu einer Humanitätsduselei führen, die unter Umständen schlimmste Folgen haben kann ... Wenn wir heute unseren politischen Gegnern und denen, die im Stillen wühlen, das Recht geben, sich nur einzig und allein vom Richter aburteilen zu lassen, dann würde die Strafe doch in vielen Fällen immer noch sehr gelinde ausfallen und wir hätten in unserem Staat nichts anderes zu tun, als diese Leute in den Gefängnissen durchzufuttern. Ein Schweinehund und ein Lump wird dann wohl am besten bestraft und erzogen, wenn er eine anständige Tracht Prügel bezieht. Es ist aber einfach unmöglich, wenn der Staatsanwalt gegen SA-Männer einschreitet, die einem Lumpen wegen Beleidigung des Reichskanzlers eine Tracht Prügel verabfolgt haben." 
Schoene schloß seinen Begleitbrief mit der Bitte, Kerrl solle „als Justizminister gegen diese reaktionäre Erscheinungsform in der Rechtsbesprechung [sic] Stellung nehmen und die SA in Schutz nehmen, wie es ihr zusteht".?

Auch der Oberlandesgerichtspräsident und der Generalstaatsanwalt Kiel berichteten noch am 10. Juli dem preußischen Justizminister über die einzelnen Eingriffe in die Justiz sowie über das Ergebnis der Unterredung mit dem Gauleiter und dem SAGruppenführer und baten, „daß mit möglichster Beschleunigung durch Verhandlungen in den Zentralinstanzen" Maßnahmen getroffen würden, die die Strafrechtspflege gegen unbefugte Eingriffe sicherten. ${ }^{10}$ Sie ergänzten ihren Bericht am nächsten Tag durch die Mitteilung, die Behauptung des Gruppenführers über seine Vereinbarung mit dem Regierungspräsidenten von Schleswig, nach der die Polizei keinen SA-Angehörigen mehr verhafte, sei nicht zutreffend: nach Auskunft des Regierungspräsidenten an Lohse habe er mit der SA-Gruppe Nordmark lediglich verabredet, daß bei der polizeilichen Inhaftierung von SA-Leuten ,die Angelegenheit vorher zwischen den beteiligten Stellen geklärt werden solle, auf richterliche Haftbefehle dagegen beziehe sich dies Abkommen nicht“. Da die Auffassung des Gruppenführers mit den Normen der Verwaltungsbehörden nicht in Einklang stehe, sei eine zentrale Regelung der Angelegenheit um so dringlicher. ${ }^{11}$

Die Altparteigenossen Kerrl und Freisler, dem die Angelegenheit auch vorgetragen worden war, waren jedoch nicht geneigt, den Justizbehörden im Streit gegen die SA an die Seite zu treten. Sie beantworteten die Berichte aus Kiel am 17.Juli 1933 mit einem Erlaß an die dortigen Behördenspitzen, in dem sie eingangs darauf hinwiesen, nach den öffentlichen Erklärungen Hitlers und Fricks ${ }^{12}$ - daß alle Aktionen, die die Autorität des nationalsozialistischen Staates bedrohten, ,als Sabotage an der deutschen Revolution“ geahndet würden - „dürften die in den Berichten erwähnten Anstände als behoben angesehen werden" - als ob sich die realen Schwierigkeiten durch die erwähnten Deklarationen von selbst auflösten. Sollten "gleichwohl“ zukünftig wieder derartige Probleme auftreten, sei umgehend zu berichten. Die Akten der in den Berichten geschilderten Strafverfahren seien baldigst an das Ministerium zu übersenden "und in ihnen von Zwangsmaßnahmen vorläufig abzusehen" ${ }^{13}$

Wie zu erwarten, waren mit Hitlers Erklärungen die Schwierigkeiten nicht beseitigt. Zusammen mit den angeforderten Akten sandten die Kieler Aufsichtsbehörden am 10. August einen weiteren Bericht aus Flensburg nach Berlin, der neue Fälle enthielt, in denen Angehörige der SA Aussagen und Erscheinen vor Gericht verweigert hatten. ${ }^{14}$ In einem Fall, bei dem ein Buchhalter in Wyk auf Föhr nachts von der SA aus seiner Wohnung verschleppt und mißhandelt worden war, hatte der im Verdacht der Beteiligung stehende SA-Standartenführer seine Vorladung zur Vernehmung mit der einzigen Begründung abgelehnt, daß es sich um eine „politische Sache“ handelte. Daraufhin antwortete ihm das Amtsgericht Husum mit ziemlicher Deutlichkeit folgendes:

9 Schr. Schoenes an Kerrl v. 10.7.33 (a.a.O.)

10 Vgl. Anm. 7.

11 Gemeinsamer Ber. des OLGPräs. u. GStA Kiel an den preuß. JM v. 11.7 .33 (a.a.O.).

12 Vom 6.7. und 11.7.33 (vgl. Anm. 40 zu Kapitel IV.1.c., S. 329).

13 Erl. des preuß. JM an den OLGPräs. u. GStA Kiel v. 17.7.33 (a.a.O.).

14 Schr. des OLGPräs. u. GStA Kiel an den preuß. JM v. 10.8.33 nebst Ber. des LGPrās. u. OStA Flensburg v. 3.8.33 (a.a.O.). 
„Es handelt sich um Körperverletzungen u. Anstiftung zur Freiheitsberaubung, die Sie am 1.Juli d.J.... begangen haben sollen und nicht um eine politische Sache. Im übrigen ist dies auch völlig gleichgültig. Sie haben selbstverständlich auch als SA-Führer, und gerade deshalb ganz besonders, die Verpflichtung, den Anordnungen, insbesondere Ladungen der Gerichte Folge zu leisten, nachdem die Justiz in den nationalsozialistischen Staat eingegliedert worden ist. Sie werden verwiesen auf die jüngsten Erlasse und Äußerungen des Herrn Reichskanzlers, des Herrn Preuß. Ministerpräsidenten und des Herrn Preuß. Justizministers ${ }^{15}$, die nach dieser Richtung hin völlig eindeutig und unmißverständlich sind. Gemäß $\S 133$ StPO wird Ihnen für den Fall Ihres Ausbleibens im Termin am 25.Juli 1933 angedroht, daß sofort ein Vorführungsbefehl gegen Sie erlassen wird." 16

Vier Tage später wurde dem Amtsgericht von der SA-Brigade Schleswig telefonisch mitgeteilt, daß der Standartenführer „auf Befehl der Obersten SA-Leitung“ zum Termin nicht erscheinen werde. ${ }^{17}$ Am 24. Juli erhielt der Gerichtsassessor, der das Schreiben an den Beschuldigten unterzeichnet hatte, folgenden Brief des SA-Brigadeführers Meyer-Quade: Auf Anordnung der Obersten SA-Führung habe

„die Brigade Schleswig dem Standartenführer L. nicht nur verboten, zu erscheinen, sondern die Brigade hat darüber hinaus dem Standartenführer L. befohlen, daß er alle die Maßnahmen vorbereitet, die notwendig sind, um eine gewaltsame Vorführung mit allen Mitteln unmöglich zu machen. Sie wollen bitte davon Kenntnis nehmen, und sich darüber klar sein, daß alle Folgen, die aus einer von Ihnen verfügten zwangsweisen Vorführung entstehen, ausschließlich Ihnen zur Last fallen. Die S.A. ist nicht gewillt, sich von S.A.-fremden Elementen, die uns all die Kampfjahre über ohne jedes Verständnis für uns und unsere Idee in die Gefängnisse geschickt haben, weiter verurteilen zu lassen, denn dafür haben wir nicht all unsere Opfer gebracht. Wenn Sie die heutige Zeit nicht verstehen können, so ist das Ihre Sache; die Angehörigen der S.A. sind uns aber zu schade, um als Opfer Ihrer Verständnislosigkeit die Dummen zu spielen.

Hiermit verlangt die Brigade die Zurückstellung des gegen den Standartenführer L. schwebenden Verfahrens bis zur Einführung der S.A.-Gerichtsbarkeit.

Im übrigen muß die Brigade es sich verbitten, daß unterstellte Führer und Männer von Ihnen mit derartig impertinenten Briefen, wie der Ihre es ist, belästigt werden. Die Brigade muß Ihnen jedes Recht absprechen, alten Kämpfern der Bewegung Lehren über ihre S.A.-Pflichten zu halten. Wir und unsere S.A. betrachten die Erlasse unseres Führers scbon seit Jabren als Evangelium; wir wissen aber nicht, wie lange Sie, Herr Gerichtsassessor, Sie, der Sie sich auf den Führer berufen, das tun. Die Brigade hat sich unter Beifügung Ihres Schriebs auf dem Dienstwege über Sie beschwert.

Der vorgesetzten Dienststelle ist von uns zu bedenken gegeben, wie weit Sie selbst für den nationalsozialistischen Staat tragbar sind, da Sie offenbar in jungen Jahren nicht umlernen können und dann erfahrungsgemäß in späteren Jahren jede Hoffnung fallen gelassen werden muß.“"18

In einer Besprechung der neu aufgetretenen Fälle mit dem Führer der SA-Gruppe Nordmark bezeichnete der Oberlandesgerichtspräsident Kiel dieses Schreiben an einen Beamten, „der lediglich seine Pflicht getan“ habe, als „untragbar“. Wie er anschlieBend nach Berlin berichtete, werde die weitere Behandlung der Vorfälle wesentlich davon abhängen, ob „das nach der Auffassung des Gruppenführers in Aussicht stehende Gesetz über die Sonderstellung der SA“ deren Angehörige tatsächlich der ordentlichen Strafgerichtsbarkeit entziehen werde. ${ }^{19}$

\footnotetext{
$15 \mathrm{Zu}$ den verschiedenen Erkl. bzw. Verf. vom 6. bis 13.7 .33 vgl. Anm. 40, 43, 44 zu Kapitel IV.1.c., S. 329 f.

16 Korresp. zwischen dem SA-Standartenf. u. dem AG Husum v. 15.7.33 u. 20.7.33 (a.a.O.).

17 Verm. des Just.Sekr. im AG Husum v. 24.7.33 (a.a.O.)

18 Schr. des Führers der SA-Brigade Schleswig, Meyer-Quade, v. 24.7.33 (a.a.O.). M.-Q. war gleichzeitig Landrat in Schleswig u. wurde 1934 Pol.-Präs. von Kiel.

19 Ber. des OLGPräs. u. GStA Kiel an den preuß. JM v. 10.8. 33 (a.a.O.).
} 
Damit hatte der Oberlandesgerichtspräsident den entscheidenden Punkt berührt. Zwar war unterdessen durch Görings Gnadenerweis „aus Anlaß der Beendigung der nationalsozialistischen Revolution" vom 22./25.Juli $1933^{20}$ für die Justizbehörden ein Ventil geöffnet worden, um die meisten der strittigen Fälle durch Straferlaß bzw. Niederschlagung bereinigen zu können, soweit es sich um Straftaten handelte, die vor dem 15.Juli 1933 begangen worden waren. Dennoch war damit das Grundproblem nicht gelöst. Sowohl die SA-Dienststellen wie auch die Justizbehörden drängten daher ihre jeweilige Spitze, eine grundlegende Entscheidung über die Behandlung der SAStraftaten herbeizuführen. Den Ausweg des Gnadenerweises hielt die SA-Führerschaft für grundlegend verkehrt. Am 17. August brachte Brigadeführer Meyer-Quade diese Ansicht gegenüber der SA-Gruppe Nordmark klar zum Ausdruck. Einige seiner SAFührer hätten ihm erklärt, „daß sie nicht daran dächten, von der Einreichung eines Gnadengesuchs Gebrauch zu machen“: SA-Leute könnten „doch nicht verurteilt werden für Dinge, die von uns gebilligt werden und die durchaus im Sinne und im Interesse der Bewegung gelegen haben“. Er wies daher "nochmals eindringlichst darauf hin, daß diese Frage ... immer wieder zu außerordentlich schweren Konflikten führen wird, solange keine endgültige und damit allgemein bekannte Regelung erfolgt ist“" ${ }^{21}$

Der SA schien eine solche Regelung nur in der Form einer Exemtion ihrer Angehörigen von der ordentlichen Strafgerichtsbarkeit denkbar. SA-Gruppenführer Schoene bat daher den Generalstaatsanwalt Kiel am 22. August, die Verfahren gegen SA-Angehörige zurückzustellen, „bis die S.A.-Gerichtsbarkeit, die mit allen Mitteln angestrebt wird, in Kraft tritt". ${ }^{22}$ Mit der Weiterleitung dieses Schreibens an den preußischen Justizminister erklärten nun auch der Generalstaatsanwalt und der Oberlandesgerichtspräsident Kiel, daß ihnen

„im Interesse der Staatsautorität, die beim Fortbestehen zweier nebeneinander herlaufenden und gegen einander wirkenden Befehlsgewalten ernstlich gefährdet ist, und einer unabhängigen und wirksamen Rechtspflege, wie im Interesse der Richter und Staatsanwälte, die in der Durchführung der durch Gesetz angeordneten Entscheidungen und Maßnahmen gehindert werden, ... eine möglichst baldige Klärung dringend erforderlich“" erscheine. ${ }^{23}$

Der Oberstaatsanwalt von Flensburg wies darauf hin, daß die vom Gruppenführer Nordmark geforderte „dilatorische Behandlung“ der Strafverfahren gegen SA-Mitglieder die Staatsautorität aufs schwerste schädige; bereits würden überall Stimmen laut, daß die Regierung nicht die Macht besitze, ihre eigenen Anordnungen durchzuführen: „Man weist auf die immer noch zunehmenden Gewalthandlungen von S.A.-Führern hin und glaubt folgern zu müssen, daß alle Anordnungen der verschiedenen Regierungsstellen, die solche Ungesetzlichkeiten und alle Eingriffe in die Zuständigkeit der Behörden verbieten, wirkungslos geblieben sind.“ Ein Fortdauern dieser Situation

20 Kundgeb. des preuß. MinPräs. v. 22.7. und AV des preuß. JM v. 25.7.33 (vgl. dazu Kapitel IV.1.c., S. 331).

21 Schr. des Führers der SA-Brigade Schleswig an die SA-Gruppe Nordmark v. 17.8.33 (a.a.O.).

22 Schr. des Führers der SA-Gruppe Nordmark an den GStA Kiel v. 22.8 .33 (a.a.O.); ein ähnl. Schr. richtete Schoene an den OLGPräs. Kiel: „Ich werde nicht dulden, daß meine SA-Führer von einer Zivil-Gerichtsbarkeit abgeurteilt werden, da diese in den meisten Fällen für die Handlungsweise der SA nicht das richtige Verständnis aufzubringen vermag" (a.a.O.).

23 Schr. des OLGPräs. u. GStA Kiel an den preuß. JM v. 25.8.33 (a.a.O.); vgl. neben anderen auch Schr. des GStA Breslau an das preuß. JM v. 24.8.33 mit der Forderung der SA-Brigade Oberschlesien an den OStA Oppeln v. 19.8.33 um dilatorische Behandlung (a.a.O.). 
werde „die Stimmung in der Bevölkerung gegen die Gesamtheit der SA in der unglücklichsten Weise beeinflussen". ${ }^{24}$

Da eine grundsätzliche Entscheidung der obersten politischen Führung wegen Hitlers zögernder Haltung und seinem problematischen Verhältnis zur SA-Führung in dieser Zeit nicht zu erreichen war ${ }^{25}$, konnte auch das preußische Justizministerium seinen nachgeordneten Behörden in dieser Lage nur recht gummiartige Vorschriften für die Behandlung einschlägiger Fälle an die Hand geben. In einer Rundverfügung an die Provinzialbehörden vom 26. August 1933 führte Kerrl aus, Unstimmigkeiten hätten sich meist dann gezeigt, „wenn zwischen der Staatsanwaltschaft und den SA.- oder SS.-Führern nicht der notwendige persönliche Zusammenhang“ bestehe. In den weitaus meisten Fällen habe die persönliche Aussprache eine Klärung und „reibungslose Durchführung des Verfahrens" bewirkt:

„Ich ersuche daher, vor Anstellung von sachlichen Ermittlungen sich sofort persönlich mit den SA.- bzw. SS.-Führern in Verbindung zu setzen und ihnen den Sachverhalt und die Zweckmäßigkeit des strafrechtlichen Einschreitens darzulegen. Festnahmen seitens der Staatsanwaltschaft sind - abgesehen von Festnahmen auf frischer Tat - nur im Einverständnis mit der SA.Führung selbst vorzunehmen und insbesondere dann zu unterlassen, wenn die SA.- oder SS.Führung selbst für die Sicherungsverwahrung des Beschuldigten sorgt und wenn sie für pünktliche Gestellung zu Terminen bürgt. Bei Festnahme auf frischer Tat ist die SA.- oder SS.-Führung sofort fernmündlich und schriftlich über Täter und Tat zu unterrichten. Soweit es sich um Prozesse mit politischem Einschlag handelt, ist mir über das Ergebnis der dortigen Aussprache beschleunigt zu berichten und vor meiner Entscheidung von weiteren Maßnahmen abzusehen. ${ }^{\text {“26 }}$

Diese Rundverfügung bedeutete nichts anderes, als daß die Justizbehörden auch nur von dem Versuch, sich unter Einsatz von Zwangsmitteln durchzusetzen, absehen sollten, daß die Durchführung strittiger Verfahren vom - je nach Durchsetzungsvermögen der streitenden Parteien verschiedenen - Ausgang der Verhandlungen auf unterer Ebene abhing und daß beim Ausbleiben einer Einigung das Ministerium die weitere Behandlung der Verfahren in die Hand bekam. Dabei wurde den örtlichen SAFührern der Rücken durch die Verfügung Röhms vom 19.Juli 1933 gestärkt, daß ,in nächster Zeit" eine eigene SA-Gerichtsbarkeit eingeführt werde, die sich aller Fälle rückwirkend selbst annehmen werde. ${ }^{27}$ Als sich SA-Angehörige gegenüber den Justizbehörden direkt darauf beriefen, daß sie "der Sondergerichtsbarkeit der SA“ unterstünden, forderten diese Behörden vom preußischen Justizministerium Auskunft darüber, ob die Einführung einer besonderen SA-Strafgerichtsbarkeit tatsächlich beabsichtigt sei. ${ }^{28}$ Kerrl fühlte sich daher veranlaßt, am 8. September eine entsprechende Anfrage an Stabschef Röhm zu richten, da er sonst nicht in der Lage sei, seine nachgeordneten Behörden mit Weisungen zu versehen, um die „bedauerlicherweise verschiedentlich" aufgetretenen Mißhelligkeiten zu vermeiden. Er bat ferner um Mitteilung, "welchen Stellen ein etwaiger Entwurf einer solchen Gerichtsordnung bereits vorliegt“. ${ }^{29}$ Auf seiten der Justiz war die einzige Stelle, die bis dahin konkret mit dieser Frage befaßt worden war, das Reichsjustizministerium. Da aber zu diesem Zeitpunkt

${ }^{24}$ Ber. des OStA Flensburg an den GStA Kiel v. 25.8 .33 (a.a.O.).

25 Vgl. Kapitel IV.5.

${ }^{26} \mathrm{RV}$ des preuß. JM an die Provinzialbehörden v. 26.8. 33 (a.a.O.); vgl. dazu die Weisung Franks an die bayer. Justizbehörden v. 20.11.33 (s. Anm. 90 zu Kapitel IV.4.c., S. 401).

27 Vgl. Anm. 87 zu Kapitel IV.4.c., S. 400.

28 Vgl. z. B. Ber. des AGDir. Flensburg an den OLGPräs. Kiel v. 6.9.33, weitergeleitet an das preuß. JM (a.a.O.).

29 Schr. Kerrls an Röhm v. 8.9 .33 (a.a.O.). 
eine Entscheidung noch in der Schwebe war ${ }^{30}$, erhielt Kerrl vom Reichsjustizministerium - das schon von den Justizstellen mehrerer Länder zu diesem überall auftauchenden Problem um Information gebeten worden war - am 18. September ein an alle Landesjustizverwaltungen gerichtetes Rundschreiben, daß die Verhandlungen über die Einführung einer SA-Strafgerichtsbarkeit noch nicht abgeschlossen seien und daher alle SA- und SS-Angehörigen selbstverständlich weiter der ordentlichen Gerichtsbarkeit unterstünden. Einschlägige Verfahren seien nach den gesetzlichen Vorschriften einzuleiten bzw. fortzuführen. Bei Behinderungen sollte in bedeutsameren Fällen dem Reichsjustizministerium unter Einsendung der Akten berichtet werden. ${ }^{31}$

Unter diesen Umständen blieb nichts anderes übrig, als an der in Kerrls Rundverfügung vom 26.August 1933 vorgeschriebenen Methode der „Vereinbarung“ zwischen den örtlichen SA- und Justizstellen über Verfahren gegen SA-Angehörige festzuhalten. Dabei neigte die SA häufig dazu, derartige Vereinbarungen zu ihren Gunsten auszulegen. So behauptete z. B. die SA-Gruppe Berlin-Brandenburg in ihrem Befehl „betr. Rechtsberater" vom 6.Dezember 1933, mit dem Generalstaatsanwalt beim Kammergericht sei „eine entsprechende Abrede“ getroffen worden, daß nach der erfolgten Verurteilung eines SA-Angehörigen „eine etwaige Strafvollstreckung durch die SA“ erfolgen solle. ${ }^{32}$ Als der Rechtsberater dieser Gruppe vom Generalstaatsanwalt forderte, den Staatsanwälten seines Bezirks entsprechende generelle Weisungen zu erteilen, mußte ihn der Generalstaatsanwalt berichtigen: es sei lediglich „besprochen worden, daß unter gewissen Umständen eine Strafaussetzung in Frage kommen könnte, wenn die S.A. eine eigene Strafvollstreckung“ übernehme. Er „bitte aber zu bemerken, daß eine bindende Abmachung nicht getroffen ist, sondern nur eine Inaussichtnahme, und die Entscheidung für jeden einzelnen Fall vorbehalten“ bleibe. ${ }^{33}$ Der Generalstaatsanwalt übersandte seine Antwort nach einer Rücksprache mit Freisler, der zwar bereit war, den Wünschen der Partei in Einzelfällen nachzugeben, jedoch immer dann allergisch reagierte, wenn der Justiz generell Zuständigkeiten entzogen werden sollten.

Teilweise scheinen diese regionalen Absprachen selbst dem preußischen Justizminister zu weit gegangen zu sein. Am 28. September 1933 hatte auch der Generalstaatsanwalt Kiel im Einvernehmen mit der regionalen SA- und SS-Führung eine vorläufige Regelung an seine Staatsanwälte verfügt, die im Hinblick auf eine möglicherweise kommende SA-Gerichtsbarkeit offenbar auf eine verzögerliche Behandlung der Strafverfahren abzielte. Als sich die Landesjustizverwaltungen von Thüringen und Anhalt im Dezember beim preußischen Justizministerium erkundigten, welche Erfahrungen mit der Kieler Regelung gemacht worden seien und ob die Absicht bestände, sie in ganz Preußen einzuführen, distanzierte sich der Justizminister von diesen Bestimmungen: sie seien ohne seinen Willen zustande gekommen und würden von ihm „nicht gebilligt, da sie eine ordnungsgemäße Strafrechtspflege nicht gewährleisten ${ }^{\text {“ }}{ }^{34} \mathrm{Zu}$ die-

30 Vgl. Kapitel IV.5, S. 421.

31 Rdschr. des RJM an die Landesjustizverwaltungen v. 18.9.33 (a.a.O.).

32 Befehl betr. Rechtsberater der SA-Gruppe Berlin-Brandenburg - Abt. III/5022/33 - v. 6.12.33, unterz. v. SA-Gruppenf. Ernst (a.a.O.).

33 Schr. des SA-Sturmf. u. Rechtsberaters der SA-Gruppe Berlin-Brandenburg an den GStA beim KG v. 9.12.33 und Antwortschr. des GStA v. 13.12.33 (a.a.O.).

34 Schr. des thüring. JM v. 12.12.33 u. des Anhaltischen StMin v. 22.12.33 an das preuß. JM; Antworten des preuß. JM v. 19.1.34 (a.a.O.). 
ser Distanzierung fühlte sich der Justizminister wohl veranlaßt, da die Kieler Regelung mit Gürtners Rundschreiben vom 18. September in Widerspruch stand, vor allem aber, da mit dem Gesetz zur Sicherung der Einheit von Partei und Staat vom 1. Dezember 1933 eine Entscheidung der obersten politischen Führung in Richtung auf eine bloße Disziplinargerichtsbarkeit für die SA gefallen war. ${ }^{35}$ In ihrer praktischen Auswirkung bedeutete jedoch die vom preußischen Justizministerium verfolgte Politik des „Einvernehmens“ mit den SA-Stellen eine weitgehende Zurückstellung der Strafverfahren gegen SA- und SS-Angehörige. Bis Ende März 1934 sollten in Preußen auf diese Weise ca. 2250 unerledigte Verfahren gegen SA-Mitglieder und ca. 420 gegen SS-Mitglieder anfallen. ${ }^{36}$ Dieser Stau sollte erst im Zuge der Beseitigung Röhms und der nach dem Tod Hindenburgs erlassenen Amnestie vom August 1934 abgetragen werden können.

\section{b. Die Bildung der Zentralstaatsanwaltschaft und ibre Tätigkeit: Verfolgung der Verbrechen in den Konzentrationslagern Bredow, Kemna und Esterwegen}

Für die Behandlung der Verfahren von größerer politischer Bedeutung wurde im Juli 1933 im preußischen Justizministerium die Zentralstaatsanwaltschaft errichtet, die später vom Reichsjustizministerium übernommen wurde. Freisler hatte die Notwendigkeit für die Einrichtung einer zentralen Strafverfolgungsbehörde in Preußen bald erkannt, nachdem wiederholt örtliche Staatsanwaltschaften in den Provinzen bei „heiklen“ Strafsachen Antrag auf Eröffnung der Voruntersuchung gestellt hatten, ohne vorher das Ministerium zu informieren, und dadurch Reibereien mit höheren Parteistellen verursacht hatten. ${ }^{37}$ Bei seinem Vorhaben fand Freisler die Unterstützung des preußischen Gestapochefs Diels, der sich durch eine zentrale Strafverfolgungsbehörde Unterstützung in der Auseinandersetzung erhoffte, die das Geheime Staatspolizeiamt mit den örtlichen SA- und SS-Einheiten in der Schutzhaftfrage auszufechten hatte: die Gestapo war an einer Aufdeckung und Verfolgung verschiedener Ausschreitungen der SA und SS aus Kompetenzgründen interessiert, da sie die Polizeitätigkeit dieser Organisationen zurückdämmen, deren Konzentrationslager „verstaatlichen“ und sich das Monopol der politischen Polizeigewalt sichern wollte, das von seiten der SS vor allem dadurch gefährdet war, daß Himmler und Heydrich im Begriff standen, von Bayern aus die politischen Polizeien der anderen Länder unter ihre Kontrolle zu bringen. ${ }^{38}$ Andererseits war die Justiz bei der Verfolgung derartiger Fälle auf die Unterstützung der Gestapo als jenem Zweig der preußischen Polizei, der für die politischen Straftaten zuständig war, besonders angewiesen. Im Juli 1933 hatte Diels in der Frage

35 Vgl. dazu Kapitel IV.5, S. $424 \mathrm{ff}$.

36 Statistik in den Akten des RJM betr. SA-Strafgerichtsordnung (Arch. des IfZ, Sign. MA 108), daraus wurden die Angaben für die SA-Gruppen Ostland, Pommern, Nordmark, Ostmark, Schlesien, Berlin-Brandenburg, Hessen, Westmark, Niedersachsen, Nordsee, Westfalen, Niederrhein entnommen, die allerdings an außerpreuß. Gebieten Danzig, Bremen, Lübeck, die Länder Braunschweig u. Oldenburg sowie einen Teil des Landes Hessen mit umfassen; für die SS: Gruppen Nordwest, West, Nord, Ost, Südost, Nordost, hier ist zusätzlich noch Hamburg einbezogen.

37 Vgl. z. B. die mahnende RV des preuß. JM an die GStAe v. 20.7.33 (Akten des preuß. JM, Geh.StArch. Berlin, Sign. Rep. 84 a/4542).

38 Zur Übernahme der politischen Polizei in den Ländern durch Himmler s. H. Buchheim, Die SS - Das Herrschaftsinstrument, in: Anatomie des SS-Staates Bd. I, Olten und Freiburg i. Br. 1965, S. $40 \mathrm{ff}$. 
einer zentralen Staatsanwaltschaft eine Unterredung mit Kerrl, Freisler und Staatsanwaltschaftsrat von Haacke im Justizministerium. ${ }^{39}$ Um die ins Auge gefaßte Zusammenarbeit zu gewährleisten, betrieb Freisler für den personellen Aufbau einer solchen Behörde beim preußischen Innenministerium die Freigabe eines Staatsanwaltschaftsrats, eines ehemaligen Rechtsanwalts und einer Angestellten, die sämtlich im Geheimen Staatspolizeiamt beschäftigt waren. ${ }^{40}$ Wegen der Bestimmungen des Gerichtsverfassungsgesetzes sollte diese Behörde als Staatsanwaltschaft beim Kammergericht in Berlin errichtet, aber ihm als Staatssekretär unmittelbar unterstellt werden. ${ }^{41}$ Offenbar im Zuge der Göringschen Beschlüsse vom 22. Juli wurde die Zentralstaatsanwaltschaft jedoch als Sonderreferat im preußischen Justizministerium selbst und mit anderer personeller Besetzung eingerichtet, so daß Freisler seine Verfügung an den Generalstaatsanwalt beim Kammergericht wieder aufheben mußte. ${ }^{42}$ Das Referat unterstand dem Minister und dem Staatssekretär unmittelbar ${ }^{43}$, seine Geschäfte wurden den Staatsanwaltschaftsräten Krug und von Haacke übertragen, die bei allen preußischen Gerichten als Staatsanwälte bestellt, dabei aber den Leitern der örtlichen Staatsanwaltschaften in personeller und sachlicher Hinsicht nicht unterstellt wurden. Die Zentralstaatsanwaltschaft, der eine Anzahl Hilfsarbeiter beigeordnet wurden, sollte "die Bearbeitung der politischen Strafsachen von besonderer Bedeutung “ übernehmen, nämlich:

„a) schwere Angriffe auf Polizeibeamte sowie Angehörige der SA- und SS-Formationen;

b) Versuche der Sabotage des nationalsozialistischen Aufbaus (Mißachtung von Anordnungen der Träger der Staatsautorität, unbefugte Eingriffe in die Wirtschaft, Amtsanmaßungen aller Art und Form)“.

Die Sachbearbeiter konnten nach eigenem Ermessen entscheiden, ob sie die Bearbeitung der Strafsache oder die Vertretung in der Hauptverhandlung jeweils selbst übernehmen oder die Bearbeitung durch die örtliche Staatsanwaltschaft lediglich überwachen wollten. Sie waren ermächtigt, ohne Einhaltung des Instanzenzuges mit den örtlichen Staatsanwaltschaften und ,im Rahmen der Gesetze auch mit den Gerichten“ direkt zu verhandeln. Ihnen wurde die höchste Beschleunigung der einschlägigen Verfahren - möglichst vor den Sondergerichten - sowie „engste Zusammenarbeit mit dem Geheimen Staatspolizeiamt, und zwar bis zur unterstützenden Mitarbeit eines Beauftragten des Geheimen Staatspolizeiamts in der Hauptverhandlung selbst“, zur Pflicht gemacht. Alle Oberstaatsanwälte wurden angewiesen, der Zentralstaatsanwaltschaft „unverzüglich - tunlichst fernmündlich -“ zu berichten, sobald ihnen ein-

39 Nach "tagebuchartigen Aufzeichnungen“ von Haackes, die R. Diels, a.a.O. (Anm. 19 zu Kapitel IV.1), S.310, zitiert. Diels überbewertet offensichtlich seine Rolle als Urheber der Zentralstaatsanwaltschaft. Haackes „Aufzeichnungen“ sprechen von dieser Unterredung als der „Geburtsstunde“ dieser Behörde, verlegen sie aber in die letzten Julitage, also in eine Zeit, in der die Gründung bereits erfolgt war.

40 Schr. Freislers an den preuß. MdI v. 13.7.33 (Akten des preuß. JM, Geh.StArch. Berlin, Sign. Rep. 84 a/ 4542).

41 Schr. Freislers an den GStA beim KG v. 13.7.33, ihm lag eine entspr. Verf. Kerrls v. 29.6.33 zugrunde (beide a.a.O.).

42 Schr. Freislers an den GStA beim KG v. 29.7.33. Die inzwischen vom preuß. MdI freigestellten Juristen fanden anderweitige Verwendung im KG-Bezirk. Zu Görings Aktivitäten am 22.7.33 vgl. Kapitel IV.1, S. $330 \mathrm{f}$.

43 Erst im Jan. 1936 wurde die ZS dem Leiter der Strafrechtspflegeabt. des RJM unterstellt, vgl. v. Haacke, Drei Jahre Zentralstaatsanwaltschaft (DJ 1936, S. 1257). 
schlägige Straftaten bekannt wurden. ${ }^{44}$ Freisler richtete am 27.Juli ein Schreiben an das Geheime Staatspolizeiamt mit der Bitte, dort oder bei den untergeordneten Polizeibehörden vorliegende Akten von Strafverfahren, die für eine Niederschlagung in Betracht kamen, unmittelbar der Zentralstaatsanwaltschaft zuzuleiten. Er bat ausdrücklich, ,von einer Zuleitung derartiger Akten an die örtlichen Staatsanwaltschaften ... abzusehen". ${ }^{45}$

In der Öffentlichkeit wurde nur der eine Aspekt der Tätigkeit der neuen Behörde hervorgehoben, der - in Freislers Worten - „die Schlagfertigkeit der staatlichen Selbstverteidigung“ durch „Zusammenfassung der Abwehr der Angriffe staatsfeindlicher Elemente in einer Hand ${ }^{\text {“46 }}$ betraf. Der weitaus wichtigere Aspekt war jedoch der, daß mit der Zentralstaatsanwaltschaft ein Instrument geschaffen wurde, um alle politisch „delikaten“ Straffälle an eine zentrale Instanz ziehen und die Frage ihrer gerichtlichen Verfolgung - wenn nötig unter Kontaktaufnahme mit der obersten politischen Führung - auf Ministeriumsebene entscheiden zu können. Zugleich sollte dadurch in den Fällen, in denen die Anklage auf diese Weise genehmigt und von der Zentralstaatsanwaltschaft selbst vor Gericht vertreten wurde, möglichst jegliche Einwirkung regionaler SA- und Parteiführer auf die örtlichen Staatsanwälte ausgeschaltet werden.

In der Zentralstaatsanwaltschaft wurde Krug spätestens im November 1933 durch Günther Joël ersetzt, der - wahrscheinlich auf Veranlassung Freislers ${ }^{47}$ - Anfang August von der Staatsanwaltschaft beim Landgericht Kassel ins preußische Justizministerium abgeordnet worden war, um die Amnestie- und Niederschlagungsfälle zu bearbeiten. ${ }^{48}$ Von Haacke und Joël, der im Januar 1934 gleichfalls zum Staatsanwaltschaftsrat befördert werden sollte, wurden nun als - im wahrsten Sinne des Wortes „fliegende" Staatsanwälte ${ }^{49}$ in Preußen eingesetzt, wobei seit Anfang 1934 ersterer die östlichen und letzterer die westlichen Oberlandesgerichtsbezirke übernahm. ${ }^{50} \mathrm{Sie}$ mußten sich mit zahlreichen Fällen befassen, in denen Ausschreitungen von Angehörigen der Bewegung gegen politische Gegner verfolgt werden sollten, örtliche Partei-

44 Vgl. Zentralstaatsanwaltschaft bei dem Justizministerium, AV des preuß. JM v. 24.7.33 (JMBl., S. 235), u. Aufgaben und Verfahren der Zentralstaatsanwaltschaft, AV des preuß. JM v. 27.7.33 (JMBl., S. 249).

45 Akten des preuß. JM (a.a.O.).

46 Freisler in einem Artikel für den Zeitungsdienst (Berliner Dienst) v. 25.7.33 (Akten des preuß. JM, a.a.O.), veröffentlicht in „Der Deutsche“ Nr. 239 v. 12.10.33. Darin führte er u.a. aus, der Staat müsse ein wachsames Auge haben, das das ganze Staatsgebiet überblicken und seine Wahrnehmungen einem zentralen Hirn zuleiten könne, und dieses Hirn müsse selbst Maßnahmen an jeder Stelle des Staatsgebietes treffen können. Die Zentralstaatsanwaltschaft müsse in der Lage sein, „heute in Königsberg, übermorgen in Aachen, zwei Tage später in Kiel und kurz danach in Oppeln selbst die Interessen des Staates als dessen Anwälte in der Hauptverhandlung wahrzunehmen“.

47 Eidesstattl. Erkl. der Sekretärin in der ZStA, Frau K., v. 3.3.47 (Nürnbg. Dok. NG-981), die vermutet, daß sich Freisler und Joël schon aus ihrer gemeinsamen Kasseler Jugendzeit kannten. Zu Joël Kapitel III.2., S. 224.

48 Aussage Joëls v. 13.12.46 (Arch. des IfZ, Sign. ZS 438).)

49 Wie aus den Akten hervorgeht, erledigten beide sehr viele Dienstreisen mit der Deutschen Lufthansa AG, was damals für Beamte dieses Ranges noch außergewöhnlich war.

so Eidesstattl. Erkl. v. Haackes v. 15.4.47 (Nürnbg. Juristenprozeß, Joël Dok. Nr.4, Dokumentenbuch der Vert. I). Wie v. Haacke wurde Joël durch die AV des preuß. JM v. 13.6.34 (Akten des preuß. JM, Geh.StArch. Berlin, Sign. Rep. 84 a/4542) gleichfalls bei allen preuß. Gerichten als StA bestellt. Im Geschäftsverteilungsplan des RuPrJM v. 22.10.34 (BA, Sign. R 2/23901) werden als StARäte in der ZStA nur noch Joël und v. Haacke angegeben, während Krug in der Abt. III (Strafrechtspflege/Strafvollzugsverwaltung) die „Gnadensachen einschl. Niederschlagungen, soweit das Gnadenrecht durch den Führer und Reichskanzler ausgeübt wird (ohne Landesverrats- und Spionagesachen)", bearbeitete. 
führer die Verfahren aber zu verhindern suchten. ${ }^{51}$ Die ersten Fälle z. B., die Joël nach seinem Eintritt in die Zentralstaatsanwaltschaft behandelte, betrafen Ausschreitungen, die im Zusammenhang mit der Volksabstimmung und Reichstagswahl vom 12. November 1933 begangen worden waren. So hatten in Stargard (Pommern) SS-Leute am Wahlabend eine Anzahl von Personen, von denen sie annahmen, daß sie nicht mit "Ja" gestimmt hatten, im Keller des Stadttheaters gefangengesetzt und mißhandelt. Dabei hatte sich ein junger Arbeiter aus Furcht vor angedrohten Torturen mit einem ihm hingeworfenen Strick erhängt. Beobachter der Vorfälle, die über ihre Wahrnehmungen sprachen, wurden von der örtlichen SS-Führerclique, die zugleich die Stettiner Staatspolizeistelle beherrschte ${ }^{52}$, wegen „Verbreitung falscher Nachrichten“ in das von ihr eingerichtete Konzentrationslager Bredow gebracht. Für die Ermittlung der Stargarder Straftaten wurde Joël nach Stettin gesandt. Mit Unterstützung der Berliner Zentralbehörden erreichte er die Freilassung der inhaftierten Zeugen und setzte schließlich die Anklage gegen die Stargarder SS-Leute durch. Um die für die Bewegung blamablen Tatsachen nicht noch weiter zu verbreiten und den Prozeß aus der erregten Atmosphäre der Stargarder und Stettiner Öffentlichkeit herauszuhalten, fand die Hauptverhandlung im Dezember 1933 unter Ausschluß der Öffentlichkeit vor dem Sondergericht Berlin statt: sechs Angeklagte wurden zu mehrjährigen Gefängnisstrafen verurteilt. ${ }^{53}$ Ein ähnlicher Fall, der Joëls Eingreifen erforderte, ereignete sich nach der Novemberwahl in Meyen (Kreis Koblenz), bei dem die Ermittlungen der Staatsanwaltschaft Koblenz durch den Führer der SS-Gruppe West, Weitzel, behindert wurden. Joël fuhr mit Berliner Polizeibeamten nach Meyen, nahm die bekannten Täter fest und brachte sie ins Gefängnis nach Köln. Auch dieser Fall endete für die angeklagten SS-Angehörigen mit Gefängnisstrafen. ${ }^{54}$ Außer mit zahlreichen Fällen dieser Art war die Zentralstaatsanwaltschaft mit einigen spektakulären Verfahren gegen Wachmannschaften der frühen Konzentrationslager befaßt, bei denen sie allerdings meist auf stärkeren Widerstand der regionalen Parteiführer stieß, die derartige Prozesse mit allen Mitteln zu unterbinden suchten.

$\mathrm{Zu}$ den seltenen Fällen, in denen die Justiz einen solchen Prozeß durchsetzte, gehörte die strafrechtliche Verfolgung der Mißhandlungen im Lager Bredow bei Stettin: hier konnte die Zentralstaatsanwaltschaft den Widerstand örtlicher Kreise der Bewegung verhältnismäßig leicht überwinden, da sie bei ihrer Aufgabe vom Geheimen Staatspolizeiamt und von Göring unterstützt wurde.

Das Lager Bredow war im Oktober 1933 vom Führer des SS-Abschnitts XIII und kommissarischen Polizeipräsidenten in Stettin, SS-Oberführer Engel, in der stillgeleg-

51 Eine Aufzählung von Fällen, aus der der konkrete Hergang und Ausgang der Sache jedoch häufig nicht ersichtlich ist, in der Aufz. Joëls v. Dez. 1946 (a.a.O., Dok. Nr.98, Dok.Buch V, S.95ff.); ferner eidesstattl. Vers. v. Haackes v. 15.4.47 (a.a.O., Dok. Nr.4, Dok.Buch I, S. 14 ff.).

52 Úber die Stapostelle Stettin und ihr Verhältnis zum Gestapa vgl. im folgenden.

53 Zum Stargarder Fall vgl. R. Thévoz, H. Branig, Lowenthal-Hensel, Pommern 1934/35 im Spiegel von Gestapo-Lageberichten und Sachakten, Köln u. Berlin 1974, Bd. I, S.32f., 36, Anm. 1, 47; Bd. II, S.258, Anm. 1); B. Drewniak, Początki ruchu hitlerowskiego na Pomorzu Zachodnim, Poznań 1962, S. 163 ff.

54 Vgl. Ber. Joëls v. Dez. 1946 (Nürnbg. Juristenprozeß, Joël Dok. Nr. 98, Dok.Buch der Vert. V, S.94 a), eidesstattl. Vers. v. Haackes v. 15.4.47 (a.a.O., Dok.Nr. 4, Dok.Buch I, S. 14 ff.), ferner Vernehm. Joëls v. 20. 10., 13.12. u. 18.12.46 (Arch. des IfZ, Sign. ZS 438). 
ten Vulkan-Werft an der Oder eingerichtet worden. ${ }^{55}$ Kommandant war SS-Sturmführer Dr. Hoffmann, der als Kriminalangestellter bei der Staatspolizeistelle Stettin zugleich deren Außenstelle III leitete. Im fensterlosen Keller des ehemaligen Fabrikgebäudes - dem „Bunker“ - wurden Häftlinge mit entblößtem Gesäß über eine Kiste gelegt, ihr Mund mit einem Handtuch verschlossen und ihnen mit Lederpeitschen und Peitschenstielen von Hoffmann angeordnete, sogenannte „Windstärken“ verabreicht, wobei Windstärke $I=25$ und Windstärke II = 50 Doppelhiebe bedeuteten. Diese Art der „Umerziehung“ wurde im Lagerjargon mit Hinblick auf den Haftort „Vulkanisieren“ genannt. Auch beim Exerzieren wurden die Gefangenen mit Peitschen mißhandelt. Mit aufgeplatztem und blutendem Gesäß mußten sie in Hockstellung herumhüpfen, so daß die Wunden nicht heilen konnten und eiterten. Solange sie im Lager blieben, wagten an Fieber erkrankte Häftlinge nicht, gegenüber dem SS-Lagerarzt über die wahre Ursache ihrer Krankheit zu sprechen; einige mußten schließlich ins Städtische Krankenhaus gebracht werden. Wie Gürtner später an Innenminister Frick berichtete, wurde

„eine Prostituierte, die mit einem der Wachmänner Differenzen hatte, völlig entkleidet und mit Peitschen und Ochsenziemern derartig geschlagen, daß die Frau noch zwei Monate später auf der rechten Gesäßhälfte zwei offene eiternde Wunden von $17,7 \times 21,5 \mathrm{~cm}$ und $12,5 \times 16,5 \mathrm{~cm}$ sowie auf der linken Gesäßhälfte eine solche Wunde von $7,5 \times 17 \mathrm{~cm}$ aufwies" ${ }^{56}$

Hoffmann, der zugleich über die Verhängung von Schutzhaft und die Einlieferung ins Lager verfügte, nutzte ferner seine Stellung dazu aus, hohe „Geldspenden“ von vermögenden Bürgern zu erpressen, die sich damit von der Schutzhaft freikaufen oder eine pflegliche Behandlung während der Haft erkaufen konnten. Die Gelder wurden zu „Gehaltsaufbesserungen“ für die Angestellten um Hoffmann verwendet.

Als sich Anfang 1934 die Gerüchte über die Zustände in Bredow verstärkten ${ }^{57}$, inspizierte Gestapochef Diels Mitte Februar das Lager, ohne einen Grund zum Einschreiten zu entdecken, da alle Spuren beseitigt und eine ordnungsgemäße Behandlung der Häftlinge vorgetäuscht wurden. In den ersten Märztagen nutzte jedoch der Regierungspräsident in Stettin den Erholungsurlaub des Polizeipräsidenten Engel, um eine eingehende Untersuchung anzuordnen. Sie wurde vom stellvertretenden Polizeipräsidenten, einem der normalen Verwaltungslaufbahn entstammenden Regierungsrat, mit Hilfe von Polizeioffizieren durchgeführt ${ }^{58}$ und brachte die Mißhandlungen ans Tageslicht, über die der Regierungspräsident im preußischen Innenministerium persönlich berichtete. Etwa zur gleichen Zeit hatten sich auch Generalfeldmarschall von Mackensen, an den entlassene Gefangene geschrieben hatten, und Rechtsanwalt Graf

$55 \mathrm{Zu}$ den Vorgängen in Bredow vgl. Urteil der 2. gr. Strafkammer des LG Stettin v. 6.4.34 (Akten des Preuß.StMin./Gestapo, Geh.StArch. Berlin, Sign. Rep. 90 P/11); Urteil des LG Flensburg gegen Fritz-Karl Engel v. 23.5.50 (Arch. des IfZ, Sign. Gf 01.01); R. Thévoz u.a., a.a.O. (Anm. 53), Bd. I, S. 29 ff., dort auch Bd. II, S. 223 ff. Abdruck des Urteils v. 6.4.34 u. S. 268 ff. in Auszügen das Urteil v. 23. 5. 50.

56 Schr. Gürtners an Frick v. 14.5.35 (Nürnbg. Dok. PS-3751, IMG, Bd. XXXIII, S. 56 ff.).

s7 Zum Folgenden vgl. Urteil des LG Stettin v. 6.4.34 (a.a.O.) u. Urteil des LG Flensburg v. 23. 5.50 (a.a.O.). Im Flensburger Prozeß sagten u.a. v. Haacke, Diels, Grauert, Graf v.d. Goltz, der ehemalige Reg.Präs. in Stettin u. ein beisitzender Richter des Bredow-Prozesses als Zeugen aus.

58 Über diese Untersuchung berichtete Hoffmann am 6.3.34 dem in Urlaub befindl. Engel in ironischem Ton, "die Herren“ hätten nach einer „Arschrevision“ zwei Häftlinge mitgenommen, um sie „gegen uns“ zu vernehmen; er hätte aber gedroht, „daß er die beiden Häftlinge erschießen werde, wenn ihnen auch nur eine einzige Frage vorgelegt würde“. $\mathbf{H}$. hielt die Untersuchung daraufhin irrtüml. für eingestellt (Wiedergabe im Urteil des LG Stettin v. 4.6.34, a.a.O.). 
von der Goltz, der als Verteidiger Goebbels' in der Kampfzeit bei der Führung persona grata war und u.a. auch in Görings Preußischem Staatsrat saß, in dieser Angelegenheit an Göring gewandt, der die sofortige Übernahme des Lagers Bredow durch die Landespolizei, seine Auflösung und die Vornahme von Ermittlungen anordnete.

Da der zuständige Oberstaatsanwalt in Stettin durch den Gauleiter Karpenstein behindert wurde, gegen die SS vorzugehen ${ }^{59}$, wurde die Zentralstaatsanwaltschaft mit den Ermittlungen beauftragt. Am 9. März traf Staatsanwaltschaftsrat von Haacke in Stettin ein. Die am nächsten Tag im Lager vorgenommene Untersuchung ergab, daß alle Gefangenen Merkmale schwerer körperlicher Mißhandlungen aufwiesen, die die völlig eingeschüchterten Opfer zunächst kaum als solche zu bezeichnen wagten. Das Bild, das sich bei der Vernehmung der ins Krankenhaus gebrachten Gefangenen bot, „war so schrecklich, daß die mitanwesende Stenotypistin ohnmächtig wurde “. ${ }^{60}$ Von welchem seelischen Druck sich die Opfer befreit fühlten, zeigt die später auch im Urteil geschilderte Szene, daß einer der im Krankenhaus Vernommenen von Haacke beide Hände drückte und sagte: „Ich danke Ihnen, Herr Staatsanwalt, daß ich das alles Ihnen sagen durfte! ${ }^{\text {(6) }}$

Noch aber schoß die örtliche SS quer: auf Veranlassung des Polizeipräsidenten Engel versuchte ein Kriminalassistent, die durch ihn vorgenommene Vernehmung der verhafteten SS-Bewacher - die sich vorläufig im Gewahrsam ihrer eigenen „Militärpolizei“, des Feldjägerkorps ${ }^{62}$, befanden - so zu „frisieren“, daß Lagerkommandant Hoffmann nicht belastet wurde. Dieser Versuch sollte dem Kriminalassistenten jedoch nur die Einreihung unter die Angeklagten wegen Begünstigung einbringen. ${ }^{63}$ Denn diesmal konnte sich die Justiz der Unterstützung durch die Berliner Zentrale der Geheimen Staatspolizei sicher sein: Im Auftrag Görings sandte Diels Regierungsassessor Dengler vom Geheimen Staatspolizeiamt als Sonderkommissar mit außerordentlichen Vollmachten nach Stettin, der die dortige Staatspolizeistelle auch personell reorganisierte. ${ }^{64}$ Um sich allen Widerständen regionaler Stellen gegenüber durchsetzen zu können, bekam von Haacke am 13. März eine schriftliche Vollmacht Görings, in der es u.a. hieß:

„Sie haben die Untersuchung mit aller Strenge fortzusetzen. Die Anklage ist von Ihnen persönlich vor dem Landgericht in Stettin zu vertreten. Sie wollen in geeigneter Weise dafür Sorge tragen, daß diese, meine Auffassung, in den Kreis der beteiligten Behörden gelangt ... Bei Schwierigkeiten haben Sie sich der Unterstützung der Landespolizei zu bedienen. Die beteiligten Richter und Strafvollzugsbehörden, von denen ich klare Erkenntnis der Staatsnotwendigkeiten erwarte, müssen meines persönlichen Schutzes sicher sein. “65

Am 29. März 1934 begann vor der 2. Großen Strafkammer des Landgerichts Stettin gegen Hoffmann und sechs weitere Angehörige des Wachpersonals - die sämtlich einige Tage vorher aus der SS ausgeschlossen worden waren - sowie den erwähnten Kri-

59 Vgl. Diels, Lucifer ante portas, Stuttgart 1950, S. 397; dort S. 398 Wiedergabe eines Erlebnisber. v. Haackes.

60 Urteil des LG Flensburg v. 23.5.50, S. 13 (a.a.O.).

61 Schr. v. Haackes an Göring v. 7.4.34 (Akten des preuß. StMin/Gestapo, Geh.StArch. Berlin, Sign. Rep. 90 $\mathrm{P} / 67$ ).

62 Uber die Behinderung der Justiz durch das FJK vgl. Anm. 33 zu Kapitel IV.5.

63 Vgl. Urteil des LG Stettin v. 6.4.34 (a.a.O.).

64 Vgl. R. Thévoz u.a., a.a.O. (Anm. 53), Bd. I, S. 23, Bd. II, S. 207 f.

${ }^{65}$ Görings Schr. zit. im Urt. des LG Flensburg v. 23.5.50. (a.a.O.). 
minalassistenten der Prozeß, der unter Ausschluß der Öffentlichkeit geführt wurde und bei dem von Haacke selbst die Anklage vertrat. Das Ergebnis der Beweisaufnahme, berichtete von Haacke am Tage nach Beendigung des Prozesses an Göring, „wirkte derartig erschütternd ..., daß am Nachmittage des 2.Verhandlungstages ein allgemeiner Nervenzusammenbruch der an dem Prozeß beteiligten Personen erfolgte“. Die Angeklagten wurden von Weinkrämpfen befallen, zwei von ihnen mußten aus dem Gerichtssaal getragen werden. „Aber auch die Richter sowie die als Beobachter der Behörden und der SS anwesenden Personen sowie die Verteidiger waren vorübergehend zu sachlicher Arbeit nicht fähig.“ Hoffmanns Verteidiger „konnte nur mit Mühe davon abgehalten werden, die Verteidigung, die er vor seinem Gewissen nicht mehr für tragbar hielt, niederzulegen“. 66

Hoffmann konnte schließlich seine Schutzbehauptung widerlegt werden, daß er unter den angeordneten „Windstärken“ lediglich Haftverschärfungen verstanden und von ihrer abweichenden Auslegung durch das Wachpersonal nichts gewußt habe. Von besonderem Interesse sind die Ausführungen im Urteil über das Problem der rechtlich nicht geordneten Befugnis zur Züchtigung von Schutzhäftlingen, da sie die Haltung der damaligen Justiz in dieser Frage erkennen lassen: zwar sei diese Befugnis gesetzlich nicht ausgesprochen und geregelt, doch könne sie sich „aus dem Zusammenhang der Rechtsordnung, also insbesondere auch aus rechtlich anerkannten Staatsnotwendigkeiten, vor allem aus der Notwendigkeit der Sicherung von Volk und Staat gegen staatsfeindliche Umtriebe, ergeben und auf ihr beruhen“; sie finde aber auf jeden Fall „ihre selbstverständliche Grenze in der staatlichen Notwendigkeit, der sie ihre Entstehung verdankt, und sie entfällt, soweit sie hierdurch nicht gedeckt wird“. Die Züchtigung in der von Hoffmann angeordneten Art und in dem Umfang sei daher als rechtswidrig anzusehen; dessen sei sich der Angeklagte auch bewußt gewesen, da er sonst ihre Anordnung gegenüber dem ermittelnden Staatsanwalt nicht geleugnet hätte. Interessant ist ferner die Feststellung, die das Gericht in diesem Prozeß - der in dieser Hinsicht als Vorläufer zahlreicher Nachkriegsprozesse gegen nationalsozialistische Gewaltverbrechen angesehen werden kann - zum Problem des Befehlsnotstandes traf: als ausführende Organe Hoffmanns könnten sich die anderen Angeklagten nicht darauf berufen,

„daß die von ihnen begangenen Körperverletzungen nicht rechtswidrig seien, weil sie auf Befehl von Hoffmann gehandelt haben. Es ist $z w a r$ richtig, daß sie als Untergebene gemäß der ihnen obliegenden Gehorsamspflicht die von ihrem Vorgesetzten Hoffmann getroffenen Anordnungen auszuführen hatten. Ebenso waren sie aber auch zur Nichtbefolgung der Anordnung nicht nur berechtigt, sondern sogar verpflichtet, falls sie die Überzeugung und Gewißheit erlangten, daß die Anordnung über die Grenzen hinausging, die ihr durch die Rechtsordnung gezogen sind."

Diese Voraussetzung habe vorgelegen, wie einer der Bewacher klar erkannt habe, der die Ausführung des Befehls verweigert hatte und deshalb auch nicht angeklagt worden war. In den nachgewiesenen Fällen hätten die Angeklagten "nach der Überzeugung des Gerichts sadistische Freude am Schlagen“ empfunden und „aus reinem Sadismus heraus in unmenschlicher Weise ihre Opfer bis zum Äußersten gequält".67

66 Ber. v. Haackes an Göring v. 7.4.34 (Akten des preuß. StMin/Gestapo, a.a.O.).

67 Urteil des LG Stettin v. 6.4.34 (a.a.O., Anm. 55). 
Am 6. April verurteilte das Gericht Hoffmann wegen gefährlicher Körperverletzung gemäß $\S \S 223,223 \mathrm{a}$ StGB in Tateinheit mit Körperverletzung im $\mathrm{Amt}^{68}$ gemäß $\S 340$ Abs. 1 StGB und teilweise mit Erpressung von Aussagen gemäß $\S 343$ StGB zu 13 Jahren Zuchthaus. Seine beiden Stellvertreter im Lager, Pleines und Salis, wurden mit 5 Jahren Zuchthaus bzw. 5 Jahren Gefängnis bestraft. Hoffmann wurden die bürgerlichen Ehrenrechte für 5 Jahre, Pleines für 3 Jahre aberkannt. Die übrigen vier angeklagten Bewacher erhielten wegen gefährlicher Körperverletzung Gefängnisstrafen zwischen 10 Jahren und 9 Monaten; der Kriminalassistent wurde wegen Begünstigung gemäß § 257 Abs. 1 StGB mit 300 RM Geldstrafe belegt, die durch die Untersuchungshaft als verbüßt galt.

Im Gegensatz zu anderen einschlägigen Strafverfolgungsfällen wurde den Verurteilten kein Gnadenerweis erteilt. Als in der Auslandspresse die Meldung verbreitet wurde, die Verurteilten seien wenige Tage nach der Urteilsverkündung begnadigt worden, konnte von Haacke in einem Schreiben vom 26.Juni 1934 an das Preußische Staatsministerium diese Nachricht dementieren: Pleines verbüße seine Strafe im Zuchthaus Brandenburg, Salis und Fink in der Strafanstalt Gollnow und drei andere in der Strafanstalt Naugard. Hoffmann befinde sich seit der Urteilsverkündung in Untersuchungshaft im Gefängnis Berlin-Moabit, da das Urteil gegen ihn - wegen eingelegter Berufung - noch nicht rechtskräftig sei. ${ }^{69}$ Doch der von von Haacke dargelegte Sachverhalt sollte keinen Beweis für die „Rechtssicherheit“ im NS-Staat abgeben: vier Tage später wurden Hoffmann, Pleines und Fink aus ihren Gefängnissen geholt und im Zusammenhang mit der Röhm-Affäre erschossen.

Wie von Haacke am 7.April 1934 Göring berichtete, wurde das Durchgreifen der Justiz bei der Stettiner Bevölkerung, „bei der man immer wieder auf die Meinung stößt, der Führer habe den Überblick verloren“(!), lebhaft begrüßt. Es erwies sich, daß die spürbar von einem Druck befreite Bevölkerung in der Justiz eine letzte Rettung gegen auftretende Willkür sah: so teilte von Haacke Göring die gerichtlich festgestellte Tatsache mit, daß zwei Stettiner Kriminalbeamte zu Jahresbeginn ihre Frauen instruiert hätten, sie sollten im Falle ihres plötzlichen Verschwindens keinesfalls das Polizeipräsidium Stettin, sondern die Zentralstaatsanwaltschaft in Berlin unterrichten. Auch die leitenden Justizbeamten Pommerns hätten sich bei ihm bedankt. ${ }^{70}$

Was der Bevölkerung wohl entging, war die Tatsache, daß die Justiz die Rolle des Ordnungsfaktors nur dann erfüllen konnte, wenn sie im konkreten Fall von höchster Stelle dazu autorisiert war. Wenn Gürtner die Hoffnung hegte, mit dem Stettiner Prozeß einen „Musterprozeß “ $^{\text {durchgefochten } z u \text { haben }}{ }^{71}$, dem weitere folgen würden, so sollte er bald enttäuscht werden. Schon bei der Strafverfolgung gegen den Polizeipräsidenten und SS-Oberführer Engel, gegen den sich erst in der Hauptverhandlung des

${ }^{68} \mathrm{Da}$ Hoffmann, Pleines und Salis als Kriminalangestellte bei der Stapostelle Stettin tätig waren, wurden sie - wenn auch nicht im staatsrechtlichen Sinn, so doch im strafrechtlichen Sinn des § 359 StGB - als Beamte angesehen.

69 Schrb. des ORegR Prinz v. Hessen im preuß. StMin an die ZStA v. 23.6.34 aufgrund der Anfrage des AA bei Lammers u. Antwortschr. v. Haackes an den preuß. MinPräs. v. 26.6.34 (R. Thévoz u.a., a.a.O. [Anm. 53], Bd. II, S. 262).

70 Ber. v. Haackes an Göring v. 7.4.34 (a.a.O., Anm. 61). Die Behauptung bei Diels (a.a.O., S. 400), nur Freisler habe v. Haacke „schwere Vorwürfe“ gemacht und „hätte die Entfernung v. Haackes aus dem Justizministerium betrieben, wenn nicht Göring seine Befriedigung über den Ausgang des Verfahrens offen gezeigt hätte", ist bislang aktenmäßig nicht belegt.

7 Vgl. folgende Anm. 105 und Kapitel IV.3., Anm. 3 u. 19, S. 368 f., 372. 
Bredow-Falles belastende Momente ergeben hatten, sollte die Zentralstaatsanwaltschaft eine Schlappe erleiden. Um den bei den Beteiligten am Bredow-Prozeß aufkommenden Verdacht zu zerstreuen, der Inhaber des goldenen Parteiabzeichens Engel sei „bewußt geschont worden, weil er eine zu hochstehende Persönlichkeit sei“ - die Verteidigung hatte von einer "gebundenen Marschroute“ gesprochen -, hatte von Haacke bereits im Anschluß an sein Plädoyer im Gerichtssaal erklärt:

"Wenn hier die Anklagebank nicht nach oben erweitert ist, so liegt das einzig und allein an der Tatsache, daß die Zeugen und insbesondere die Angeklagten im Ermittelungsverfahren und zum Teil auch noch in der Hauptverhandlung sich aus falsch verstandener Kameradschaft oder unter dem Drucke des hier herrschenden Terrors bemüht haben, gewisse Personen unter allen Umständen zu decken. ${ }^{\text {" }} 2$

Aber bereits am 11. April bat Staatssekretär Körner vom Preußischen Staatsministerium Freisler, zu veranlassen, daß seitens der Staatsanwaltschaft gegen Engel einstweilen nichts unternommen werde. ${ }^{73}$ Erst nachdem Engel Ende April 1934 als Polizeipräsident abgelöst worden war, leitete die Zentralstaatsanwaltschaft gegen ihn Ermittlungen ein. Das geschah vor allem aufgrund der belastenden Aussagen, die Fink in der Strafhaft machte und die ihm höchstwahrscheinlich am 30.Juni 1934 das Leben kosteten. Die Ermittlungen ergaben den dringenden Verdacht, daß Engel von den Gefangenenmißhandlungen nicht nur gewußt, sondern sie sogar mehrmals angeordnet hatte, ferner daß auch er Gefangene zu seiner persönlichen Bereicherung erpreßt hatte. Engel wurde zwar im Juni in Untersuchungshaft genommen, aber er hatte in Himmler, der sich Engel vorführen ließ, und im damaligen Chef der preußischen Ordnungspolizei, Generalleutnant und SS-Gruppenführer Daluege, hohe Fürsprecher: Himmler setzte sich für die Niederschlagung ein, da Engel Altparteigenosse und verdienter Offizier sei, sich infolge eines Lungenschusses mit asthmatischen Folgeerscheinungen an Morphium gewöhnt und nur deshalb in Stettin versagt habe. Noch bevor Anklage erhoben werden konnte, mußte das Verfahren - für das das Sondergericht in Berlin vorgesehen und in dem nach Ansicht von Haackes eine langjährige Zuchthausstrafe zu erwarten war - aufgrund des Amnestiegesetzes vom August 1934 eingestellt werden. ${ }^{74}$

Ein weiterer wichtiger Komplex, mit dem sich die Zentralstaatsanwaltschaft befaßte, ohne allerdings wie im Falle Bredow einen Prozeß zu erreichen, waren die Vorgänge im Konzentrationslager Kemna (Wuppertal-Beyenburg). Dieses provisorische Lager hatte die SA-Untergruppe Wuppertal auf Anordnung des Polizeipräsidenten, des berüchtigten SA-Brigadeführers Veller, Anfang Juli 1933 in einer stillgelegten Putzwollfabrik eingerichtet, da die Strafanstalten des Regierungsbezirks mit politischen Schutzhaftgefangenen überbelegt waren. In diesem entlegenen Fabrikgebäude kam es zu unmenschlichen Quälereien: die Häftlinge wurden „zur Vernehmung“ mit entblößtem Körper, den Mund mit Stoffetzen zugestopft, auf besonderen Prügelbän-

72 Ber. v. Haackes an Göring v. 7.4.34 (a.a.O.).

73 Schr. Körners an Freisler v. 11.4.34 (R. Thévoz u. a., a.a.O. [Anm. 53], Bd. II, S. 260 f.).

${ }^{2}$ Vgl. Zeugenaussage v. Haackes im Flensburger Prozeß (Urteil des LG Flensburg v. 23. 5. 50, a.a.O.); ferner Ber. Heydrichs an Himmler v. 27.1.37 aufgrund der vertraul. Auskunft v. Haackes, ferner die Schr. Dalueges an Heydrich v. 12.11.36 u. Himmlers an Schwede-Coburg v. 13.5.37 (R. Thévoz u.a., a.a.O., Bd.II, S. 265 ff.). Der auf eigenen Antrag 1934 aus der SS entlassene Engel wurde im Sept. 1941 als Hauptsturmf. wieder aufgenommen u. 1943 Polizeimajor u. SS-Sturmbannf. Am 23.5.50 wurde E. durch das LG Flensburg zu 5 J. u. 1 Mon. Gefängnis, nach Aufhebung d. Urt. durch den BGH am 22.4.52 zu 2 J. u. $6 \mathrm{Mon}$. Gefängnis verurteilt, die durch die U-Haft als verbüßt galten. 
ken festgehalten und mit Gummiknüppeln, Peitschen und Stöcken blutig geschlagen. Sie wurden anschließend in einen Verschlag unter der Treppe, der nur eine hockende Stellung erlaubte, oder für mehrere Stunden in enge Kleiderspinde gezwängt, in denen sie weder stehen noch sitzen konnten, wobei durch die Luftlöcher gelegentlich Zigarettenrauch eingeblasen wurde. Vorher wurden sie zum Verzehr sogenannter „Appetitshäppchen“ - ungewässerter, mit Staufferfett oder Kot beschmierter Salzheringe - und bei Erbrechen zum Auflecken des Erbrochenen gezwungen; anschließend wurde ihnen für längere Zeit jegliches Getränk verweigert. Noch im November wurden sie mit frischen Verletzungen und voll bekleidet in die angrenzende eiskalte Wupper getrieben, ohne danach die Kleidung wechseln zu können. Mehrere Selbstmordversuche von Gefangenen mißglückten, zwei Häftlinge starben nach Verlegung aus dem Lager, einer davon in der Irrenanstalt Galkhausen. ${ }^{75}$ Am 19.Januar 1934 wurde das Lager, dessen Übernahme in die staatliche Verwaltung abgelehnt worden war, aufgelöst und die Gefangenen in die Emslandlager überführt.

Obwohl zahlreiche schwer mißhandelte Häftlinge in die Städtischen Krankenanstalten von Wuppertal-Barmen eingeliefert wurden, verbreitete sich die Wahrheit über die Zustände im Lager nur in der Form vorsichtiger Gerüchte, da die örtliche NSFührung deren Verbreitung rücksichtslos mit Schutzhaft bedrohte. Der politische Sachbearbeiter bei der Staatsanwaltschaft in Wuppertal, Staatsanwaltschaftsrat Winckler, wies erstmals in einem Bericht an die Zentralstaatsanwaltschaft vom 8. März 1934 auf derartige Gerüchte hin. Nach Rücksprache mit Joël wurde jedoch zunächst von einer Untersuchung Abstand genommen. Erst nachdem mit den Ereignissen vom 30. Juni $1934 \mathrm{Röhm}$ und die Oberste SA-Führung entmachtet worden waren, gab Joël den Auftrag, über die Vorgänge im ehemaligen Lager „vertrauliche“ Ermittlungen anzustellen. Wincklers vorsichtige Erkundigungen brachten die erwähnten Bestialitäten ans Tageslicht. Dem Bericht nach Berlin wurde jedoch hinzugefügt, Wincklers Vertrauensmann habe „ausdrücklich um Geheimhaltung seines Namens gebeten“, er sei aber in der Lage, für die behaupteten Tatsachen Zeugen zu benennen. ${ }^{76}$ Unterdessen beschlagnahmte die Gestapo bei Postkontrollen einen Zeitungsausschnitt, der in Wuppertal verbreitet wurde und die gleichen Behauptungen über die Vorgänge in Kemna enthielt. Der Bericht stammte von einem ehemaligen Kemna-Häftling, der infolge eines Irrtums aus dem Konzentrationslager Papenburg entlassen worden und ins Ausland geflohen war. ${ }^{77}$ Auch unter Parteiangehörigen regte sich nun Mißfallen über das Gebaren der örtlichen SA-Führerclique um Veller, der mit seiner Leibwache auch persönliche Gegner terrorisierte. Am 31.Juli 1934 erschienen beim zuständigen Bearbeiter für politische Einzelstrafsachen im preußischen Justizministerium sechs Wuppertaler Alt-Parteigenossen, darunter zwei SA-Führer und ein Truppführer der SS, und berichteten vertraulich über das „strafbare Verhalten einiger Partei- und SA-Führer in ihrer Heimat", u.a. des ehemaligen Kommandanten von Kemna, SA-Sturmführer Hilgers, des Leiters der politischen Abteilung im Polizeipräsidium, SA-Sturmfüh-

\footnotetext{
75 Ber. der Staatsanwaltschaft beim LG Wuppertal v. 18.1.36 (Akten des RJM, BA, Sign. R 22/5032); Urteil der 5. Strafkammer des LG Wuppertal v. 15.5.48 (Archiv des IfZ, Sign. Gw 04.02), die das Verfahren nach dem Kriege durchführte: vgl. dazu die Broschüre v. K. Ibach, Kemna. Wuppertaler Lager der SA 1933, Wuppertal 1948. Nachdruck: Wuppertal 1981.

76 Ber. des OStA Wuppertal v. 9.7.34 auf Joëls fernmündl. Auftrag v. 6.7.34 (Akten des RJM, a.a.O.).

77 Ber. des OStA Wuppertal v. 16.7.34 (a.a.O.).
} 
rer Pfeiffer, und des Kreisleiters von Düsseldorf-Mettmann. Für die Vorgänge in Kemna nannten sie eine Reihe von Zeugen. Sie betonten jedoch, daß „die Beschuldigten einen zu großen Einfluß hätten. Unverständlicherweise greife selbst die Gauleitung nicht ein." Eine Untersuchung dürfe keinesfalls über die Gestapo laufen, da Hilgers' ehemaliger Vertreter Wolff jetzt in der Stapostelle Düsseldorf sitze. ${ }^{78}$ Vor ihrem Besuch im Justizministerium waren die Informanten im Berliner Verbindungsstab der in München sitzenden Dienststelle des Stellvertreters des Führers der NSDAP gewesen und hatten dort einschlägige Unterlagen abgegeben. Obwohl jeder der Informanten von Joël einen regelrechten Schutzbrief ${ }^{79}$ ausgestellt bekam, traf fünf Tage später bei Joël ein persönlich an ihn gerichtetes, nächtliches Telegramm eines Informanten ein, daß der zu ihrem Kreis gehörende SS-Truppführer soeben durch den Kreisleiter in Schutzhaft genommen worden sei und "sofortiges Eingreifen“ erbeten werde. ${ }^{80}$ Joël reiste daraufhin sofort nach Wuppertal und erreichte offensichtlich die Freilassung des Verhafteten. Unterdessen war auch der Vorstoß beim Stellvertreter des Führers nicht wirkungslos geblieben. Am 14. August kam der Reichsinspekteur der NSDAP, Freiherr von Holzschuher, zu Winckler nach Wuppertal und erhielt nach telefonischer Genehmigung durch Joël anhand der bisherigen Ermittlungsergebnisse die gewünschte „rückhaltlose Aufklärung der Zustände in Wuppertal“, auch soweit sie strafbare Handlungen der SA- und Parteiführer außerhalb des Kemna-Komplexes betrafen. ${ }^{81}$ Als unmittelbare Folge wurden schon vier Tage später Veller, Pfeiffer, Hilgers, Wolff und weitere drei höhere SA-Führer durch eine einstweilige Verfügung des Stellvertreters des Führers aus der Partei ausgestoßen. ${ }^{82}$ Somit schien sich zunächst das Blatt zugunsten der Justiz zu wenden: Joël erwirkte durch persönliche Vorsprache bei der Staatspolizeistelle Düsseldorf einen Schutzhaftbefehl gegen den ehemaligen KZKommandanten Hilgers. Offensichtlich vorgewarnt, floh Hilgers und wurde von einem seiner Sturmführer in einer SA-Feldjägerkaserne beherbergt. Nach Entdeckung des Aufenthaltsortes wurde dieser Sturmführer wegen Verdachts der Fluchtbegünstigung auf Veranlassung Wincklers gleichfalls festgenommen, aber auf die Behauptung, er habe von dem Schutzhaftbefehl gegen Hilgers nichts gewußt, nach einigen Tagen wieder freigelassen und das Verfahren gegen ihn eingestellt. ${ }^{83}$ Diese Randepisode wird hier deshalb erwähnt, weil dieser Sturmführer daraufhin einen Beschwerdebrief über das Verhalten der Justizbehörden an den „Pg. Dr. Freisler“ richtete - mit dem ausdrücklichen Bemerken, nur dieser biete die Gewähr, daß die Angelegenheit „einer entsprechenden Prüfung unterzogen“" werde -, der die Einstellung dieser SA-Führer gegenüber einer objektiven Rechtsprechung treffend zum Ausdruck bringt. Er schrieb:

\footnotetext{
${ }^{78}$ Verm. des Sachbearbeiters im RJM v. 1.8.34 (a.a.O.).

79 Wortlaut s. Joël-Verteid., Dok. Nr. 14, Dok.Buch I, Nürnbg. Juristenprozeß (Fall III); der letzte Satz lautete: ,Jeder Versuch, auf die Anzeigenden in irgendeiner Weise Einfluß zu nehmen, um auf diese Weise das Ermittlungsverfahren zu sabotieren, wird strafrechtlich als Begünstigung der durch die Anzeige Beschuldigten von mir verfolgt werden."

80 Telegr. v. 4.8.34, aufgegeben 23.07 Uhr (Akten des RJM, BA, Sign. R 22/5032).

81 Ber. Wincklers an die ZStA v. 15.8.34 (a.a.O.).

${ }^{82}$ Einstw. Verf. des Stellv. d. F. v. 18.8.34 (BA, Sign. NS 36/14). SA-Brigadeführer Veller wurde daraufhin auf einen niedrigeren SA-Führerrang degradiert und nach Dresden versetzt.

${ }^{83}$ Ber. Wincklers v. 12.11.34 (Akten des RJM, a.a.O.), vgl. auch Diensttagebuch des RJM, Bd.1, Eintr. v. 20.11.34 (BA, Sign. R 22/131).
} 
„Die hiesige Staatsanwaltschaft bediente sich, zur Erreichung gewisser Ziele, Mittel die mit den nationalsozialistischen Ideen keineswegs im Einklang stehen ... Die z. Zt. herrschende Empörung in der Bevölkerung Wuppertals gegen die Staatsanwaltschaft [!] ist kaum zu beschreiben. Auf Grund von Mitteilungen irgend welcher Denunzianten und Intriganten werden Verfahren gegen bewährte Kämpfer angestrengt, die seit 1925 und noch länger im Kampf für Führer und Vaterland gestanden haben, die aus der Revolutionszeit gegen Kommunisten stammen, und bedient man sich als Zeugen wegen Sprengstoff- und Hochverratsaffären abgeurteilter und im Gefängnis sitzender Kommunisten."

Als Winckler ihm seine Beteuerungen nicht geglaubt und geäußert habe, als Sturmführer würde er einem Kommunisten bei einer Vernehmung wohl auch nicht ohne weiteres glauben, habe er sich „als SA-Mann, der im schwersten Kampf seine Pflicht getan hat, einen derartigen Vergleich von Herrn Pg. Winckler entschieden verbieten“ müssen. ${ }^{84}$ Diese Auffassung, daß der Wahrheitsgehalt einer Aussage von der politischen Einstellung des Aussagenden abhängt, sollte in der Frage einer Strafverfolgung der Verbrechen von Kemna eine wesentliche Rolle spielen.

Nunmehr schaltete sich auch die Gauleitung ein, weil sie sich durch das Vorgehen der Staatsanwaltschaft übergangen fühlte, das über ihren Kopf hinweg in Wuppertal zum Ausschluß von Parteigenossen durch die Reichsleitung geführt hatte. Am 17. September erschien Gaurechtsstellenleiter Schroer in Wincklers Dienstzimmer und protestierte, daß Gauleiter Florian und er von anfallenden Strafsachen gegen Partei- und SA-Angehörige nicht unterrichtet würden. Als Reichsinspektor des BNSDJ habe er auf seinen Reisen auch an anderen Orten feststellen müssen, daß die Justizbehörden „die Parteiinstanzen als Instanzen zweiter Ordnung betrachteten und sie übergingen. Die Partei, insbesondere aber der Gau Düsseldorf, ließe sich eine derartige Behandlung nicht gefallen", er werde sich bei Heß und dem Stabschef der SA Lutze beschweren. Seine Aufforderung, die Wuppertaler Vorgänge sofort mit dem Gauleiter zu besprechen, lehnte Winckler jedoch mit dem Hinweis ab, er habe von Joël strikte Weisung erhalten, keiner Stelle Auskunft zu erteilen. Schroer erwiderte, daß Freisler dieses Verhalten zweifellos nicht billige und Joël, der außer der Gauleitung alle möglichen anderen Stellen im Gaubezirk besuche und informiere, „dementsprechende Vorhaltungen machen würde“. Demgegenüber wies Winckler darauf hin, daß die Staatsanwaltschaft aufgrund der letzten Verfügung des Reichsjustizministers ${ }^{85}$ bei Strafverfahren gegen SA-Angehörige nur verpflichtet sei, dem vorgesetzten SA-Gruppenführer und der zuständigen Gaurechtsstelle der NSDAP den Beschluß über die Eröffnung des Hauptverfahrens und das rechtskräftige Urteil mitzuteilen. ${ }^{86}$ Gauleiter Florian rief noch am selben Tag Freisler an, der sich laut Schroer über das Verhalten der Wuppertaler Strafverfolgungsbehörde „sehr erstaunt und ungehalten“ zeigte. ${ }^{87}$ Auf Weisung Freislers führte Joël anläßlich seiner nächsten Dienstreise nun doch ein Gespräch mit Florian, Schroer und dem Vorsitzenden des Gaugerichts der NSDAP, blieb jedoch bei

84 Schr. des Sturmführers an Freisler v. 22.10.34 mit Anlage (Akten des RJM, BA, Sign. R 22/5032). Laut Diensttagebuch (s. vorherige Anm.) ist dieser Brief, von dem der OStA Wuppertal der ZStA am 16.11.34 eine Abschrift übersandte, „im Geschäftsgang nicht durch das Ministerbüro gegangen“, d.h., Freisler hatte ihn Gürtner vorenthalten.

85 Es handelte sich um die AV des RJM v. 20.7.34 (DJ, S. 926). Vgl. dazu Kapitel IV.5, S. 429 f.

${ }^{86}$ Bericht Wincklers v. 18.9.34. Der Leiter der Staatsanwaltschaft beim LG Wuppertal, bei dem Schroer am nächsten Tag auftauchte, bestätigte, „daß die von Staatsanwaltschaftsrat Winckler erwähnten Anweisungen vorlägen". Bericht des OStA v. 18.9.34 (Akten des RJM, a.a.O.).

87 Persönl. Mitteil. Schroers an Winckler noch am 17.9.34, von diesem in seinem Ber. (vorhergehende Anm.) erwähnt. 
seiner Einstellung, daß die Mitteilung jedes Ermittlungsverfahrens gegen Angehörige der Partei und ihrer Gliederungen an die Gauleitung „technisch nicht möglich und auch nicht immer sachlich zweckmäßig" sei. $^{88}$

Unterdessen lief das Ermittlungsverfahren weiter, das aufgrund der Angaben eingeleitet worden war, die die sechs Informanten Ende Juli im Ministerium zu Protokoll gegeben hatten. Am 18. Oktober berichtete Joël dem Verbindungsstab Heß in Berlin, daß die Ermittlungen zwar noch nicht abgeschlossen seien, „aber schon heute ein Bild grauenhafter Mißhandlungen ergeben“ hätten. „Mit Rücksicht auf die politische Bedeutung der Sache - die Vorgänge sind in der Emigranten- und sonstigen ausländischen Presse erörtert worden -“"werde das Verfahren von der Zentralstaatsanwaltschaft betrieben und Auskünfte könnten, wie der Gauleitung Düsseldorf erklärt worden sei, „nur von dem Sachbearbeiter des Ministeriums erteilt“ werden. ${ }^{89}$

Die Gauleitung begann nunmehr ein Kesseltreiben gegen Winckler, der u.a. vor das Düsseldorfer Gaugericht geladen wurde, um sich als Parteigenosse gegen Beschuldigungen zu verantworten, die von Parteiseite gegen ihn erhoben worden waren. ${ }^{90}$ Ferner wurde seitens der Gauleitung die Rehabilitierung der aus der Partei Ausgestoßenen, die gegen die einstweilige Verfügung Einspruch eingelegt hatten, beim Obersten Parteigericht in München betrieben. Auf Anordnung Freislers, der die Partei hinsichtlich seiner Eigenschaft als „Trojanisches Pferd“ innerhalb der Mauern der Justiz nicht enttäuschte, mußten zu diesem Zweck Mitte Dezember 1934 die Ermittlungsakten der Wuppertaler Staatsanwaltschaft an die Gauleitung abgegeben werden.9 ${ }^{11}$

Im Januar 1935 sprachen - diesmal beim persönlichen Adjutanten in Görings Ministerpräsidentenbüro - abermals Beschwerdeführer aus Wuppertaler Parteikreisen vor und berichteten, daß der festgefügte Kreis um den abgesetzten Veller und den offensichtlich wieder auf freien Fuß gesetzten Hilgers immer noch Einfluß ausübe und offen damit prahle, „daß die aus der Partei Ausgestoßenen in Kürze wieder in ihre alten Rechte eingesetzt würden“, was bei der Bevölkerung erhebliche Beunruhigung auslöse. ${ }^{92}$ Als das über den Gesamtkomplex nicht informierte und daher ungläubige Büro Görings daraufhin von der Zentralstaatsanwaltschaft die Vorgänge anforderte, ergriff Joël diese willkommene Gelegenheit, die Akten von der Düsseldorfer Gauleitung zurückzuverlangen. Damit begann ein typisches Tauziehen um die Akten, das weniger hier als in manchen anderen Fällen zur Verschleppung oder - bei eintretendem „Verlust" der Akten - zur Einstellung der Partei ungelegener Verfahren führte ${ }^{93}$ : Die Gauleitung teilte der Wuppertaler Staatsanwaltschaft mit, daß die Unterlagen an Reichsleiter Grimm vom Obersten Parteigericht nach München gesandt worden seien. Eine telefonische Rückfrage Joëls in München wiederum ergab, daß im Gegenteil auch die dort vorhandenen Vorgänge zu diesem Komplex an Gauleiter Florian geschickt worden seien. Auf erneute Aufforderung der Staatsanwaltschaft an die Gauleitung erwi-

88 Vgl. Schr. Joëls an Florian v. 22.9.34 bez. des Termins seiner Dienstreise u. seinen Ber. an den Verbindungsstab der NSDAP v. 18.10.34 (Akten des RJM, a.a.O.).

89 S. voranstehende Anm.

90 Schr. Wincklers an die ZStA v. 17.11.34 nebst Ladung des Gaugerichts vom Vortage (Akten des RJM, a.a.O.); W. war seit Mai $1933 \mathrm{Pg}$.

91 Aktenverm. Joëls v. 13.12.34 (a.a.O.).

92 Schr. zweier Informanten an Görings Adjutanten v. 10.1 .35 bez. ihrer Unterredung am 8.1.35 (a.a.O.). Es handelte sich um einen der Informanten v. 31.7.34 u. einen in Schutzhaft gewesenen Polizeibeamten.

93 Ein Beispiel der Verhinderung von Verfahren durch „Aktenverlust“ s. Kapitel VI.4.a., S.639. Zum folgenden vgl. die Verm. Joëls vom 11. bis 16.1.35 (Akten des RJM, a.a.O.) 
derte Gaurechtsstellenleiter Schroer, „zunächst mit dem Gauleiter Florian sprechen zu müssen“. Am nächsten Tag teilte sein Büro mit, die Akten seien "gestern Abend mit dem Nachtzug nach München an Reichsleiter Grimm abgegangen". ${ }^{94}$ Nachdem sie bei der Nachfrage Joëls dort wiederum noch nicht vorlagen, konnte er Grimm nur ersuchen, sie nach Eingang baldigst an die Zentralstaatsanwaltschaft zu schicken. Am 17. Januar endlich konnten die Vorgänge an Görings Büro gegeben werden, wo Joël anschließend auch mündlich „über die im Laufe der Ermittlungen eingetretenen Schwierigkeiten mit politischen Stellen“ berichtete. ${ }^{95}$ Bevor jedoch die Akten mit weiterem, im Ministerpräsidentenbüro eingegangenen Beweismaterial an das Justizministerium zurückkamen ${ }^{96}$, hatte die Partei zum entscheidenden Schlag ausgeholt, um einem Strafverfahren zuvorzukommen: aufgrund der bisher vorliegenden staatsanwaltschaftlichen Ermittlungen hatte sie beim Obersten Parteigericht gegen die Hauptbeschuldigten ein Verfahren in Gang gebracht, das mit dem Beschluß vom 1. April 1935 endete. Durch diesen Beschluß wurde der vorläufige Ausschluß der Betroffenen aus der Partei zurückgenommen, Veller und Hilgers erhielten lediglich eine Verwarnung, Pfeiffer und Wolff wurde zusätzlich die Fähigkeit zur Bekleidung von Parteiämtern für ein Jahr aberkannt. Mit einem Seitenhieb auf die Justiz wurde in der Begründung ausgeführt, daß die bisherigen Ermittlungen höchst einseitig geführt worden seien; man habe nur unglaubwürdige Staatsfeinde gehört, den Angeschuldigten und ihren Entlastungszeugen hingegen keine Möglichkeit (!) zur Stellungnahme gegeben. Verschiedene Besichtigungen des Lagers Kemna durch den Polizeipräsidenten von Düsseldorf, den Regierungspräsidenten und eine Kommission des Preußischen Innenministeriums hätten indessen seinerzeit keinen Anlaß zu Beanstandungen gegeben. Zwar seien die Angeschuldigten „über das zur Brechung des Widerstandes erforderliche $\mathrm{Maß}$ hinausgegangen“ und hätten „damit gegen den vom Führer gegebenen Befehl, daß der nationalsozialistische Staat seine Gegner wohl unschädlich zu machen weiß, darüber hinaus aber auf jede Rache verzichtet, verstoßen und der Bewegung einen sehr schlechten Dienst geleistet“. Es sei jedoch zu berücksichtigen, daß es die SA im Wuppertaler Industriegebiet mit besonders hartnäckigen kommunistischen Gegnern zu tun gehabt habe, die sich auch nach der Machtergreifung immer wieder illegal zu organisieren versucht hätten. Gerade das Verhalten der Staatsanwaltschaft habe diesen Elementen wieder Auftrieb gegeben und sie zu dem Versuch veranlaßt, die Angeschuldigten mit allen Mitteln moralisch zu vernichten. „Mit Rücksicht auf die außerordentlichen Verhältnisse des Jahres 1933, auf den guten Glauben der Angeschuldigten, im Interesse von Partei und Staat zu handeln, und auf die Verdienste der Angeschuldigten um die Bewegung" habe es das Parteigericht mit den verkündeten Maßnahmen bewenden lassen. ${ }^{97}$

94 Verm. Joëls v. 12.1 .35 (a.a.O.).

95 Begleitschr. Joëls v. 17.1.35 (a.a.O.).

96 Schr. des Büro Preuß. Ministerpräs. v. 30.3.35 mit Anlagen (a.a.O.), darunter der eidesstattl. Vers. eines ehemaligen SA-Sturmführers, der in einer Korruptionssache gegen Hilgers als Zeuge benannt war und deshalb von diesem vom 2. bis 24. Juni 1933 in Schutzhaft genommen und bei seiner Entlassung mit folgenden Worten abgesetzt worden war: „Hilgers sagte zu mir: Wenn Sie noch einmal gegen mich meckern, werde ich Sie erschießen. Wer in Wuppertal erschossen wird, bestimme ich und sonst niemand; da kümmert sich auch kein Staatsanwalt drum. Jetzt können Sie gehen, Sturmführer sind Sie nicht mehr.“"

97 Beschl. des OPG, II. Kammer, v. 1.4.35 (BA, Sign. NS 36/14). Während die Ausschlußverf. v. 18.8.34 Verstoß gegen $\S 4$ Abs. 2a (ehrenrührige Handlungen) und $2 b$ (Zuwiderhandeln gegen die Bestrebungen der NSDAP) festgestellt hatte, sprach der Beschl. nur noch von Verstoß gegen Abs. 2b. 
Dieser hinsichtlich der Milde der Disziplinarstrafe wahrlich als „Aprilscherz“ zu bezeichnende Beschluß des Obersten Parteigerichts und vor allem seine Begründung kamen in der Auswirkung einer Sabotage des ordentlichen Strafverfahrens gleich. Gürtner, der am Tage der Hauptverhandlung vor dem Parteigericht abends länger im Ministerium geblieben war, um den telefonischen Bericht des als Zeuge nach München geladenen Staatsanwaltschaftsrats Winckler entgegenzunehmen, zeigte wie alle unmittelbar am Ermittlungsverfahren Beteiligten „tiefste Enttäuschung “9 ${ }^{98}$ In Wuppertal gewannen nunmehr die Parteikreise Oberwasser: die Angriffe gegen Winckler, dem Schroer in einem Brief an den Stabschef der SA Lutze eine "verständnislose und geradezu reaktionäre Haltung" zuschrieb"9, steigerten sich zu handfesten Drohungen und nächtlichen Anrempelungen. Schließlich war es nicht mehr zu umgehen, ihn auf Vorschlag des zuständigen Generalstaatsanwalts in Düsseldorf und mit seinem Einverständnis nach Kassel zu versetzen. ${ }^{100}$ Auf die Justiz wirkte der Beschluß des Parteigerichts allenthalben lähmend: in einer Unterredung mit dem Generalstaatsanwalt am 9. Mai 1935 mußte sich Joël damit abfinden, daß bis zur Beurlaubung des Leiters der Staatsanwaltschaft beim Landgericht Wuppertal - eines Oberstaatsanwaltes, der sich in „seiner Kritiklosigkeit allzu eng an die örtlichen Parteistellen angeschlossen“ hatte - in Sachen Kemna zunächst ,nichts veranlaßt werden“ sollte. ${ }^{101}$ Nachdem diese Beurlaubung erfolgt war, verfügte Joël am 23. August die Fortsetzung des Ermittlungsverfahrens. ${ }^{102}$ Einen Monat später brachte der offensichtlich zögernde Generalstaatsanwalt jedoch in Berlin erneut Bedenken gegen die Durchführung eines Prozesses vor $^{103}$ : einmal würden sich die Beschuldigten auf den „Grauertschen Erlaß ${ }^{\text {"104 }}$ berufen, der die Anwendung körperlicher Gewalt zur Aufklärung hoch- und landesverräterischer Handlungen indirekt genehmigt habe; zum anderen würden die Beweismittel, die hauptsächlich in Zeugenaussagen der Gefangenen und nur in wenigen ärztlichen Gutachten bestanden, nicht durchschlagen; auch beim Parteigericht hätte ja der bis

98 Eidesstattl. Versicherung des damaligen GStA Düsseldorf v. 12.7.47, der an diesem Tage bei Gürtner zum Vortrag war (Nürnbg. Juristenprozeß, Joël Dok. Nr. 6, Dok.Buch der Vert. I).

99 Eidesstattl. Vers. (s. voranstehende Anm.); laut Diensttagebuch des RJM, Bd. 2, Eintragung v. 25.3.35 (BA, Sign. R 22/603) übersandte Lutze die Beschwerde Schroers dem RJM: „Win[c]kler sei Repräsentant der Stahlhelmreaktion“. Im Diensttagebuch wird demgegenüber vermerkt: „Win[c]kler wird von Herrn Direktor Crohne [Leiter der Strafrechtspflegeabteilung] und Herrn Joël als ausgezeichneter Beamter beurteilt, der die Staatsautorität in seinem schwierigen Bezirk energisch zu wahren versuche. Der Angriff gegen Win[c]kler ist zusammenzuhalten mit der Beschwerde des Gauleiters Florian gegen Herrn Joël.“

${ }^{100}$ Eidesstattl. Vers. (s. Anm. 98) u. eidesstattl. Vers. Wincklers v. 15.5.47 (Nürmbg. Juristenprozeß, Joël Dok. Nr. 1, Dok.Buch der Vert. I). W. wurde zunächst in Düsseldorf beschäftigt (Diensttageb. des RJM, Bd. 4, Eintr. v. 8.7.35, BA, Sign. R 22/1059) und laut Personalnachweis (DC Berlin) Ende August 1935 von Wuppertal wegversetzt.

${ }^{101}$ Eidesstattl. Vers. des damaligen GStA Düsseldorf v. 12.7.47 (Anm. 98) u. Verm. Joëls v. 16.5.35 (Akten des RJM, BA, Sign. R 22/5032). Zur Charakterisierung jenes OStA u. den Schwierigkeiten Wincklers vgl. auch Ber. des GStA Düsseldorf v. 13.5.35 (Diensttageb. des RJM, Bd. 3, Eintr. v. 18.5.35, BA, Sign. R 22/1056; ferner Eintr. v. 8.7.35, a.a.O., Bd. 4, Sign. R 22/1059).

${ }^{102}$ Verm. Joëls v. 23.8.35 (Akten des RJM, a.a.O.). Die Beurlaubung des OStA erfolgte durch ein Dienststrafverfahren wegen einer anderen Sache (vgl. Diensttageb. des RJM, Bd. 6, Eintr. v. 22. 10.35, BA, R 22/1089).

${ }^{103}$ Bei seiner Anwesenheit anläßlich einer Bespr. aller GStAe im RJM am 23.9.35 (Verm. Joëls v. selben Tag, Akten des RJM, a.a.O.).

${ }^{104}$ In dem von Sts. Grauert gezeichneten Erl. des preuß. MdI v. 29.5.33 an alle RegPräs. wurde ausgeführt, die Erfahrung habe ,gezeigt, daß die Vernehmung wegen Verdachts politischer Straftaten oder staatsfeindlicher Umtriebe festgenommener Personen durch Beamte der ordentlichen Polizei in vielen Fällen nicht den Erfolg gehabt hat, der bei der Vernehmung derselben Personen durch Angehörige der SA und SS erzielt werden konnte“. Es erscheine daher angezeigt, ,in geeigneten Fällen in polizeilichem Gewahrsam befindliche 
jetzt ermittelte Sachverhalt nur zur Verhängung der mildesten Strafe geführt. Da Gürtner entschieden auf der Durchführung des Prozesses bestand, wurde dem Generalstaatsanwalt mitgeteilt, daß seine Verzögerungsmanöver und seine Absicht, nunmehr eine Niederschlagung anzustreben, „unmöglich“ seien. Gürtner verfügte, daß dem Zögernden die Urteile in den vergleichbaren, durchgeführten Prozessen wegen Mißhandlungen in den Lagern Bredow und Hohnstein zugeschickt wurden. ${ }^{105}$ Nunmehr verlegte sich der Generalstaatsanwalt auf eine andere Taktik: er behauptete, „für diesen ungeheuer schwierigen Fall keinen geeigneten Sachbearbeiter zur Verfügung" zu haben, und beantragte, ihm aus einem anderen Bezirk einen Sachbearbeiter zuzuweisen. ${ }^{106}$ Gürtner und Freisler waren „über diesen Antrag ungehalten“ und ordneten erneut eine Besprechung Joëls mit dem Generalstaatsanwalt an, in der dieser und der Erste Staatsanwalt, der nunmehr mit der Bearbeitung des Falles betraut worden war, die alten Bedenken vorbrachten und insbesondere betonten, daß „man in Wuppertal das Verfahren für längst erledigt", $d . h$. für niedergeschlagen halte. ${ }^{107}$ Unter dem Eindruck der Meldung vom 29. November 1935, daß Hitler den Verurteilten im Hohnstein-Prozeß die Strafen auf dem Gnadenwege zu erlassen beabsichtige ${ }^{108}$ - ein Umstand, der alle Anstrengungen zur Überwindung der zweifellos zu erwartenden Prozeßschwierigkeiten im Grunde als vergebliche Arbeit erscheinen lassen mußte -, erfolgte auch bei der Justizleitung der Umschwung: das Ministerium erklärte sich damit einverstanden, daß der Erste Staatsanwalt die noch notwendigen Vernehmungen durchführen, $d . h$. die Tatsachen möglichst eindeutig feststellen, dann aber mit dem Vorschlag auf Niederschlagung berichten möge. ${ }^{109}$

Dieser Bericht, der deutlich durch den Schock geprägt war, den der Beschluß des Obersten Parteigerichts bei der Justiz ausgelöst hatte, erfolgte am 18.Januar 1936. In ihm wurde dargelegt, daß eine Reihe der noch in einem Vorbericht Wincklers vom 29. Dezember 1934 angeführten belastenden Aussagen von Verletzten ausscheiden müsse, da sie „mit Rücksicht auf deren Persönlichkeit zur Überführung nicht ausreichen“. Zwei weitere im Vorbericht genannte Fälle hätten sich im Hinblick „auf den

Häftlinge ... von den nationalen Verbānden zu benennenden, mit Hilfspolizeibeamten zu besetzenden Dienststellen zur verantwortlichen Vernehmung ... zu überstellen“. (Staatl. Wojewodschafts-Arch. Stettin, Sign. Rep. 65 a [Reg. Stettin], akc. 1948, Polizei Nr. 85; abgedruckt in: Boguslaw Drewniak, Początki ruchu hitlerowskiego na Pomorzu Zachodnim 1923-1934 [Die Anfänge der Hitler-Bewegung in Pommern], Posen 1962, S. 273.)

${ }^{105}$ Verm. Joëls v. 29.9. und 3.10.35 (Akten des RJM, a.a.O.); auch Freisler trat für einen Prozeß ein. Noch kurz vor dem Beschl. des Obersten Parteigerichts, am 29.3.35, hatte auch der GStA eine andere Haltung eingenommen und berichtet, „daß in mehreren Polizeigefängnissen seines Bezirks ... in nicht unerheblichem Umfange gemißhandelt würde“, „daß die Mißhandlungsfälle aus dem Lager Kemna nachdrücklich verfolgt werden und daß diese Verfolgung gefährdet erscheint, wenn die in der Sache Kemna Beschuldigten sich etwa auf eine milde Behandlung der hier in Frage stehenden Mißhandlungen [in den Polizeigefängnissen] berufen könnten“ (Diensttageb. des RJM, Bd. 2, Eintr. v. 2.4.35, BA, Sign. R 22/603).

${ }^{106}$ Verm. für Joël v. 8. 10. 35 (Akten des RJM, a.a.O.).

${ }^{107}$ Verm. Joëls v. 12., 17. u. 29.10.35 (a.a.O.). Es konnte nicht geklärt werden, ob der EStA, der vorher in Köln tätig war, auf den erwähnten Antrag des GStA hin nach Wuppertal versetzt oder nur mit der Bearbeitung des Falles beauftragt wurde.

${ }^{108}$ Verm. des Ministerbüros für Gürtner über den Anruf Sts Meissners v. 29.11.35 (Nürnbg. Dok. PS-786). In seiner eidesstattl. Vers. v. 12.7.47 (Anm. 98) behauptet der frühere GStA Düsseldorf sogar, er habe damals erfahren, daß Hitler die Durchführung des Kemna-Prozesses nicht wünsche; das von ihm darüber informierte RJM habe daraufhin entsprechende Erkundigungen eingezogen, die dies bestätigten. In den Unterlagen lassen sich keine Belege dafür finden.

${ }^{109}$ Verm. Joëls v. 15.12.35 (Akten des RJM, a.a.O.). 
inzwischen eingetretenen Tod der Häftlinge nicht mehr aufklären lassen“. Auf zwei „außerhalb der eigentlichen Mißhandlungen“ liegende Fälle könne „unbedenklich das Straffreiheitsgesetz vom 7.August 1934 ( 3 Ziffer 3$)^{110}$ Anwendung finden“. In den übrigen Fällen könne dieses Gesetz jedoch nicht angewendet werden, weil die Art der - im Bericht genau dargestellten - Mißhandlungen „eine gemeine Gesinnung der Täter erkennnen läßt ( $\S 6$ des genannten Gesetzes)“. Jedoch hätten „die Überprüfung der Erfolgsmöglichkeit des Strafverfahrens ... und die Betrachtung des voraussehbaren Bildes einer etwaigen Hauptverhandlung und ihrer Auswirkungen sowie die Berücksichtigung des inzwischen bekannt gewordenen parteigerichtlichen Verfahrens“ zu „erheblichen Bedenken gegen die weitere Durchführung des Verfahrens Anlaß gegeben": Es müsse damit gerechnet werden, daß die wenigen unbeteiligten Zeugen - wie schon im Parteiverfahren - ihre früheren Aussagen wesentlich einschränkten, und auch die Verletzten ,in ihren Aussagen zurückhaltend sein werden“, da sie „neue Unannehmlichkeiten befürchten“. Ferner könnten den Beschuldigten - zum Teil SAFührer und alte Parteigenossen - als Beweismittel nur Zeugen gegenübergestellt werden, die großenteils Kommunisten seien und teilweise noch wegen Hochverrats verhängte Strafen verbüßten. Wie die Wachmannschaften im Parteigerichtsverfahren „die Darstellung der Verletzten in den Ermittlungsakten der Staatsanwaltschaft" mit der Behauptung pariert hätten, „daß nur Züchtigungen vorgenommen worden seien, die zur Aufrechterhaltung strenger Disziplin in dem mit durchaus unzulänglichen Mitteln gesicherten Lager, zur Brechung von Widerstand einzelner und zur Erzwingung von Aussagen über kommunistische Umtriebe erforderlich gewesen seien", würden sie sicher auch in der Hauptverhandlung derartige Schutzbehauptungen aufstellen, die „sich nicht immer [würden] ausräumen lassen“. Wegen der Anwendung körperlicher Gewalt bei Vernehmungen würden sich die Beschuldigten zudem auf den „Grauertschen Erlaß“ berufen. Die Kenntnis bei den Wachmannschaften, daß einzelne Gefangene vor ihrer Inhaftierung gegen SA-Angehörige handfeste Drohungen geäußert hätten, gebe „immerhin eine Erklärung dafür“, daß die Wachen bei der Aufdeckung dieser Umtriebe jede Hemmung verloren. Die außerordentlich starken Spannungen zwischen Nationalsozialisten und Kommunisten im Wuppertaler Bezirk seien, wie der Bericht sehr instruktiv feststellt, ,ja offenbar auch der Grund dafür gewesen, daß eine Reihe von Ermittlungsverfahren über Fälle von Tötungen s.Zt. niedergeschlagen worden" seien. ${ }^{11}$ Unter diesen Umständen würde die Aufrollung „dieser allgemeinhin in Vergessenheit geratenen Vorkommnisse" durch einen Prozeß nur eine unerwünschte neue Beunruhigung im Bezirk verursachen und auch der Auslandspresse willkommenen Anlaß geben, ,ihre alten Hetzereien wieder aufzugreifen und dem deutschen Ansehen neuen Schaden zuzufügen“. Gegenüber diesen Nachteilen müsse die „Unbefriedigung eines normalen Rechtsempfindens“ darüber, daß einzelne Täter ihre verdiente Strafe nicht erhielten, in Kauf genommen werden. Denn wenn auch der Spruch des Obersten Parteigerichts als „bedauerlich milde“ angesehen werden müsse, so bringe er doch eine Auffassung zum Ausdruck, der sich die Justiz ,im jetzigen Zeitpunkt wenigstens“ werde anschließen müssen: es gehe nicht an, Ereignisse, „die sich ganz kurze

${ }^{110}$ Es handelt sich um den „Übereifer“-Paragraphen dieses G., vgl. Kapitel IV.1.d., S. 335.

${ }^{111}$ Hier folgen im Text als Beispiele - keineswegs als erschöpfende Aufzählung - die Aktenzeichen von sieben Ermittlungsverfahren, die sämtlich 1933 anhängig geworden waren. 
Zeit nach der formalen Beendigung der Revolution ereignet haben, ... nach Ablauf von nahezu $2 \frac{1}{2}$ Jahren mit der Rechtsauffassung normaler Zeit zu werten und ihnen mit Tatbeständen des ordentlichen Strafgesetzbuchs wirklich gerecht zu werden“. Mit fortschreitendem zeitlichen Abstand werde man „die Vorkommnisse im Lager Kemna als einen Teil der zur Niederzwingung des Kommunismus erforderlichen revolutionären Gewalthandlungen“ ansehen müssen, „unter denen sie zwar eine wenig rühmliche Rolle spielen, aber doch wohl bei einer solch gewaltigen Umwälzung ... hingenommen werden“ müßten. Der Staatsanwalt übergebe dem Reichsjustizministerium die Akten daher mit dem Vorschlag, „dem Führer und Reichskanzler die Niederschlagung des gesamten Verfahrens anzuempfehlen “. ${ }^{112}$

Auf der Grundlage dieses Berichts entwarf die Zentralstaatsanwaltschaft ein Schreiben mit einem entsprechenden Antrag an Hitler. Anders als im Bericht der Staatsanwaltschaft Wuppertal wurden jedoch etwaige Beweisschwierigkeiten mit keinem Wort erwähnt, sondern die sadistischen Quälereien ausführlich und als feststehende Tatsachen berichtet. Die ungeschminkt und kraß dargestellten Beschuldigungen stehen hier in einem merkwürdigen Gegensatz zu dem wesentlich kürzer als im Staatsanwaltschaftsbericht begründeten Antrag auf Niederschlagung - so als wollten die über den Ausgang des von ihnen mit zäher Energie betriebenen Verfahrens enttäuschten Sachbearbeiter der Zentralstaatsanwaltschaft Hitler die Absurdität einer solchen Entscheidung vor Augen führen und ihn zu einer nochmaligen Überprüfung veranlassen. Der Entwurf wurde von Gürtner ohne Änderungen gebilligt, das Schreiben am 10. Februar 1936 von ihm unterzeichnet und abgesandt. ${ }^{113}$ Zehn Tage später kam der von Hitler vollzogene Niederschlagungserlaß von der Präsidialkanzlei an das Ministerium zurück $^{114}$ : damit hatte das Verfahren in Sachen Kemna ein vorläufiges Ende gefunden, es sollte nach dem Sturz des Regimes wiederaufgenommen werden.

Anders als bei den Komplexen Bredow und Kemna hatte es die preußische Justiz bei der Untersuchung der Vorgänge im Lager Esterwegen mit einem „staatlich anerkannten“ Konzentrationslager zu tun, das im Laufe der hier geschilderten Ereignisse nicht aufgelöst, sondern Himmlers zentralem Inspekteur der Konzentrationslager unterstellt wurde. Diese Tatsache erschwerte den Justizbehörden die Arbeit und trug zu dem mageren Ergebnis ihrer Bemühungen wesentlich bei.

Esterwegen gehörte zu jenen Lagern, die auf Betreiben des Gauleiters von WeserEms und Reichsstatthalters für Oldenburg und Bremen, Röver, vom preußischen Innenministerium ab März 1933 in den Moorgebieten des Emslandes eingerichtet wurden. Bewacht wurden sie seit dem Sommer nicht mehr von der Schutzpolizei, sondern durch meist erwerbslose SS-Angehörige, die der Führer der SS-Gruppe West, Fritz

${ }^{112}$ Ber. des OStA beim LG Wuppertal an das RJM v. 18.1.36, „in Vertretung“ gezeichnet vom erwähnten EStA (Akten des RJM, a.a.O.), vgl. auch Diensttageb. des RJM, Bd. 7, Eintr. v. 21.1.36 (BA, Sign. R 22/928).

113 Akten des RJM, a.a.O. Der Entw. war auch von MinDir. Crohne ohne Änderungen gebilligt und gezeichnet worden.

${ }^{114}$ Schr. Meissners an das RJM v. 20.2.36 (a.a.O.). Als das Verfahren 1947 wieder aufgenommen wurde, wurde Winckler, der damals als Hilfsarbeiter in einer Wuppertaler Herdfabrik arbeitete, als StA wieder eingesetzt und - als bester Kenner der Prozeßmaterie - mit der Anklage betraut. Der Prozeß vor dem LG Wuppertal (s. Anm. 75) endete am 15.5.48 mit einem Todesurteil für Hilgers (Veller war unterdessen verstorben), vier lebenslänglichen Zuchthaus- und weiteren Freiheitsstrafen. 
Weitzel, aus dem Ruhrrevier abgestellt hatte. ${ }^{115}$ Außer zu zahlreichen Mißhandlungen kam es in Esterwegen im September und Oktober 1933 zu mehreren Tötungen „auf der Flucht“. So wurde u.a. der frühere sozialdemokratische Polizeipräsident von Altona, Eggerstedt, nach vorangegangenen Mißhandlungen am 12. Oktober von einem SS-Scharführer mit dem Karabiner in den Rücken geschossen, als er bei Außenarbeiten zusammen mit drei anderen Häftlingen einen schweren Baumstamm trug. Als er schwerverletzt am Boden lag, schoß ihm ein zweiter Scharführer in den Hinterkopf. Der Richter des zuständigen Amtsgerichts in Sögel, der von dieser „Erschießung auf der Flucht" unterrichtet wurde, vernahm am nächsten Tag die beiden SS-Leute, die angaben, sie hätten nach Anruf mit dem Gewehr aus einer Entfernung von 80-100 Meter bzw. mit der Mauserpistole aus 35-40 Meter Entfernung auf den Flüchtenden geschossen. Da die Art der Einschüsse berechtigte Zweifel an den Aussagen aufkommen ließ, eröffnete der Oberstaatsanwalt beim Landgericht Osnabrück nach Eingang des Untersuchungsberichtes ein Ermittlungsverfahren. Die Ermittlungen ergaben, daß die Absicht, Eggerstedt zu töten, dem Leiter der Gestapodienststelle in Osnabrück schon vorher vertraulich mitgeteilt worden war, und daß sich Angehörige des Wachpersonals in einem Lokal dieses Mordes gerühmt und weitere angekündigt hatten. Der um Stellungnahme gebetene Osnabrücker Gestapoführer sandte jedoch die Akten kommentarlos an die Staatsanwaltschaft zurück. ${ }^{116}$

Die ruchbar gewordenen Zustände und zahlreiche Beschwerden der umwohnenden Bevölkerung über Ausschreitungen des Wachpersonals führten dazu, daß noch während der Ermittlungen die Bewachung der Emslandlager auf Befehl Görings und gegen den Widerstand des SS-Gruppenführers Weitzel im November 1933 von der preußischen Schutzpolizei übernommen wurde. Kommandant wurde jedoch ein SAHauptsturmführer, Heinrich Remmert. Ob tatsächlich das Eingreifen der Zentralstaatsanwaltschaft, d.h. Joëls, zu diesem Entschluß beigetragen hat - wie Diels berichtet - muß angesichts der ungenügenden Quellenlage dahingestellt bleiben. ${ }^{117}$ Für die Justiz hatte die Wachablösung jedenfalls die nachteilige Folge, daß die Ermittlungen erschwert wurden, da die SS-Führung über den neuen Aufenthaltsort der als Zeugen in Frage kommenden ehemaligen SS-Bewacher keine Auskunft gab. Das Verfahren gegen die beiden Scharführer mußte schließlich eingestellt werden. ${ }^{118}$

${ }^{115}$ Ưber Errichtung und Zustände in den Emslandlagern vgl. die dreibändige Dokumentation v. E. Kosthorst u. B. Walters, Konzentrations- und Strafgefangenenlager im Dritten Reich: Beispiel Emsland, Düsseldorf 1983; ferner W. Perk, Die Hölle im Moor, Frankfurt a. M. 1970. Durch RdErl. des preuß. MdI v. 14.10.33 (Arch. des IfZ, Sign. MA 198/2) wurden diese Lager als staatl. KZs anerkannt.

${ }^{116}$ Zur Ermordung E.s u. den nachfolg. Ermittlungen vgl. Urt. des Schwurgerichts Oldenburg gegen Groten v. 29.10.49 (Arch. des IfZ, Sign. Go 02.03, abgedruckt bei Kosthorst, a.a.O., S. 319 ff.), in dem aus den Ermittlungsakten des OStA Osnabrück 4J 228/34 aus den Jahren 1933/34 zitiert wird.

${ }^{117}$ Diels, Lucifer ante portas, S. 261 f., seine eidesstattl. Vers. v. 9.5.47 (Nürnbg. Juristenprozeß, Joël, Dok. Nr. 7, Dok. Buch der Verteid. I, S. 44 f.); eidesstattl. Vers. des ehemal. Sts. Grauert v. 21.3.47 (Joël, Dok. Nr. 5, a.a.O., S. 25 f.). Ob es bei der Wachablösung tatsächlich zu der von Diels (Lucifer, a.a.O.) geschilderten dramatischen Situation kam, daß sich die mit Maschinengewehren bewaffnete SS verschanzte, sich zur Verteidigung sogar mit den Gefangenen verbrüderte und von zwei Hundertschaften Schutzpolizei regelrecht belagert werden mußte, bis Verhandlungen zu einem unblutigen Abzug der SS führten, ist gleichfalls dokumentarisch nicht belegbar. Hinweise finden sich lediglich bei W. Langhoff in dem nach seiner Haftentlassung in der Schweiz veröffentlichten Bericht von 1935: Die Moorsoldaten, 4. Aufl., Stuttgart 1978, S. $262 \mathrm{ff}$.

${ }^{118}$ Verm. aus den Ermittl.Akten 4J 228/34 des OStA Osnabrück, zit. bei Perk, a.a.O., S. 17. 
Während alle anderen Emslandlager im Frühjahr 1934 als Konzentrationslager aufgelöst und als Strafvollzugslager von der Justizverwaltung übernommen wurden ${ }^{119}$, kam Esterwegen Anfang August 1934 in die Zuständigkeit Himmlers und wurde dem Inspekteur der Konzentrationslager, SS-Gruppenführer Eicke, unterstellt. Neuer Kommandant wurde SS-Standartenführer Loritz.

Auch unter Remmert, der im Range eines SS-Sturmbannführers von der SA in die SS übernommen wurde und Führer der Wachtruppe des Lagers blieb, wurden die Schutzhäftlinge, die bei unzureichender Ernährung schwere Arbeit im Moor verrichten mußten, brutal mißhandelt, u.a. zur Quälerei vorübergehend lebendig eingegraben. ${ }^{120}$ Als die staatsanwaltschaftlichen Ermittlungen gegen Remmert begannen, wurde er zu einem Ausbildungslehrgang ins Konzentrationslager Dachau versetzt. Am 2. September 1934 erließ das Amtsgericht Sögel auf Veranlassung des Oberstaatsanwalts beim Landgericht Osnabrück jedoch Haftbefehl gegen ihn ${ }^{121}$, der auch vollzogen werden konnte, da die Ermittlungen auf Anordnung Görings erfolgten und von der Zentralstaatsanwaltschaft unterstützt wurden. Als zwei Vertreter der Osnabrücker Staatsanwaltschaft - ein Staatsanwaltschaftsrat und ein Gerichtsassessor - im September 1934 den Auftrag erhielten, im Lager Vernehmungen zu den Vorfällen und gegebenenfalls Verhaftungen von SS-Wachleuten durchzuführen, baten sie den Regierungspräsidenten von Osnabrück, ihnen für diese Aufgabe Beamte der Staatspolizei zur Verfügung zu stellen. Der Regierungspräsident wandte sich jedoch an das für die Verhaftung von Angehörigen der SA und SS zuständige SA-Feldjägerkorps ${ }^{122}$ in Münster, das dem Staatsanwaltschaftsrat ein Kommando von fünfzehn Mann beigab. Über die weiteren Vorgänge berichtete der Regierungspräsident "streng geheim“ an seinen Vorgesetzten, den Oberpräsidenten der Provinz Hannover, Stabschef der SA Lutze:

„Der Staatsanwalt begab sich darauf - zunächst ohne die Feldjäger - ins Lager und bat den Kommandanten, SS-Standartenführer Lorenz [richtig: Loritz], ihm die Vernehmung und gegebenenfalls Verhaftung der in Betracht kommenden Täter zu gestatten. Der Standartenführer L. verweigerte dies. Erst nach längerer Verhandlung, als sich die Feldjäger dem Lager näherten, gab Lo-

${ }^{119}$ Als Strafgefangenenlager wurden eingerichtet: I (= Börgermoor), IV (= Brual-Rhede), V (= Neusutrum) und VI (= Oberlangen), vgl. DJ v. 25. 5.34, S. 661. Esterwegen (=Teillager II und III) blieb bis September 1936 KZ und wurde erst im Jan. 1937 von der JVerw. übernommen. Die Strafgefangenenlager wurden nicht, wie bei Vollzugsanstalten sonst üblich, dem zuständigen GStA, sondern dem RJM direkt unterstellt. Ihr „Kommandeur" Werner Schäfer war zwar beamteter Vorgesetzter des Strafvollzugs (ab 1937 ORRat), zugleich aber Führer des SA-Sturmbanns z.b.V. (ab 1937 SA-Pionierstandarte 10) der SA-Gruppe Nordsee, dem als Wachtruppe der RJVerw. die Bewachung oblag. Daher gelang es dem RJM als Aufsichtsbehörde nicht, sich bei Übergriffen der Wachleute gegenüber Schäfer durchzusetzen. Auf das 1938 gegen ihn wegen Mißhandlungen u. a. von der Dienststrafkammer des OLG Celle durchgeführte Verfahren, das dank des von Gauleiter Röver ausgeübten Drucks mit einem bloßen Verweis endete, kann in unserem Zusammenhang nicht eingegangen werden. Schäfer konnte erst 1953 wegen Körperverletzung im Amt zu zweieinhalb Jahren Gefāngnis verurteilt werden (vgl. E. Kosthorst, a.a.O., S. 2323 ff., 2459 ff., 2745 ff.).

120 Vernehmungsprotok. der StAschaft Osnabrück v. 3. u. 7.9.34, zusammenfassender Ber. des OStA Osnabrück an den preuß. JM v. 9.9.34 - 1J852/34 - (in Ausz. zit. bei Perk, a.a.O., S. 25 ff., 29 ff.).

121 Haftbefehl u. Schr. des OStA Osnabrück an die OSAF v. 2.9.34 (Personalunterlagen Remmert, BA Berlin), in dem es hieß, es handle sich um einen ähnlichen Vorfall, ,wie er von dem Führer in der Zeit vom 30. Juni bis 2. Juli 1934 gesühnt worden" sei. Gemeint war die bei der Röhm-Aktion erfolgte Erschießung der drei SS-Angehörigen Hoffmann, Fink und Pleines, angeblich wegen Gefangenenmißhandlung (vgl. dazu Anm. 102 zu Kapitel V.1.d.).

122 Zum FJK vgl. Anm. 33 zum Kapitel IV.5., S. 424. 
renz nach (!) und liess den Staatsanwalt die erforderlichen Amtshandlungen vornehmen. Im Laufe dieses Tages wurden dann zwei Verhaftungen durchgeführt. Der Fortgang der Aktion geschah zwei Tage später, ebenfalls unter dem Schutz der Feldjäger. “123

Bei dieser Aktion vernahmen die Beamten der Staatsanwaltschaft vierzehn Häftlinge, die den bemerkenswerten Mut zu Aussagen aufbrachten, sowie einige beschuldigte SS-Leute, die sich auf die geltende Lagerordnung beriefen, nach der Prügelstrafen und unter gewissen Umständen sogar Todesstrafen vorgeschrieben seien. Nach einigem Zögern händigte der Lagerkommandant dem Staatsanwalt die von Eicke am 1.August 1934 für Esterwegen erlassene und von Himmler gebilligte Disziplinar- und Strafordnung aus. Sie sah nicht nur das äußerst qualvolle „Pfahlbinden“ und die Prügelstrafe - z. B. je 25 Stockhiebe zu Beginn und am Ende eines vierzehntägigen „strengen Arrestes" - vor; bei bestimmten Handlungen, zu denen auch die Weitergabe von "wahren oder unwahren Nachrichten“ über das Lager gehörte, konnte der Gefangene „kraft revolutionären Rechts als Aufwiegler gehängt“ werden. ${ }^{124}$ Die Vernehmungen ergaben, daß bei der mit zweifachen Ochsenziemern vollzogenen Prügelstrafe tatsächlich die doppelte Anzahl der angeordneten Schläge verabreicht wurde und die Häftlinge danach häufig ins Lazarett gebracht werden mußten. ${ }^{125}$

Wie der zuständige Generalstaatsanwalt in Celle Anfang November 1934 an das Reichs- und Preußische Justizministerium berichtete, wurde der Staatsanwaltschaftsrat, der die Vernehmungen im Lager durchgeführt hatte, von Osnabrücker Gestapobeamten gewarnt; in Esterwegen sei „in aller Öffentlichkeit“ erklärt worden, das Lager sei nunmehr vollständig ummauert, mit Maschinengewehren ausgerüstet und stelle eine „bewaffnete Macht" dar: „wenn nochmals Staatsanwalt oder Feldjäger in der Nähe gesehen werde, so werde gleich das Feuer eröffnet“. Der Staatsanwaltschaftsrat solle erschossen werden, falls er irgendwo beim Lager angetroffen werde. Am 27. Oktober sei Gauleiter Röver mit dem aus der Untersuchungshaft wieder entlassenen Remmert $^{126}$ in einer Versammlung von 1200 Personen erschienen, die sich daraufhin regelrecht zu einer Kundgebung für Remmert ausgewachsen habe. Der Gauleiter habe u.a. erklärt: „Von Rechts wegen gehörten diejenigen Personen ins Gefängnis, die Remmert hineingebracht hätten. “127 Nachdem die Ermittlungsakten von der Zentralstaatsanwaltschaft in Berlin geprüft worden waren, erteilte sie mit Görings Einverständnis die Weisung, das Verfahren gegen Remmert zu eröffnen. Der Prozeß, der Mitte November 1934 vor dem Landgericht Osnabrück stattfand, endete mit der Verurteilung Remmerts zu fünfzehn Monaten Gefängnis. ${ }^{128}$ Das Urteil brachte dem

${ }^{123}$ Ber. des Reg.Präs. v. Osnabrück v. 27.9.34 (Nürnbg. Dok. NO-2520, abgedruckt bei E. Kosthorst, a.a.O., S. 215).

${ }^{124}$ A.a.O., S. 205 ff. Zu dieser Disziplinar- u. Strafordnung, die Eicke am 1.10.33 bereits im KZ Dachau eingeführt hatte, vgl. Kapitel VI.4.b., S.645f., 648.

${ }^{125}$ Ber. des RegPräs. von Osnabrück (a.a.O.).

${ }^{126}$ Der SA-Standartenführer in Osnabrück hatte sich für Remmerts Entlassung mit der Begründung eingesetzt, „daß die Verhaftung nur auf Grund römischen Rechts erfolgt sei, sie sei nicht nationalsozialistisch“ (Ber. des GStA Celle an das RJM v. 26.9.35, Diensttageb. des RJM, Bd. 5, Eintr. v. 30.9.35, BA, Sign. R 22/1088).

${ }^{127}$ Ber. des GStA Celle an das RJM v. 9.11 .34 (Diensttageb. des RJM, Bd. 1, Eintr. v. 12.11.34, BA, Sign. R 22/ 131). Die berichtende Stapostelle Osnabrück wandte sich gegen diese Äußerungen, da sie der Staatsautorität schadeten.

${ }^{128}$ Vgl. Diensttageb. des RJM, Eintr. v. 13.11.34 (a.a.O.). Die Höhe d. Strafe geht aus R.s SS-Stammkarte (DC Berlin) hervor, danach hat R. aber nur 13 Wochen U-Haft verbüßen brauchen, was offensichtl. mit der Niederschl. durch Hitler (vgl. Anm. 134) zusammenhängt. R. blieb Wachtruppenf. in Esterwegen u. wurde April 1935 Kommandant d. KZ Lichtenburg. 
Staatsanwaltschaftsrat in Osnabrück, der im Lager Esterwegen ermittelt hatte, wegen "unnationalsozialistischen Verhaltens" als SA-Mann erhebliche Schwierigkeiten von seiten seiner SA-Vorgesetzten ein. ${ }^{129}$

Hatte die strafrechtliche Verfolgung im Falle Remmert zu einem Erfolg geführt, so wurde das Vorgehen der Justiz gegen die an den Mißhandlungen in Esterwegen beteiligten SS-Wachen - offensichtlich durch die Intervention Himmlers bei Hitler - verhindert. Bereits in der ersten Novemberhälfte wurde der Oberstaatsanwalt Osnabrück von der Zentralstaatsanwaltschaft telefonisch angewiesen, neue Fälle von Mißhandlungen im Lager Esterwegen nicht mehr zu verfolgen. ${ }^{130}$ Aber auch die noch anhängigen Ermittlungsverfahren stagnierten: Ende November berichtete der Oberstaatsanwalt, daß er gegen einen SS-Kompanieführer wegen Marterung eines holländischen Staatsangehörigen, der im Juni völlig entstellt aus dem Lager entlassen worden war, nicht weiter ermitteln könne, da ihm der Lagerkommandant erklärt habe, „er habe Weisung, Ermittlungen im Lager nicht zu dulden “. ${ }^{131}$ Die zunehmenden Widerstände, auf die die Staatsanwaltschaft in dieser Zeit bei ihrer Tätigkeit auch in anderen Lagern stieß, die Eicke unterstellt worden waren, hingen mit dem Ausbau des Systems der Konzentrationslager zusammen, deren Bewacher seit Ende 1934 nicht mehr zur Allgemeinen SS gehörten, sondern in eigenen, kasernierten „SS-Wachverbänden“ zusammengefaßt waren ${ }^{132}$, für die die SS-Führung militärähnliche Sonderstrafbefugnisse anstrebte. ${ }^{133}$ Am 3. Dezember 1934 teilte die Zentralstaatsanwaltschaft dem Oberstaatsanwalt in Osnabrück schließlich mit, daß Hitler das Verfahren gegen die Angehörigen der Lagerbesatzung von Esterwegen durch einen Erlaß vom 29. November niedergeschlagen habe. $^{134}$

Außer mit diesen spektakulären KZ-Fällen war die Zentralstaatsanwaltschaft mit einer Unmenge kleinerer, keineswegs hochpolitischer Fälle befaßt, in denen der Justiz durchaus Erfolg beschieden war. Bei der Beurteilung ihrer Tätigkeit kann davon ausgegangen werden, daß ihre Referenten in der überwiegenden Zahl der Fälle für eine Durchführung der anfallenden Strafverfahren eintraten und Niederschlagungen nicht auf ihre, sondern auf die Initiative politischer Stellen zurückgingen. Durch diese Haltung machten sich ihre Mitarbeiter bei den Funktionären der verschiedenen Organisationen der NS-Bewegung nicht gerade beliebt. Bei einer Begegnung in Berlin hielt z.B. der Essener Gauleiter Terboven Staatsanwaltschaftsrat Joël vor, „daß er sich in seiner

${ }^{129}$ Ber. des GStA Celle an das RJM v. 26.9.35 (Diensttageb. des RJM, Bd. 5, Eintr. v. 30.9.35, BA, Sign. R 22/1088). Nach der Verhandlung erklärte der Osnabrücker SA-Standartenf. dem StARat, „daß es gelogen sei, daß Göring die Verfolgung angeordnet habe. Die Anklage sei von einem Manne, der noch 1932 gegen die Nationalsozialisten vorgegangen sei, der Mann müsse erschossen werden."

${ }^{130}$ Diensttageb. des RJM, Bd. 1, Eintr. v. 13.11.34 (BA, Sign. R 22/131).

${ }^{131}$ Ber. des OStA Osnabrück an das RJM v. 26.11.34 (Diensttageb. des RJM, Eintr. v. 28.11.34, a.a.O.). Auch vorangegangene Ermittlungen der Stapo Osnabrück waren ergebnislos geblieben. Himmler hatte in einem Schr. v. 5. 10.34 behauptet, die SS komme als Täter „nicht in Frage“ (a.a.O., Eintr. v. 9.10.34).

${ }^{132}$ Vgl. M. Broszat, Nationalsozialistische Konzentrationslager 1933-1945 (Anatomie des SS-Staates, Bd. II, Olten u. Freiburg i. Br. 1965), S. 72.

${ }^{133}$ Zur Auseinandersetzung zwischen Justiz und SS- und Polizeiführung wegen der Zuständigkeit für die Verfolgung von Straftaten in den $\mathrm{KZ}$ vgl. Kapitel VI.4.a. und VI.4.c.

${ }^{134}$ Schr. der ZStA an den OStA Osnabrück v. 3.12.34 (Perk, a.a.O., S. 33). Da die Akten dem Verf. nicht zur Verfügung standen, konnte nicht geklärt werden, welche Stellen die Niederschlagung bei Hitler durchsetzten. Ähnlich negativ wie im Fall Esterwegen verlief offensichtlich die Verfolgung von Mißhandlungen und „Tötungen auf der Flucht“ im KZ Neusustrum, das gleichfalls zu den Emslandlagern gehört hatte (vgl. Ber. des OStA Osnabrück v. 9.11. und 5.12.34, Diensttageb. des RJM, Eintr. v. 15.11. und 17.12.34, a.a.O.). 
Amtsführung nicht als Diener, sondern als Gegner des Dritten Reiches zeige“. Joël erwiderte, daß seiner Meinung nach die Staatsordnung außer durch Gesetzesbrecher auch durch diejenigen gefährdet werde, die Ungesetzlichkeiten duldeten. ${ }^{135}$ Während es innerhalb des Justizministeriums zwischen Mitgliedern der Zentralstaatsanwaltschaft und Staatssekretär Freisler mehrmals zu Auseinandersetzungen gekommen zu sein scheint ${ }^{136}$, fanden die Mitarbeiter dieser Behörde Rückhalt und Unterstützung bei Gürtner, nachdem dieser die Geschäfte des preußischen Justizministers übernommen hatte. Ihre Erfolge - meist in politisch weniger wichtigen „Feld-, Wald- und Wiesenfällen" - sind der Justiz in der Auseinandersetzung mit der NS-Bewegung als Positivum anzurechnen und haben zur Verteidigung der Rechtsordnung beigetragen. Daß die Zentralstaatsanwaltschaft zugleich als Informationszentrale für die politische Führung über einschlägige Fälle diente und deren Entscheidung für Niederschlagungen oder Straferlasse widerspruchslos in juristische Formen bringen mußte ${ }^{137}$, war in ihrer Aufgabenstellung und ihren klar umrissenen Kompetenzen begründet. Gerade weil aber die politische Führung in wichtigen Verfahren jederzeit eingreifen und eine Einstellung der Strafverfolgung anordnen konnte, konnte die Aktivität der Zentralstaatsanwaltschaft für die Aufrechterhaltung der gesetzlichen Ordnung keine entscheidende Auswirkung haben. Mit dem Übergang der Landesjustizverwaltungen auf das Reich wurde diese Behörde vom Reichsjustizministerium übernommen und ihr Tätigkeitsbereich auf das ganze Reichsgebiet ausgedehnt. ${ }^{138}$ Abschließend sei erwähnt, daß sich ihre Aktivität bis zu ihrer Auflösung im Oktober $1937^{139}$ außer auf politische Ausschreitungen, die in diesem Zeitraum an Zahl und Umfang abnahmen, auch auf das Gebiet der Korruption von NS-Funktionären erstreckte. Auch in den folgenden Jahren betraute Gürtner Joël mit der Bearbeitung heikler Einzelfälle, so z. B. mit den Mißständen, die sich unter Streicher in der Gauleitung von Franken anläßlich der „Arisierung “ jüdischen Eigentums entwickelt hatten.

${ }^{135}$ Vgl. eidesstattl. Erklärung des Zeugen dieses Gesprächs, RegRat Dr. H., v. 3.3.47 (Nürnberger Juristenprozeß, Joël Vert. Dok. Nr. 63, Dok.Buch der Verteidigung III, S. $56 \mathrm{f}$.).

${ }^{136}$ Vgl. eidesstattl. Vers. v. Haackes v. 15.4.47 (a.a.O., Dok. Nr. 4, Dok.Buch der Verteidigung I, S. 18f.), eidesstattl. Vers. des ehemal. GStA Hamburg v. 8.5.47 (a.a.O., Dok. Nr. 21, Dok.Buch der Verteidigung II, S. 3 f.). Der spätere Gen.Oberstabsrichter Dr. Lehmann, der bis 1937 als MinRat in der Gesetzgebungsabt. des RJM arbeitete, berichtete: „Ich war einmal im Zimmer von Staatssekretär Freisler, als dieser ein erregtes Telefongespräch mit Joël führte. Joël schien stark zu opponieren, denn der Staatssekretär sagte schließlich in schärfster Form: ,Herr Joël, ich verbitte mir diesen Ton. Sie haben das zu tun, was ich anordne!'. Dann warf er wütend den Hörer auf den Apparat und setzte sich mit feuerrotem Kopf wieder zu uns an den Tisch" (eidesstattl. Vers. v. 21.3.47, a.a.O., Dok. Nr. 26, Dok.Buch der Verteidigung II, S. 18 f.).

${ }^{137}$ Diese Tatsache führte zu einer Kontroverse bei der Vernehmung Joëls am 19.12.46 durch Beauvais (Arch. des IfZ, Sign. ZS 438), der meinte, Joël habe von sich aus die Niederschlagung des Verfahrens in Sachen Kemna beantragt, weil der von Gürtner unterzeichnete Entwurf des Antrags an Hitler v. 10. 2.36 (vgl. Anm. 113) seine Paraphe trug (vgl. dazu auch die Fälle Vogel und Hohnstein, Kapitel IV.3, S.372 f.).

${ }^{138}$ Vgl. RV des RJM v. 4.7.35, abgedruckt in: Krug, Schäfer, Stolzenburg, Strafrechtliche Verwaltungsvorschriften, 1.Aufl. Berlin 1936, S. 17.

${ }^{139}$ RV des RJM v. 6. 10.37 (Akten des RJM, Hauptbüro, Arch. des BJM). 


\section{Probleme bei der Strafverfolgung in Sachsen und Hamburg: die Mißhandlungen in den Konzentrationslagern Hohnstein und Fuhlsbüttel}

Zwei bemerkenswerte Fälle strafrechtlicher Verfolgung von Mißhandlungen in frühen Konzentrationslagern in Sachsen und Hamburg, mit deren Auswirkungen auch das Reichsjustizministerium befaßt wurde, nahmen eine für die Beleuchtung unserer Problematik sehr aufschlußreiche, wenn auch unterschiedliche Entwicklung: die Komplexe Hohnstein und Fuhlsbüttel.

Bei Hohnstein handelte es sich neben Bredow um den zweiten größeren Fall, in dem die Justiz ein Gerichtsverfahren gegen die Wachmannschaften von Konzentrationslagern durchsetzte. Die Berliner Zentralstaatsanwaltschaft, die zu dieser Zeit für außerpreußische Gebiete noch nicht zuständig war, sollte hier im Verlauf der Verreichlichung der sächsischen Justizverwaltung mit der Abschirmung des Verfahrens gegen Eingriffe des sächsischen Reichsstatthalters und Gauleiters Mutschmann sowie mit den Nachwehen des Prozesses befaßt werden.

Das „Schutzhaftlager Hohnstein“ war im März 1933 auf der gleichnamigen Burg über dem Polenztal in der Sächsischen Schweiz eingerichtet worden. Nach einer Vereinbarung des sächsischen Innenministeriums mit dem Justizministerium war das Lager zunächst von Beamten der Gefangenenanstalt I Bautzen geführt worden. Bald kam es indes mit dem abgeordneten SA-Bewachungskommando zu Unstimmigkeiten, da „die Einrichtung des Lagers und die Behandlung der Schutzhäftlinge nach dem $\mathrm{Mu}$ ster einer Gefangenenanstalt ... nicht für vereinbar gehalten wurden mit dem durch die Verhängung der Schutzhaft beabsichtigten Zweck "1; die Folge war die Übernahme der Lagerleitung durch die SA am 5.April 1933. Von nun an wurden die Gefangenen schon bei ihrer Aufnahme einem sogenannten „Einstand“ unterworfen, d.h. in der Schreibstube geschlagen und auf der „Kammer" bei der Ausgabe der Schlafdecken mit Stöcken, Peitsche und Gummiknüppeln längere Zeit durchgeprügelt, aber auch beim täglichen Exerzieren, bei Vernehmungen oder völlig ohne Anlaß in ihren Zellen schwer mißhandelt. Der Sadismus der Bewacher äußerte sich z. B. darin, daß sie brennende Zigaretten auf den Gesichtern der Inhaftierten ausdrückten, ihnen die Bärte herausrissen oder ihnen den SA-,Ehrendolch“ ins Gesäß stießen. Wie Gürtner später an Reichsinnenminister Frick berichtete, „mußten Häftlinge solange unter einem eigens zu diesem Zweck konstruierten Tropfapparat stehen, bis ihre Kopfhaut von den in gleichmäßigen Abständen herunterfallenden Wassertropfen schwere eitrige Verletzungen aufwies“.2 Mehrere der Opfer mußten ins Krankenhaus überführt werden, und es gab Selbstmorde. Hatte sich Gürtner von der Durchführung des Stettiner Prozesses (Bredow) eine abschreckende Wirkung erhofft, so mußte er später enttäuscht feststellen, daß die Mißhandlungen in Hohnstein „ihren Höhepunkt im April

\footnotetext{
Vgl. Urteil des LG Dresden v. 15.5.35 gegen Jähnichen u. a. (DC Berlin, Akten des OPG).

2 Schr. Gürtners an Frick v. 14.5.35 mit Az. der ZStA (Nürnbg. Dok. PS-3751, abgedruckt in: IMG, Bd. XXXIII, S. $56 \mathrm{f}$.); zu den Vorgängen im Lager ferner Urteil des LG Dresden v. 15.5.35 (a.a.O., Anm. 1) u. Schr. des RJM v. Dez. 1935 (Nürnbg. Dok. PS-785, vgl. Anm. 25). Nach dem Krieg veröffentlichte die VVN, Kreis Dresden, Erlebnisber. ehemaliger Häftlinge: Von der Jugendburg Hohnstein zum Schutzhaftlager Hohnstein, Berlin-Potsdam, 1949.
} 
1934“ erreichten, „mehrere Wochen nachdem das Urteil in dem Stettiner Mißhandlungsprozeß in der gesamten deutschen Presse zur Abschreckung und Warnung veröffentlicht worden war". 3

Die Ermittlungen im Hohnsteiner Fall wurden in der Kompetenz der sächsischen Justiz durch die Staatsanwaltschaft beim Landgericht Dresden geführt. Das Geheime Staatspolizeiamt in Dresden, seit Januar 1934 Himmler unterstellt, unterstützte die Ermittlungen gegen die Schutzhaftlager-,Konkurrenz“. Der gleichzeitig als Ministerpräsident amtierende SA-Obergruppenführer in Sachsen, von Killinger, legte der Untersuchung nichts in den $\mathrm{Weg}^{4}$; dazu mochte beitragen, daß der damalige sächsische Justizminister Thierack selbst als Standartenführer im Stab der SA-Gruppe Sachsen saß. ${ }^{5}$ Das Lager Hohnstein wurde Mitte August 1934 aufgelöst.

Als die Staatsanwaltschaft Ende Oktober gegen den Lagerkommandanten, SAObersturmbannführer Jähnichen, und weitere 24 Bewacher Anklage erhoben hatte, teilte Gauleiter Mutschmann dem Reichsjustizminister am 19. Dezember mit, daß er das Verfahren niederzuschlagen beabsichtige, da eine Durchführung dem Ansehen der Bewegung schade. ${ }^{6}$ Nachdem sich Gürtner von der Zentralstaatsanwaltschaft über den Fall hatte berichten lassen ${ }^{7}$, antwortete er am 18. Januar 1935, daß seit der Neuregelung vom Frühjahr $1934^{8}$,das Recht zur Niederschlagung anhängiger Strafsachen in den Fällen, in denen die Tat nach dem 20. März 1934 begangen worden ist, nicht mehr den Reichsstatthaltern, sondern ausschließlich dem Führer und Reichskanzler" zustehe, daß er sich aber im vorliegenden Falle außerstande sehe, Hitler eine Niederschlagung vorzuschlagen. Soweit die Taten vor dem erwähnten Stichtag lägen und damit in Mutschmanns Niederschlagungskompetenz fielen, mache er auch gegen diese Absicht „die größten Bedenken geltend“: die Mißhandlungen zeugten

„von einer Roheit und Grausamkeit der Täter, die deutschem Empfinden und Fühlen völlig fern liegt. Derartige an orientalischen Sadismus erinnernde Grausamkeiten können auch in der größten kämpferischen Erbitterung keine Erklärung und Entschuldigung finden.“

Im Hinblick auf die Erfahrungen mit den bisherigen Prozessen könne er die Befürchtung nicht teilen, daß derartige Verfahren dem Ansehen der Bewegung abträglich seien, vor allem, weil die Verhandlung unter Ausschluß der Öffentlichkeit stattfinden könne. ${ }^{9}$

So begann am 20. März 1935 die Hauptverhandlung unter Ausschluß der Öffentlichkeit vor der 12. Großen Strafkammer des Landgerichts Dresden. Durch die Verhandlung spukte noch einmal der Geist Röhms, als der Verteidiger Jähnichens auf jene ominöse Verfügung des ermordeten Stabschefs vom 31.Juli 1933 Bezug nahm, wonach als Sühne für einen getöteten SA-Mann „Angehörige der feindlichen Organisation, von der der Mord vorbereitet wurde, gerichtet werden“ dürften: nun erst sollte

\footnotetext{
Schr. des RJM v. Dez. 1935 (a.a.O.).

Aussage des ehemal. SA-Obergruppenf. Jüttner v. 16.6.46 (IMG, Bd. XXI, S. 255).

Personalakten Thierack (DC Berlin).

Diensttageb. des RJM, Bd. 1, Eintr. v. 22.12.34 (BA, Sign. R 22/131)

Vgl. eidesstattl. Vers. v. Haackes v. 26.8.47 (Nürnbg. Juristenprozeß, Joël Dok. Nr. 88, Dok.Buch der Verteidigung V, S. $51 \mathrm{ff}$.).

Vgl. Kapitel IV.1.d., S.334f.

9 Schr. Gürtners an Mutschmann v. 18.1.35 mit Az. der ZStA im RuPrJM (Nürnbg. Dok. PS-783, abgedruckt in: IMG, Bd. XXVI, S. $300 \mathrm{f}$.).
} 
es der Justiz gelingen, mit Hilfe des Geheimen Staatspolizeiamtes Sachsen den genauen Wortlaut dieser Verfügung zu erhalten. ${ }^{10}$ Aber das Argument, daß die Mißhandlungen „Vergeltung für kommunistische Gewaltakte“ dargestellt hätten, fand keine Anerkennung, da eine große Anzahl der betroffenen Opfer niemals einer Linkspartei angehört hatte, einige von ihnen sogar alte Anhänger der Bewegung waren, die sich bei Parteifunktionären unbeliebt gemacht hatten. Am 3. Mai beantragte der Staatsanwalt gegen Jähnichen 5 Jahre Zuchthaus, gegen zwei weitere Angeklagte gleichfalls mehrjährige Zuchthausstrafen und gegen die anderen Täter Gefängnisstrafen $z$ wischen $3 \frac{1}{2}$ Jahren und 7 Monaten; in einem Falle plädierte er für Einstellung des Verfahrens aufgrund des Amnestiegesetzes vom August 1934. ${ }^{11}$

In diesem Stadium des Prozesses intervenierte Mutschmann erneut, diesmal mit einem Schreiben an den Gerichtsvorsitzenden, in dem es u.a. hieß:

„Ohne in das Verfahren eingreifen zu wollen oder die Absicht zu haben, Sie als Richter irgendwie zu beeinflussen [!], möchte ich doch vor der Urteilsfällung noch einmal darauf hinweisen, daß die Verhältnisse, wie sie durch den Umschwung im Jahre 1933 geschaffen worden waren und sich zweifellos bis Anfang 1934 auswirkten, bei der Urteilsfällung nicht außer Acht gelassen werden können.“

Es müsse berücksichtigt werden, daß Jähnichen keine gemeine Gesinnung nachgesagt werden könne, und daß ,in Hohnstein der Auswuchs der Menschheit zu betreuen war“. Er wolle daher ,anheimstellen, zu prüfen, ob ... nicht vielmehr ein Freispruch in Erwägung zu ziehen“ sei. Jedenfalls halte er es für seine „Pflicht, als Gauleiter nochmals auf die besonderen Umstände hinzuweisen". ${ }^{12}$

Trotz dieses Eingriffs ließ sich die Justiz nicht beirren. Jedoch fielen die Strafen geringer aus, als sie der Staatsanwalt beantragt hatte, da das Gericht alle denkbaren Milderungsgründe berücksichtigte. So erwuchs z. B. den Angeklagten aus der Tatsache, daß sie als Hilfspolizisten Beamte im Sinne des Strafrechts waren und wegen Körperverletzung im Amt ( $\$ 340 \mathrm{StGB}$ ) verurteilt werden mußten, kein Nachteil bei der Strafzumessung: im Urteil wurde berücksichtigt, daß sie „als Beamte keine zweckentsprechende Ausbildung genossen haben und auf ihre Beamteneigenschaft nicht besonders nachdrücklich hingewiesen worden" seien. Auch erkannte das Gericht an, daß „bei den Mißhandlungen z.B. der Gedanke maßgebend gewesen sei(n), Angaben zur Verhütung weiterer staatsfeindlicher Umtriebe zu erlangen“; es stellte jedoch unmißverständlich fest, bei den Vernehmungen hätten

"die Mißhandlungen doch in vielen Fällen ein Ausmaß angenommen, das sich mit dem gesteckten Ziele nicht mehr vereinbaren und erkennen läßt, daß es den Beteiligten nicht nur darauf ankam, Angaben zu erlangen, sondern daß sie aus reiner Lust an Quälereien gehandelt haben“.

Das Gericht kam daher zu dem Schluß, die zur Aburteilung stehenden Mißhandlungen seien

10 Ber. des OStA beim LG Dresden an das RJM v. 11.6.35 mit Begleitschr. des GStA Dresden v. 22.6.35 (Akten des RJM, Arch. des IfZ, Sign. MA 108). Vgl. auch Kapitel IV.1.c., S.329. Wortlaut der Verf. im Urteil des LG Dresden v. 15.5.35 (a.a.O.) zitiert.

11 Gürtners Ber. an Heß v. 5.6.35, Az. der ZStA (Nürnbg. Dok. PS-784, abgedruckt in: IMG, Bd. XXVI, S. $301 \mathrm{ff}$.$) .$

12 Schr. Mutschmanns an LGDir. Dr. Roth v. 8.5.35, Abschrift im Ber. Gürtners an Heß v. 5.6.35 (a.a.O.). 
„auch nicht etwa als Ausfluß nationalsozialistischer Weltanschauung im Übereifer im Kampfe um den nationalsozialistischen Gedanken begangen worden. Sie sind verübt worden an wehrlosen Gefangenen ohne jeden begründeten Anlaß nicht zum Zwecke der Erziehung, sondern aus reiner, roher Lust am Schlagen und Quälen ... Nach Ansicht des Gerichts sind die Handlungen einer rohen und gemeinen Gesinnung entsprungen, die nichts mit dem Nationalsozialismus gemein hat." ${ }^{\text {"13 }}$

Das am 15. Mai 1935 verkündete Urteil sprach dem unterdessen zum Standartenführer beförderten Jähnichen ,wegen Körperverletzung im Amte in Tateinheit mit deren Duldung in zwei Fällen, teilweise gemeinschaftlich begangen“, eine Strafe von 6 Jahren Gefängnis, weiteren 22 Angeklagten Gefängnisstrafen zwischen 33/4 Jahren und 10 Monaten zu; gegen zwei Angeklagte wurde das Verfahren aufgrund der August-Amnestie eingestellt. Die Gauleitung Sachsen rächte sich auf der Stelle: die beiden Schöffen, die an der Verhandlung als Richter mitgewirkt hatten, wurden drei Tage nach der Urteilsverkündung mit sofortiger Wirkung aus der NSDAP ausgeschlossen, da sie „den Bestrebungen der NSDAP zuwidergehandelt" hätten ( $\S 4$ Abs. 2b der Satzung). ${ }^{14}$ Derartige Strafen, wie sie das Landgericht verhängt habe, schrieb der Gaubeauftragte an das für den Ausschluß zuständige Dresdener Kreisgericht der NSDAP, gingen

„gegen jedes nationalsozialistische Rechtsempfinden, und mußten vor allen Dingen die beiden nationalsozialistischen Schöffen ... nicht den formalen Rechtsstandpunkt des Gerichtsvorsitzenden teilen, sondern als Nationalsozialisten sich darüber klar sein, daß es sich bei den Mißhandelten um üble Marxisten gehandelt hat ... Ich vertrete den Standpunkt, daß Parteigenossen, die ein derartiges Urteil gutheißen, gegen die nationalsozialistischen Grundsätze verstoßen und ein bewußtes parteischädigendes Verhalten an den Tag legen." ${ }^{\text {"S }}$

Den anklagevertretenden Staatsanwalt, der der SA angehörte, versuchten seine SAVorgesetzten schon bei Bekanntwerden des Strafantrags aus der SA auszuschließen. Da der Ausschluß jedoch vor der Urteilsverkündung lag, wurde ihm von der Obersten SA-Führung nicht stattgegeben, da er einen Eingriff in ein laufendes Verfahren dargestellt hätte; dem Staatsanwalt wurde aber von seinem Obersturmbannführer nahegelegt, von sich aus auszutreten. ${ }^{16}$

Gürtner nahm diese Vorgänge zum Anlaß, beim Stellvertreter des Führers Heß am 5.Juni auf diese „äußerst bedenkliche und höchst unerwünschte Folge des gesetzlich völlig einwandfreien Strafverfahrens“ hinzuweisen. Habe schon Mutschmanns Schreiben an den Gerichtsvorsitzenden bei diesem den Eindruck erwecken können, „daß hier von hoher Stelle auf seine richterliche Entschlußfassung eingewirkt werden sollte“, so müsse das in erhöhtem Maße von den Maßnahmen gegen die beiden Schöffen gelten: Ein derartiges Vorgehen gegen Laienrichter

13 Urteil des LG Dresden v. 15.5.35 (a.a.O.). Im Schr. des RJM v. Dez. 1935 (Nürnbg. Dok. PS-785, vgl. Anm. 25) heißt es, die Mißhandlungen seien ,weder zur Erzielung eines politischen Zweckes (Erlangung eines Geständnisses, Brechung von Widersetzlichkeit oder dergl.) noch in Erwiderung früherer, von kommunistischer Seite erlittener persönlicher Unbill begangen worden“, sondern stellten sich als „Ausfluß sadistischer Brutalität" dar.

14 Schr. Gürtners an Heß v. 5.6.35 (Nürnbg. Dok. PS-784, a.a.O.). Nachdem der Einspruch der beiden Schöffen gegen ihren Ausschluß v. Gaugericht Sachsen abgelehnt worden war, kam die Sache im Dez. 1935 vor das OPG, dessen Entscheid. aus den Unterlagen nicht hervorgeht (DC Berlin, Akten der OPG).

15 Schr. v. 31.5 .35 (a.a.O.). Der Gaubeauftr. war als Vertreter Mutschmanns bei der Urteilsbegründung im Verhandlungssaal des LG zugegen gewesen.

16 Undat. Ber. d. Kreisleiters Dresden an das Gaugericht (a.a.O.); Schr. Gürtners an Heß v. 5.6.35 (Nürnbg. Dok. PS-784, a.a.O.). 
„würde in diesen naturnotwendig das Gefühl erwecken, daß sie einer bestimmten Stelle für ihre als Richter vorzunehmenden Handlungen verantwortlich seien. Damit würde die als Grundlage jeder ordnungsmäßigen Strafrechtspflege anzusehende richterliche Unabhängigkeit hinfällig werden. Außerdem würde aber der Laienrichter, der bei seinem Dienstantritt einen Eid dahin ablegen muß, daß er seine Stimme nach bestem Wissen und Gewissen abgeben werde, auf diese Weise in die schwersten inneren Konflikte gebracht werden. Nicht weniger bedenklich wären die Folgen derartiger Maßnahmen gegen den Vertreter der Anklagebehörde. Der Beamte würde ebenfalls in schwerste Konflikte bei der Ausübung seiner Dienstpflicht kommen. Damit würde die ordnungsgemäße sachliche Arbeit der Behörden der Strafrechtspflege so ernstlich gefährdet, daß ich mich verpflichtet halten würde, zu prüfen, ob bei einer derartigen Sachlage Staatsanwälte und Richter überhaupt noch Amtswalter der Partei oder Mitglieder der SA sein können.“

Damit schnitt Gürtner das Problem der „doppelten Loyalität“ gegenüber Parteiorganisation und Staatsapparat an, das auch bei den Verhandlungen über ein neues Beamtengesetz eine zentrale Rolle spielte. Er bat dafür zu sorgen, daß derartige für die Rechtssicherheit untragbare Vorkommnisse künftig unterbleiben. Ein in Teilen gleichlautendes Schreiben richtete Gürtner an den Stabschef der SA Lutze. ${ }^{17}$

Noch vor Beginn des Hohnstein-Prozesses, am 14. März 1935, hatte die Staatsanwaltschaft gegen den Oberregierungsrat beim sächsischen Geheimen Staaatspolizeiamt Vogel Anklage erhoben. Vogel hatte im Sommer 1933 im sächsischen Grenzgebiet zur Tschechoslowakei mehrere Verhaftungsaktionen gegen „politisch unzuverlässige“ Personen durchgeführt, die Schutzhäftlinge ins Lager Hohnstein bringen lassen und sich dort wiederholt an den Mißhandlungen beteiligt. Am 10. Mai 1935 hatte Vogel an Mutschmann ein Niederschlagungsgesuch gerichtet, das der Gauleiter befürwortend an Gürtner weiterreichte. ${ }^{18}$ Der Justizminister schrieb jedoch am 18. Juni an Hitler, daß er dieses Gesuch nicht befürworten könne. Die in Hohnstein begangenen Mißhandlungen seien weit zahlreicher und schwerwiegender als die Fälle im Lager Bredow, und „wie in dem Falle Bredow ein maßgeblicher Beamter der Geheimen Staatspolizei, ähnlich [= nämlich] der am 30.Juni erschossene SS-Sturmführer Dr. Hoffmann, von den Mißhandlungen gewußt und sie sogar zum großen Teil selbst angeordnet hatte“, so habe in Hohnstein Vogel als Angehöriger der zuständigen Aufsichtsbehörde die Mißhandlungen nicht nur gebilligt, sondern sogar selbst ausgeführt und damit die SA-Männer in ihrem Tun bestärkt. Man könne daher diesen Mittäter, der aufgrund seiner amtlichen Stellung den größten Teil der Verantwortung an den strafbaren Handlungen trage, nicht straflos ausgehen lassen, „während die SA-Führer und -Männer erhebliche, wenn auch im Vergleich zu ihrem Tun nicht sehr schwere Strafen erhalten" hätten. Gürtner argumentierte nicht ungeschickt, daß eine Niederschlagung in diesem Falle „eine unverdiente Bevorzugung eines höhergestellten und daher mit höherer Verantwortung ausgestatteten Mittäters darstellen“ und auch „so von allen Beteiligten aufgefaßt werden“ würde, und schloß: „Mit der Behandlung der Stettiner Fälle stünde sie im schroffsten unlösbaren Widerspruch. “19 Eine Woche später teilte der Chef der Präsidialkanzlei mit, daß Hitler die Angelegenheit vor einer Entscheidung mit Mutschmann persönlich besprechen wolle, und bat, „bis dahin dem

17 Schr. Gürtners, a.a.O.

18 Schr. Mutschmanns v. 20.5.35 (Diensttageb. des RJM, Bd. 3, Eintr. v. 31.5.35, BA, Sign. R 22/1056): V. leide an allgemeiner Nervenschwäche, so daß die Durchf. des Verfahrens „schwere gesundheitsschädigende Folgen" für ihn haben müsse.

19 Schr. Gürtners an Hitler v. 18.6.35, Az. der ZStA (Nürnbg. Dok. PS-787, abgedruckt in: IMG, Bd. XXVI, S. 322 ff.). 
Verfahren keinen Fortgang zu geben“" ${ }^{20}$ Bei der Unterredung mit Hitler aber trug Mutschmann den Sieg davon: am 9. September benachrichtigte Meissner den Reichsjustizminister, daß Hitler sich für eine Niederschlagung entschieden habe und den Entwurf eines entsprechenden Niederschlagungserlasses übersandt haben wolle. ${ }^{21}$

Unter dem Einfluß Mutschmanns entschloß sich Hitler, die Unstimmigkeit, die durch diese Niederschlagung gegenüber den Verurteilungen im Hohnstein-Prozeß entstanden war, auf eine Weise zu bereinigen, die den Absichten Gürtners geradewegs entgegenlief. Nachdem sich die Justiz Ende Oktober 1935 bereitgefunden hatte, die Strafen der Verurteilten mit einer Ausnahme nach Verbüßung des größeren Teils bedingt auszusetzen - so sollte z. B. Jähnichen statt nach 6 Jahren nunmehr nach $4 \frac{1}{2}$ Jahren auf Bewährung entlassen werden ${ }^{22}$-, betraute Hitler den Justizminister nochmals mit einer Prüfung, in welchen Fällen rein sadistische Motive verneint und daher weitere Gnadenerlasse ermöglicht werden könnten. Besondere Ermittlungen waren dafür noch im Gange, als Meissner am 29. November Gürtners persönlichem Referenten im Ministerbüro telefonisch mitteilte, der Chef der Kanzlei des Führers, Reichsleiter Bouhler, habe Hitler das Ergebnis neuerer Ermittlungen mitgeteilt ${ }^{23}$, die Bouhler und Mutschmann im Fall Hohnstein angestellt hätten. Daraufhin habe sich Hitler entschlossen, „nunmehr sämtliche Reststrafen zu erlassen“, und bitte um Vorlage eines entsprechenden Erlasses. Auf den Einwand, daß das Reichsjustizministerium von Hitler gleichfalls mit weiteren Untersuchungen beauftragt worden sei, wurde erwidert, daß es „dem Justizminister unbenommen bleibe“, seine Auffassung bei Hitler vorzutragen, nur solle es noch im Laufe der nächsten Woche geschehen. Falls Gürtner nach seiner Prüfung keine Gesamtbegnadigung befürworte, solle aber neben dem von ihm vorgeschlagenen Erlaßentwurf auf jeden Fall auch ein Entwurf für eine Vollbegnadigung vorgelegt werden. ${ }^{24}$

In einem sechzehnseitigen, von der Zentralstaatsanwaltschaft ausgearbeiteten Schreiben legte nunmehr der Justizminister dar, warum er sich bei elf der Verurteilten nicht in der Lage sehe, weitere Gnadenerlasse zu befürworten. In den anderen Fällen schlug er aufgrund der neuerlichen Ermittlungen Vergünstigungen vor, weil er „immerhin mit der Möglichkeit rechnen zu können glaube [!], daß der Täter sich auch von revolutionären Beweggründen hat mitleiten [!] lassen“. So sollte z. B. Jähnichen nunmehr schon nach $3 \frac{1}{2}$ Jahren bedingt entlassen werden. Im Entwurf des Erlasses war jedoch hinter dem Vorschlag des Reichsjustizministers jeweils schon eine Spalte für die Eintragung von Hitlers abweichender Entscheidung freigelassen worden. Offensichtlich war den Verurteilten von Parteiseite ihre Begnadigung bereits als feststehende Tatsache mitgeteilt worden, denn das Schreiben endete mit der Bemerkung,

${ }^{20}$ Schr. Meissners an Gürtner v. 25.6.35 (Nürnbg. Dok. PS-788, abgedruckt a.a.O.).

21 Schr. Meissners an Gürtner v. 9.9.35 (a.a.O.). Nach der GnadenO v. 6.2.35 (DJ, S. 203) oblag die Vorbereitung der Hitler vorbehaltenen Gnadenentschließungen im Bereich der ordentl. Gerichte dem RJM.

22 Die Gnadenerweise erfolgten durch Hitler mit Erl. v. 31.10.35 (vgl. Schr. des RJM v. Dez. 1935, Nürnbg. Dok. PS-785, Anm. 25), bis auf einen minder schweren Fall, in dem Hitler die Begnadigung dem RJM überließ (Schr. Meissners v. 27.9.35, Diensttageb. des RJM, Bd. 5, Eintr. v. 28.9.35, BA, Sign. R 22/1088).

23 Bouhler hatte sich schon Ende Juni/Anfang Juli für eine Begnadigung mit dem Argument eingesetzt, „die Notwendigkeit besonderer Züchtigungsmittel ergebe sich daraus, daß im April 1934 ein Schutzhäftling entflohen sei und in der Pfingstnacht ein weiterer Fluchtversuch entdeckt worden sei“ (Diensttageb. des RJM, Bd. 4, Eintr. v. 8.7.35, BA, Sign. R 22/1059).

${ }^{24}$ Verm. des Ref. v. 29.11.35 f. Gürtner, den Meissner nicht erreichen konnte (Nürnbg. Dok. PS-786, abgedruckt in: IMG, Bd. XXVI, S. 321 f.). 
„daß seit dem 29. November 1935 bei den Verurteilten wie auch bei den Verteidigern die Ansicht aufgetaucht" sei, durch Hitlers Entscheidung seien allen Verurteilten nunmehr endgültig „die gesamten Reststrafen erlassen“. Dem Ministerium sei bekannt geworden, daß in diesem Falle die „Verurteilten mit Musik abgeholt bzw. mit Musik in ihren Heimatorten festlich empfangen werden sollen". ${ }^{25}$ Es war, als wollte die Justiz noch einmal verdeutlichen, welchen Triumph eine volle Begnadigung für jene in Deuschland entfesselten Kräfte darstellen mußte, die das Recht im buchstäblichen Sinne mit Pauken und Trompeten zu Grabe tragen wollten. Hitler besiegelte mit seiner Entscheidung die Niederlage der Justiz: er bestätigte den Straferlaß für die Hohnsteiner Täter. ${ }^{26}$

Anders als im Fall Hohnstein kam es bei der Verfolgung der Mißhandlungen von Häftlingen im Konzentrationslager Hamburg-Fuhlsbüttel nicht zu einem Prozeß, da sich der Chef der Hamburger Justizverwaltung - der am 8. März 1933 zum Justizsenator ernannte Landgerichtsdirektor und Nationalsozialist Rothenberger - durch eine besonders enge Zusammenarbeit mit dem Gauleiter und Reichsstatthalter Kaufmann auszeichnete.

Ende März 1933 war der Hamburger Staatspolizei ein leerstehendes Werkgebäude in der Strafanstalt Fuhlsbüttel für die Verwahrung von Schutzhäftlingen zur Verfügung gestellt worden, von denen ein Teil allerdings auch im Sternbau des Zuchthauses untergebracht werden mußte. Da die Gefangenen von altgedienten Strafvollzugsbeamten bewacht wurden, waren sie zumindest hier vor Mißhandlungen sicher, wenn sie die brutalen Verhöre des aus SA- und SS-Angehörigen zusammengesetzten „Kommandos zur besonderen Verwendung“ im Hamburger "Stadthaus“ hinter sich gebracht hatten. Das gleiche galt für das Lager Wittmoor, das im April in einer Torfverwertungsfabrik nördlich von Hamburg eingerichtet worden war und von Beamten der Ordnungspolizei - wenn auch unter Hinzuziehung von SA-Hilfspolizei - geführt wurde. Die Tatsache, daß in Fuhlsbüttel die Häftlinge der politischen Polizei durch normale Wachbeamte der Justizverwaltung beaufsichtigt wurden, erschien dem Hamburger Gauleiter und anderen Führern der Bewegung nach einer Besichtigung untragbar, da diese Beamten ihrer Meinung nach "nicht energisch genug durchgriffen“. ${ }^{27}$

25 Nürnbg. Dok. PS-785 (Arch. des IfZ, auch abgedruckt in: IMG, Bd. XXVI, S. 307 ff.). Das Schr. trägt das Az. $\operatorname{der}$ ZStA, ist undat. u. nicht unterzeichnet und war offensichtlich für die Präsidialkanzlei zur Vorl. bei Hitler bestimmt. Da es auf Ereignisse v. 29.11.35 Bezug nimmt, kann es erst vom Dez. stammen, auch der zugehörige Erl.Entw. trägt den Ausfertigungsverm.: „Berlin, den ... Dezember 1935“, das Datum ist hier, wie bei derartigen Vorlagen üblich, für den Eintrag durch Hitler freigelassen. Da das Dok. ein Durchschlag ist, kann es sich um ein Doppel des abgegangenen Schr. handeln; es ist aber auch möglich, daß Hitler schließlich nur den Entw. für die Vollbegnadigung anforderte, das Schr. daher gar nicht an ihn abging und deshalb auch der Durchschlag nicht paraphiert wurde.

${ }^{26}$ Bei dieser Sachlage ist es nicht verwunderlich, daß der OStA Dresden im Februar 1936 das Verfahren gegen einen SA-Obersturmf. (zeitweiliger stellv. Lagerkommandant in Hohnstein), unter dessen Leitung ein Gefangener 1934 zum 60\% erwerbsunfähigen Krüppel geschlagen worden war, von vornherein aufgrund des G. v. 7.8.34 einstellte, ebenso ein neues Verfahren gegen Jähnichen aufgrund des $\$ 154$ StPO: „da die zu erwartende Strafe gegenüber der gegen ihn bereits verhängten Strafe nicht ins Gewicht falle“ (Ber. des GStA Dresden, Diensttageb. des RJM, Bd. 7, Eintr. v. 2.3.36, BA, Sign. R 22/928).

${ }^{27}$ Vgl. dazu Urt. des Schwurgerichts beim LG Hamburg gegen Dusenschön v. 16.10.62 (Arch. des IfZ, Sign. Gh 02.15). Über Errichtung u. Zustände im KZ Fuhlsbüttel ferner: H. Timpke, Das KL Fuhlbüttel (Studien zur Geschichte der Konzentrationslager, Stuttgart 1970, S. 11 ff.); ders. (Herausg.), Dokumente zur Gleichschaltung des Landes Hamburg, Frankfurt a. M. 1964, S. 227 ff.; G. Meyer, Nacht über Hamburg. Berichte und Dokumente 1933-1945, Frankfurt a. M. 1971, S. $173 \mathrm{ff}$. 
Auf der anderen Seite beschwerten sich auch die Justizbehörden, daß bei der gemeinsamen Unterbringung von Polizeihäftlingen und Strafgefangenen die Ordnung in der Strafanstalt durch die häufigen Vernehmungen der Schutzhäftlinge erheblich gestört wurde. Daraufhin wurde Anfang September 1933 für alle - auch die in Wittmoor befindlichen - Schutzhäftlinge in dem getrennt gelegenen Gebäude des ehemaligen Frauengefängnisses Fuhlsbüttel ein Konzentrationslager eingerichtet, das Kaufmanns Adjutant, der zum Regierungsrat ernannte ehemalige SA-Brigadeführer Ellerhusen, leitete. De facto wurde das Lager jedoch von SS-Sturmführer Dusenschön, dem Stellvertreter Ellerhusens und Kommandanten der aus erwerbslosen SA-, SS- und MarineSA-Angehörigen zusammengestellten Wachmannschaft, geführt. Nunmehr begann für die Häftlinge in Fuhlsbüttel eine Schreckenszeit: sie wurden geschlagen und getreten und im Keller mit Peitschen, Ochsenziemern und Stuhlbeinen teilweise bis zur Bewußtlosigkeit mißhandelt. Nach einem späteren Bericht Gürtners an Frick „wurden vier Häftlinge tagelang - einmal 3 Tage und Nächte, einmal 5 Tage und Nächte ununterbrochen in Kreuzesform an ein Gitter gefesselt und dabei so dürftig mit trockenem Brot verpflegt, daß sie beinahe verhungerten". ${ }^{28}$ Eine Anzahl von Gefangenen nahm sich das Leben, darunter der jüdische Sozialdemokrat und Redakteur des Lübecker "Volksboten“ Solmitz. ${ }^{29}$

Von den Vorgängen im Lager erfuhren Teile der Hamburger Bevölkerung durch anonyme Rundschreiben, die entlassene Häftlinge verfaßten und die in hektographierter Form u.a. auch Richtern, Justizbeamten und Rechtsanwälten in die Briefkästen geworfen wurden. ${ }^{30}$ Justizsenator Rothenberger tat alles, um ein Bekanntwerden der Mißhandlungen in der Öffentlichkeit zu unterdrücken. Als der im April 1933 neu eingesetzte Generalstaatsanwalt gegen den Führer und Angehörige des „Sonderkommandos z.b.V.“, die einen inhaftierten Arzt schwer mißhandelt hatten, ermitteln lassen wollte, wurde er von Rothenberger angewiesen, das Verfahren „im höheren Staatsinteresse“ einzustellen, da „tunlichst vermieden werden müsse, daß die Öffentlichkeit durch eine Gerichtsverhandlung von diesen Vorgängen Kenntnis erhalte“. ${ }^{31}$ Rothenberger scheint mit Reichsstatthalter Kaufmann, dem Leiter der Hamburger Staatspolizei, SS-Sturmbannführer Streckenbach, und dem Generalstaatsanwalt auch eine vertrauliche Absprache getroffen zu haben, daß die Leichen von „Selbstmördern“ aus dem Lager Fuhlsbüttel ohne die nach $\S 159$ StPO vorgeschriebene Einschaltung der Justizbehörden der Verbrennungsanstalt zugeführt werden sollten, um die Spuren vorangegangener Mißhandlungen zu verbergen bzw. zu beseitigen. Jedenfalls erfuhren die unteren Justizbehörden von der Existenz einer solchen Absprache ${ }^{32}$ - die es auch ermöglichte, die Tötung von Häftlingen ohne Nachprüfung durch die Justiz als Selbstmorde zu deklarieren - durch die Gestapo, als ein Sachbearbeiter der Staatspolizei am 17. September 1934 versehentlich bei der Staatsanwaltschaft um die Erlaubnis zur

${ }^{28}$ Schr. Gürtners an Frick v. 14. 5.35 (Nürnb. Dok. PS-3751; abgedruckt in: IMG, Bd. XXXIII, S. 45.ff.).

29 Solmitz' Schilderung der Vorgänge im Lager ist auf Zetteln erhalten geblieben, die seine Witwe im Gehäuse der ausgehändigten Taschenuhr des Toten fand, Inhalt wiedergegeben im Urt. des LG Hamburg v. 16. 10.62 (a.a.O.), in dem Dusenschön v. d. Anklage des Mordes an S. mangels Beweisen freigesprochen wurde.

30 Schr. Streckenbachs an GStA Hamburg v. 7.2.34 mit einem Exemplar als Anlage (Timpke, Dokumente zur Gleichschaltung des Landes Hamburg 1933, S. 254 ff.; das Flugbl. auch Arch. des IfZ, Sign. Fa 248).

31 Timpke, a.a.O., S. 257.

32 Ber. des Hamburger OStA für die Reichsleitung der NSDAP v. 19.11.34 (Arch. des IfZ, Sign. Fa 248), desgl. sein Ber. v. 31.7./28.8. 47 (Nürnbg. Dok. NG-656, Arch. des IfZ). 
Feuerbestattung eines Häftlings nachsuchte, der sich bereits drei Tage vorher (!) unter fragwürdigen Umständen - er war an beiden Händen gefesselt - im Lager Fuhlsbüttel nach Mißhandlungen erhängt hatte. Als die Staatsanwaltschaft beim Amtsgericht die Obduktion veranlaßte, wurde die Leiche unter Berufung auf die Absprache trotz gegenteiliger Anordnung des Amtsrichters ins Krematorium gebracht, konnte aber dort noch rechtzeitig sichergestellt und zurückgeholt werden. ${ }^{33}$

Als Anfang April 1934 einer der am Zellengitter ,gekreuzigten“ Gefangenen mit eiternden Handgelenken und geschwollenen Beinen ins Untersuchungsgefängnis eingeliefert wurde und sofort ins Lazarett gebracht werden mußte, erstattete ein Arzt Anzeige. Daraufhin leitete die Staatsanwaltschaft gegen Dusenschön und zwei Mitbeschuldigte ein Ermittlungsverfahren ein. Gauleiter Kaufmann ließ sich die Akten kommen, ordnete am 11. Mai an, daß die Ermittlungen nicht fortzuführen seien, und erbat den persönlichen Vortrag des Generalstaatsanwalts. Als die Akten Mitte Juni zurückkamen, wurden jedoch die Ermittlungen auf Drängen der Staatsanwaltschaft fortgesetzt. Der vernommene Dusenschön behauptete, der Häftling habe nur einen Tag am Gitter gefesselt stehen sollen, es handle sich folglich um eine Übertretung seines Befehls. Seine Angaben wurden durch die Aussagen von Wachmännern widerlegt, daß ihn ein SS-Scharführer mehrmals gefragt habe, ob der Gefangene wieder zu entfesseln sei. Nunmehr gab Dusenschön an, die Anweisung zur Dauerfesselung von Ellerhusen erhalten zu haben, der jedoch einen solchen Einzelbefehl als völlig unüblich abstritt. Die Ermittlungen ergaben, daß diese Art „Kreuzigung“ noch in mehreren anderen Fällen durchgeführt worden war. Gauleiter Kaufmann forderte vom Generalstaatsanwalt, daß das Verfahren aufgrund des inzwischen erlassenen Amnestiegesetzes vom 7. August 1934 eingestellt werden sollte. Als der zuständige Sachbearbeiter eine entsprechende Einstellungsverfügung mit den Akten vorlegte, lehnte der Oberstaatsanwalt - der die Amnestievorschläge in Vertretung des Generalstaatsanwalts zu prüfen hatte - die Gegenzeichnung mit der Begründung ab, daß die Amnestie keine Handlungen einschließe, die aus gemeiner Gesinnung begangen wären: „als Jurist, Mensch und Christ" müsse er einem Einstellungsbeschluß in diesem Falle energisch widersprechen. Er unterbreitete dem Generalstaatsanwalt eine eigene Stellungnahme ${ }^{34}$ und schlug vor, der Vorlage an die Justizverwaltung hinzuzufügen, daß Personen, die „mit schwerer Zuchthausstrafe bedrohte Verbrechen gegen ihrer Obhut anvertraute wehrlose Gefangene begehen, nicht an ihrem Platze sind und schleunigst mit ihren Helfern entfernt werden müssen“. Wer sich dieser Forderung nicht anschließe, laufe Gefahr,

„sich mitschuldig zu machen, wenn solche Torturen bei uns in Deutschland sich wiederholen und solche verbrecherischen Handlungen nicht ausgerottet werden. Jeder die geschlossene und festgefügte deutsche Volksgemeinschaft erstrebende deutsche Mann und Kämpfer sollte mit allen Mitteln zu verhindern suchen, daß solche ... Gepflogenheiten nicht in Deutschland sich einschleichen und nicht mehr als Gemeinheit empfunden werden."

Er schloß seine Stellungnahme mit dem Satz: „Wie der Führer selber über solche Handlungen denkt, geht klar aus seiner Äußerung in seiner Reichstagsrede hervor, wonach er 3 SS-Männer wegen Mißhandlung polit. Gefangener hat erschießen las-

33 Die Obduktion bestätigte lediglich den Tod durch Erhängen (Ber. des stellv. GStA an die LJVerw. Hamburg v. 17.9. u. 2.11.34; Korresp. zwischen Justizbeh. u. Polizei, Nürnbg. Dok. NG-2489, a.a.O.).

34 Ber. für den GStA v. 15.8.34 (Arch. des IfZ, Sign. Fa 248). 
sen." ${ }^{\text {35 }}$ Er riet dem Generalstaatsanwalt bei der unterschiedlichen Auffassung, die innerhalb der Staatsanwaltschaft über diesen Fall herrsche, die Frage einer Anwendung der Amnestie gemäß $\S 10$ des Amnestiegesetzes durch das Gericht entscheiden zu lassen und dem Gauleiter diese Absicht zu unterbreiten. Der Generalstaatsanwalt aber entschied entsprechend dem Wunsch des Gauleiters und legte dem Chef der Hamburger Justizverwaltung die Einstellungsverfügung vor. In diesem Falle neigte selbst Rothenberger dazu, einen Prozeß durchführen zu lassen, sah aber davon ab, als Kaufmann ankündigte, daß er das Verfahren dann kraft seiner Befugnis als Reichsstatthalter niederschlagen werde. ${ }^{36}$ Da sich die Vorgänge vor der „Verreichlichung“ der Hamburger Justizverwaltung abspielten, wurde das Reichsjustizministerium nicht informiert.

Daß die Hamburger Justizleitung derartige strafbare Handlungen deckte, brachte den Oberstaatsanwalt und einige seiner Kollegen in Gewissenskonflikte, weil sie sich durch Duldung dieser Machenschaften der Teilnahme an einer Begünstigung im Amt (§346 StGB) schuldig machten, die immerhin mit einer Zuchthausstrafe bedroht war. $\mathrm{Da}$ ein in den folgenden Wochen unternommener Versuch, bei einem Berlinbesuch vertraulich an Gürtner oder dessen persönlichen Referenten von Dohnanyi heranzutreten, fehlschlug ${ }^{37}$, vertraute sich der Oberstaatsanwalt - selbst Parteigenosse - verschiedenen höheren Stellen der Bewegung an, in denen die Angelegenheit von Gegnern Kaufmanns als des Hauptverantwortlichen für die Hamburger Zustände aufgegriffen wurde. Am 18. November 1934 wurde der Oberstaatsanwalt durch einen Sonderbeauftragten des Stellvertreters des Führers zur Berichterstattung nach Hannover vorgeladen. Die Verletzung der Loyalität gegenüber seinen unmittelbaren Dienstvorgesetzten, deren sich der Oberstaatsanwalt durchaus bewußt war, begründete er bezeichnenderweise mit dem höherstehenden Treueverhältnis zum Führer und Reichskanzler: durch die beanstandeten Foltermethoden gegenüber Schutzhäftlingen werde der Aufbau der Volksgemeinschaft gestört, Empörung im Volk und neuer Haß geweckt, der möglicherweise „auch gegen die oberste Spitze zur Entladung kommen“ könne. Der Sonderbeauftragte sicherte ihm ausdrücklich den Schutz der Partei zu, falls ihm wegen seiner Meldung Nachteile entstehen sollten. Der Bericht des Oberstaatsanwalts wurde dem Stabsleiter beim Stellvertreter des Führers Bormann und von dort dem Obersten Parteigericht und Himmler zugeleitet, der ein Disziplinarverfahren des SS-Gerichts gegen Dusenschön und dessen Beurlaubung als SS-Führer anordnete. Der Chef des SS-Gerichts vertrat jedoch die Ansicht, man könne kein Verfahren gegen Dusenschön eröffnen, ohne auch Kaufmann zur Verantwortung zu ziehen, der als SS-Gruppenführer gleichfalls seiner Disziplinargerichtsbarkeit unterstand. ${ }^{38}$ Auch der

$35 \mathrm{Zu}$ Hitlers Reichstagsrede v. 13.7.34 vgl. Kapitel V.1.d., Anm. 102, S. 458, zur Erschießung der im Stettiner Bredow-Prozeß Verurteilten Hoffmann, Pleines und Fink vgl. Kapitel IV.2.b., S. 352.

36 Da die Tat vor dem 21.3.34 begangen wurde, hatte der Reichsstatthalter das Niederschlagungsrecht. Zum Voranstehenden vgl. Ber. des OStA für die Reichsleitung der NSDAP v. 19.11.34; Schr. des OStA an den Chef des OPG Buch v. 8.2.35; Verm. des Beauftr. der Parteileitung v. 2.12.34; Ber. SS-Oberf. Frhr. v. Schade v. 2.2.35 über sein Gespr. mit dem GStA; ders., Ber. v. 5.2.35 (Arch. des IfZ, Sign. Fa 248); Ber. des Hamburger OStA v. 31.7./28.8.45 (Nürnbg. Dok. NG-656, a.a.O.); Urteil des LG Hamburg v. 16.10.62 (Arch. des IfZ, Sign. Gh 02.15).

37 Schr. des OStA an Buch v. 8.2.35 (Arch. des IfZ, Sign. Fa 248)

38 Verm. Frhr. v. Schades v. 22.1.35 (a.a.O.). 
Chef des Obersten Parteigerichts, Reichsleiter Buch, bat die SS, die Untersuchung gegen Kaufmann „im Einverständnis mit [dem] Stellv. des Führers in aller Schärfe“ zu handhaben. ${ }^{39}$ Nachdem Himmler - wohl auf Weisung Hitlers - dazu vermerkt hatte: „zunächst nicht“, stellte sich nunmehr auch das SS-Gericht auf den Standpunkt, es läge nicht in seiner Zuständigkeit zu beurteilen, ob Kaufmanns Verhalten als Gauleiter und Reichsstatthalter richtig war oder „dem Ansehen der Partei geschadet“ habe. Gemäß seinem Vorschlag wurden daher die Akten Dusenschön Anfang März 1935 dem Obersten Parteigericht „mit der Bitte um weitere Veranlassung“ übersandt ${ }^{40}$; Himmler hob gleichzeitig die Beurlaubung Dusenschöns auf. Das Oberste Parteigericht aber unternahm nichts. ${ }^{41}$

War damit die Angelegenheit für den Beschuldigten erledigt, so galt das noch lange nicht für den Ankläger. Als Reaktion der Hamburger Stellen auf seine Schritte wurde der Oberstaatsanwalt am 4. Februar 1935 auf Betreiben Kaufmanns bis auf weiteres beurlaubt. Da Kaufmann verschiedentlich persönliche Gegner - so den Ortsgruppenleiter von St.Pauli, Bartholomä, und den SD-Vertreter Oberg - hatte verhaften und durchprügeln lassen, verließ der Oberstaatsanwalt Hamburg und begab sich in den benachbarten Gau Ost-Hannover. ${ }^{42}$ In einem Schreiben an Reichsleiter Buch, in dem er um jenen Schutzbrief der Reichsleitung bat, den ihm der Sonderbeauftragte bei der persönlichen Unterredung zugesagt hatte, geißelte der Oberstaatsanwalt nochmals in deutlichen Worten das Konzentrationslagerwesen:

„Wenn ich eingeliefert werde ins $\mathrm{KZ}$ und ich werde totgeprügelt, ... dann hängt man mir schnell noch im warmen Zustand eine Schlinge um den Hals, so daß eine Strangulationsmarke entsteht, und meine Frau bekommt dann eine Mitteilung, ihr Mann habe, offenbar im Bewußtsein seiner Schuld, durch Selbstmord seinem Leben ein Ende gemacht. Denn die (untergeordneten) Organe, die die Totprügelung direkt zu verantworten haben, finden auch noch einen Physikus, der einen Totenschein aufgrund eines Befundes mit Strangulationsmarke ausstellt, daß die Todesursache offenbar Selbstmord durch Erhängen ist ...

Im KZ Gestorbene werden, wenn Selbstmord ,feststeht', unter Umgehung der gesetzlich vorgeschriebenen Leichenschau usw. der Feuerbestattung zugeführt, alles geschieht mit Wissen und zum Teil offenbar unter Einwirkung und Druck des Reichsstatthalters, der in solchen Fällen die Amnestierung ,wünscht und dadurch jedenfalls mitverantwortlich wird ...

Ist das kein unmöglicher Zustand, ist das ein Zustand der eines Rechtsstaates würdig ist? Und da soll ich nicht berechtigt sein, über allen formalistischen Kram hinweg, mir den Kopf darüber zu zerbrechen, wie da Abhilfe geschaffen werden kann ... Sich da auf den Standpunkt zu stellen, unsere Vorgesetzten haben sich vor der Verantwortung gedrückt, die Sache ist nun für uns erledigt, wäre einer Selbstberuhigung des Gewissens gerade und lediglich durch rein formale Momente gleich gekommen und hätte nationalsozialistischer Pflichtauffassung in keiner Weise entsprochen."

Der Oberstaatsanwalt bat Buch, sich beim Reichsjustizministerium wegen der Aufhebung seiner Beurlaubung zu verwenden. ${ }^{43}$

Kurz darauf erhielt der Oberstaatsanwalt ein Schreiben der Hamburger Justizverwaltung, daß sie von einem Disziplinarverfahren gegen ihn absehe, ihn jedoch in den

39 Telegr. SS-Oberf. Frhr. v. Schade an SS-Brigadef. Scharfe v. 22. 1.35 mit Verm. Himmlers (a.a.O.).

${ }^{40}$ Aufz. Frhr. v. Schades v. 5.2.35, Schr. an das OPG v. 6.3.35 (a.a.O.).

${ }^{41}$ Die StAschaft beim LG Hamburg erbat die Akten schließlich am 2.12.35 zurück (a.a.O.).

42 Mitteil. des GStA Hamburg an den OStA v. 4. 2.35; Ber. Buchs an den Stellv. d. F. v. 5.2.35 (a.a.O.); zum Fall Oberg vgl. ferner Auss. des späteren SS-Obergruppenführers Oberg v. 4.10.60 (Akten der StAschaft beim LG München I, $3 \mathrm{Ks} 4 / 57$, Bd. XIV, Bl. $1240 \mathrm{a}$ ).

${ }^{43}$ Schr. des OStA an Buch v. 8. 2.35 (Arch. des IfZ, Sign. Fa 248). 
Ruhestand zu versetzen beabsichtige und ihn innerhalb einer festgesetzten Frist um seine Zustimmung ersuche. Am 19. Februar gelang es ihm, dem zweiten persönlichen Referenten Gürtners, Landgerichtsrat Kaulbach, seinen Fall und die Bitte um Weiterverwendung vorzutragen, wodurch das Reichsjustizministerium erstmals von $\operatorname{der}$ Angelegenheit Kenntnis bekam. ${ }^{44}$ Zwei Tage später hatte er auch ein Gespräch mit dem Chef der Kanzlei des Führers Bouhler im Beisein von Bormann, die seine Motive als der Pflichterfüllung entspringend anerkannten und ihm ihre Unterstützung zusagten, daß er im Amt bleiben, aber aus Hamburg wegversetzt werden solle: um den Eindruck einer Strafversetzung zu vermeiden, solle er dabei sogar befördert werden. Nachdem die Justizverwaltung der Länder endgültig auf das Reich übergegangen war, wurde er am 13. April 1935 von Freisler zu einer Unterredung ins Reichsjustizministerium bestellt. Freisler, der trotz seines Eintretens für alle "Notwendigkeiten“ des Regimes stets dann empfindlich reagierte, wenn die Zuständigkeit der Justiz beeinträchtigt wurde, bezeichnete die Hamburger Absprache zur Ausschaltung der Justizbehörden bei der Nachprüfung von Selbstmorden in der Schutzhaft als ,geradezu ein Ding der Unmöglichkeit“. Als Folge dieser Aussprache wurde dem Oberstaatsanwalt die Stelle des Landgerichtspräsidenten in Prenzlau angeboten. Die Justizstellen in Hamburg, wo Rothenberger nach der „Verreichlichung“ nunmehr als Oberlandesgerichtspräsident fungierte, durchkreuzten jedoch diesen Schritt, indem sie eine Eingabe des Oberstaatsanwalts in einer Personalsache vom Januar 1923 (!) - die Zweifel an seiner antisemitischen Einstellung aufkommen ließ - ausgruben und nach Berlin sandten. Nunmehr eröffnete ihm Freisler in einer erneuten Unterredung Anfang August 1935, daß er „ungeeignet für einen leitenden Posten“ sei. Nachdem er sich in einer eingehenden schriftlichen Stellungnahme gerechtfertigt hatte, wurde der Oberstaatsanwalt schließlich ab Februar 1936 als Senatspräsident beim Oberlandesgericht Köln verwendet. ${ }^{45}$

Der Fall Fuhlsbüttel macht erneut deutlich, daß auch Justizbehörden, die durchaus willens waren, die Ausschreitungen zu verfolgen, die Hände gebunden waren, wenn die vorgesetzten Leiter der Justizverwaltung - hier der Justizsenator und der Generalstaatsanwalt - die entgegenstehenden Wünsche der regionalen Parteiführer teilten; er zeigt aber auch, daß ein Erfolg bei dem Versuch, Rivalitäten innerhalb der Partei für die Verfolgung von Rechtsverletzungen auszunutzen, ganz von den Machtverhältnissen im Dschungel der Interessen- und Kompetenzkonflikte der NS-Bewegung abhing.

44 Gegen die erfolgte Niederschlagung der Sache Dusenschön aufgrund des G. v. 7.8.34 durch die Hamburger Justiz konnte Gürtner nach Lage der Dinge kaum etwas unternehmen. Er hatte jedoch daraufhin in der zweiten Märzhälfte 1935 mit Kaufmann eine Unterredung in Berlin, bei der auch noch ein anderer Mißhandlungsfall anläßlich eines Gestapoverhörs zur Sprache kam. Während die Hamburger Stapo der Ansicht war, daß nach dieser Aussprache der von der Justiz angeforderte Bericht über den Hergang der Vernehmung nicht mehr erstattet zu werden brauchte, hieß es dazu seitens des Ministeriums: „Nach Mitteilung des Herrn Ministers muß hier ein Mißverständnis vorliegen. Herrn Statthalter Kaufmann gegenüber hat Herr Min. auf den Bericht in der Sache W. nicht verzichtet." (Diensttageb. des RJM, Bd. 3, Eintr. v. 16. 5. 35, BA, Sign. R 22/1056). Derartige „Mißverständnisse“ waren bei Kaufmann offensichtlich nichts Ungewöhnliches: Gürtners Äußerung bei der Besprechung der Sache Dusenschön, daß unter alle Hamburger Fälle, soweit sie „amnestierfäbig"(?) seien, ein Strich gezogen werden sollte, interpretierte Kaufmann als Zusicherung Gürtners, daß alle Hamburger Fälle, die zeitlich unter die August-Amnestie fielen, niedergeschlagen werden sollten (so seine Äußerung gegenüber dem GStA Hamburg im Juni 1935, Diensttageb. des RJM, Eintr. v. 27.6.35, a.a.O.).

45 Vgl. Ber. des OStA v. 31.7./28.8.45 (Nürnbg. Dok. NG-656, Arch. des IfZ). 


\section{Probleme bei der Strafverfolgung in Bayern}

\section{a. Die Eingriffe der konkurrierenden Stellen der Bewegung und ibre Beilegung aufgrund der Straffreibeitsverordnung vom 2. August 1933}

In Bayern hatte sich nach der dortigen Machtübernahme im März 1933 die Justiz unter ihrem neuen Minister Hans Frank inmitten eines besonders verwirrenden Geflechts von Staats-, Partei-, SS- und SA-Positionen und -Kompetenzen zu behaupten. Das Innenministerium lag in der Hand des Gauleiters von Oberbayern, Adolf Wagner, demgegenüber sich Reichsstatthalter von Epp und Ministerpräsident Siebert als Vertreter des Staatsapparates nicht durchzusetzen vermochten, da ihnen eine Hausmacht innerhalb der Bewegung fehlte. Auch Franks Stellung beruhte in erster Linie auf seinem persönlichen Verhältnis zu Hitler, das sich in den vorangegangenen Jahren durch die anwaltliche Vertretung Hitlers und der NSDAP vor Gericht entwickelt hatte. Kommandeur der politischen Polizei, die alsbald die polizeiliche Bearbeitung aller Straftaten von Angehörigen der Partei und ihrer Gliederungen beanspruchen sollte, wurde am 1. April Reichsführer-SS Himmler, der schon im März als kommissarischer Polizeipräsident in München eingesetzt worden war. Die politische Polizei wurde aus der Polizeidirektion München ausgegliedert und als eigene Sonderbehörde innerhalb des bayerischen Innenministeriums eingerichtet. Der ,politische Polizeikommandeur Bayerns" und sein Vertreter Heydrich erhielten dabei Befugnisse, die Diels und das Geheime Staatspolizeiamt in Preußen vergeblich anstrebten: ihnen wurden alle in Bayern „bereits bestehenden und noch einzurichtenden Konzentrationslager“ einschließlich der Bewachung unterstellt ${ }^{1}$, so auch das am 20. März auf dem Gelände einer Pulverfabrik eingerichtete Lager Dachau. Obwohl dem Innenminister nachgeordnet, baute Himmler die politische Polizei durch Besetzung ihrer führenden Positionen mit SS-Männern zu einem eigenen Machtinstrument aus, von dem die Justiz - anders als von dem Geheimen Staatspolizeiamt in Preußen - bei der Verfolgung von Ausschreitungen durch Angehörige der NS-Gliederungen kaum Unterstützung erwarten durfte. Bei Konflikten mit dem staatlichen Behördenapparat fand Himmler zudem Rückendeckung beim Stabschef der SA Röhm, dem er damals noch unterstellt war. Andererseits war Himmler als Kommandeur der staatlichen politischen Polizei in Bayern von Röhm wiederum soweit unabhängig, daß er mit Stützung durch den Innenminister auch gegen SA-Angehörige vorgehen konnte. Der zum „Staatskommissar z.b.V.“ ernannte Röhm wiederum hatte die allgemeine innere Verwaltung auf sämtlichen Ebenen bis hinunter zu den Bezirksämtern mit SA-Sonderkommissaren ${ }^{2}$ durchsetzt, die - in Konkurrenz zur Politischen Organisation (P.O.) der Partei - die Stellen des Staatsapparates mit unklar umrissenen Aufgaben kontrollierten. Ihnen stand die aus SA-Männern gebildete „Sicherheits-Hilfspolizei“ zur Verfügung, während Himmler das Kommando über die „Politische Hilfspolizei“ aus eingezogenen SS-Angehörigen erhielt. Um den Kompetenzwirrwarr zu vervollständigen, gab es in Bayern neben Wagner noch fünf weitere Gauleiter ${ }^{3}$, von denen jeder mit seinem Apparat von Partei-

\footnotetext{
Anordnung des StMdI v. 1.4.33 (GVBl. f. d. Freistaat Bayern 1933, S. 95).

Vgl. Kapitel IV.4.c., S. $396 \mathrm{ff}$.

Wahl in Schwaben, Schemm (zugleich bayer. Kultusminister) in Oberfranken (Bayerische Ostmark), Streicher in Mittelfranken, Hellmuth in Unterfranken (Mainfranken) und Bürckel in der Rheinpfalz.
} 
funktionären (Kreisleiter, Ortsgruppenleiter usw.) die staatliche Verwaltung zu überwachen suchte. Da sich Himmler mit seiner politischen Polizei gegenüber dem Innenminister Wagner weitgehend verselbständigte, stützte Wagner zeitweise die Befugnisse des SA-Apparates gegenüber den Parteidienststellen, um sich auch in den Machtbereichen seiner bayerischen Gauleiter-„,Kollegen“ durchsetzen zu können. In diesem Kompetenzdschungel, in dem - wie sich ein SA-Kommissar im Juli 1933 beim bayerischen Ministerpräsidenten beschwerte ${ }^{4}$ - jeder kleine NS-Funktionär Verfügungen erließ, „die in die unteren Befehlsgewalten der Ministerien eingreifen, also in die Befehlsbefugnisse der Kreisregierungen, Bezirksämter, herunter bis zur kleinsten Gendarmerie-Station“, und damit „bei den besten und zuverlässigsten Beamten geradezu eine Instanzenunsicherheit" schuf, und in dem ,jeder jeden verhaftete“ - in einem solchen Dschungel tat sich die Justiz besonders schwer, Ausschreitungen und Verbrechen der SA und SS zu verfolgen.

Das bayerische Justizministerium hielt seinerzeit eine Anzahl der 1933/34 auftretenden Behinderungen und Eingriffe in die Rechtspflege in einer tabellenartigen $\mathrm{Zu}$ sammenstellung fest, in der das Datum, die eingreifende Stelle und in Kurzform die Art des Eingriffs sowie der „Erledigung“ des Falles vermerkt wurden. ${ }^{5}$ Aus dieser erhalten gebliebenen Übersicht geht hervor, daß sich die Justiz in jenen Fällen, die zeitlich unter die bayerische Straffreiheitsverordnung vom 2. August 1933 fielen, auch meistens dieses Mittels bediente, um den aufgetretenen Konflikt mit den NS-Stellen zu lösen. Dafür seien drei Beispiele angeführt, die in der genannten Aufstellung enthalten sind und für die ergänzende Quellen herangezogen werden konnten.

Beim ersten dieser Fälle handelte es sich um den Eingriff eines SA-Kommissars in das Ermittlungsverfahren. In der Nacht zum 7. Mai 1933 wurde in Pösing (Bezirk Roding/Oberpfalz) von Nationalsozialisten ein gewalttätiger Überfall auf den Pfarrhof verübt. Entsprechend dem Antrag der Staatsanwaltschaft eröffnete der Untersuchungsrichter beim Landgericht Regensburg die gerichtliche Voruntersuchung und beraumte den Termin zur Vernehmung der Angeschuldigten und Zeugen auf den 3. Juli an. Während der Vernehmung des ersten Zeugen erschien plötzlich der Beauftragte des Sonderkommissars der Obersten SA-Führung beim Bezirksamt Roding, ein SA-Sturmbannarzt, und erzwang vom Untersuchungsrichter „unter Berufung auf die für ihn maßgebenden Vorschriften“, daß die Vernehmungen abgebrochen und mit der Durchführung der Voruntersuchung innegehalten wurde.

Daraufhin schrieb der bayerische Justizminister Frank am 12. Juli an Innenminister Wagner, er erblicke in dem Vorgehen „einen überaus bedenklichen, der Rechtslage widersprechenden Eingriff in die Unabhängigkeit der Strafrechtspflege, der geeignet ist, die Autorität des Staates aufs schwerste zu erschüttern“. Unter Hinweis auf das gerade ergangene Rundschreiben des Reichsinnenministers Frick vom 11. Juli $1933^{6}$ bat er Wagner, „zu veranlassen, daß die ungestörte Durchführung der Voruntersuchung

4 Der stellv. SA-Sonderkommissar bei der Reg. v. Oberbayern, ein Sturmbannführer, der sich „doch wirklich nicht zu den Leisetretern“ rechnete, in einem Schr. an Siebert v. 1.7.33 (GehStArch. München, Sign. MA 105 482).

5 Eingriffe in die Strafrechtspflege („Die mit Dachau zusammenhängenden Fälle sind unberücksichtigt geblieben“), ungefähr bis Mitte April 1934 (Akten des bayer. JM, BayHStArch. Abt. II, Sign. MJu 12003); vgl. auch $\mathrm{H}$. Weinkauff, Die deutsche Justiz und der Nationalsozialismus, Bd. 1, S.113 ff.

6 Vgl. dazu Anm. 40 in Kapitel IV.1.c. 
sichergestellt wird und derartige Übergriffe, die eine gesetzmäßige Aufbauarbeit unmöglich machen, ein für allemal unterbunden werden“. Den Beauftragten des Sonderkommissars ersuchte er schriftlich, sich künftig jeder Einmischung zu enthalten, um ihn (Frank) „nicht zu zwingen, weitere Schritte zu unternehmen“. Auch Stabschef Röhm unterrichtete er von dem Vorkommnis. Der Konflikt wurde durch den Erlaß der Straffreiheitsverordnung vom 2. August 1933 und ihre Anwendung, d.h. durch Einstellung des Verfahrens, beigelegt. ${ }^{7}$

Im zweiten Fall verhinderte die Bayerische Politische Polizei im Zusammenwirken mit den örtlichen SA-Führern die Ermittlungen. Am 13. Juni 1933 drangen in Landshut nach einem "Kameradschaftsabend" gegen vier Uhr morgens neun SA-Leute einschließ3lich eines SA-Sturmführers in das Haus des Landtagsabgeordneten der - zu diesem Zeitpunkt noch legal bestehenden - BVP Schlögl ein, demolierten Einrichtung und Fensterscheiben und zwangen das Dienstmädchen unter schweren Mißhandlungen, den Aufenthaltsort der Familie anzugeben. Daraufhin beschlagnahmten sie beim Verleger der „Landshuter Zeitung“ einen Kraftwagen und fuhren zu fünft zum Haus der Verwandten Schlögls in Tittling, brachten seine Angehörigen, darunter den fünfjährigen Sohn, in den Garten und bearbeiteten Schlögl in einem Zimmer mit Gummiknüppeln und Fußtritten, bis er bewußtlos war. Dann ergriffen sie mit dem Auto die Flucht. ${ }^{8}$

Obwohl der SA-Sturmführer als Täter erkannt und diese Tatsache den Behörden mitgeteilt wurde, gelang es der Staatsanwaltschaft nicht, eine Festnahme oder eine polizeiliche bzw. richterliche Vernehmung der Beschuldigten zu erreichen, weil sich die örtlichen Polizeistellen auf eine entgegenstehende Weisung der Bayerischen Politischen Polizei beriefen. Es nutzte auch nichts, daß der 2. Vorsitzende der BVP-Fraktion Fürst von Wrede beim Reichsstatthalter von Epp intervenierte und dieser über Siebert von Innenminister Wagner einen Bericht erbat: die politische Polizei antwortete Siebert lediglich ausweichend, daß die Kriminalpolizei die "Gesamtverhandlungen“ der Staatsanwaltschaft zugeleitet hätte, daß die Täter flüchtig seien und „über den derzeitigen Stand des Verfahrens ... hier nichts bekannt" sei."

Die Oberste SA-Führung äußerte am 14. September gegenüber der Staatsanwaltschaft beim Landgericht Landshut über die Beweggründe der Tat, Schlögl habe in seiner Zeitschrift „Der Niederbayerische Bauer“ eine „jahrelange unerhörte Begeiferung all dessen, was sich nationalsozialistisch nannte" betrieben und dadurch eine ,verständliche Erbitterung" bei der SA hervorgerufen, und konstatierte:

„Die Tat und der Wille der SA-Männer war nur gerichtet auf das Wohl der nationalsozialistischen Bewegung. Das politische Moment sowie die Lauterkeit des Wollens steht somit außer Zweifel. Die Oberste SA-Führung hält daher die Voraussetzungen für gegeben, um das Verfahren gemäß Gesetz für Straffreiheit vom 2.8.33 ... einzustellen.“10

7 Eingriffe in die Strafrechtspflege (Anm. 5), Schr. Franks an Wagner u. an den Beauftragten des SK der OSAF beim Bezirksamt Roding v. 12.7.33 (BayHStArch. Abt. II, Sign. MJu 12003). Die Tat selbst ist erwähnt im Halbmonatsber. des RegPräs. v. Niederbayern u. der Oberpfalz v. 19.5.33 (BayHStArch. Abt. II, Sign. MA 106672).

8 Zum Vorgang vgl. Ber. der Reg. v. Niederbayern u. der Oberpfalz an Frick v. 30.6.36 betr. Ausgleichssache (Akten der bayer. StKanzlei, GehStArch. München, Sign. MA 106311, Bd. II) u. J. Klenner, Verhältnis von Partei und Staat 1933-1945. Dargestellt am Beispiel Bayerns, München 1974, S. 136.

9 Schr. der BPP an Siebert v. 24.8.33; Schr. v. Epps an Siebert v. 19.6.33 und Weiterleitungsverm. an Wagner (Akten der bayer. StKanzlei, a.a.O.).

10 Zit. im Ber. der Reg. v. Niederbayern u. der Oberpfalz v. 30.6.36 (Anm. 8). 
Da die Ermittlungen aussichtslos waren, stellte die Staatsanwaltschaft fünf Tage später das Verfahren aufgrund der genannten Verordnung auch tatsächlich ein. Schlögl legte dagegen gemäß $§ 2$ Abs. 2 der Verordnung ${ }^{11}$ Einspruch ein. Nun wandte sich der Münchener Kardinal Faulhaber an den Reichsstatthalter und erinnerte daran, daß Schlögl Frontoffizier und Mitglied des Freikorps Epp beim Kampf um München gewesen sei; er könne nicht glauben, daß die Täter strafrechtlich nicht verfolgt und „daß in einem Lande, das auf den Namen eines Kulturstaates Anspruch erhebt, solche Tscheka-Methoden an den höchsten Regierungsstellen anerkannt" würden. ${ }^{12}$ Aber der ungläubige Kardinal sollte eines Besseren belehrt werden, und auch der „Muttergottesgeneral“ - wie von Epp wegen seiner regelmäßigen Wallfahrten nach Altötting im Volke genannt wurde - sollte sich als machtlos erweisen. Am 4. Dezember folgte das zuständige Amtsgericht Landshut dem Antrag der Staatsanwaltschaft und stellte das Verfahren aufgrund der Straffreiheitsverordnung ein. In der Begründung wurde ausgeführt, die Handlungen der SA seien „zur Durchsetzung des nationalsozialistischen Staates begangen“ worden, weil sie bezweckten, „Schlögl vor weiterer politischer Betätigung abzuhalten"; andere Motive - etwa Eigennutz oder niedere Beweggründe seien für die Taten nicht zu finden. ${ }^{13}$

Beim dritten Beispiel war die Gauleitung Rheinpfalz die eingreifende Stelle. Am 22. Juni 1933 wurden in Wolfstein (Bezirk Kusel/Pfalz) ein Pfarrer und vier Angehörige des „Stahlhelm“ von SA-Leuten unter Mißhandlungen nachts aus ihren Wohnungen geholt, z.T. auf der Stadthaustreppe an den Pranger gestellt und anschließend in Schutzhaft genommen. Ein Mißhandelter - Justizobersekretär beim Amtsgericht Wolfstein und Bezirksleiter des "Stahlhelm“ - wurde dabei so schwer verletzt, daß er ins Krankenhaus nach Kaiserslautern gebracht werden mußte, wo er am 4. Juli an einer Blutvergiftung durch eiternde Wunden und einer Lungenentzündung starb. Es konnte nicht einwandfrei festgestellt werden, ob die erlittenen Verletzungen den Tod verursacht hatten.

Da eine Klärung der Tatbestände durch polizeiliche Vernehmung auf Schwierigkeiten stieß - die örtliche Gendarmerie fühlte sich „den Vorgängen gegenüber machtlos“ -, beantragte die Staatsanwaltschaft beim Landgericht Kaiserslautern am 27. Juni Voruntersuchung und Haftbefehl gegen den Haupttreiber, einen SA-Sturmführer. ${ }^{14}$ Die Vernehmung durch den Untersuchungsrichter am 4. Juli, bei der bezeichnenderweise der Polizeidirektor von Kaiserslautern, der Kreisleiter der NSDAP und der zuständige Standartenführer der SA zugegen waren, führte zur Verhaftung des Sturmführers und eines Angehörigen des in der Nähe gelegenen Arbeitsdienstlagers. Während letzterer in das Gefängnis Wolfstein kam, mußte der Sturmführer „zunächst vom Untersuchungsrichter der Gauleitung in Neustadt in Verwahr gegeben“" werden. ${ }^{15}$ Die Gauleitung, die die Verhaftung ,nicht für gerechtfertigt" hielt, forderte vom bayerischen Justizministerium telegrafisch eine Weisung an den Untersuchungsrichter, von

1 Der Passus lautete : „Über die Einstellung entscheidet auf Antrag der Beteiligten das Gericht.“

12 Schr. Faulhabers an v. Epp v. 30.10.33 (GehStArch. München, Sign. Reichsstatthalter 38).

13 Beschl. des AG Landshut v. 4.12.33 (Nürnbg. Dok. D-936, IMG, Bd. XXXVI, S. 62 ff.).

14 Ber. der StAschaft beim LG Kaiserslautem an den GStA Zweibrücken v. 27.6.33 (BayHStArch. Abt. II, Sign. MInn 71715)

15 Ber. des GStA Zweibrücken an das bayer. JM v. 5.7.33; Ber. der Reg. der Pfalz an die bayerStKanzlei, das StMdI und die BPP v. 11.7.33 (a.a.O.). 
der Verhaftung abzusehen. Das Justizministerium wies jedoch den zuständigen Generalstaatsanwalt in Zweibrücken an, ,daß die Anordnungen der Träger der Staatsautorität unter allen Umständen durchgeführt werden " müßten; die Staatsanwaltschaft beantragte daraufhin die Verbringung des Beschuldigten ins Gefängnis nach Kaiserslautern. Aus dieser Kraftprobe wurde die Justiz durch die bayerische Amnestie vom 2. August 1933 erlöst: nach „Besprechung mit Gauleiter Bürckel“ wurde das Verfahren eingestellt. ${ }^{16}$

Waren die Taten in den dargestellten Niederschlagungsfällen noch eindeutig durch Abrechnung mit politischen Gegnern motiviert, so sei an einem Beispiel gezeigt, daß es der SA-Führung gelang, auch Straftaten unter die Amnestie zu bringen, bei denen dieses Motiv fragwürdig war. In diesem Fall handelte es sich allerdings um keinen direkten Eingriff in das Strafverfahren. ${ }^{17}$

Am 22. April 1933 fielen ein SA-Truppführer und zwei SA-Männer in einer Gastwirtschaft in Feldmoching bei München über einen SS-Mann her, „weil er einige Zeit vorher die SA-Leute von Feldmoching beleidigt habe", und verprügelten ihn so, daß er zwei Wochen bettlägerig war. Nach den Schlägen zwangen sie ihn, ,auf den Boden zu knieen und um Verzeihung zu bitten“, ferner drohten sie, ihn zu erschlagen, wenn er die Mißhandlung bei der Polizei anzeige. Anschließend erklärte der SA-Truppführer das Motorrad des SS-Mannes „für kommissarisch beschlagnahmt“ und ließ sich damit zwei Tage lang von einem der SA angehörenden Mechaniker herumfahren. Vor der Rückgabe wurde das Motorrad durch Einwerfen von Zucker in den Tank unbrauchbar gemacht.

Nach Anzeige durch den SS-Mann erhob die Staatsanwaltschaft Anklage. Der auf den 3. November anberaumte Hauptverhandlungstermin mußte jedoch abgesetzt werden, da die Angeklagten einen Antrag auf Anwendung der Straffreiheitsverordnung vom 2. August 1933 stellten, über den das Amtsgericht München zunächst entscheiden mußte. Die Staatsanwaltschaft beantragte demgegenüber, das Verfahren nicht einzustellen, da die Angeklagten aus niedrigen Beweggründen gehandelt hätten. ${ }^{18}$

Daraufhin erbat das bayerische Innenministerium die Akten vom Amtsgericht für eine Stellungnahme. Im Ministerium wurden sie vom dortigen Verbindungsführer der Obersten SA-Führung und Sonderbevollmächtigten für das Land Bayern, SA-Gruppenführer Fuchs, geprüft. In seiner Stellungnahme an das bayerische Justizministerium führte das Innenministerium aus, daß die Staatsanwaltschaft „vollständig die Vẹrhältnisse, unter denen sich die Straftat überhaupt entwickeln konnte", übersehe: in Feldmoching habe die KPD einen besonders starken Stützpunkt gehabt und deshalb sei hier die Erbitterung der politischen Gegner gegeneinander besonders groß gewesen; der SS-Mann aber sei einer derjenigen, „die allgemein als Kommunisten angesehen [!] wurden". Er habe sich daher nach der Revolution auch nicht bei der Feldmochinger SA - wo er keine Aufnahmechance gehabt hätte -, sondern ,auswärts zur SS gemeldet". Zur Täuschung habe er behauptet, er sei nur deshalb nicht zur SA Feldmoching gegangen, „weil dort zuviel ,Geschmeiß` sei“. Die Angeklagten hätten daher mit

16 Eingriffe in die Strafrechtspflege (Anm. 5).

17 Der Fall ist daher in der erwähnten Aufstellung (Anm. 5) nicht vermerkt.

18 Ber. des OStA beim LG München I an den GStA München v. 16.6. u. 4.11.33 (BayHStArch. Abt. II, Sign. MInn 72438). 
der Tracht Prügel nur beabsichtigt, diese Beleidigung ihrer SA zu sühnen. „Eine niedrige Gesinnung im Sinne des $\S 3$ der Verordnung vom 2.8.1933 dürfte man keineswegs annehmen. Denn sonst wäre die Verordnung über die Gewährung von Straffreiheit in den meisten Fällen [!] wohl unanwendbar." Was aber die unbefugte Benutzung des Motorrades angehe, so werde dem Truppführer „nicht widerlegt werden können, daß er sich von der Fahrbereitschaft des Motorrades habe überzeugen wollen [?]“. Falls die Straffreiheitsverordnung auf die Motorradsache nicht angewendet werden könne, sei hier die Einstellung des Verfahrens wegen Geringfügigkeit zu rechtfertigen. Bei den Beschuldigten handele es sich überdies um „anständige Persönlichkeiten“, die „sich bei der Durchführung der nationalen Revolution gewisse Verdienste erworben“ hätten. Der Truppführer habe „nur unbedeutende Vorstrafen wegen fahrlässiger Körperverletzung“, die Vorstrafen des Mechanikers seien „zwar zahlreicher, aber sie liegen auch nicht auf dem Gebiete der Roheitsdelikte“. Das Schreiben endete mit dem Ersuchen, die Angelegenheit im Justizministerium zu prüfen und den Staatsanwalt anzuweisen, seinen Antrag zurückzunehmen und sich dem Antrag der Verteidigung auf Niederschlagung anzuschließen. ${ }^{19}$ Mit Beschluß vom 25. Januar 1934 stellte das Amtsgericht tatsächlich das Verfahren aufgrund der bayerischen Straffreiheitsverordnung und - soweit der unbefugte Gebrauch eines Kraftfahrzeuges in Frage kam - gemäß $\S 153$ Abs. 3 StPO gegen sämtliche Angeklagte ein. Wie der Oberstaatsanwalt an den Generalstaatsanwalt berichtete, beabsichtigte er gegen diesen Beschluß keine Beschwerde einzulegen. ${ }^{20}$

Es gab wiederum auch Fälle, bei denen die bayerische Justiz eine Verurteilung der Täter trotz der Störungsversuche von seiten der Bewegung durchsetzte. Am 30. Mai 1933 erließ das Amtsgericht Pottenstein (Bezirk Bayreuth/Oberfranken) gegen drei SA-Leute einen Strafbefehl über je zwei Wochen Gefängnis, weil sie am 1. Mai in Volsbach einen ehemaligen Angehörigen der Bayernwacht mit ihren Schulterriemen mißhandelt hatten. Daraufhin tauchten der Sonderkommissar der Obersten SA-Führung bei der Kreisregierung von Oberfranken, ein SA-Oberführer, und sein Beauftragter für Stadt und Bezirksamt Bayreuth am 8. Juni in der zuständigen Gendarmeriestation auf und beschuldigten die "schwarzen“ Beamten der falschen Anzeigenerstattung: „nicht die SA-Leute hätten angezeigt gehört, sondern der ... - Anzeigeerstatter - hätte festgenommen werden sollen. Eine weitere Anzeigeerstattung gegen SA-Leute verbaten sie sich in der Zukunft und befahlen, sich in solchen Fällen an sie zu wenden“, damit sie die Angelegenheit regeln könnten. ${ }^{21}$ Danach nahmen sie ohne Wissen der Polizei in Volsbach selbst Vernehmungen der Beteiligten und Zeugen vor und zwangen sie unter Mißhandlungen und Androhung von Schutzhaft, ein Protokoll zu unterschreiben. Der Anzeigeerstatter, der sich „weigerte, seine Unterschrift unter ein Schriftstück zu setzen, das nicht seine, sondern ganz entstellte Angaben enthielt, wurde mit einem Buche mehreremale auf den Kopf geschlagen. Schließlich erfaßte

19 Schr. des bayMdI an das bayJM v. 7.12 .33 (a.a.O.). Der Truppführer war wegen fahrlässiger Körperverletzung und Sachbeschädigung mit zwei Geldstrafen, der Mechaniker siebenmal wegen Kraftfahrzeugvergehen, einmal wegen Vergehens gegen das SchußwaffenG mit Geldstrafen und wegen Abtreibung mit einem Monat Gefängnis vorbestraft.

20 Ber. v. 31.1 .34 (a.a.O.) $§ 153$ Abs. 3 StPO betr. die Einstellung des Verfahrens wegen geringfügiger Schuld und unbedeutender Folgen bei Vergehen.

21 Ber. der Gendarmeriestation an den Amtsanwalt am AG Pottenstein v. 18.6.33 (Akten des bayerStMdI, BayHStArch. Abt. II, Sign. MInn 71719). 
ihn ein Herr aus Bayreuth am Kopf und drückte ihn so fast auf den Tisch.“22 Er unterschrieb aber trotzdem nicht. Nach diesem „Ermittelungsergebnis“ legte der SA-Kommissar beim Oberstaatsanwalt des Landgerichts Bayreuth Einspruch ein und ersuchte ihn, den Amtsanwalt anzuweisen, daß er die Klage fallenlasse. Der Oberstaatsanwalt lehnte $a b$ und ließ sich vom Amtsanwalt einen genauen Gendarmeriebericht über die „Erhebungen“ der beiden SA-Führer vorlegen. Wie er an den zuständigen Generalstaatsanwalt von Bamberg schrieb, fand er die darin festgehaltenen Tatsachen „so ungeheuerlich, daß ich geradezu das Staatsministerium der Justiz um Schutz gegen solche eigenmächtigen und widerrechtlichen Eingriffe in die Rechtspflege bitten muß". Falls er keine gegenteilige Weisung erhalte, werde er auch diesen Vorgang strafrechtlich verfolgen. ${ }^{23}$ Der Generalstaatsanwalt wurde jedoch angewiesen, wegen des Eingreifens des Sonderkommissars nichts zu veranlassen. ${ }^{24}$ Diese Sache wurde vielmehr durch eine Besprechung mit dem betreffenden SA-Führer im Justizministerium am 5. Oktober beigelegt, in der er „auf das Unzulässige seines Vorgehens hingewiesen“ wurde. ${ }^{25}$ Nachdem der standhafte und bei den örtlichen NS-Stellen höchst unbeliebte Oberamtsrichter von Pottenstein versetzt worden war, konnte dort am 6. Februar 1934 endlich die Hauptverhandlung gegen die drei SA-Leute stattfinden, die mit einer Verurteilung zu geringfügigen Geldstrafen endete.

\section{b. Die Auseinandersetzung mit der Bewegung wegen politischer Straftaten nach Beendi- gung der „Revolution": die Fälle Pflaumer und Hörstein}

Hartnäckiger gestaltete sich das Tauziehen zwischen der bayerischen Justiz und den Stellen der Bewegung, die die Straftaten decken bzw. rechtfertigen wollten, in jenen Fällen, die zeitlich nicht mehr unter die bayerische Straffreiheitsverordnung vom 2. August 1933 fielen und daher dem Bestreben der Vertreter einer Wiederherstellung der Staatsautorität entgegenwirkten - zumal diese Fälle nur durch den Reichsstatthalter niedergeschlagen werden konnten. Ein eklatantes Beispiel dafür bot der Fall Pflaumer in Nürnberg.

Am 17. August 1933 wurde in Nürnberg der am Vortag festgenommene Mechaniker Pflaumer auf der SA-Wache am Hallplatz - die hohnsprechenderweise den Namen "Samariterwache“ trug - „wegen Verdachts kommunistischer Umtriebe“ vernommen und vom Sturmbannführer des dort als Hilfspolizei stationierten „SASturms z.b.V." sowie von einem Scharführer mit Gummiknüppeln mißhandelt, weil er angeblich gegen sie „tätlich vorgehen wollte“. Anschließend wurde er in die Polizeihauptwache zurückgebracht, von wo er zur nächtlichen Vernehmung abgeholt worden war; eine halbe Stunde später fand ihn der Gefängniswärter in seiner Arrestzelle tot auf. Der sofort herbeigerufene Arzt konnte die Todesursache nicht feststellen. Der leitende Oberstaatsanwalt beim Landgericht Nürnberg-Fürth ließ die Leiche beschlag-

22 Aussage eines Verhörten im Ber. der Gendarmeriestation v. 21.6.33 (a.a.O.). Die Aussage des Betr., der unterschrieben hatte („um meine Ruhe zu bekommen“), endete mit dem bezeichnenden Satz: „Ich wäre froh, wenn eine Gerichtsverhandlung stattfinden würde, damit ich die Wahrheit sagen und beweisen könnte." Das zeigt, wie weit die Gerichte bei den einfachen Leuten noch als ein Hort der Gerechtigkeit galten.

23 Ber. des OStA an den GStA v. 9.7.33 (a.a.O.).

24 Ber. Franks an das StMdI v. 18.7.33 (a.a.O.).

25 Am 5. 10.33, Verm. v. 30.10.33 (Akten des bayJM, BayHStArch. Abt. II, Sign. 12003), Eingriffe in die Strafrechtspflege (Anm. 5). 
nahmen und ordnete Obduktion an. Die beiden SA-Führer wurden von einem Beauftragten der Nürnberger Polizeidirektion vernommen. Sie behaupteten, daß Pflaumer mit einem Karabiner, der sich im Wachraum befand, auf sie losgegangen sei und "sich weiterhin so renitent gebärdete, daß alle Verletzungen, die Pflaumer aufwies, auf Notwehrhandlungen zurückzuführen seien“. Dieses Ermittlungsergebnis wurde der Staatsanwaltschaft zugeleitet. ${ }^{26}$ Die Obduktion des Opfers ergab, daß die Haut des Gesäßes und der Oberschenkel ,in Form des Reithoseneinsatzes tiefblau-rot verfärbt“ und an beiden Fußsohlen „von dem massenhaft darunter angesammelten Blut vorgewölbt“ war. Daraus ging hervor, daß der Häftling vermutlich „übergelegt“ und „im Sinne der orientalischen Bastonade“ mißhandelt worden und durch Schockwirkung gestorben war. ${ }^{27}$ Der Landgerichtsarzt berichtete dem Oberstaatsanwalt „noch mündlich, daß nach seinem Befund Pflaumer in grausamster qualvoller Weise mit stumpfen Gegenständen zu Tode geprügelt worden sei“ ${ }^{28}$ Da die Verletzungen dem Toten keinesfalls in Notwehr zugefügt sein konnten, beantragte der Oberstaatsanwalt wegen , hinreichenden Verdachts eines Verbrechens der Körperverletzung mit Todesfolge die Eröffnung der Voruntersuchung und den Erlaß von Haftbefehlen gegen die beiden SA-Führer, weil Verdunkelungsgefahr und der Verdacht bestand, daß sich weitere unbekannte Täter an dem Verbrechen beteiligt hatten. Am 21. August wurde der Oberstaatsanwalt jedoch von der Polizeidirektion aufgefordert, die Sache „zunächst bis zu einer Rücksprache mit dem zur Zeit erkrankten [Leiter der politischen Abteilung] Regierungsrat Dr. Martin“29 liegenzulassen. „Auch die Gauleitung sei an der Sache interessiert.“ Der Oberstaatsanwalt lehnte dieses Ansinnen unter Hinweis auf Franks Bekanntmachung vom 4. August $1933^{30}$ und die sich daraus ergebende Pflicht ab, alle nach dem 25. Juli begangenen Straftaten unnachsichtig zu verfolgen. ${ }^{31}$ Der Untersuchungsrichter am Landgericht Nürnberg-Fürth sah jedoch im Einvernehmen mit der Staatsanwaltschaft vom Erlaß eines Haftbefehls ab, da keine Fluchtgefahr bestand und auch eine Verhaftung wegen Verdunkelungsgefahr kaum mehr sinnvoll war, nachdem eine sofortige Festnahme unterblieben war. Als er einige Polizeibeamte als Zeugen vernehmen wollte, verweigerten sie die Aussage mit der Begründung, daß die Abgabe des Zeugnisses das „Wohl des Reiches gefährden könne“. Der Untersuchungsrichter ersuchte daraufhin den Polizeipräsidenten ${ }^{32}$, die Beamten von der Pflicht zur Amtsverschwiegenheit zu entbinden, und fragte an, ob auch die SA-Hilfspolizisten als öffentliche Beamte im Sinne des $\S 54$ der StPO anzusehen seien ${ }^{33}$; er erhielt aber ,auf

26 Undat. Ber. des vernehmenden Assessors von der polit. Abt. an die Bayer. Polit.Polizei (Akten des bayer. MdI, BayHStArch. Abt. II, Sign. MInn 71719).

27 Prot. der Gerichtskommission v. 18.8.33 (Akten des RJM, BA Sign. R 22/1138).

28 Ber. des OStA an den GStA Nürnberg v. 21.8.33, am 22.8.33 an das bayerJM weitergeleitet (a.a.O.).

29 M. wurde am 5.9.33 stellv. Pol.Präs., am 1.10.34 Pol.Präs. von Nürnberg-Fürth. Vgl. U. Grieser, Himmlers Mann in Nürnberg. Der Fall Benno Martin: Eine Studie zur Struktur des Dritten Reiches in der „Stadt der Reichsparteitage“, Nürmberg 1974, S. 309 f.

30 Vgl. Kapitel IV.1.c., S. 333, Anm. 59.

31 Vgl. Anm. 28.

32 Der von Himmler eingesetzte kommissar. Leiter der Pol.Dir. Nürnberg-Fürth, SS-Oberführer Frhr. v. Malsen-Ponickau, war am 15.8.33 gerade abberufen worden, neuer Pol.Präs. wurde am 1.9.33 SA-Gruppenführer v. Obernitz (vgl. U. Grieser, a.a.O.).

33 Schr. des U-Richters v. 22.8.33 (Akten des bayerMdI, a.a.O.). Nach §54 StPO durften Beamte „über Umstände, auf welche sich ihre Pflicht zur Amtsverschwiegenheit bezieht, als Zeugen nur mit Genehmigung ihrer vorgesetzten Dienstbehörde vernommen werden“. Sie durfte „nur versagt werden, wenn die Ablegung des Zeugnisses dem Wohle des Reiches oder eines deutschen Landes“ Nachteil bereitete. 
wiederholte fernmündliche Anfragen bei der Polizeidirektion keinen bestimmten Bescheid, sondern nur ausweichende Antworten“. Den Bericht des Oberstaatsanwalts legte der Generalstaatsanwalt Nürnberg dem bayerischen Justizminister mit folgendem Kommentar vor:

„Wenn durch eine öffentliche Verhandlung bekannt würde, daß ein Festgenommener unter Anwendung orientalischer Züchtigungsmittel totgeprügelt wurde, so wäre dies wohl für das Staatsinteresse abträglich. Dieser Gefahr kann aber durch Ausschließung der Öffentlichkeit in der Hauptverhandlung vorgebeugt werden. Jedenfalls liegt es vor allem im Staatsinteresse, daß nicht der Anschein erweckt wird, als decke die Polizei und die Staatsanwaltschaft Verbrechen von so empörender Roheit."

Er richtete daher an das Justizministerium die dringende Bitte, ,im Einvernehmen mit dem Staatsministerium des Innern und der SA-Führung die Voraussetzungen für die ungehinderte Durchführung dieses Strafverfahrens zu schaffen". ${ }^{34}$

Am 26. August rief Martin den Untersuchungsrichter an und teilte ihm nunmehr definitiv mit, daß eine Vernehmung der Polizeibeamten nicht gestattet werde und daß er auch die beiden Angeschuldigten „nicht entbehren könne, da er sonst keine Gewähr für die Sicherheit des Parteitages der NSDAP übernehmen [!] könne“ “. ${ }^{35}$ In der schriftlichen Bestätigung dieses Entscheides wurde zugleich festgestellt, „daß die Hilfspolizeibeamten einen Diensteid geleistet haben und als Beamte im Sinne des $\S 54$ StPO zu erachten" seien. ${ }^{36}$

Nach Eingang der Berichte über diese Vorgänge und die Ereignisse, die sich am 28. August in Hörstein zugetragen hatten ${ }^{37}$, entschloß sich Frank, die Durchführung der Strafverfahren zu erzwingen. Wenn seine Bekanntmachung vom 4. August, daß nunmehr den gesetzwidrigen Ausschreitungen durch strafrechtliche Verfolgung ein Ende gesetzt werden müsse, nicht eine papierene Deklaration bleiben sollte, mußte sich die Justiz jetzt durchsetzen. Er beabsichtigte daher, die Frage vor den bayerischen Ministerrat zu bringen, wo er der Unterstützung durch jene Kabinettskollegen, die den Staatsapparat vertraten, gegenüber dem janusköpfigen Gauleiter/Innenminister Wagner sicher sein konnte. In einem Schreiben an Wagner vom 6. September schilderte er die Vorkommnisse, die ihm „zu ernster Besorgnis Anlaß“ gäben. Sie ließen erkennen,

„daß die wiederholten parteiamtlichen Befehle und Anordnungen der Träger der Staatsautorität, durch die nach dem siegreichen Abschluß der deutschen Revolution rechtswidrige Eingriffe in den Rechtskreis Privater und Einzelhandlungen aus selbsterteilter Befugnis unter Androhung disziplinärer Maßnahmen strengstens untersagt wurden, noch nicht die unbedingt erforderliche allgemeine Beachtung finden und daß sich Angehörige der SA. und SS. noch immer zu unzulässigen, des Nationalsozialismus unwürdigen Mißhandlungen von Gegnern hinreißen lassen, ohne zu bedenken, daß dadurch das Ansehen der SA. und der SS. und nicht zuletzt des nationalsozialistischen Staates aufs Schwerste gefährdet wird. Die Vorkommnisse zeigen weiter, daß leider auch jetzt noch Versuche unternommen werden, in den gesetzmäßigen Gang der Rechtspflege einzugreifen."

Durch die Straffreiheitsverordnung vom 2. August sei ein Schlußstrich unter die revolutionären Ereignisse gezogen worden, und in seiner Bekanntmachung vom 4. Au-

34 Ber. des GStA Nürnberg an das bayer. JM v. 26.8.33 nebst Ber. des OStA v. Vortage (Akten des RJM, a.a.O.).

35 Ber. des OStA v. 26.8.33 an den GStA, am selben Tag an das bayerJM weitergeleitet (a.a.O.).

36 Schr. der Pol.Dir. an den U-Richter v. 6.9.33 (Akten des bayerMdI, a.a.O.).

37 Vgl. dazu im folgenden. 
gust habe er als gemeinsamen Willen der bayerischen Regierung und aller maßgebenden Stellen kundgegeben, daß die Justiz jeden Störer der Rechtsordnung nach den bestehenden Gesetzen zur Verantwortung ziehen sollte. Er fuhr fort:

„Mit dieser feierlichen Kundgebung wäre es unvereinbar, wenn die erwähnten beiden Straffälle nicht mit aller Entschiedenheit durchgeführt würden. Voraussetzung hierfür ist aber, daß die zur Mitwirkung bei der Aufklärung der Straftaten berufenen Stellen die Staatsanwaltschaft und das Gericht nach besten Kräften unterstützen und alle Hindernisse beseitigt werden, die einer restlosen Aufklärung der schweren Ausschreitungen und einer ungesäumten Sühne entgegenstehen. Im Falle Pflaumer insbesondere halte ich es im Interesse der Wahrung der Staatsautorität und des Ansehens der Justiz und der Polizei für dringend geboten, auch nur den leisesten Anschein zu vermeiden, als decke die Polizei das Verbrechen."

Einer Gefährdung des Staatsinteresses könne durch Ausschluß der Öffentlichkeit bei der Hauptverhandlung begegnet werden. Im übrigen, so drohte Frank, werde die Durchführung der Hauptverhandlung durch eine Verweigerung der Aussagegenehmigung nicht verhindert werden: nach dem bisherigen Geständnis der beiden SA-Führer und dem Ergebnis der Obduktion müsse das Verfahren sogar unter allen Umständen eröffnet werden. Wegen der prinzipiellen Bedeutung, die dieser Angelegenheit zukäme, habe er den Ministerpräsidenten gebeten, sie in der nächsten Kabinettssitzung zu behandeln und hierzu Stabschef Röhm und Polizeikommandeur Himmler einzuladen.

Einen Abdruck des Schreibens sandte er mit der entsprechenden Bitte an Siebert und legte eine zweite Kopie zur Weiterleitung an den Reichsstatthalter bei. ${ }^{38}$ Siebert nahm daraufhin den Punkt „Strafverfahren gegen Angehörige der SA und SS“ in die Tagesordnung der Ministerratssitzung vom 12. September auf.

Unterdessen hatte gleichfalls am 6. September der neue Polizeipräsident von Nürnberg-Fürth, SA-Gruppenführer von Obernitz - Führer der SA-Gruppe Franken und zugleich Sonderkommissar für Mittelfranken -, einen Bericht an Stabschef Röhm geschickt, in dem er betonte, bei der Nürnberger Aktion der Hilfspolizei habe es sich darum gehandelt, „wohlvorbereitete kommunistische Störungsversuche des Reichsparteitages“, ja sogar „etwa geplante Anschläge auf das Leben des Führers rechtzeitig aufzudecken“. Pflaumer habe die SA-Männer ,in heimtückischer Art“ angegriffen, und es sei zu verstehen, „wenn sie bei der Abwehr über das gebotene Maß hinausgegangen sein sollten“. Außerdem stehe fest, daß Pflaumer nicht von den SA-Männern getötet worden sei, sondern „wahrscheinlich infolge eines Magenleidens später nach Ablieferung bei der ordentlichen Polizei in der Arrestzelle gestorben“ sei. Die Nürnberger Staatsanwaltschaft, die ,in keiner Weise den Sinn und den Geist der neuen Zeit sich auch nur zu begreifen gemüht" habe, habe „unbegreiflicherweise“ Anzeige erstattet; er habe jedoch in seiner Eigenschaft als Polizeipräsident ihr Ersuchen, das Dienstgeheimnis für Zeugenaussagen aufzuheben, mehrfach abgelehnt. ${ }^{39}$

Nachdem sich von Obernitz mit der Rechtsabteilung der Obersten SA-Führung in Verbindung gesetzt hatte, kam es am 11. September - einen Tag vor der Kabinettssitzung - zu einer Aussprache Franks mit Vertretern dieser Rechtsabteilung und der

38 Schr. Franks an Wagner u. an Siebert v. 6.9.33 (Akten des RJM, a.a.O.; auch Akten der bayerStKanzlei, GehStArch. München, Sign. MA 105 483); Wagner leitete am 8.9.33 eine Abschr. an Himmler weiter (Akten des bayerMdI, a.a.O.).

39 Schr. v. Obernitz an Röhm v. 6.9.33 (Akten des bayerMdI, a.a.O.). 
Nürnberger Polizeidirektion. Laut vertraulichem Bericht der politischen Abteilung der Polizeidirektion an die Bayerische Politische Polizei äußerte Frank dabei, „daß von einer unbekannten Persönlichkeit [!] ein bis in die Einzelheiten gehender Bericht an das Reichsjustizministerium geleitet worden sei“. Es sei daher „sein dringender Wunsch“, daß die Aussagegenehmigung erteilt werde; sei der Tatbestand geklärt, könne „die Angelegenheit in irgendeiner Weise ins Reine gebracht" werden. Er habe jedenfalls den leitenden Oberstaatsanwalt „anweisen lassen, nach Abschluß der Vernehmungen vor weiteren Amtshandlungen zum Bericht ins Ministerium zu kommen “. ${ }^{40}$ Ob Frank die Möglichkeit, die Angeschuldigten außer Verfolgung zu setzen, nur aus taktischen Gründen andeutete, oder ob er schon zu diesem Zeitpunkt nicht mehr ernsthaft an eine Durchführung des Verfahrens dachte, muß offenbleiben. Es kann jedoch nicht ausgeschlossen werden, daß der durch von Obernitz informierte Röhm eine entsprechende Entscheidung Hitlers erwirkt hatte, die natürlich auch Frank zu akzeptieren hatte. In diesem Falle wäre Franks Eintreten für die Fortsetzung der Ermittlungen nur noch Ressortegoismus gewesen: die Polizei sollte bei der Feststellung des Tatbestandes gegenüber der Justiz ihre Pflicht erfüllen; wenn die Täter straffrei ausgingen, so sollte die Entscheidung darüber durch die Justiz herbeigeführt werden.

Am Tage der Ministerratssitzung erhielt Siebert einen Brief Röhms, daß er erkrankt und an der Teilnahme verhindert sei. In dem Schreiben hieß es weiter:

„Gleichzeitig bitte ich, daß der Punkt 3 Strafverfahren gegen Angehörige der SA und SS von der Tagesordnung abgesetzt wird. Ich halte diese Erörterung auch nicht mehr für nötig, weil die Bearbeitung der SA-Strafgerichtsordnung im Einvernehmen mit dem Reichsjustizminister abgeschlossen und sie vom Führer gebilligt ist. Sie wird in allernächster Zeit in Kraft treten. Bis dahin können und müssen allenfalls schwebende Verfahren zurückgestellt werden.“

Röhms Behauptung über die unmittelbar bevorstehende Einführung einer SAStrafgerichtsbarkeit war beim derzeitigen Stand der Verhandlungen auf höchster Ebene zweifellos stark übertrieben. ${ }^{41}$ Dennoch wurde die Erörterung des Problems auf der Sitzung des Ministerrats allein durch Röhms Abwesenheit verhindert. ${ }^{42}$

$\mathrm{Ob}$ nun die politische Polizei auch ohne förmlichen Kabinettsbeschluß eine entsprechende Anordnung bekam, oder ob sie nach der Andeutung Franks über eine mögliche Niederschlagung von sich aus in der Fortsetzung der Ermittlungen keine Gefahr mehr sah: jedenfalls erteilte Heydrich der Nürnberger Polizeidirektion die Weisung, die in Betracht kommenden Beamten vom Dienstgeheimnis zu befreien. ${ }^{43}$ Schon am 13. September benachrichtigte Martin die Staatsanwaltschaft, daß wenigstens drei der betroffenen Polizeibeamten für die Zeugenvernehmung zur Verfügung stünden; nach Intervention des Generalstaatsanwalts wurde die Genehmigung schließlich auf alle beteiligten Beamten ausgedehnt. ${ }^{44}$ Ein Verzeichnis der SA-Leute, die in

40 Undat. vertraul. Bericht (vgl. Anm. 26). Nach einem Verm. in den Akten des RJM gingen Abschriften der Sache Pflaumer dort ohne Hinweis auf den Absender vor dem 21.9.33 ein (Archiv des IfZ, Sign. MA 108).

41 Vgl. Kapitel IV.2.a., S. 343 f., und den dort angeführten Erl. des RJM an alle Landesjustizverwaltungen v. 18.9.33.

42 Schr. Röhms an Siebert v. 12.9.33 u. Verm. Sieberts (Akten der bayerStKanzlei, GehStArch. München, Sign. MA 105 483).

43 Ber. Heydrichs an Wagner v. 5.10 .33 über die bereits früher gegebene Weisung (Akten des bayerMdI, a.a.O.).

44 Korrespondenz des U-Richters mit der Pol.Dir. v. 13. bis 16.9.33 (Akten des bayerMdI, a.a.O.); Ber. des OStA v. 14. u. 18.9.33 (Akten des RJM, a.a.O.). Der U-Richter betonte, daß das JM die „allergrößte Beschleunigung“ der Voruntersuchung wünsche. 
der Nacht zum 17. August Dienst getan hatten, konnte die Polizeidirektion dagegen nicht vorlegen, da diese SA-Männer nicht von ihr zugeteilt gewesen seien, sondern aufgrund einer allgemeinen Weisung des SA-Führers von Obernitz zur Verfügung gestanden hätten. Auch ein Protokoll der nächtlichen „Vernehmung“ Pflaumers, dem der Untersuchungsrichter die Namen der vernehmenden Personen und des Protokollführers zu entnehmen hoffte, existierte bei der Polizeidirektion nicht ${ }^{45}$ - ein Zeichen dafür, welcher Art die Vernehmung gewesen war. Der Aufenthaltsort des in derselben Nacht auf der „Samariterwache“ verhörten Schutzhäftlings Göhring wurde dem Untersuchungsrichter dagegen mitgeteilt: er war noch am 17. August schleunigst ins Lager Dachau weggebracht worden. ${ }^{46}$ Als ihn der Richter am 27. September dort als Zeugen vernehmen wollte, beauftragte die Bayerische Politische Polizei einen Kriminalbeamten, der Einvernahme beizuwohnen; trotz seines Protestes bei der Lagerkommandantur unter Hinweis auf die prozessuale Unzulässigkeit wurde der Richter den Aufpasser nicht los. ${ }^{47}$ Frank übersandte Wagner den Bericht des Untersuchungsrichters mit der Bitte, diese Einmischung in die richterliche Unabhängigkeit abzustellen. Er erhielt fünf Wochen später tatsächlich ein Schreiben Heydrichs, es sei nunmehr „Vorsorge getroffen, daß in Zukunft die Herrn Ermittlungs- und Untersuchungsrichter im Konzentrationslager Dachau gemäß den Bestimmungen der Strafprozeßordnung ungestört und ohne Beisein von Polizeibeamten ihre Vernehmungen durchführen können "48; - bereits ein Jahr später sollten sich in dieser Hinsicht die Machtverhältnisse weitgehend verschoben haben. ${ }^{49}$

Die Zeugenaussage Göhrings ergab, daß er in der gleichen Weise wie Pflaumer geprügelt worden war und daß die Behauptung der beiden SA-Führer von einem Angriff Pflaumers auf sie falsch war. ${ }^{50}$ Gerade in diesem Punkt sollten sich die Ermittlungen erschweren, da die Angeschuldigten ihre früheren Angaben plötzlich widerriefen: sie hätten sich nur vor die ihnen untergebenen Kameraden stellen wollen, selbst seien sie weder an den Mißhandlungen beteiligt gewesen, noch hätten sie eigene Kenntnis von den Tätern. ${ }^{51}$ Die Staatsanwaltschaft versuchte nun unter Einschaltung der Polizeidirektion vergebens, die Schuldigen anhand einer Vereidigungsliste mit dreiunddreißig dort namentlich aufgeführten SA-Leuten zu finden, die am 23. August als Hilfspolizisten verpflichtet worden waren, aber bereits in der fraglichen Nacht $-d$.h. ohne zur Tatzeit rechtlich Polizeibeamte zu sein - auf der "Samariterwache“ Dienst getan hatten. Auch der Versuch, die Ermittlungen unter Mitwirkung des Rechtsberaters der SA-Gruppe Franken weiterzubringen, blieb erfolglos. Nach diesem Mißerfolg bestand

45 Korresp. U-Richter mit Pol.Dir. v. 19./22.9.33 (Akten des bayerMdI, a.a.O.).

46 Schr. Martins v. 15.9 .33 (a.a.O.). Göhring hatte in einer Höhle im Fränkischen Jura bei Königstein kommunistische Druckschriften hergestellt. Pflaumers Beitrag bestand lediglich darin, daß er für den Zugang zur Höhle eine Strickleiter gebaut hatte (vgl. H. Beer, Widerstand gegen den Nationalsozialismus in Nürnberg 1933-1945, Nürnberg 1976, S. 121).

47 Ber. des U-Richters v. 28.9.33 an den LGPräs., der über den OLGPräs. ans bayerJM ging; Franks Weitergabeverm. an Wagner v. 14.10.33 (Akten des RJM, a.a.O.).

48 Schr. Heydrichs an das bayerJM v. 23.11 .33 (a.a.O.). Vgl. demgegenüber das Verbot v. 6.12.33(!), wegen dreier Mordfälle im KZ Dachau zu ermitteln (Kapitel VI.4.a., S.643).

49 Vgl. dazu Kapitel VI.4.a., S.644f.

50 Ber. des U-Richters an die Pol.Dir. v. 28.9.33 (Akten des bayerMdI, a.a.O.), außer Göhring wurden noch zwei weitere Häftlinge als Zeugen vernommen, die am 17.8.33 gleichfalls auf der "Samariterwache" verhört worden waren.

51 Ber. des OStA v. 11.12.33 an den GStA, der ihn an das bayerJM weiterleitete (Akten des RJM, a.a.O.). 
nur die Möglichkeit, den nunmehr jede Beteiligung leugnenden SA-Sturmbannführer wegen Beihilfe zum Verbrechen der Körperverletzung mit Todesfolge anzuklagen, da er die methodisch angewendeten Mißhandlungen angeordnet oder zumindest von ihnen gewußt hatte, ohne als Vorgesetzter pflichtgemäß dagegen einzuschreiten. ${ }^{52}$

Am 5. Oktober brachte Frank die ungenügende Unterstützung der Arbeit der Justiz durch die Polizei bei den „Vorfällen in München ${ }^{53}$ und Nürnberg“ im Ministerrat zur Sprache und forderte,

„daß im Interesse der Staatsautorität die Justiz unbedingt wieder zu ihrem Rechte kommen müsse. Es sei so weit, daß die Polizeibehörden sich weigerten, Ansuchen der Justizbehörden um Feststellung des Tatbestandes zwecks Verfolgung schwerer Straftaten durch SA- und SS-Leute Folge zu leisten. Wenn das so weiter gehe, müsse er nach anderen Wegen suchen, damit die Justiz ihre Untersuchungen durchführen könne."

Der Reichsstatthalter, der sich als verantwortlich „für die Einhaltung der Richtlinien der Politik des Reichskanzlers und der Reichsregierung in Bayern" bezeichnete, bramarbasierte, daß er, „wenn in diese Polizeiangelegenheiten keine Ordnung komme, auch nicht davor zurückschrecke, sogar die Reichswehr [?] in Anspruch zu nehmen ". ${ }^{54}$

Diese starken Worte änderten nichts an der Tatsache, daß das Ermittlungsergebnis in der Sache Pflaumer mager blieb. Das dürftige Ergebnis wiederum mag der Justiz die Absicht einer Niederschlagung des Verfahrens erleichtert haben, für die sich Frank im Gegensatz zu seinen starken Worten vom September 1933 - ob auf Eingreifen Hitlers, ist nicht feststellbar - nunmehr entschieden hatte. Nach vorbereitenden Gesprächen mit dem obersten SA-Führer für Bayern, SA-Obergruppenführer Schneidhuber, und nach Vortrag bei Frank schrieb der Strafrechtsreferent im bayerischen Justizministerium, Ministerialrat Döbig, dem leitenden Oberstaatsanwalt am 27. Februar 1934 einen persönlich gehaltenen „Referentenbrief“, er möge doch dafür „sorgen, daß die gerichtliche Voruntersuchung in der besprochenen Weise zu Ende geführt" werde, und Schritte unternehmen, damit eine Niederschlagung eingeleitet werden könne: da das Gesuch von der Polizeidirektion Nürnberg-Fürth ausgehen müsse, solle er sich mit Polizeipräsident von Obernitz in Verbindung setzen. ${ }^{55}$ Am 17. April reichte von Obernitz einen entsprechenden Antrag bei der Staatsanwaltschaft ein. Er begründete ihn damit, daß die Mißhandlung als Todesursache ,nicht einwandfrei festgestellt" worden sei und daß es sich bei Pflaumer um eine „schon lange berüchtigte Persönlichkeit“ handele, die sich „an den kommunistischen Störungsvorbereitungen aus Anlaß des Parteitags 1933 beteiligt hatte“. Pflaumers Züchtigung sei durch „die Erregung der Beteiligten über einen derartig gewissenlosen Menschen verständlich, auch wenn sie in ihrem Ergebnis keineswegs gebilligt werden" könne. Vor allem aber würde ein Prozeß „im feindlich gesinnten Auslande das größte Interesse erwecken und dem Ansehen der SA, aber auch der nationalen Regierung einen ungeheuerlichen Schaden zu-

52 Gemäß $\S 340$ (vorsätzliche Körperverletzung im Amt) u. $§ 343$ StGB (Aussagenerpressung durch Zwangsmittel), Ber. des OStA v. 11.12.33 (a.a.O.) u. Verm. über das bisherige Ergebnis der Voruntersuchung v. 20.1.34 (a.a.O.).

53 Es handelte sich um die Todesfälle im KZ Dachau, insbesondere um den Fall Handschuch, vgl. Kapitel VI.4.a., S.640f.

s4 Aufzeichn. Sieberts v. 7.10 .33 (richtig: 6.10.33) über die „gestrige“ Sitzung des bayer. Ministerrats (Akten der BayerStKanzlei, GehStArch. München, Sign. MA 105257 ).

55 Schr. u. Verm. Döbigs (Akten des RJM, a.a.O.); der OStA meldete dem GStA am 5.4.34, daß die Voruntersuchung am 19.3.34 abgeschlossen wurde (a.a.O.). 
fügen“ und „zu einer willkommenen Quelle für Greuelmärchen“ werden. ${ }^{56}$ Drei Tage nach Eingang des Gesuchs gab der leitende Oberstaatsanwalt unter nochmaliger Schilderung des Sachverhalts und des Ergebnisses der Voruntersuchung die gutachtliche Stellungnahme der Staatsanwaltschaft ab, in der er sich dem Antrag ,aus wohlerwogenen Gründen" anschloß. Eine einfache Außerverfolgungsetzung gemäß $\S 153$ StPO wäre nach Sachlage höchstens gegen den SA-Scharführer möglich. Dagegen wäre gegen den Sturmbannführer eine Anklage nicht zu umgehen und die Untersuchung gemäß $§ 152$ Abs. 2 dann unweigerlich auch auf Mittäter, Anstifter und Begünstiger auszudehnen. Durch einen solchen Prozeß aber würden auch bei Ausschluß der Öffentlichkeit die Vorgänge bekannt werden und die vom Polizeipräsidenten befürchtete Schädigung des nationalsozialistischen Staates eintreten. Da die Tätigkeit der Kommunisten wegen der Sicherheit des bevorstehenden Parteitages in kürzester Frist habe aufgedeckt werden müssen, hätte „die gewöhnliche Art des Vorgehens, wie es etwa durch die StPO geregelt ist“, nicht genügt: so sei es begreiflich, daß durch die SA-Hilfspolizei „Methoden angewendet wurden, die mit dem Gesetz nicht mehr vereinbar waren“. Wäre die Tat drei Wochen früher begangen worden, so wäre sie aufgrund der Straffreiheitsverordnung vom 2. August 1933 amnestiert worden:

„Da die Tat keinem unedlen Beweggrund entsprang, vielmehr der Erreichung eines im höchsten Grade vaterländischen Zieles und zur Durchsetzung des nationalsozialistischen Staates diente, erscheint eine Niederschlagung des Verfahrens ... nicht unvereinbar mit einer geordneten Strafrechtspflege."

\section{Der Generalstaatsanwalt Nürnberg trat dem Standpunkt der Staatsanwaltschaft bei. $^{57}$}

Das Gesuch der Polizeidirektion und die Stellungnahme der Staatsanwaltschaft sandte Frank am 23. Mai an Siebert zur Weiterleitung an den Reichsstatthalter - mit einem Begleitschreiben an von Epp, in dem er beantragte, das Strafverfahren sowohl wegen der an Pflaumer begangenen Straftat wie auch wegen der weiteren strafbaren Handlungen der Teilnahme und Begünstigung, die „zur Abwehr der auf Störung des Reichsparteitages 1933 gerichteten kommunistischen Bestrebungen“ begangen worden seien, niederzuschlagen. Drei Tage vor der Röhm-Affäre verfügte von Epp die Niederschlagung ${ }^{58}$ und sandte darüber einen Bericht an den Reichsjustizminister zur Weiterleitung an Reichspräsident von Hindenburg. Gürtner - der in Fällen ausgesprochen sadistischer Straftaten stets für eine Durchführung des Verfahrens eintrat - antwortete, daß er "gegen die Niederschlagung Bedenken erhoben hätte“, wenn ihm „die Absicht, das Strafverfahren niederzuschlagen, mitgeteilt worden wäre“. Dieser Feststellung verlieh er auch in seinem Begleitschreiben an den Reichspräsidenten Ausdruck. ${ }^{59}$

Bei den Vorkommnissen in Hörstein (Bezirksamt Alzenau), die Frank in seinem Schreiben an Innenminister Wagner vom 6. September 1933 als weiteren Beschwerdepunkt genannt hatte, handelte es sich um die unzulässige Einmischung in ein Strafverfahren durch die SS. In Hörstein waren am 28. August 1933 drei Juden von mehre-

56 Schr. der Pol.Dir. an den OStA beim LG Nürnberg-Fürth v. 17.4.34, Eingang: 25.4 .34 (a.a.O.).

57 Schr. des OStA v. 28.4.34 an den GStA, mit Verm. des GStA (a.a.O.)

58 Schr. Franks v. 23.5.34 an Siebert u. Epp; Verf. Epps v. 27.6.34 (a.a.O).

s9 Schr. v. Epps an den Reichspräs. v. 27.6.34, Schr. Gürtners an v. Epp u. den Reichspräs. v. 9.7.34 (Akten des RJM, Arch. des IfZ, Sign. MA 108). 
ren SS-Leuten in einem Auto aufs freie Feld entführt und mit Fäusten und Gummiknütteln schwer mißhandelt worden. Einer von ihnen mußte mit zerschmettertem Kinn ins Krankenhaus nach Aschaffenburg gebracht werden. Ein an der Mißhandlung beteiligter Hörsteiner SS-Mann wurde aufgrund eines Haftbefehls des Amtsgerichts Alzenau und im Einvernehmen mit dem Kreisleiter der NSDAP in Untersuchungshaft genommen. Weitere vier, in Aschaffenburg wohnende SS-Leute konnten jedoch weder vernommen noch vorläufig verhaftet werden, da sie „sich auf den Standpunkt stellten, daß die Polizei der SS. nichts zu sagen habe und insbesondere keinen SSMann festnehmen dürfe“. Der zuständige Aschaffenburger SS-Sturmbannführer suchte bei der Gendarmerie unter massiven Drohungen sogar die Freilassung des Verhafteten durchzusetzen. Der SA-Sonderkommissar beim Bezirksamt Alzenau rief deshalb bei der Bayerischen Politischen Polizei in München an und bekam vom dortigen Adjutanten Himmlers, Polizeihauptmann Rattenhuber, die Anordnung, daß der SSMann freizulassen sei. Nach Übermittlung dieses Bescheides durch das Bezirksamt hob das Amtsgericht den Haftbefehl am 29. August wieder auf. Damit kamen die polizeilichen Ermittlungen zum Stillstand. Da nunmehr das Untersuchungsergebnis durch Verdunkelung gefährdet war, beauftragte die Staatsanwaltschaft die Gendarmerie, die Erhebungen wieder aufzunehmen und nötigenfalls vorläufige Verhaftungen durchzuführen. In dem erwähnten Schreiben an Wagner sprach Frank daher seine Erwartung aus,

„daß die Beamten der Gendarmerie und Polizei mit der gebotenen Entschiedenheit vorgehen und sich nicht nochmals durch Einschüchterungen von der Erfüllung ihrer Pflicht abhalten lassen. Ich wäre andernfalls genötigt, die Staatsanwaltschaft anzuweisen, der Gendarmerie und Polizei die Ermittlungen zu entziehen und durch staatsanwaltschaftliche und gerichtliche Vernehmungen den Fall zu klären.“

Frank bat Wagner, die Durchführung des Verfahrens durch entsprechende Maßnahmen sicherzustellen. ${ }^{60}$

Auf Rückfrage Wagners rechtfertigte Heydrich das Vorgehen der politischen Polizei damit, daß Rattenhuber aufgrund der Darstellung des SA-Sonderkommissars angenommen habe, der SS-Mann habe sich in Schutzhaft befunden. Rattenhuber selbst gab an, er sei der Ansicht gewesen, „daß in einem so kleinen Ort eine Schutzhaft von SS.-Leuten im Interesse des Ansehens der SS. unter gar keinen Umständen notwendig sei ..., noch dazu es sich um einen Konflikt zwischen SA. und SS. handle [?]“. In seiner dienstlichen Erklärung machte Rattenhuber dabei eine recht umständliche Verbeugung vor der Unantastbarkeit der Justiz: „Von einer Untersuchungshaft war mir nichts bekannt, da es, was mir genau bekannt ist, unmöglich ist, eine Untersuchungshaft von einer außergerichtlichen Stelle aus aufzuheben. “61

Unterdessen hatte das antisemitische Hetzblatt „Der Stürmer“ des mittelfränkischen Gauleiters Streicher den Fall aufgegriffen. In einem Artikel mit der Überschrift „Der Skandal von Aschaffenburg. Die Staatsanwaltschaft provoziert das Rechtsempfinden des Volkes" hieß es:

60 Schr. Franks an Wagner v. 6.9.33 (Anm. 38), zu den Vorgängen in Hörstein ferner: Halbmonatsber. des Reg.Präs. Unterfranken v. 6.9.33 (Bayern in der NS-Zeit. Soziale Lage und politisches Verhalten der Bevölkerung im Spiegel vertraulicher Berichte, hrsg. v. Broszat, E. Fröhlich, F. Wiesemann, München 1977, S. 436); Schr. Heydrichs an Wagner v. 5.10 .33 (BayHStArch. Abt. II, Sign. MInn 71719).

61 Ber. Rattenhubers v. 22.9.33 u. Schr. Heydrichs v. 5.10.33 (a.a.O). 
„Die Oberstaatsanwaltschaft in Bamberg (wann wird endlich das Bamberger Justizhaus gesäubert?) veranlaßte nun eine Voruntersuchung!! ... Nun sollen die SS-Männer auf die Anklagebank kommen und die drei Juden sollen gegen sie als Ankläger und Zeugen aufmarschieren. Und dies alles ein halbes Jahr nach der nationalsozialistischen Revolution! Ist das nicht eine Schweinerei? ... Das bayerische Justizministerium tut gut, wenn es in diesen volksparteilich verseuchten Gerichtshäusern möglichst bald einen Personenwechsel herbeiführt.“62

Das Justizministerium reagierte darauf mit einer Beschwerde an den für das Pressewesen in Bayern zuständigen Chef der Staatskanzlei, Staatsminister Esser, und mit einem Schreiben an Streicher, daß derartige unbegründete Angriffe „das Zutrauen der Öffentlichkeit zur Rechtspflege erschüttern müssen und damit die öffentliche Ordnung gefährden“. Artikel, die Kritik an den Behörden der Justizverwaltung enthielten, sollten daher künftig vor ihrem Erscheinen dem Justizministerium zur Kenntnis gebracht werden. ${ }^{63}$ In seiner nächsten Nummer wiederholte aber das Blatt seine Attacke, griff diesmal den Oberstaatsanwalt beim Landgericht Aschaffenburg unter Namensnennung an und forderte seine Abberufung, da er diesen „Skandal“ aus reiner „Judenfreundlichkeit" absichtlich verursacht habe. ${ }^{64}$ Nunmehr erließ Esser eine pressepolizeiliche Bekanntmachung, daß „herabwürdigende Angriffe gegen Beamte wegen ihrer amtlichen Tätigkeit“ - nur weil sie „nicht die Haltung einnahmen, die der Schriftleitung wünschenswert erschien" -, ferner die Nennung von Namen und Anschrift einzelner Personen in der Absicht, ihr Ansehen zu schädigen „oder verhüllt zu Gewalttätigkeiten gegen sie aufzufordern“, nicht in die Zeitung gehörten: Kritik am Verhalten einzelner Personen solle der nationalen Regierung „unmittelbar und nicht durch die Presse mitgeteilt werden“. Die Bezirkspolizeibehörden sollten die Durchführung dieser Anordnung überwachen und nötigenfalls „mit den Mitteln der Pressepolizei gegen die Schriftleitungen" vorgehen. ${ }^{65}$ Frank verständigte Siebert und von Epp. Am 10. Oktober wurden die Angriffe des „Stürmer“ gegen die Justizbehörden in Bamberg und Aschaffenburg im Ministerrat behandelt. Esser legte dem Kabinett ein pressepolizeiliches Verbot der Zeitschrift nahe, doch „nach Besprechung der grundsätzlichen und politischen Auswirkungen eines derartigen Beschlusses“ wurde Esser nur „zu einer scharfen Verwarnung " der Schriftleitung im Namen des Ministerrats ermächtigt. ${ }^{66}$

62 Der Stürmer Nr. 37 v. Sept. 1933 (Arch. des IfZ, Sign. MZ 17/3).

${ }^{63} \mathrm{Ob}$ dieses in der Übersicht des bayerJM (s. Anm. 5) erwähnte Schr. an Streicher von Frank selbst oder auf seine Veranlassung von Siebert geschrieben wurde, ist unklar. In Essers Weisung an die Pol.Dir. NürnbergFürth v. 13.10.33 heißt es, Streicher sei „von maßgebender Stelle“ auf diese Gesichtspunkte hingewiesen worden (Akten des bayerJM, BayHStArch. Abt. II, Sign. MJu 12003).

64 Der Stürmer Nr. 38 v. Sept. 1933 (Arch. des IfZ, a.a.O.).

63 Bek. des Chefs der Staatskanzlei v. 4.10.33 über Pressepolizei (Bayer. Staatsanz. Nr. 234 v. 10.10.33). Ihr ging noch folgendes voraus: in Nr. 30 (Juli) u. 31 (August) des "Stürmer" war ein Nürnbg. RA, der den gegen das Bonzentum Streichers angehenden SA-Gruppenführer Stegmann vor Gericht vertreten hatte, grundlos als ,Judenbastard“ u. Verräter angeprangert u. daraufhin auf offener Straße geschlagen worden. Der RA hatte Esser am 23.8. geschrieben, daß die Polizei die Untersuchung verschleppe und die Sache der StAschaft gegenüber als „völlig sporadischen“ Vorfall herunterspiele. Esser wollte die Kritik an der Polizei am 12.9. im Ministerrat vorbringen, war aber an der Teilnahme verhindert. Der rückfragende Wagner wurde daraufhin schriftl. unterrichtet (Akten der BayerStKanzlei, GehStArch. München, Sign. MA 105 484).

66 In Ausführung des Beschl. wies Esser die Pol.Dir. Nürnberg-Fürth am 13.10.33 (vgl. Anm. 63) entsprechend an und fügte hinzu, er werde "alle zur Verfügung stehenden Mittel der Pressepolizei einsetzen“, wenn „die Schriftleitung auch künftig wieder derartige maßlose Angriffe gegen Einrichtungen und Maßnahmen der Nationalen Regierung“ richte. Die Bedenken gegen ein Verbot des „Stürmer“ formulierte der Vorstand der Nürnberger Pol.Dir. so: „Wenn eine nationalsozialistische Regierung ein nat.soz. Kampfblatt gegen die Juden verbieten würde, würde das ohne Zweifel wie ein erster neuer Sieg des Judentums nicht nur 
Hinsichtlich des Hörsteiner Falles selbst bestand im Kabinett Übereinstimmung, daß „den Vertretern der staatlichen Polizei, die etwa Schwierigkeit bei der Ausübung ihrer Tätigkeit in Franken finden, die volle Unterstützung des Staates zu gewähren sei“ ${ }^{67}$ In der erwähnten tabellarischen Ủbersicht des bayerischen Justizministeriums findet sich daraufhin der abschließende Vermerk: „Das Verfahren wird - wenn auch mit erheblicher Verzögerung - durchgeführt." ${ }^{\text {(68 }}$

\section{c. Die Unstimmigkeiten mit der SA-Führung und ibren Sonderkommissaren}

In seiner Eigenschaft als bayerischer „Staatskommissar z.b. V.“ setzte Stabschef der SA Röhm einen „Sonderbevollmächtigten für das Land Bayern“, SA-Gruppenführer Fuchs, mit Dienstsitz im bayerischen Innenministerium ein, der zugleich als Verbindungsführer der Obersten SA-Führung in seinem Auftrag die „Sicherheits-Hilfspolizei“ der SA leitete. Ihm unterstanden die „Sonderkommissare des Obersten SA-Führers“ bei den Kreisregierungen, diesen wiederum die „Beauftragten der Sonderkommissare des Obersten SA-Führers" bei den Bezirksämtern und kreisunmittelbaren Städten. ${ }^{69}$

Die Eingriffe der SA-Sonderkommissare in die Justiz wurden durch die ungenaue Abgrenzung ihrer Befugnisse gegenüber den staatlichen Dienststellen außerordentlich begünstigt. Im Erlaß Wagners vom 18. März 1933 war bestimmt worden, daß sie der ordentlichen Polizei keine Befehle erteilen durften, soweit sie nicht selbst zu örtlichen Polizeichefs ernannt waren. Wenn staatliche Stellen die Anordnungen und Maßnahmen der nationalsozialistischen Regierung mißachteten oder verschleppten, sollten die Kommissare an das Innenministerium berichten. Von selbständigen Eingriffen in die Verwaltung war nirgends die Rede; die Justiz war überhaupt nicht erwähnt. ${ }^{70}$ Röhm ergänzte diese Bestimmungen in einer vertraulichen Verfügung vom 20. März dahingehend, daß die Kommissare Mängel bei der Durchführung der neuen Gesetze und Verordnungen vor einer Meldung nach oben ,zunächst mit der betreffenden Dienststelle zu beheben“ suchen sollten, wobei sie „sich in Wahrung der ihnen anvertrauten Interessen rücksichtslos durchzusetzen“ und ein „energisches und zielbewußtes Auftreten " an den Tag zu legen hatten. ${ }^{71} \mathrm{Da}$ aber die Aktivität der Sonderkommissare in Röhms Sinne „an manchen Orten noch sehr zu wünschen übrig“ ließ, verschärfte er seine Anweisungen in einer Verfügung vom 31. März, die diesmal offensichtlich nicht nachrichtlich an die Leiter der staatlichen Ressorts ging:

in Deutschland, sondern auch im Ausland gewertet werden." Streicher habe zugesagt, daß Angriffe auf Einzelpersönlichkeiten nicht mehr erfolgen würden (Schr. v. 12.10.33 an Esser, BayHStArch. Abt. II, Sign. MJu 12003).

${ }^{67}$ Prot. der Ministerratssitzung v. 10. 10.33 (GehStArch. München, Sign. 99525).

${ }_{68} \mathrm{Vgl}$. Anm. 5. Über den Ausgang des Verfahrens lagen dem Verfasser keine Unterlagen vor. Eine Anfrage bei der Registratur des OLG Bamberg u. des LG Aschaffenburg brachte kein Ergebnis, ebensowenig eine Durchsicht der damaligen Lokalzeitungen.

69 Ab September 1933 hießen die Sonderkommissare „Sonderbevollmächtigte des OSAF“, die Beauftragten „Sonderbeauftragte des OSAF“. Nach der Röhm-Affäre wurden diese Einrichtungen durch Verf. des neuen Stabschefs Lutze am 10.7.34 aufgehoben (Erl. Wagners v. 19.7.34, Akten des bayerJM, BayHStArch., Sign. MJu 12003); die „Sicherheits-Hilfspolizei““ wurde bereits mit Wirkung v. 31.12.33 aufgelöst (VO Wagners v. 22.12.33 GehStArch. München, Sign. MA 106 288).

70 Erl. Wagners als kommissar. bayerMdI v. 18.3.33 (Arch. des IfZ, Sign. Fa 115). Zur Kontrolle der Staatsverw. durch die SA-Sonderkommissare allgemein s. J. Klenner, a.a.O. (Anm. 8), S. 95 ff.

7 Vertraul. Verf. Röhms v. 20.3.33 (Arch. des IfZ, a.a.O.). 
„Die aktive, treibende Kraft im zugewiesenen Bezirk ist der Sonderkommissar, der alle für Ruhe und Ordnung notwendigen Maßnahmen selbständig anordnet, die Überwachung gegnerischer und verdächtiger Kräfte vornehmen läßt, Haftbefehle gegen alle Schädlinge der nationalsozialistischen Freiheitsbewegung und damit des Deutschen Volkes veranlaßt ... Grundsätzlich muß der Sonderkommissar der Herr in seinem Bezirk sein, dem sich alles unterzuordnen hat. Grundsatz für ihn ist: Nicht handeln ist schlimmer als ein Fehlgreifen in der Wahl der Mittel.“72

Bei solchen Befehlen war es nicht verwunderlich, daß sich die Eingriffe mehrten und Röhm sowie Wagner vom Ministerrat ersucht wurden, die Funktionäre von SA und NSDAP eingehend über die Grenzen ihrer Aufgaben gegenüber der staatlichen Verwaltung zu belehren. ${ }^{73}$ Röhm erließ am 26. April tatsächlich eine Verfügung betr. Wahrung der Disziplin, die hinsichtlich der Justiz wichtige Ausführungen enthielt. Er wies darauf hin, daß nach der Amnestieverordnung vom 21. März 1933 begangene Straftaten von der Staatsanwaltschaft und Polizei verfolgt werden müßten und ,jede Einmischung von SA- und SS-Männern und -Führern sowie von Sonderkommissaren in die Tätigkeit der Strafverfolgungsbehörden unzulässig und daher verboten“" sei. Die Verfügung wurde von Frank an alle Staatsanwaltschaften geschickt. ${ }^{74}$ Diese offensichtlich zur Beruhigung der Vertreter des Staatsapparats und wohl auch voreilig erlassene Anordnung schloß spätere, entgegenstehende interne Weisungen Röhms nicht aus. ${ }^{75}$ Wie wirkungslos diese Verfügung bei dem hintergründigen Doppelspiel Röhms war, berichtete ein Amtsgerichtsrat aus Landau (Pfalz) am 26. Juni brieflich an Ministerpräsident Siebert, mit dem er befreundet war: Gegen SS-Leute, die städtische Beamte und Juden mißhandelt hatten, hatte der zuständige Oberstaatsanwalt Haftbefehl erlassen. Daraufhin forderten ein örtlicher SA- und ein SS-Führer die Freilassung der Verhafteten, sie könnten „sonst für nichts einstehen; es wäre doch schauerlich, wenn Schutzpolizei und SS aufeinander schießen [sic] würden“. Als der Oberstaatsanwalt auf Röhms Verfügung hinwies, erklärten ihm beide, ,sie hätten bei einer in Kaiserslautern stattgefundenen Führerbesprechung die Weisung erhalten, daß die Revolution weitergehe. Ihre Anweisungen seien anders“" ${ }^{76}$ Bei der Aussprache über die Angelegenheit, die Siebert im Ministerrat vorbrachte, und über andere Eigenmächtigkeiten der SASonderkommissare äußerte von Epp, es sei „untragbar, daß die Kommissare sich als Beauftragte der Obersten SA-Führung, nicht der Staatsregierung betrachteten“, und das Kabinett beschloß, „die Dienstanweisung für die Kommissare im Benehmen mit der Obersten SA-Führung neu zu fassen“. ${ }^{77}$ Als die Grundsätze für eine solche Neufassung auf der Ministerratssitzung vom 26. Juli mit Röhm beraten wurden, erklärte

72 Verf. Röhms v. 31.3 .33 (a.a.O.). Der Sonderkommissar bei der Reg. v. Oberbayern bestätigte Röhm, daß es de facto beim zuständigen Sonderkommissar liege, sich zum Vorsteher jenes Amts zu machen, das ,ihm als Garant anvertraut“ sei; er beschwor Röhm, ,jeder Detailbenennung von Zuständigkeiten der Sonderkommissare" auszuweichen (Schr. v. 6.7.33, GehStArch. München, Sign. MA 105 256).

73 Entschl. des Ministerrats v. 19.4.33 (Prot., GehStArch. München, Sign. MA 99525 ), vgl. auch v. Epps Erl. v. 8.4.33 an die bayer. Gauleiter: „Die Arbeit der staatlichen Behörden darf unter keinen Umständen durch irgendwelche Einmischungsversuche gestört werden“ (Akten des bayerJM, BayHStArch., Sign. MJu 12003).

74 Verf. Röhms v. 26.4.33 u. RdSchr. Franks v. 8.5.33 (Akten des bayerJM, a.a.O.).

75 Vgl. Röhms Verf. v. 19.7.33 (vgl. folgende Anm. 87), 31.7.33 (vgl. Kapitel IV.1.c., Anm. 41) u. 2.3.34 (vgl. folgende Anm. 92).

${ }^{76}$ Schr. des AGRats an Siebert v. 26.6.33 mit zwei Anlagen (Akten der bayer. StKanzlei, GehStArch. München, Sign. MA 105 482). Im vorliegenden Fall wurden die SS-Leute nach einem vollen Geständnis aus der Haft entlassen, da keine Verdunkelungsgefahr mehr bestand. Die weitere Entwicklung des Verfahrens geht aus den Akten nicht hervor.

77 Ministerratssitzung v. 4.7.33 (Prot., GehStArch. München, Sign. MA 99 525). 
Frank in äußerst euphemistischer Beurteilung der Realität, „auf dem Gebiet der Rechtspflege habe er Eingriffe von Sonderkommissaren ferngehalten [was ihm in Wirklichkeit gerade nicht immer gelungen war], um das Vertrauen der Bevölkerung in die Rechtspflege nicht zu erschüttern“. Wohl im Hinblick auf Röhms „Disziplin-Verfügung“ vom April fügte er hinzu, ,in diesem Bestreben sei er von Stabschef Röhm stets unterstützt worden“ - eine sehr pauschale Aussage, die meist nur auf diejenigen konkreten Fälle zutraf, in denen Frank dafür den Preis einer Niederschlagung zahlte. Immerhin hielt er es für erforderlich, bei einer neuen Zuständigkeitsregelung für die Kommissare eindeutig

„festzulegen, daß sie in die Rechtspflege nicht eingreifen dürften ... Er sei froh, daß Stabschef Röhm heute bestätigt habe, daß ein polizeiliches Vorgehen gegen unzuverlässige Elemente und Provokateure in SA-Uniform zulässig sei und daß bei Verfehlungen die Schuldigen aus der SA entfernt und der Gerichtsbarkeit übergeben würden.“

In den Grundsätzen, die der Ministerrat für die auszuarbeitenden neuen Richtlinien beschloß - die in sich so widersprüchlich waren, daß sie eine Fortdauer des Antagonismus geradezu garantierten -, lautete jedenfalls der Passus über die Justiz eindeutig: „Zuständigkeiten auf dem Gebiet der Rechtspflege, das Recht zu Verhaftungen und zu unmittelbaren Anweisungen an die Vollzugsorgane soll [sic] den Sonderbeauftragten nicht mehr zustehen. ${ }^{.78} \mathrm{Wie}$ zu erwarten, löste die von Röhm ausgearbeitete, von Wagner und Siebert gebilligte Dienstanweisung für die „Sonderbevollmächtigten und Sonderbeauftragten des Obersten SA-Führers" - wie die Sonderkommissare nunmehr hießen - vom 1. September $1933^{79}$ das Problem in keiner Weise. Die Bevollmächtigten wurden darin zwar als „Organe der Staatsgewalt“ bezeichnet, waren jedoch bei ihrer Tätigkeit in das Normensystem staatlicher Verwaltung nicht eingebunden. Sie sollten den Staatsapparat kontrollieren und dafür die „Möglichkeit der Einsichtnahme in die Dienstgeschäfte“ besitzen; andererseits war ihnen „ein Eingreifen in die innere Verwaltung, insbesondere in die Justizverwaltung" untersagt. Bei einem Dissens ließ die Dienstanweisung die beiden Antagonisten auf jeder Ebene des zweigleisigen Instanzenzuges gleichgeordnet nebeneinanderstehen und eine Entscheidung auf der nächsthöheren Ebene suchen, bis der Konflikt im äußersten Falle durch Hitler entschieden wurde, der die Ämter des Obersten SA-Führers und des Reichskanzlers in sich vereinigte. Aus der Tatsache, daß bei dem aufgeführten Instanzenzug nur Behörden der inneren Verwaltung genannt waren, ging eigentlich hervor, daß sich die Tätigkeit der Sonderbevollmächtigten auf die Justiz überhaupt nicht erstrecken sollte. Aber bei der im Grunde weiterhin unklar bleibenden Kompetenzabgrenzung war den Eingriffen ,revolutionsbewußter" SA-Führer auch in den Justizbereich Tür und Tor geöffnet. Den erwähnten Eingriff im Amtsgerichtsbezirk Pottenstein z. B. ${ }^{80}$ rechtfertigte

${ }^{78}$ Ministerratssitzung v. 26.7 .33 (a.a.O.). Bezeichnenderweise erklärte es Frank ,in diesem Zusammenhang [für] wesentlich, auch die Rechtslage des Judentums zu klären“. Solange nämlich Juden den anderen deutschen Staatsangehörigen vor dem Gesetz gleichgestellt waren, mußte Frank - der ,gesetzlich“ fundierte antisemitische Schritte wie die Ausschaltung der Juden aus der Justizverwaltung und Anwaltschaft voll bejahte (vgl. Kapitel III.1.a.) - bei seiner Verteidigung der "Gesetzlichkeit“" stets dann in Konflikt mit seiner antisemitischen Gesinnung geraten, wenn die strafbaren Handlungen von Anhängern der NS-Bewegungen gegen Juden begangen worden waren.

79 Akten des bayerJM (BayHStArch. Abt. II, Sign. MJu 12003). Frank hatte an der Ausarbeitung nicht mitgewirkt; der Ministerrat nahm am 29.8.33 lediglich von der Billigung Sieberts und Wagners „ohne Erinnerung Kenntnis“ (Prot., Arch. des IfZ, Sign. Fa 115).

80 Vgl. Kapitel IV.4.a., S. $385 \mathrm{f}$. 
der Sonderbevollmächtigte für den Kreis Oberfranken in der Besprechung mit dem Justizministerium am 5. Oktober 1933 mit einer ihm vorliegenden Weisung, „nach der es seine Aufgabe sei, alle Organe und Einrichtungen des Staates zu überwachen“. Als Frank daraufhin bei der Obersten SA-Führung in München rückfragte, „ob tatsächlich eine derartige Anordnung besteht, gegebenenfalls ob sie sich auch auf den Geschäftsbereich der Justizverwaltung erstreckt", ging aus der Antwort hervor, daß der Sonderbevollmächtigte die Dienstanweisung vom 1. September 1933 so interpretiert hatte. ${ }^{81}$ Es lag in der Natur der Sache, daß auch eine neue Dienstanweisung Röhms vom 15. Januar $1934^{82}$ hier keine Änderung herbeiführen konnte. Auf einer Besprechung im Ministerium am 6. April 1934 schärfte Frank seinen Oberlandesgerichtspräsidenten und Generalstaatsanwälten nochmals ein, Übergriffen unbefugter Organe nicht stattzugeben; er tat das in Worten, die die damalige Lage der Justiz zugleich treffend kennzeichnen:

„Bestehen Sie draußen im Lande grundsätzlich darauf, daß Sie lediglich Staatsorgane sind und lediglich den Weisungen Ihrer vorgesetzten Dienststelle zu entsprechen haben ... Es ist unsere Sache hier im Ministerium, ausschließlich im Streitfall zu entscheiden, ob der Staat unter Aufrechterhaltung seines Primates im Einzelfall einmal der Partei entgegenkommt ... Das Recht ist auch im nationalsozialistischen Staat keine Handelsware, wo man sagen kann, in diesem Falle X wende ich das Gesetz nicht an, weil es sich um den und den Fall handelt ... Wir haben im letzten Jahr allerhand getragen. Ich glaube kaum ein Instrument des Staates hat so viel Opfer gebracht wie die Justiz. Wir haben nicht nur ein Auge, sondern wiederholt beide Augen zugedrückt. Ich bin mir selbst bewußt, daß draußen im Lande oft die Meinung bestand, die Berufung auf die SA oder auf die Partei genüge, um irgendwelche Rechtsfolgen abzuwenden ... [Demgegenüber müsse] festgestellt werde[n], daß es sich grundsätzlich nur um ein Entgegenkommen handle, daß aber niemals ohne weiteres angenommen werden dürfe, es könne nichts geschehen, weil der Betreffende SA.-Mann sei. Er würde nicht davor zurückschrecken, im Interesse der ewigen $\mathrm{Ge}$ rechtigkeit mit dem Führer selbst die Debatte aufzunehmen."

Frank, der sich in Reden vor Justizangehörigen leicht in die Rolle des Rocher de bronze für die Justiz hineinsteigerte, mußte wohl nachträglich aufgegangen sein, daß er mit der letzten Äußerung zu weit gegangen war; in der endgültigen Fassung des Protokolls wurde dieser Satz geändert in: „Er würde unter Umständen sogar eine Entscheidung des Führers herbeiführen." ${ }^{\text {"83 }}$ Alle starken Worte konnten jedoch nichts daran ändern, daß die Übergriffe der SA-Bevollmächtigten bzw. -beauftragten in den Justizbereich bis zu ihrer Abschaffung nach der Röhm-Affäre anhielten.

Der Justiz blieb es überlassen, anläßlich eines konkreten Falles zu klären, wie weit die Sonderbevollmächtigten tatsächlich „Organe der Staatsgewalt“ darstellten, wie sie noch in der Dienstanweisung vom 1. September 1933 bezeichnet worden waren. Der frühere Bürgermeister in Rehling (Bezirk Aichach) hatte wegen falscher Anschuldigung Anzeige gegen drei Personen erstattet, die ihn beim Sonderbeauftragten für das

81 Schr. Franks v. 10.10.33 u. Antwort des OSAF (i. V. Obergruppenführer v. Kraußer) v. 13.10.33 (Akten des bayerJM, a.a.O.).

82 Akten des bayerJM (a.a.O.). Úber die Justiz hieß es darin: „Für strafrechtliche Angelegenheiten sind die Strafgerichtsbehörden zuständig. “ Epp erreichte nachträglich, daß er „auf Grund der ihm vom Führer erteilten Vollmacht" in Bayern als letzte Entscheidungsinstanz bei Meinungsverschiedenheiten zwischen der OSAF und dem bayer. Innenministerium vorgesehen wurde (ergänzende Verf. Röhms v. 10.3.34, Arch. des IfZ, Sign. Fa 115), eine völlig unwirksame Bestimmung, da sich Röhm als Stabschef der SA und Wagner als Gauleiter stets unmittelbar an Hitler wandten.

83 Niederschr. über die Bespr. der JVerw. mit den OLGPräs. u. GStAen am 5. u. 6.4.34 (Akten des bayerJM, BayHStA, Abt. II, Sign. MJu 16997). 
Bezirksamt Aichach strafbarer Handlungen bezichtigt und damit seine Inschutzhaftnahme herbeigeführt hatten. Der Oberstaatsanwalt beim Landgericht Augsburg stellte jedoch das Verfahren gegen die Denunzianten ein, „weil der Sonderbeauftragte weder eine Behörde noch ein zur Entgegennahme von Anzeigen zuständiger Beamter" im Sinne des $\S 164 \mathrm{StGB}^{84}$ sei. Als der Exbürgermeister sich gegen die Einstellung beschwerte, ersuchte der Generalstaatsanwalt München das Justizministerium um eine Äußerung über die Rechtsstellung der Sonderbeauftragten. In einem Schreiben an den Innenminister vom 26. April 1934 schloß sich Frank der Ansicht des Oberstaatsanwalts an und betonte, die Sonderbevollmächtigten und -beauftragten könnten „die ihnen obliegende Aufgabe, als Garanten der nationalsozialistischen Revolution den Geist dieser Revolution durchzusetzen und Anregungen und befruchtende Vorschläge von außen in den Staatsapparat hineinzutragen, nicht wohl erfüllen, wenn sie Beamte eben dieses Staatsapparates" seien. Deshalb seien sie in der neuen Dienstanweisung vom 15. Januar 1934 nunmehr auch als „staatlich anerkannte Organe des Obersten SA-Führers" bezeichnet worden. Der Kampf gegen das Angebertum werde durch diese Auffassung insofern nicht beeinträchtigt, als die Strafbestimmung des $\S 164$ StGB auch zur Anwendung komme, wenn die Sonderbevollmächtigten die Anzeige an eine Behörde weiterleiteten. ${ }^{85}$ Wagner stimmte dem zu, ließ aber zugleich durchblicken, daß die Sonderbevollmächtigten und -beauftragten verpflichtet seien, die vorgebrachten Anzeigen nicht nur an die zuständige Behörde, sondern auch ,auf dem Dienstweg höheren Dienststellen zur Weiterbehandlung zuzuleiten“. ${ }^{86}$

Außer durch Eingriffe, die die SA-Kommissare aufgrund ihrer ungenau abgegrenzten Befugnisse in die Justiz vornahmen, wurden die Strafverfahren gegen SA- und SSAngehörige vor allem durch die wiederholten Hinweise der Obersten SA-Führung auf die bevorstehende Einführung einer eigenen SA-Gerichtsbarkeit gehemmt. Am 19. Juli 1933 führte Röhm in einer Verfügung an alle Obergruppen, Gruppen und Brigaden - d.h. auf Reichsebene - aus, es werde

„in der nächsten Zeit eine vom Führer bereits genehmigte und gegenwärtig beim Reichsjustizministerium zur formalen Überprüfung [!] befindliche SA-Strafgerichtsordnung eingeführt werden, die alle SA-Männer der ordentlichen Gerichtsbarkeit entzieht und sie den einzuführenden SA-Gerichten unterstellt".

Sie werde sich „auch auf die Aburteilung von Vergehen und Verbrechen erstrekken“ und „rückwirkende Kraft erhalten“. Soweit daher SA-Angehörige in Verfahren verwickelt seien, die sich auf politische $-d$.h. nicht aus eigensüchtigen Motiven entstandene - Straftaten bezögen, ersuchte Röhm die SA-Gruppen, „bei den einschlägigen Gerichten sofort deren Freilassung und Übereignung [sic] an die SA-Dienststellen zu veranlassen"; im Weigerungsfall sei ihm zu berichten. ${ }^{87}$ Diese Anordnung stand der Entschließung diametral entgegen, die Frank rund einen Monat später an die

$84 \oint 164$ StGB: „Wer einen anderen bei einer Behörde oder einem zur Entgegennahme von Anzeigen zuständigen Beamten ... wider besseres Wissen einer strafbaren Handlung oder der Verletzung einer Amts- oder Dienstpflicht in der Absicht verdächtigt, ein behördliches Verfahren oder andere Maßnahmen gegen ihn herbeizuführen oder fortdauern zu lassen, wird wegen falscher Anschuldigung ... bestraft.“

85 Aktenverm. u. Schr. Franks an den bayerMdI u. den Sonderbevollm. des OSAF für Bayern, Obergruppenführer Fuchs, v. 26.4.34 (Akten des bayerJM, BayHStArch. Abt. II, Sign. MJu 12003).

86 Schr. Wagners an das bayerJM v. 28.5.34 (a.a.O.).

87 Verf. des OSAF v. 19.7.33, Chef d. Stabes, unterzeichnet I.A. Gruppenführer Schmid, Chef der Abt. III (Akten des RJM, Arch. des IfZ, Sign. MA 108). 
bayerischen Staatsanwaltschaften richtete. Zwar war auch in ihr von Verhandlungen die Rede, die über die Einführung einer besonderen Gerichtsbarkeit für SA- und SSMitglieder im Gange seien. Dann aber hieß es eindeutig:

„Bis zu dieser reichsgesetzlichen Regelung unterstehen jedoch alle Mitglieder der SA. und SS. der ordentlichen Gerichtsbarkeit im selben Umfang wie andere Staatsbürger. Die Vornahme von Untersuchungshandlungen, die Einleitung von Strafverfahren, der Erlaß und die Aufhebung von Haftbefehlen bemißt sich nach den hierfür bestehenden gesetzlichen Vorschriften. Hiernach sind alle Strafverfahren gegen Mitglieder der SA. und SS. nach Maßgabe der Gesetze durchzuführen."

Etwaige Ersuchen um Freilassung oder Auslieferung von Verhafteten sowie um Abgabe von Akten seien dem Justizministerium vorzulegen; Auskünfte über derartige Strafverfahren dagegen seien den Rechtsberatern der SA-Dienststellen zu erteilen. ${ }^{88}$ Mitte Oktober brachte Frank überdies allen Justizbehörden das Rundschreiben Fricks vom 6. Oktober zur Kenntnis, daß sich die Behörden Eingriffen der SA nicht beugen dürften, sondern strafbare Handlungen von SA-Mitgliedern nachdrücklich zu verfolgen hätten, und machte die Amtsvorstände dafür verantwortlich, daß diese Anordnung unter allen Umständen beachtet würde. ${ }^{89}$ Als jedoch im Laufe der Zeit zahlreiche Verfahren „steckenblieben“, weil entweder die Ermittlungen oder die Hauptverhandlung durch die SA bzw. SS sabotiert wurden, schwenkte Frank auf ein nachgiebigeres Verfahren ein. Im November wies er die Justizbehörden darauf hin, daß zwischen ihnen und den Führern der Bewegung „ein vertrauensvolles Zusammenwirken“ stattgreifen müsse: in einschlägigen Fällen müßten die Vorstände der Justizbehörden „mit den örtlichen Führern und ihren Rechtsberatern persönliche Verbindung aufnehmen und in allen geeigneten Fällen durch sachgemäße Besprechung mit diesen den im Interesse des Staates und des Volkes gebotenen Ausgleich zwischen den Belangen der nationalsozialistischen Bewegung und den gesetzmäßigen Aufgaben der Rechtspflege herbeizuführen suchen“.

Gelinge ein solcher Ausgleich nicht, sei dem Oberlandesgerichtspräsidenten bzw. Generalstaatsanwalt zu berichten. Schlügen auch deren Bemühungen fehl, sei die Angelegenheit dem Justizministerium vorzulegen. In allen Fällen sollten die Staatsanwälte sofort nach Eingang einer Anzeige mit dem obersten örtlichen Führer oder dem örtlichen Rechtsberater des betreffenden Verbandes Fühlung aufnehmen und diesen vom weiteren Verlauf des Verfahrens ,in geeigneter Weise“ unterrichten. ${ }^{90}$

Diese Weisung verhinderte zwar, daß die Verfahren gegen SA-Angehörige wie in den meisten außerbayerischen Ländern vorläufig ruhten.91 $\mathrm{Da}$ aber bei den unteren SA-Führern die Hoffnung auf Einführung einer eigenen Gerichtsbarkeit von oben her weiter genährt und damit eine Widerstands- und Verzögerungstaktik geradezu provoziert wurde, gelang auch in Bayern der gewünschte „Ausgleich“ in den wenigsten Fällen - es sei denn, daß die Justiz nachgab und auf Strafverfolgung verzichtete. Zur Unnachgiebigkeit in dieser Frage wurden die SA-Führer von Röhm ausdrücklich angehalten. In seiner Verfügung vom 2. März 1934 wies er abermals darauf hin, daß „eine SA-Dienststrafgerichtsordnung fertiggestellt“ und lediglich „aus politischen Gründen

88 Entschl. des bayer. JM v. 22.8.33 (GehStArch. München, Sign. MA 105 482).

89 Schr. Franks v. 13.10.33 (a.a.O., Sign. MA 105 257), zum Rdschr. Fricks vgl. Kapitel IV.1.a., Anm. 42.

90 Weisung Franks v. 20.11.33, nachrichtl. an Röhm u. Himmler (Akten des bayerJM, BayHStArch. Abt. II, Sign. MJu 12003).

91 Vgl. die Ausführungen Döbigs in der Bespr. der JVerw. mit den bayer. OLGPräs. u. GStAen am 6.4.34 (Akten des bayerJM, BayerHStArch. Abt. II, Sign. MJu 16997). 
... erst später in Kraft treten“ könne. Da aber „mit Rücksicht auf das wiederholt in Aussicht gestellte Inkrafttreten" die strittigen Strafsachen bei der ordentlichen Strafverfolgungsbehörde ,fast ausnahmslos ruhen [!]“, müßte für sie nunmehr „eine zweckentsprechende Erledigung“ gefunden werden. Eine „Aburteilung durch die bürgerlichen Strafgerichte“, erklärte Röhm apodiktisch, „verbietet sich aus grundsätzlichen Erwägungen“; vielmehr solle die SA eine „Erledigung der Strafsachen je nach Lage des Falles durch Einstellung mangels Beweises [!] oder mangels Bewußtseins der Rechtswidrigkeit ins Auge fassen, oder eine Einstellung durch Gerichtsbeschluß gemäß $\S 153$ StPO anstreben, oder eine Niederschlagung ... in die Wege leiten“. Um eine Niederschlagung durch die zuständigen staatlichen Stellen zu erreichen, sei aber notwendig, daß die SA-Angehörigen, „die nach dem Sachverhalt strafwürdig sind“, zuvor durch die SA disziplinär bestraft würden. Hierzu biete das Gesetz zur Sicherung der Einheit von Partei und Staat vom 1. Dezember 1933 die Rechtsgrundlage, ohne daß eine Ausführungs- oder Ergänzungsverordnung erlassen zu werden brauche, denn schon nach diesem Gesetz könnten SA-Angehörige im Dienstwege „mit Arrest von unbeschränkter Dauer" bestraft werden. ${ }^{92}$ Da das erwähnte Gesetz vorerst nur Rahmenvorschriften für eine Disziplinargerichtsbarkeit der Partei und der SA enthielt, deren Aufbau, Verfahren und Inkrafttreten erst durch entsprechende Anordnungen Hitlers geregelt werden sollten, hätte Röhms Weisung bei einem Einverständnis der Justizbehörden nichts weniger als die Einführung der SA-Gerichtsbarkeit auf kaltem Wege bedeutet.

Immerhin legte das Gesetz vom 1. Dezember 1933 den Mitgliedern der Partei und der SA besondere Pflichten auf und unterstellte sie wegen Verletzung dieser Pflichten einer besonderen Disziplinargerichtsbarkeit, die neben der öffentlichen Strafgewalt des Staates existierte. Somit war es notwendig geworden, alle schweren Verletzungen der Strafgesetze den zuständigen SA-Führern zur Kenntnis zu bringen, weil sie zugleich Verstöße gegen die aus der Mitgliedschaft zur SA fließenden Sonderpflichten darstellten. Deshalb hielt es Frank für erforderlich, die in seiner Weisung vom 20. November 1933 angekündigte „nähere Regelung des Verkehrs der Strafverfolgungsbehörden mit den Dienststellen der SA“ nunmehr mit den Rechtsberatern der SA abzusprechen und auszuarbeiten. Zugleich wollte er das ebenfalls in jener Weisung niedergelegte „Ausgleichs“-Verfahren technisch verbessern und - da auch die Polizei involviert war - zusammen mit dem bayerischen Innenminister eine "Gemeinschaftliche Entschließung“ entwerfen, die als Übergangslösung in Kraft treten sollte, bis gemäß Gesetz vom 1. Dezember 1933 eine Durchführungsverordnung bezüglich der SA-Gerichtsbarkeit erlassen würde. Zunächst sollte die Benachrichtigung des nunmehr dafür allein zuständigen Rechtsberaters der betreffenden SA-Standarte bei einer Anzeige gegen einen SA-Angehörigen - bei der mit Verhängung einer Freiheitsstrafe zu rechnen war - durch ein genormtes Meldeblatt formalisiert werden, das schon der mit der Feststellung befaßte Polizeibeamte, spätestens aber der Staatsanwalt dem Rechtsberater zu übersenden hatte. Nahm die SA an dem Strafverfahren Interesse, so sollte sich der

92 Verf. Röhms v. 2.3.34 (Akten des RJM, Arch. des IfZ, Sign. MA 108). Das G. v. 1.12.33 (RGBl. I, S. 1016) bestimmte in $\S 5$, daß außer den üblichen Dienststrafen auch Haft u. Arrest verhängt werden konnten. Eine interne Disziplinarregelung besaß die SA durch ihre „Allgemeine Dienstordnung“ v. 12.12.33. Schon nach dem G. v. 28.4.33 (RGBl. I, S. 230) unterlagen die Mitglieder der SA u. SS „einer öffentlich-rechtlichen Dienststrafgewalt nach Maßgabe der Vorschriften, die der Reichskanzler als oberster SA-Führer erläßt“. 
Rechtsberater mit dem zuständigen Oberstaatsanwalt - der bereits auf dem Meldeformblatt angegeben werden mußte - in Verbindung setzen; der Oberstaatsanwalt war verpflichtet, ihm die erbetenen Mitteilungen über Sachverhalt und Gang des Verfahrens zu machen. Erforderlichenfalls sollte der Oberstaatsanwalt mit dem Rechtsberater und den von diesem beigezogenen Führern den bereits in Franks Weisung vom November als „geboten“, nunmehr aber als „unerläßlich“ bezeichneten Ausgleich herbeiführen. „Einzelanweisungen“, hieß es bezeichnenderweise weiter, „können hierfür wegen der Vielgestaltigkeit der Fälle nicht gegeben werden.“ Mißlang die Einigung, waren auch hier Verhandlungen auf der jeweils höheren Ebene vorgesehen.

Der Entwurf dieser gemeinschaftlichen Entschließung gelangte über den Rechtsberater der Obersten SA-Führung, SA-Gruppenführer und Rechtsanwalt Luetgebrune, im Laufe der Verhandlungen über eine SA-Gerichtsbarkeit auf Reichsebene am 20. März 1934 in die Hand des Reichsjustizministers. ${ }^{93}$ In einem Schreiben an Frank erhob Gürtner gegen die darin aufgestellte Forderung nach einem „unerläßlichen Ausgleich zwischen den Belangen der SA. und den gesetzmäßigen Aufgaben der Rechtspflege“ in jedem Einzelfall starke Bedenken. Dieser Satz könne „zu Mißdeutungen und Mißverständnissen begründeten Anlaß geben“, und zwar vor allem deshalb, weil er sich offensichtlich nicht auf Milderung bereits erkannter Strafen, sondern „wohl nur auf zukünftige Strafverfahren beziehen“ könne. Da es ihm darüber hinaus unzweckmäßig erscheine, daß eine Entschließung von derart grundsätzlicher Bedeutung in $e i$ nem Lande allein erlassen werde, bat er Frank, den Erlaß dieser Entschließung vorerst zurückzustellen. ${ }^{94}$ In der Tat hätte Franks Vorschlag so etwas wie ein Mitwirkungsund Vetorecht der SA an der Rechtspflege begründet und die unabhängige Entscheidung der Justiz über eine Berücksichtigung der „Belange der SA“ beeinträchtigt.

Obwohl die Herausgabe der Entschließung daraufhin unterblieb, wurden derartige Verhandlungen zwischen Justiz und SA in der Praxis schon aufgrund Franks Weisung vom November 1933 gepflogen. Als Beispiel sei hier die Verfolgung von Straftaten genannt, die 1934 in Gunzenhausen (Mittelfranken) begangen wurden - wobei sich die Verhandlungspartner hier zwar auf eine Durchführung des Prozesses einigten, aber im voraus um das Ergebnis des Verfahrens feilschten. Nach längerem Anheizen der antisemitischen Stimmung durch den SA-Sonderbeauftragten beim Bezirksamt Gunzenhausen war es hier in der Nacht zum 26. März unter Anführung durch SA- und SSAngehörige zu pogromartigen Aussschreitungen gegen ortsansässige Juden gekommen, die unter Gewaltanwendung und Mißhandlungen aus ihren Häusern geholt und als „Schutzhäftlinge“ ins Amtsgerichtsgefängnis gebracht wurden. Dabei kamen zwei Juden ums Leben, die sich dem Zugriff der johlenden Meute offenbar in panikartiger Kurzschlußreaktion durch Selbstmord entzogen ${ }^{95}$; Mord konnte jedoch deshalb nicht völlig ausgeschlossen werden, weil in beiden Fällen die Verfolger als erste bei den Opfern waren. Wegen des allgemeinen Aufsehens wurde die Behandlung der Sache am 11. April zwischen dem Strafrechtsreferenten im bayerischen Justizministerium, Ministerialrat Döbig, und dem SA-Sonderbevollmächtigten bei der Regierung von Mittel-

93 Wortlaut des Entschl.Entw. u. Verm. Gürtners v. 20.3.34 (Akten des RJM, Arch. des IfZ, Sign. MA 108).

94 Schr. Gürtners an Frank v. 26.3.34 (a.a.O.).

95 Einer war durch einen Sprung aus dem Fenster geflüchtet und wurde in einem Schuppen des Nachbargrundstücks erhängt aufgefunden, der zweite starb durch Stichverletzungen an der Brust in seinem Zimmer. Ber. der Gendarmeriehauptstation Gunzenhausen v. 26.3.34 (Akten des bayerMdI, BayHStArch., Sign. MInn 73708). 
franken, Gruppenführer von Obernitz, besprochen. Es wurde vereinbart, daß ein SAFührer bei der Vernehmung der Beschuldigten, die am nächsten Tag durch Kriminalbeamte unter der Leitung des Oberstaatsanwalts beim Landgericht Ansbach stattfand, zugegen sein sollte. Um die „besonders mit Takt zu behandelnden Vorgänge“ im Auftrag des Justizministeriums selbst zu bearbeiten, hatte der Oberstaatsanwalt eigens seinen Urlaub unterbrochen. Die Vernehmungsprotokolle wurden dem SA-Bevollmächtigten übermittelt und das Ermittlungsergebnis zwischen dessen Stellvertreter und dem Oberstaatsanwalt besprochen. ${ }^{96}$ Am 3. Mai fand im bayerischen Innenministerium über das weitere Verfahren eine regelrechte Konferenz statt, an der neben Döbig, dem Oberstaatsanwalt, Vertretern des Innenministeriums und der Polizei auch der Sonderbevollmächtigte der Obersten SA-Führung für Bayern, Obergruppenführer Fuchs, teilnahm. Döbig legte den Standpunkt des Justizministeriums dar, „daß unter allen Umständen durchgegriffen werden müsse, um Wiederholungen derartiger Fälle zu vermeiden “. Daher werde gegen zwei SS-Männer, achtzehn SA-Angehörige, darunter den Haupträdelsführer SA-Obersturmführer Bär, und zwei weitere Personen das Verfahren wegen schweren Landfriedensbruchs gemäß $\S 125$ Abs. 2 eröffnet werden. Bei der Hauptverhandlung werde jedoch die Öffentlichkeit ausgeschlossen und die Zuziehung jüdischer Zeugen „auf das Mindestmaß beschränkt“ werden. „Besonderer Wert werde auf die Herausstellung der Todesursache der beiden Juden gelegt werden; nach den bisherigen Anhaltspunkten komme nur Selbstmord in Betracht." Fuchs forderte, bei der Urteilsfindung müsse aber berücksichtigt werden, daß durch die intensive antisemitische Propaganda des Gauleiters Streicher ${ }^{97}$ in Franken „ein besonders starker Haß gegen die Juden“ herrsche, „der nur allzu leicht zu derartigen Explosionen führen müsse". Das treffe in gesteigertem Maße auf Gunzenhausen zu, da dort der Prozentsatz der Juden besonders hoch sei. Den Tätern müsse zugute gehalten werden, daß sie „zum größten Teil noch sehr jung, Bär erst 22 Jahre alt“, seien und daher zum Übereifer neigten. Vor allem aber seien ihre Motive „nicht ehrenrühriger Art, sondern die Beschuldigten hätten mit einem Vorgehen gegen die Juden sicher im Sinne der Reichsregierung zu handeln geglaubt“. Die Vertreter der Justiz „sagten eine Berücksichtigung dieser Momente beim Strafausmaß zu“; als Gegendienst forderte jedoch der Oberstaatsanwalt, „die SA-Führung möge darauf bedacht sein“, daß die Beschuldigten zur Hauptverhandlung auch erschienen. ${ }^{98}$ Der Prozeß, der im Juni 1934 ohne Behinderungen vor der großen Strafkammer des Landgerichts Ansbach stattfand, endete mit „der jeden Zweifel ausschließenden Feststellung“, daß die beiden Todesfälle jener Nacht Selbstmorde gewesen seien, und mit der Verurteilung der Schuldigen zu Gefängnisstrafen von drei bis zehn Monaten"9: die Justiz hatte sich an die Abmachung gehalten und wegen mildernder Umstände auf die an sich vorgeschriebene, ehrenrührige Zuchthausstrafe verzichtet. Die nachsichtige Haltung der Justiz

96 Ber. des OStA beim LG Ansbach v. 26.4.34; undat. Ber. des Adjutanten des stellv. Sonderbevollmächtigten bei der Reg. Mittelfranken; Ber. des stellv. Sonderbevollmächtigten v. 24.4.34 (GehStArch. München, Sign. MA 105 494).

97 Als die Straftat am 17.7.34 im bayer. Ministerrat zur Sprache kam, äußerte der anwesende Streicher kaltschnäuzig, er sei „sofort dafür eingetreten ..., daß ohne Rücksicht auf die Zugehörigkeit zur Partei vorgegangen werden solle" (Prot., GehStArch. München, Sign. MA 99 526).

98 Verm. Fuchs über die Bespr. v. 3.5.34 (Akten des bayerMdI, BayHStArch. Abt. I, Sign. MInn 73708)

99 Halbmon.Ber. des RegPräs. v. Oberfranken u. Mittelfranken v. 21.6.34 (GehStArch. München, Sign. MA 106677). 
sollte in diesem Falle allerdings schwerwiegende Folgen zeitigen: am 15. Juli rächte sich Bär, der offensichtlich durch Einlage der Revision ${ }^{100}$ seine Strafverbüßung noch nicht anzutreten brauchte, indem er den jüdischen Gastwirt Strauß in Gunzenhausen erschoß und dessen Sohn schwer verletzte. Bei der polizeilichen Vernehmung äußerte er, „wenn die verurteilten SA.-Männer von Gunzenhausen nicht frei werden, gibt es mindestens noch 20 Tote“. Bär, der nach seiner ersten Verurteilung aus Partei und SA ausgeschlossen worden war, wurde am 1. Oktober 1934 vom Schwurgericht Ansbach nunmehr ohne Komplikationen zu einer lebenslänglichen Gefängnisstrafe verurteilt. $^{101}$

\section{d. Die Auseinandersetzung mit Himmlers politischer Polizei um die Ermittlung bei Straftaten}

Während sich die Schwierigkeiten der bayerischen Justiz mit der SA nach der RöhmAffäre im wesentlichen legten, sollten verschiedene jener Probleme, die sich in Bayern aus der Konkurrenz der Justiz mit Himmlers politischer Polizei bei der politischen Strafverfolgung entwickelten, auch noch später auf Reichsebene fortdauern. ${ }^{102} \mathrm{Wie}$ die dargestellten Fälle Schlögl und Pflaumer ${ }^{103}$ exemplarisch zeigen, war die Bayerische Politische Polizei nicht bereit, die Polizeibehörden in Fällen, bei denen es um Straftaten von Angehörigen der Bewegung bei der Verfolgung politischer Gegner ging, als verlängerten Arm der Staatsanwaltschaft fungieren zu lassen. Im Gegenteil kamen die Polizeistellen den Ersuchen der Staatsanwaltschaften zur Ermittlung solcher strafbaren Handlungen gar nicht oder nur verzögerlich nach, obwohl sie dazu gesetzlich verpflichtet waren. ${ }^{104}$ Zum anderen reichten sie Anzeigen, die bei ihnen über derartige Fälle eingingen - ebenfalls im Widerspruch zu den gesetzlichen Vorschrif$\operatorname{ten}^{105}$-, nicht an die Staatsanwaltschaft weiter. Schon beizeiten suchte die Bayerische Politische Polizei die Bearbeitung von Anzeigen, verständlicherweise vor allem gegen SS-Angehörige, an sich zu ziehen, um sie gewissermaßen „vorzusieben“. Im Oktober 1933 kam es dabei zu einer bezeichnenden, angeblich nur mündlich verabredeten Vereinbarung zwischen Himmler und dem Münchener Polizeipräsidenten, SA-Obergruppenführer Schneidhuber, „daß im Bezirk der Pol.Dir. München aus Zweckmäßig-

${ }^{100}$ Im Revisionsprozeß am 21.8.34 wurden alle Angeklagten außer dem Rädelsführer Bär freigesprochen.

${ }^{101}$ Die eingelegte Revision wurde am 14.12.34 zurückgenommen, Ber. des OStA beim LG Ansbach an den GStA Nürnberg v. 14.12.34; ferner dazu: Ber. des SA-Sonderbeauftragten beim Bez.Amt Gunzenhausen v. 15.7.34, Ber. des Obergruppenf. Fuchs an die OSAF v. 1.8.34 (Akten des bayerMdI, BayHStArch. Abt. II, Sign. MInn 73708); Halbmonatsber. des RegPräs. von Ober- u. Mittelfranken v. 21.7.34, veröffentlicht in: Bayern in der NS-Zeit (s. Anm. 60), S. 440.

${ }^{102}$ Vgl. dazu Kapitel VI.3.a., S. 584.

${ }^{103}$ Vgl. Kapitel IV.4.a., S. 382 f., u. Kapitel IV.4.b., S. 386 ff.

${ }^{104}$ Vgl. §152 GVG: „Die Beamten des Polizei- und Sicherheitsdienstes sind Hilfsbeamte der Staatsanwaltschaft und sind in dieser Eigenschaft verpflichtet, den Anordnungen der Staatsanwälte ihres Bezirks und der diesen vorgesetzten Beamten Folge zu leisten“; ähnlich $§ 161$ StPO.

${ }^{105} \S 163$ StPO: „Die Behörden und Beamten des Polizei- und Sicherheitsdienstes haben strafbare Handlungen zu erforschen und alle keinen Aufschub gestattenden Anordnungen zu treffen, um die Verdunkelung der Sache zu verhüten. Sie übersenden ihre Verhandlungen ohne Verzug der Staatsanwaltschaft.“ 
keitsgründen Anzeigen gegen SA-Angehörige von der Polizeidirektion München und gegen SS-Angehörige von der Bayerischen Politischen Polizei bearbeitet werden“" ${ }^{106}$

Diese innerdienstliche Regelung galt auch nach der Ermordung Schneidhubers bei der Röhm-Aktion weiter und wurde erst im Februar 1936 auf Veranlassung des Reichsinnenministers aufgehoben. ${ }^{107} \mathrm{Die}$ Maßnahmen des sich allmählich verselbständigenden Apparats der Bayerischen Politischen Polizei wurden für Frank und die anderen Mitglieder der bayerischen Staatsregierung immer undurchschaubarer: da in der Ministerratssitzung am 26. Juli 1933 auch Wagner zugeben mußte, daß er als der verantwortliche Innenminister über die sehr eigenmächtigen Regelungen der politischen Polizei nur noch unzureichend informiert wurde, regte Siebert an, ,in die verantwortliche Leitung der Politischen Polizei noch einen gewiegten Verwaltungsjuristen einzuberufen“. ${ }^{108}$ Nachdem sich die Unzuträglichkeiten der Justiz mit der politischen Polizei vermehrt hatten, griff Frank den Gedanken Sieberts in der Ministerratssitzung vom 5. Oktober auf und forderte, daß in die politische Polizei endlich „auch Beamte kämen, die von der Polizei und ihren Verwaltungsaufgaben etwas verstünden “. ${ }^{109}$ Anläßlich einer Aussprache über strittige Fälle kamen Frank und Himmler schließlich überein, daß das Justizministerium einen Beauftragten zur Bayerischen Politischen Polizei abstellen solle. ${ }^{10}$ Mit Wirkung vom 16. Oktober 1933 wurde daher der Erste Staatsanwalt beim Landgericht München I, Dr. Stepp, Parteigenosse und SA-Mitglied seit 1931, zum Verbindungsmann zwischen dem Strafrechtsreferenten im Justizministerium und Himmler bestellt. Er sollte „dem Leiter der Bayerischen Politischen Polizei als rechtskundiger Berater zur Seite“ stehen und dafür sorgen, „daß bei Behandlung politischer Strafsachen schon von Beginn des Verfahrens an nach einheitlichen Gesichtspunkten verfahren wird“. Stepp blieb in persönlicher und sachlicher Hinsicht der Staatsanwaltschaft beim Landgericht München I unterstellt und konnte als eine Art Mini-Ausgabe der Zentralstaatsanwaltschaft in Preußen - vom Justizministerium „mit der Bearbeitung und Vertretung einzelner politischer Strafsachen betraut werden". ${ }^{111}$

Als Heydrich die Kritik am Verhalten der Bayerischen Politischen Polizei im Falle Hörstein zu Ohren kam, die Frank am 10. Oktober im Ministerrat geäußert hatte ${ }^{112}$, rief er am nächsten Tag Ministerialrat Döbig an: sein Vertrauen zum Justizminister sei erschüttert und er habe gegenüber der geplanten „Einrichtung eines Verbindungs-

${ }^{106}$ Schr. des bayerStMdI (d.h. Stepps) an die bayerStKanzlei v. 30.9 .35 (GehStArch. München, Sign. MA 105617). Das Schr. war durch Rückfragen des RuPrMdI v. 16. u. 18.9.35 veranlaßt worden: nach Mitteil. des RJM hatte ein SS-Sturmführer, der polizeiwidrig die Straße überquert hatte, gegen einen amtsgerichtl. Strafbefehl über 6 RM mit der Begründung Einspruch eingelegt, die Anzeige hätte über die BPP gehen müssen.

${ }^{107}$ Ersuchen Fricks um Aufhebung v. 11.1.36 u. Meldung der Aufhebung durch Schr. des bayerStMdI v. 12.2.36 (a.a.O.).

${ }^{108}$ Prot. (GehStArch. München, Sign. MA 99525$)$.

${ }^{109}$ Aufz. Sieberts von der Sitzung, datiert v. 7. (richtig: 6.) 10.33 (a.a.O., Sign. MA 105 257).

${ }^{110}$ Erwähnt in Schr. Wagners an Frank v. 29.11 .33 (a.a.O., Sign. MA 105 487).

${ }^{11}$ Schr. Franks an das bayerMdI v. 11.10 .33 (a.a.O., Sign. MA 105 484). Hier taucht bereits Franks „Ausgleichsformel" auf, die er in seiner Weisung v. 20.11.33 hinsichtlich der Zusammenarbeit mit den SA-Führern (vgl. Anm. 90) verwendete: Stepp habe bei der Behandlung besonderer politischer Strafsachen „den im Interesse des Staates und Volkes gebotenen Ausgleich zwischen den Belangen der Politischen Polizei und den gesetzmäßigen Aufgaben der Rechtspflege herbeizuführen“.

112 Vgl. Kapitel IV.4.b., S. $395 \mathrm{f}$. 
mannes Mißtrauen“. ${ }^{113}$ Heydrich konnte die Absprache seines Chefs Himmler nicht rückgängig machen - aber seine Befürchtung, daß Stepp als „Trojanisches Pferd“ der Justiz innerhalb der Bayerischen Politischen Polizei wirken würde, war überflüssig. Stepp wechselte bald die Fronten: im November trat er von der SA zur SS über, brachte es innerhalb eines Jahres zum Standartenführer, wurde Anfang 1935 im Zuge der Verreichlichung des bayerischen Justizministeriums als Oberregierungsrat zur politischen Polizei abgeordnet, dort stellvertretender Leiter der Bayerischen Politischen Polizei und später Chef der Staatspolizeileitstelle München. ${ }^{114}$ Aber auch sein Wirken als Verbindungsmann machte die Tätigkeit der politischen Polizei für die Justiz nicht transparenter und erreichte nicht, daß beider Funktionen bei der Verfolgung politischer Straftaten aufeinander abgestimmt wurden.

Als Himmler und Heydrich im Frühjahr 1934 durch die Übernahme der politischen Polizeien in außerbayerischen Ländern ihre Machtposition verbreitert hatten, gingen sie daran, ihre in Bayern bisher mehr oder weniger verdeckt gehandhabte $\mathrm{Me}$ thode einer „Vorsiebung“ der Anzeigen gegen Anhänger der NS-Bewegung zu formalisieren. Am 20. März 1934 erließ Heydrich folgende Anordnung an alle bayerischen Polizeibehörden:

„Anzeigen gegen Angehörige der NSDAP, der SA, SS und HJ dürfen an die Staatsanwaltschaft nicht weitergeleitet werden, bevor nicht die gesamten Verhandlungen der Bayer. Politischen Polizei zur Prüfung vorgelegen haben." ${ }^{115}$

Auf einer Konferenz aller bayerischen Oberlandesgerichtspräsidenten und Generalstaatsanwälte im Ministerium am 6. April 1934, bei der u.a. der Generalstaatsanwalt beim Oberlandesgericht München über die Auswirkungen dieser Anordnung in seinem Bezirk berichtete, ging Frank mit dem eigenmächtigen Vorgehen der politischen Polizei scharf ins Gericht:

„Ich lehne es ab, derartige Verfügungen entgegenzunehmen. Solche Rechtsanordnungen kann meines Erachtens nur der Minister erlassen, und ich werde im nächsten Ministerrate wieder warnend dagegen meine Stimme erheben. Es wäre nicht möglich, daß eine Abteilung in unserem Ministerium irgendwie vollkommen selbständig eine Rechtsanordnung hinausgehen lassen könnte, wie sie etwa der Personalreferent für irgendwie seinen Dienstbezirk betreffende Angelegenheiten erläßt... Wir haben schon manche Auseinandersetzung gehabt und man kann dann schließlich gegen meine Reichsleitereigenschaft nicht an. Ich gehöre den Mitgliedern der Partei an, deren Mitgliedsnummer niedriger ist als die des Führers und diese meine Autorität kann ich immer wieder voll und ganz in die Waagschale werfen." ${ }^{116}$

Frank bat Ministerialrat Döbig festzustellen, ob Heydrichs Anordnung dem Innenminister überhaupt bekannt sei. Als Döbig erwiderte, Wagner „werde vermutlich davon nichts wissen“, ersuchte ihn Frank, „telefonisch dafür zu sorgen, daß die Entschließung aufgehoben würde“; wenn er „nicht bis heute nachmittag 3 Uhr die Meldung habe“, werde er einen außerordentlichen Ministerrat erzwingen. Frank verband seine Unmutsäußerungen mit bemerkenswerten Erwägungen, die durch die grundle-

\footnotetext{
${ }^{113}$ Verm. Döbigs; Schr. Franks an Siebert v. 16.10.33 (a.a.O., Sign. MA 106288 ).

${ }^{114}$ Himmler schrieb am 27.3.35 ans RJM, Stepp solle dort als ORRat etatisiert bleiben, bis eine entsprechende Stelle bei der BPP frei werde (Diensttageb. des RJM, Bd. 2, Eintr. v. 29.3.35, BA, Sign. R 22/603). Zu Stepps weiterem Werdegang s. Kapitel III.2., S.235f.

115 Die Anordn. ging außer an die Pol.Behörden auch an die SA-Sonderbevollmächtigten u. -beauftragten (GehStArch. München, Sign. Reichsstatthalter 611)

${ }^{116}$ Frank, der in freier Rede leicht in Großspurigkeit verfiel, ließ den letzten Satz für die redigierte Fassung des Protokolls wieder streichen.
} 
gende Tatsache ausgelöst waren, daß die "dritte Gewalt“ zur Ohnmacht verdammt ist, wenn die Exekutive ihr die Mitwirkung versagt. Diese Überlegungen wurden allerdings nachträglich aus dem Konferenzprotokoll wieder entfernt:

„Man hat den Eindruck, als ob die Justiz von der Polizei nicht gestützt wird, sondern umgekehrt noch die Polizei ein Hilfsobjekt der Aktionen gegen den Staat wäre. Das ist natürlich ein absolut unmöglicher Zustand... Ich schaffe mir eben dann meine eigene Polizeitruppe, wenn ich den Schutz der Staatspolizei nicht genieße - das habe ich schon angedroht -, etwa in der Form, daß die Gefängnisbeamten etwas militärisch uniformiert und ausgerüstet werden. Ich werde dann die Leute selber verhaften lassen oder ihre Einvernahme vornehmen. Ich werde mir die Mittel selber beschaffen. Denn die Justiz werde ich nicht verkrachen lassen... Ich würde für jeden Oberlandesgerichtsbezirk ein fliegendes Corps von etwa 100 Mann zusammenstellen und die Staatsanwaltschaft die Erhebungen durchführen lassen. Es wird das eine Kampfsache sein, wobei ich darauf vertraue, daß Sie durchhalten würden."

Im weiteren Verlauf der Sitzung teilte Döbig mit, er habe soeben erfahren, daß Heydrichs Anordnung bereits gestern „dahin geändert worden sei, daß die Anzeigen pflichtgemäß der Staatsanwaltschaft vorzulegen und die Politische Polizei lediglich von der Tatsache einer Anzeige gegen einen Angehörigen der SA., SS. oder HJ. zu verständigen sei“. ${ }^{117}$

Diese Information war eine Irreführung seitens des Innenministeriums. In einer Ergänzungsverfügung vom 5. April hatte Heydrich die angeordnete Maßnahme für Verbrechen und Vergehen politischer Art aufrechterhalten. Soweit „die Staatsanwaltschaft oder das Gericht ohne Zutun der Polizeibehörden eingegriffen " hätten, sei zwar ihren Aufträgen "ohne Verzug zu entsprechen“, doch der "Sachverhalt gleichfalls und schnellstens zu berichten". Lediglich für unpolitische, rein kriminelle Straftaten von Angehörigen der NS-Bewegung war die Vorprüfung der Anzeigen fallengelassen worden, hier sollte die Einreichung einer Abschrift der Ermittlungen nach Abgabe an die Justizbehörden genügen. ${ }^{118}$

Unterdessen hatten auch die Regierungspräsidenten berichtet, daß Heydrichs Anordnungen bei ihren Behörden auf Bedenken stießen, da sie den Vorschriften der Strafprozeßordnung zuwiderliefen. Ferner hätten diese Weisungen die falsche Meinung aufkommen lassen, „daß Parteiangehörige, SA- und SS-Männer keinem ordentlichen Gericht mehr unterständen", und dadurch die Aufrechterhaltung von Autorität und Ordnung im Lande erheblich erschwert. ${ }^{119}$ Als dem Reichsstatthalter diese Berichte zur Kenntnis kamen, ersuchte er das Innenministerium über Siebert, ihm Wortlaut und Gründe für diese Anordnungen mitzuteilen. Wagner begründete die Mitteilungspflicht für rein kriminelle Fälle damit, daß Parteileitung und SA-Führung über strafbare Handlungen ihrer Mitglieder informiert sein wollten, um „die Sauberhaltung der Bewegung“ durch disziplinarische Schritte zu gewährleisten. Das war zweifellos ein berechtigtes Motiv, dem auch durch die späteren Verfügungen des Reichsjustizministeriums über „Mitteilungen in Strafsachen“ an bestimmte Dienststellen der Bewegung durch die Justizbehörden Rechnung getragen werden sollte. Für die angeordnete Behandlung der politischen Strafsachen gab Wagner eine recht bezeichnende Begründung: Die politische Polizei müsse kontrollieren,

${ }^{117}$ Niederschr. über die Bespr. der Justizverw. mit den OLGPräs. u. GStAen am 5. u. 6.4.34 (Akten des bayerJM, BayHStArch. Abt. II, Sign. MJu 16997).

${ }^{118}$ GehStArch. München, Sign. Reichsstatthalter 611.

119 Ber. der Reg. v. Ober- u. Mittelfranken v. 30.3.34; Halbmonatsber. des RegPräs. v. Schwaben u. Neuburg v. März 34 (Auszüge in: GehStArch. München, a.a.O.). 
„ob die örtlich zuständigen Polizeiorgane den Tatbestand auch wirklich objektiv festgestellt haben. Die Erfahrung hat gelehrt, daß es noch eine große Anzahl von Polizeibeamten gibt, welche noch nicht den Weg zur nationalsozialistischen Staatsauffassung gefunden haben und welche noch heute feindselig gegen SA. und SS. und Parteimitglieder eingestellt sind. Einzelne Anzeigen haben diese Tatsache einwandfrei bewiesen, es sind in vielen Fällen Erhebungen einseitig gegen Nationalsozialisten durchgeführt worden...“

Deshalb ergänze die Bayerische Politische Polizei etwaige einseitige Erhebungen, damit „sich die Gerichte ein wahres Bild über die tatsächlichen Vorkommnisse machen können und Fehlurteile sich vermeiden lassen“. Das geschähe im Interesse der Kämpfer, die der „Bewegung zum Siege verholfen haben“. ${ }^{120}$

Die Vorgänge wurden durch Ministerpräsident Siebert dem Justizministerium zur rechtlichen Nachprüfung vorgelegt. In seiner Stellungnahme bedauerte Frank, daß die Bayerische Politische Polizei eine derart einschneidende Verfügung habe treffen können, ohne daß das verantwortliche Innenministerium sich vorher mit dem unmittelbar betroffenen Justizministerium in Verbindung gesetzt habe. Er protestierte gegen diese "für eine geordnete Rechtspflege untragbare Regelung" und stellte ihre rechtliche Unzulässigkeit fest. Die einzige „mit der Handhabung des staatlichen Strafklagerechts betraute Behörde" sei die Staatsanwaltschaft, sie allein habe „das gesamte Interesse, welches der Staat an der Strafverfolgung hat, wahrzunehmen (§152 StPO)“; dagegen seien die Polizeibeamten "in kriminalpolizeilichen Dingen Organe der Staatsanwaltschaft" (§ 152 GVG). Es sei daher gesetzlich unzulässig, ,wenn sich die Bayerische Politische Polizei als Kontrollstelle zwischen die polizeilichen Beamten des Außendienstes und die Staatsanwaltschaft einschiebt". Statt daß die polizeilichen Feststellungen der Staatsanwaltschaft ohne Verzug zugingen $(\S 163$ StPO), verursache Heydrichs Anordnung Verzögerungen, so daß die Tätigkeit der Staatsanwaltschaft

„erst verspätet einsetzen kann und die Aufklärung des Sachverhalts und die Ermittelung der Täter dadurch gefährdet wird. Das widerstreitet nicht nur den fundamentalen Interessen des Staates an der Aufrechterhaltung einer geordneten, raschen und schlagkräftigen Rechtspflege, sondern bringt auch die hierfür verantwortlichen Beamten in die Gefahr einer Strafverfolgung nach $§ 346$ StGB. “121

Davon abgesehen sei die getroffene Anordnung aber auch unzweckmäßig: gerade politische Straftaten würden schnell weiteren Kreisen und damit auch der Staatsanwaltschaft bekannt, die daraufhin sofort Erhebungen einleiten und Ermittlungen durch Polizeibeamte anordnen müsse. Die Ermittlungen der Staatsanwaltschaft und der politischen Polizei würden dann aber nebeneinander herlaufen und sinnlose Mehrarbeit bedeuten. Am Schluß versicherte Frank, daß die Justiz bei der Würdigung des Einzelfalles die Interessen der Kämpfer der Bewegung durchaus berücksichtige und das von der Bayerischen Politischen Polizei als Motiv angegebene Ziel bei vertrauensvoller Zusammenarbeit daher auch ohne die unzulässige Anordnung erreicht werden könne. ${ }^{122}$

\footnotetext{
${ }^{120}$ Schr. Wagners an Siebert v. 17.4.34 (a.a.O.), am 20.4.34 an Epp weitergeleitet (a.a.O., Sign. MA 105617).

121 § 346 StGB: „Ein Beamter, der vermöge seines Amtes zur Mitwirkung bei einem Strafverfahren oder bei der Vollstreckung einer Strafe ... berufen ist und wissentlich jemand der im Gesetz vorgeschriebenen Strafe oder Maßregel entzieht, wird ... bestraft."

122 Schr. Franks an Siebert v. 4.6.34 (a.a.O., Sign. Reichsstatthalter 611).
} 
Auf diese Stellungnahme Franks hin forderte von Epp am 29. Juni 1934 die Aufhebung der beiden Verfügungen Heydrichs vom 20.3./5.4.34 und erwartete „bis spätestens 6.7.34 Vollzugsmeldung". Sollten die vom Justizministerium als unbedenklich angesehenen Teile der Verfügungen in einer neuen Anordnung herausgegeben werden, so habe das durch das Innenministerium ,und nicht durch eine diesem untergeordnete Stelle" zu geschehen. ${ }^{123}$ Die weitere Entwicklung dieser Sache sollte jedoch zeigen, wie weit Himmlers Polizeiapparat in Bayern aus dem Innenministerium de facto bereits ausgegliedert war und sich gegenüber der bayerischen Staatsregierung verselbständigt hatte. Der Vertreter Himmlers als Kommandeur der Bayerischen Politischen Polizei in München, Regierungsrat Beck - Heydrich wirkte schon im Geheimen Staatspolizeiamt in Berlin -, hielt sich nicht für befugt, die Verfügungen selbst aufzuheben, und leitete den Erlaß von Epps an Himmler nach Berlin weiter. ${ }^{124}$ Erst am 17. Juli antwortete das bayerische Innenministerium mit einem offensichtlich vom "Referat Bayerische Politische Polizei“" entworfenen, aber von Wagner unterzeichneten Schreiben, daß die beiden Verfügungen nicht aufgehoben, sondern mit Wirkung vom 3. Juli abgeändert worden seien. Der Erlaß der beiden beanstandeten Verfügungen wurde in Ausführungen verteidigt, die eine massive Kritik an der bayerischen Justiz enthielten: Es habe

„sich nämlich herausgestellt, daß zahlreiche Beamte der Justizverwaltung, die politisch und weltanschaulich noch in den Gedankengängen der B.V.P. und des politischen Katholizismus lebten, mit besonderer Schärfe Anzeigen gegen Angehörige der nat.soz. Bewegung nachgingen, während sie bei Anzeigen gegen politisierende kath. Geistliche feststellten, daß auf Grund der vorliegenden Gesetze ein Einschreiten nicht möglich sei“.

Darüber hinaus hätten die sich vor der „Säuberungsaktion“ vom 30. Juni 1934 häufenden Übergriffe von SA-Führern eine zentrale Kontrolle erfordert, da „deren Kenntnis, wie sich ja bei der Durchführung der Säuberungsaktion erwiesen hat, aus nachrichtentechnischen Gründen für Polizei und Partei wichtig war". ${ }^{125}$ Die letztere Begründung war allerdings kaum stichhaltig: um das Sündenregister der konkurrierenden SA zu vervollständigen, hätte es lediglich der Benachrichtigung der politischen Polizei bei gleichzeitiger Weitergabe der Anzeigen an die Staatsanwaltschaft bedurft.

Die geänderte Anordnung Heydrichs vom 3. Juli 1934 sah nunmehr vor, daß bei rein kriminellen Straftaten nicht mehr die Bayerische Politische Polizei, sondern die zuständige Gauleitung bzw. SA-Standarte oder HJ-Bann unmittelbar zu informieren waren, „unbeschadet der Abgabe der Anzeige an die Strafverfolgungsbehörde“. Bei Verbrechen und Vergehen politischer Art hieß es jedoch ohne diesen Zusatz nach wie vor, daß der Bayerischen Politischen Polizei „unverzüglich Abschriften der Verhandlungen zur Stellungnahme vorzulegen" seien. Eine Berichtigung Heydrichs vom 15. Juli änderte diesen Passus dahingehend, daß „unverzüglich die abschriftlichen (also nicht urschriftlichen) Verhandlungen vorzulegen" seien, äußerte sich aber im Gegensatz zu der klar formulierten Bestimmung über die kriminellen Straftaten wiederum nicht eindeutig darüber, was mit den urschriftlichen Unterlagen zu geschehen habe. ${ }^{126}$ Die von von Epp veranlaßte rechtliche Nachprüfung auch dieser Anordnung vom

\footnotetext{
${ }^{123}$ Schr. Epps an Siebert v. 29.6.34, an die BPP weitergeleitet (a.a.O., Sign. MA 105617).

${ }^{124}$ Schr. Becks an Siebert v. 10.7.34, dem Tage, bis zu dem Epps "Ultimatum“ fernmündlich verlängert worden war (a.a.O.).

${ }^{125}$ Schr. des bayerMdI an Siebert v. 17.7.34, an Epp weitergeleitet (a.a.O.).

${ }^{126} \mathrm{Klammer}$ im Zitat Orig. Beide Anordn. Heydrichs a.a.O.
} 
3./15. Juli 1934 durch das Justizministerium ergab, daß die Bayerische Politische Polizei offensichtlich auch weiterhin gewillt war, „ohne jede gesetzliche Grundlage als Kontrollstelle" $z$ wischen Polizeibehörden und Staatsanwaltschaft tätig zu werden; es müsse dagegen den Polizeidienststellen ,in unmißverständlicher Weise bekanntgegeben werden“, daß sie der Staatsanwaltschaft sämtliche Anzeigen sofort zuzuleiten hätten. Auf die Anschuldigungen gegen die Justiz im Schreiben des Innenministeriums vom 17. Juli eingehend, konstatierte Staatsrat Spangenberger - der die Stellungnahme in Vertretung Franks unterzeichnete -, sie enthielten

„den ungeheuerlichen Vorwurf, daß zahlreiche Beamte der Justizverwaltung sich Verbrechen der Rechtsbeugung, der Begünstigung im Amt und der Strafverfolgung Unschuldiger nach §§ 336, 346, 344 StGB zuschulden kommen ließen und ihre beschworene Pflicht gegenüber dem nationalsozialistischen Staat aufs schwerste verletzt hätten“.

Im Auftrage Franks habe er daher das Innenministerium um Aufklärung ersucht. „Sollte der Justizverwaltung und ihren Beamten nicht volle Genugtuung gegeben werden", werde Frank im Ministerrat darauf zurückkommen. ${ }^{127}$

In seiner Antwort vom 6. September gab Heydrich endlich eine Interpretation seiner Anordnung dahingehend, daß die urschriftlichen Anzeigen gegen Angehörige der Bewegung auch in politischen Strafsachen „unverzüglich an die zuständige Staatsanwaltschaft zu übermitteln" seien. Entweder hatte das unterdessen erlassene Amnestiegesetz vom 7. August 1934, das die Niederschlagung der seit der letzten bayerischen Straffreiheitsverordnung vom August 1933 begangenen einschlägigen Straftaten nunmehr ermöglichte, die Vereitelung von Ermittlungen weniger dringlich gemacht oder Heydrich gab diese beruhigende Interpretation nur gegenüber der Justizverwaltung ab. ${ }^{128}$ Bei dieser seiner eindeutigen Auslegung der fraglichen Anordnung, schrieb Heydrich, erübrige es sich, auf strittige Einzelfälle einzugehen, die Spangenberger offenbar angeschnitten hatte. Der Vorwurf der politischen Unzuverlässigkeit in jenem Schreiben des Innenministeriums habe zwar von Beamten der Justizverwaltung gesprochen, sei aber allgemein gemeint gewesen: es treffe „für Beamte aller Zweige zu, was die allgemeine Erfahrung gelehrt" habe. Großzügig versicherte Heydrich, es solle nicht untersucht werden, ,inwieweit dies auf die weltanschauliche Einstellung des Einzelnen zurückzuführen" sei. ${ }^{129}$ Spangenberger gab die Anordnung der Bayerischen Politischen Polizei vom 3./15. Juli nebst Heydrichs Interpretation den bayerischen Staatsanwälten am 8. Oktober 1934 in einem vertraulichen Rundschreiben bekannt und bat sie, die Einhaltung seitens der Polizeibehörden zu beobachten und bei Verzögerungen zu berichten. ${ }^{130}$ Dieses Mißtrauen seitens der Justiz war nur zu berechtigt: wie der Generalstaatsanwalt München Anfang Dezember auf einer Besprechung im Ministerium anhand verschiedener Beispiele darlegte, stand Heydrichs Anordnung lediglich „auf dem Papier“. ${ }^{131}$ Es wurde deutlich, daß sich die politische Polizei bei der Erfüllung ihrer Aufgaben niemals an normative Regeln binden lassen würde.

\footnotetext{
${ }^{127}$ Schr. des bayerJM (I. V. Spangenberger) an Siebert v. 23.8.34 (GehStArch. München, Sign. MA 105617).

${ }^{128}$ Eine eindeutige Weisung an die Dienststellen der BPP, daß die urschriftlichen Anzeigen gemäß $§ 163$ Abs. 2 der StPO an die StAschaft abzugeben seien, ist erst mit dem von Stepp gez. RdErl. v. 21.7.36(!) nachweisbar, der die beiden Anordnungen v. 3./15.7.34 aufhob u. ersetzte (Akten des RJM, BA, Sign. R 22/1462).

${ }^{129} \mathrm{Schr}$. Heydrichs an das bayer. JM v. 6.9.34 (GehStArch. München, Sign. MA 105617).

${ }^{130}$ RV des bayerJM v. 8. 10.34 (BayHStArch. Abt. II, Sign. MJu 12003).

${ }^{131}$ Niederschr. über die Bespr. der JVerw. mit den OLGPräs. u. GStAen am 7. u. 8.12.34 (a.a.O., Sign. MJu 16835).
} 
Gegen Jahresende teilte der Oberstaatsanwalt beim Landgericht München II seine Beobachtung mit, daß hinsichtlich SS-Angehöriger „die Reichsführung der S.S. gleichzeitig als oberste Spitze der Politischen Polizei - auf dem Standpunkt zu stehen scheint, daß zur Durchführung von Strafverfahren, insbesondere auch zu richterlichen Vernehmungen ... die Genehmigung der Reichsführung notwendig sei“; dieser Standpunkt werde vor allem dann eingenommen, wenn es sich um kasernierte SS-Angehörige handelte. ${ }^{132}$ Mit diesem Bericht, der das bayerische Justizministerium am letzten Tage seines offiziellen Bestehens erreichte, sprach der Oberstaatsanwalt einen Teil jener Probleme an, über die sich das Reichsjustizministerium in den folgenden Jahren mit Himmlers SS und Polizei auseinanderzusetzen haben sollte und die 1939 schließlich mit der Einrichtung einer eigenen SS- und Polizeigerichtsbarkeit zugunsten Himmlers entschieden wurden.

\section{Amnestie oder Exemtion: der Widerstand des Reichsjustiz- ministeriums gegen eine eigene SA-Strafgerichtsbarkeit}

Die Absichten, die Röhm mit der Einführung einer eigenen SA-Strafgerichtsbarkeit verfolgte, sind in seiner nur bis zu den Standarten verteilten Verfügung betr. Disziplin vom 31 . Juli $1933^{1}$ zusammengefaßt. Das wichtigste Ziel war sicherlich, die strafrechtliche Behandlung von Taten SA-Angehöriger, die zwar gegen die Gesetze verstießen, aber dem „Interesse der SA“ dienten - und die Röhm daher „zu decken und zu verantworten" bereit war -, der ordentlichen Justiz zu entziehen und in eigener Regie zu erledigen. Zugleich aber sollte der SA mit der Errichtung einer der Wehrmachtgerichtsbarkeit vergleichbaren Sondergerichtsbarkeit der Charakter einer geschlossenen Militärorganisation verliehen werden, die als eine Art Volksmiliz konkurrierend neben die Reichswehr treten sollte: das Ziel war, ,in jeder Richtung die Rechte der SA als staatlich anerkannter Truppe der nat.soz. Revolution zu sichern und zu wahren. Die bevorstehende Verordnung über die SA-Gerichtsbarkeit“, führte Röhm in der Verfügung aus, „wird diesem Bestreben die gesetzliche Grundlage geben.“ Darüber hinaus aber hatte Röhm die durchaus ernst zu nehmende Absicht, ohne Einschaltung einer außenstehenden Institution jene Handlungen rücksichtslos zu ahnden, die nicht „im Interesse“ der SA-Führung lagen und die Disziplin des braunen Massenheeres zu untergraben drohten, das bei seiner raschen Vermehrung seit der Machtergreifung zahlreiche unruhige und kriminelle Elemente aufgenommen hatte. Auch dieser Aspekt kommt in der genannten Verfügung Röhms zum Ausdruck: ihm lägen, „wenn auch nur vereinzelt“, Meldungen vor, daß sich SA-Angehörige „Befriedigung persönlicher Rachebedürfnisse, unzulässige Mißhandlungen, Raub, Diebstahl und Plünderung“ hätten zuschulden kommen lassen; es widerspreche „dem Ehrbegriff der SA und dem wahren Kameradschaftsbegriff, solche Schurken zu decken“. Bei der Verfolgung dieses Zieles zeigte sich jedoch ein erschreckender Radikalismus, der durch die Einführung eines eigenen, geordneten Justizverfahrens vielleicht hätte gemildert werden können:

\footnotetext{
${ }^{132}$ Ber. des OStA anl. einer Strafsache gegen einen SS-Wachmann des KZ Dachau v. 20.12.34 an den GStA München, weitergeleitet an das bayerJM u. dort am 31.12.34 eingegangen (a.a.O., Sign. MJu 12003).

1 Verf. des OSAF Ch. Nr. $1415 / 33$ v. 31.7.33 (Akten des RJM, Arch. des IfZ, Sign. MA 108).
} 
„Solange nicht die SA-Gerichtsbarkeit eingeführt ist, sind diese Verbrecher, wenn ihre Tat nicht sofort Sühne durch den Tod [!] als Exempel erforderlich macht, mit Schimpf und Schande aus der SA auszuschließen.“ Die Anweisung, diese Täter dann „dem zuständigen Gericht zu überstellen“, zeigt jedoch, daß die Behandlung dieser eindeutigen Fälle nicht das Kernproblem darstellte, das durch die Einführung einer SA-Strafgerichtsbarkeit gelöst werden sollte. Gewiß hätte eine unauffälligere, interne SA-gerichtliche Erledigung auch dieser Fälle dem Ansehen der SA in der Öffentlichkeit weniger geschadet; dennoch war die Behandlung der Konfliktfälle zwischen SA und ordentlicher Justiz das eigentliche Problem, das dem Gedanken der SA-Strafgerichtsbarkeit zugrunde lag.

Mit der Frage einer SA-Sondergerichtsbarkeit wurde das Reichsjustizministerium überraschend konfrontiert. Am Vormittag des 19. Juli 1933 ließen sich die Rechtsanwälte Betz und Mayr aus München bei Staatssekretär Schlegelberger melden. „Sie verlangten“, notierte Schlegelberger am selben Tage,

„, auf Weisung der Obersten SA-Führung sofort auf wenige Minuten den Herrn Minister zu sprechen. Ich erwiderte, daß der Herr Minister auf Urlaub abwesend sei. Die Herren baten, ihnen den Aufenthaltsort des Herrn Ministers zu sagen. Die Sache sei so eilig, daß sie dem Herrn Minister nachfahren würden. Ich erklärte, daß mir der gegenwärtige Aufenthaltsort des auf einer Bootsfahrt befindlichen Herrn Ministers nicht bekannt sei; handele es sich um eine Angelegenheit des Ministeriums, so stände ich zur Verfügung. Die Herren erwiderten, sie seien ohne besondere Ermächtigung nicht befugt, mit mir über die Sache zu sprechen, sie würden mich gegen 6 Uhr anrufen, um zu erkunden, ob ich dann Näheres über den Aufenthalt des Herrn Ministers mitteilen könnte."2

Da Gürtners Aufenthalt nicht zu erfahren war - vielleicht wollte Schlegelberger dem Minister die Belästigung im Urlaub auch ersparen -, kamen die beiden Rechtsanwälte, die unterdessen aus München neue Weisung eingeholt hatten, am nächsten Tag erneut ins Ministerium und übergaben Schlegelberger den Entwurf eines Gesetzes über die SA-Gerichtsbarkeit, in Urschrift von Röhm und Betz am 14. Juli unterzeichnet. Sie baten Schlegelberger, diesen Entwurf schnellstens durchzusehen. Schon für den folgenden Tag wurde eine Besprechung vereinbart, an der zusätzlich der Rechtsberater der Obersten SA-Führung, der Berliner Rechtsanwalt und SA-Gruppenführer Luetgebrune, und der Strafrechtsreferent des Ministeriums teilnehmen sollten. ${ }^{3} \mathrm{Da}$ jedoch Luetgebrune verreist und Mayr nach München zurückgerufen worden war, mußte die vorgesehene Besprechung unterbleiben. Das gab Schlegelberger Gelegenheit, mit Betz eine „vertrauliche Aussprache“ zu führen und über Entstehung sowie Motive des Entwurfs Näheres zu erfahren. Wie Betz ausführte, sei die Ausarbeitung "des Entwurfs, der auf der Reichenhaller Führertagung auch bereits die Zustimmung des Herrn Reichskanzlers gefunden habe “4 (!), erfolgt, weil die ordentlichen Gerichte nicht ausreichten, das gesetzmäßige Verhalten der SA-Mitglieder sicherzustellen. „Das liege vor allem daran“, konstatierte Betz in völliger Umkehrung der Tatsachen, daß

2 Verm. Schlegelbergers v. 19.7.33 (a.a.O.).

3 Verm. Schlegelbergers v. 20.7.33 (a.a.O.).

4 Vgl. die Ausf. des SA-Gruppenführers Schoene gegenüber dem OLGPräs. u. dem GStA Kiel am 10.7.33: „Es sei auch bei der Reichenhaller Führertagung eine gesetzliche Regelung in Aussicht gestellt worden, wonach die Strafrechtspflege gegen Mitglieder der SA besonderen Behörden übertragen werden sollte." (Ber. an den preuß. JM v. 10.7.33, Akten des preuß. JM, GehStArch. Berlin, Sign. Rep. 84 a/12004). S. dazu Kapitel IV.2.a., S. 338. 
„die Organe der ordentlichen Gerichtsbarkeit nicht den Entschluß aufbrächten, rücksichtslos gegen SA-Leute vorzugehen“. Die SA-Gerichtsbarkeit solle hier Wandel schaffen und "sei dazu bestimmt, im ganzen Volk das Vertrauen zu begründen und zu stärken, daß es sich bei den etwa 3 Millionen Leuten nicht um eine zusammengelaufene Horde, sondern um eine straffe Zusammenfassung handele, deren Mitglieder absolut an die allgemeinen Gesetze gebunden seien“. Dafür sei die Einschaltung von Juristen unbedingt notwendig; diese Meinung vertrete er ,gegenüber Auffassungen anderer maßgebender Herren, die rein militärisch eingestellt seien".

Selbst wenn man den SA-Juristen zubilligt, daß auch sie die aus der SA sich entwikkelnde Gefahr für die Rechtsordnung erkannten und ernsthaft beabsichtigten, die bei der ordentlichen Justiz steckengebliebenen Verfahren gegen SA-Straftäter unnachsichtig durchzuführen, war es eine illusorische Annahme, daß sie sich mit dieser Absicht gegen Röhm und die revolutionären, „rein militärisch“ denkenden SA-Führer würden durchsetzen können. Das war auch Schlegelberger klar. Er suchte das Problem zunächst mit der Wiedereinführung der Militärgerichtsbarkeit bei der Reichswehr zu koppeln, die durch das Gesetz vom 12. Mai $1933^{5}$ angekündigt war und im Herbst erfolgen sollte, und wies auf die dafür laufenden Vorarbeiten hin. Doch Betz bestand darauf, daß die SA-Gerichtsbarkeit unabhängig davon, und zwar sofort, eingeführt werden müsse. Schlegelberger sicherte dem „Bestreben, auch gegenüber SALeuten die allgemeinen Gesetze anzuwenden“, die „vollste Unterstützung“ des Reichsjustizministeriums zu; allerdings müsse er „vom Standpunkt des Rechts aus ... größtes Gewicht darauf legen, daß die Neuordnung auf absolut sicherer rechtlicher Grundlage beruhe“. Diese Grundlage könne er aber in dem Gesetz vom 28. April $1933^{6}$, auf das der vorgelegte Entwurf die SA-Gerichtsbarkeit rechtlich begründet sehen wollte, nicht erblicken, da dieses Gesetz zwar „von der Einrichtung einer ,öffentlich-rechtlichen Dienststrafgewalt', nicht aber von der Exemtion der SA-Leute von der ordentlichen Gerichtsbarkeit handele“. Betz räumte die Berechtigung dieses Einwandes ein, und beide zogen daraus schließlich die Konsequenz, daß sich auf jeden Fall das Reichskabinett mit dem Entwurf befassen müsse. Sie vereinbarten daher, den Entwurf gemeinsam mit dem Reichswehrministerium genau durchzusprechen. Auf dringende Empfehlung Schlegelbergers versprach Betz, „dafür zu sorgen, daß der Entwurf nicht etwa in der vorliegenden Form auf Grund des Gesetzes vom 28. April erlassen“" werde. $^{7}$

Damit war die unmittelbare Gefahr zunächst abgewendet. Mit der Einbeziehung des Reichswehrministeriums hatte sich die Justiz zugleich einen Verbündeten gesichert: Die Reichswehrführung konnte kein Interesse daran haben, die laufenden Verhandlungen mit den ohnehin mißtrauischen ehemaligen Feindmächten über eine militärische Gleichberechtigung sowie die geheime Wiederaufrüstung dadurch zu erschweren, daß sich die SA-Armee durch die Einführung einer eigenen Gerichtsbarkeit ein betont militärisches Gepräge gab.

5 RGB1. I, S. 264; vgl. dazu die Niederschr. der Bespr. der Reichsminister v. 28.4.33 nachm. 4.15 Uhr (Akten der Reichskanzlei. Die Regierung Hitler, Teil I: 1933/34 [s. Kapitel I, Anm. 3], Band 1, Dok. Nr. 115, S. 416).

6 RGBl. I, S. 230. Das G. betr. die Dienststrafgewalt über die Mitglieder der SA und SS lautete: „Die Mitglieder der SA. und SS. unterliegen einer öffentlich-rechtlichen Dienststrafgewalt nach Maßgabe der Vorschriften, die der Reichskanzler als oberster SA.-Führer erläßt.“

7 Verm. Schlegelbergers v. 21.7.33 (Akten des RJM, Arch. des IfZ, Sign. MA 108). 
Nach dem vorgelegten Gesetzentwurf sollte die SA-Gerichtsbarkeit für alle strafbaren Handlungen von SA-Angehörigen - einschließlich der SA-Anwärter und „Angehörigen aller anderen der obersten SA-Führung unterstehenden Gliederungen und dergl.“, also auch der SS - zuständig sein. Zu den strafbaren Handlungen sollten auch Zuwiderhandlungen gegen Finanz-, Polizei-, Fischerei- und Jagdgesetze gehören, soweit sie nicht lediglich mit Geldstrafe oder Einziehung geahndet wurden. Auf die Tatbestände sollten die allgemeinen reichsrechtlichen Strafgesetze angewandt werden, also anders als bei der Wehrmachtgerichtsbarkeit kein eigenes "SA-Strafgesetzbuch“ geschaffen werden. Vergehen und Verbrechen gegen Zucht und Ordnung innerbalb der SA sollten dagegen nach dem Militärstrafgesetzbuch von $1872^{8}$ sinngemäß abgeurteilt werden. Die Gerichtsbarkeit sollte wie bei der Militärjustiz durch Gerichtsherren und erkennende Gerichte ausgeübt werden, die Sondergerichte im Sinne des $\S 14$ GVG darstellten: dabei bildeten Stabschef und Oberstes SA-Gericht sowie die Gruppenführer und die Gruppengerichte die höhere SA-Gerichtsbarkeit, während die Standartenführer und Standartengerichte die niedere SA-Gerichtsbarkeit ausmachten ${ }^{9}$, der nur die unteren Ränge bis einschließlich Obertruppführer unterstanden. Die Gerichte sollten ,auf Befehl der zuständigen Gerichtsherrn von Fall zu Fall“ (') zusammentreten, wobei die richterlichen Mitglieder jeweils von den Gerichtsherren ernannt wurden. Rechtsmittelgericht für die Entscheidungen der Standartengerichte waren die Gruppengerichte, für die Gruppengerichte aber das Oberste SA-Gericht, gegen dessen Entscheidung es keine Rechtsmittel mehr gab. Für das Verfahren sollten die Vorschriften der StPO gelten. Sobald ein Vorgesetzter vom Sturmführer an aufwärts von der strafbaren Handlung eines SA-Angehörigen Kenntnis erhielt, hatte er - sofern die Tat nicht nur „nach Maßgabe der Dienststrafordnung zu ahnden“ war (!) - dem zuständigen Gerichtsherrn einen Tatbericht einzureichen. Die weiteren Ermittlungen sollte „auf Anweisung des Gerichtsherrn“ dessen Rechtsberater vornehmen, der ihm bei hinreichendem Verdacht dann auch die Anklageschrift übermittelte. Daraufhin entschied der Gerichtsherr unter gleichzeitiger Bestimmung des zuständigen Gerichts über Eröffnung oder Einstellung des Verfahrens; er konnte, „falls besondere Gründe dies gerechtfertigt erscheinen lassen“ (!), den Fall dem zuständigen SA-Führer zur Erledigung „auf dem disziplinären Wege der Dienststrafordnung“ übergeben. Wurde das Verfahren eröffnet, so beraumte der Vorsitzende des Gerichts den Termin zur mündlichen Hauptverhandlung an, der allen Beteiligten spätestens drei Tage vorher bekanntzugeben war, während der Gerichtsherr den Anklagevertreter - in der Regel seinen Rechtsberater - bestimmte. Der Angeklagte konnte „zu seiner Verteidigung sich des Beistandes eines S.A.-Angehörigen vom Sturmführer aufwärts oder eines Rechtsberaters der S.A.“ bedienen. „In sinngemäßer Anwendung“ des Grundsatzes, daß für die Tatbestände die allgemeinen Strafgesetze galten, sollten „bis zum Erlaß eines besonderen Gesetzes“ folgende Strafen verhängt werden können: Arrest verschiedenen Grades bis zu 10 Tagen, Einschließung, Gefängnis, Zuchthaus, Todesstrafe, wobei zusammen mit den letzteren drei Strafarten als Nebenstrafen Aberkennung des Dienstgrades und Ausstoßung ausgeprochen werden konnten. Das Urteil wurde vom Vorsitzenden

8 Zuletzt i.d. F. der Bek. v. 16.6.26 (RGBl. I, S. 275) mit den Änderungen v. 26. 5. 33 (RGBI. I, S. 295).

9 Vorgesehene Zusammensetzung der Gerichte: Oberstes SA-Gericht: 1 Obergruf., 2 Gruf., 2 Rechtsberater; Gruppengerichte: 1 Gruf. oder Brigadef., 1 Oberf. oder Standartenf., 1 Rechtsberater; Standartengerichte: 1

Standartenf. oder Obersturmbannf., 1 Sturmbannf. oder Sturmf., 1 Rechtsberater. 
mündlich begründet und verkündet, die schriftliche Ausfertigung mußte innerhalb einer Woche zugestellt werden. Legte der Angeklagte innerhalb von zwei Wochen keine Berufung ein, so wurde das Urteil dem Gerichtsherrn zur Bestätigung oder Verwerfung vorgelegt. Im Falle der Verwerfung wurde die Sache „vor einem SA-Gericht in vollkommen anderer richterlicher Besetzung" erneut verhandelt; das neue Urteil konnte der Gerichtsherr nicht ein zweites Mal verwerfen. Auf die Strafvollstreckung sollten die Bestimmungen der StPO angewendet werden, soweit nicht eine besonders zu erlassende Dienstanweisung der Obersten SA-Führung etwas anderes bestimmte. Das Gesetz sollte mit dem Tag seiner Verkündung rückwirkend ab 1. (!) Januar 1933 in Kraft treten; bereits von der ordentlichen Justiz eingeleitete Verfahren waren nach den Vorschriften dieses Gesetzes zu behandeln, d.h. an die SA-Gerichtsbarkeit abzugeben. ${ }^{10}$

Dieser Entwurf hätte den Gerichtsherren, d.h. den zuständigen Standarten- bzw. Gruppenführern, das Recht verliehen, Verstöße von SA-Leuten gegen die allgemeinen Strafgesetze lediglich disziplinarisch zu bestrafen oder sogar ungesühnt zu lassen. Darüber hinaus konnten sie durch die Bestimmung und die Zusammensetzung des Gerichts von Fall zu Fall erheblichen Einfluß auf das Verfahren nehmen. Zu diesem Entwurf gab noch am 21. Juli 1933 Gürtners Vertrauter und Mitarbeiter bei der Strafrechtsreform, von Dohnanyi, eine Stellungnahme ab, die vom Leiter der Strafrechtsabteilung Ministerialdirektor Schäfer am selben Tage Schlegelberger vorgelegt wurde. ${ }^{11}$ Dohnanyi führte aus, daß der Gesetzentwurf nicht aufgrund des Gesetzes vom 28. April 1933 erlassen werden könne, da das April-Gesetz nur zum Erlaß von Disziplinarstrafvorschriften im engeren Sinne ermächtigte; ebenso sollte die SA-Sondergerichtsbarkeit keinesfalls vor der Wiedereinführung der Militärgerichtsbarkeit erfolgen. Für den Grundgedanken des Vorhabens lasse sich anführen, daß die genannten Verbände nach Struktur und Bewußtsein ihrer Angehörigen „einen quasi geschlossenen Stand ..., ähnlich etwa wie das Reichsheer" darstellten. Außerdem seien die ordentlichen Gerichte zur Zeit gegenüber Straftaten von Angehörigen dieser Verbände verhältnismäßig ohnmächtig, was ,auf der einen Seite eine gefährliche Steigerung des Selbstbewußtseins der Mitglieder dieser Verbände, auf der anderen ein immer mehr um sich greifendes Gefühl allgemeiner Rechtsunsicherheit“ bewirke. Hier könne eine Sondergerichtsbarkeit zweifellos Wandel schaffen - allerdings nur unter der Voraussetzung, daß das berufsrichterliche Element an diesen Sondergerichten verstärkt würde. Gegen das Vorhaben lasse sich außer den auf der Hand liegenden außenpolitischen Bedenken einwenden, daß die Angehörigen der Verbände als Vertreter bürgerlicher Berufe normalerweise ,ihrem zivilen Tageswerk nachgehen und nur zeitweise als Verbandsmitglieder auftreten"; sie sollten daher der Sondergerichtsbarkeit nur soweit unterstellt werden, ,als sie Straftaten im Dienst oder aus Anlaß des Dienstes begehen“. Man werde allerdings nicht umhinkommen, dann auch anderen geschlossenen Verbänden wie etwa der Schutzpolizei eine Sondergerichtsbarkeit zuzugestehen. Dennoch kam Dohnanyi bei Abwägung aller Vor- und Nachteile zu dem Ergebnis, die Errichtung der vorgeschlagenen Sondergerichtsbarkeit - wenn auch in zögernden Formulierungen - zu bejahen: da Hitler nach den Informationen, die dem Reichsjustiz-

10 Entw. eines G. betr. die SA-Gerichtsbarkeit (Akten des RJM, Arch. des IfZ, Sign. MA 108).

11 Verm. v. Dohnanyis v. 21.7.33 (a.a.O.). 
ministerium bisher vorlagen, die Einführung einer SA-Strafgerichtsbarkeit gebilligt zu haben schien, wäre mit einer bloßen Ablehnung nichts gewonnen gewesen. Vielmehr mußte das Ministerium unter diesen Umständen auf die Ausgestaltung dieser Gerichtsbarkeit in einer Weise Einfluß zu nehmen suchen, daß die gefährlichen Mängel des vorliegenden Entwurfs nach Möglichkeit beseitigt wurden. Deshalb schlug Dohnanyi vor, „die Rechtsgarantien in dem Entwurf weiter auszubauen“, und zwar durch folgende Forderungen:

1. „Restlose Durchführung des Legalitätsprinzips“, d.h. der Verpflichtung, daß jede strafbare Handlung auch verfolgt würde. Dafür sollte die Einführung eines Beschwerderechts des Verletzten beim Reichsgericht zur Klageerzwingung sorgen, wie sie auch der Entwurf der neuen Militärstrafgerichtsordnung vorsah. ${ }^{12}$

2. Errichtung einer Revisionsinstanz. Auch hierfür sollte in Anknüpfung an die vorgesehene Militärstrafgerichtsordnung für die schwereren Straftaten das Reichsgericht vorgesehen werden.

3. Als Mitglieder der Sondergerichte sollten neben Angehörigen der genannten Verbände statt der "Rechtsberater“ Berufsrichter zugezogen werden und ihre Anzahl gegenüber der im Entwurf vorgesehenen Zahl erhöht werden.

4. Die Sondergerichte sollten als ständige Gerichte berufen werden und nicht von Fall zu Fall zusammentreten.

5. Die Zuständigkeit der Sondergerichte sollte nach objektiven Gesichtspunkten geregelt und nicht im Einzelfall durch den Gerichtsherrn bestimmt werden.

6. Die Möglichkeit der Abgabe von Strafsachen an die ordentlichen Gerichte sollte vorgesehen werden, vor allem für Delikte, die SA-Angehörige außerhalb des Dienstes begingen.

7. Soweit die allgemeinen Strafgesetze angewendet würden, sollten auch die dort genannten Strafrahmen gelten; die Unklarheit, die in dieser Hinsicht durch die Aufzählung spezifischer Strafen wie Arrest, Einschließung usw. geschaffen werde, müsse beseitigt werden.

Ferner schlug Dohnanyi vor, die Anwendung des Militärstrafgesetzbuches auf Verbrechen und Vergehen gegen die innere Disziplin der SA durch die Schaffung neuer strafrechtlicher Tatbestände zu ersetzen ${ }^{13}$, ferner die Unterscheidung zwischen höherer und niederer SA-Gerichtsbarkeit zu vermeiden.

Die gemeinsame Besprechung mit dem Reichswehrministerium fand - unter Einschluß des Reichsinnenministeriums - am 4. August unter dem Vorsitz Schlegelbergers im Reichsjustizministerium statt. Vom Justizministerium nahmen außerdem Ministerialrat Mettgenberg, von Dohnanyi als Protokollführer sowie zwei weitere Referenten teil. Die SA war durch Luetgebrune, die Reichswehr durch Geheimrat Semler und Hauptmann Böhme, das Innenministerium durch Ministerialrat Hoche vertreten. Der Beratung lag eine von Professor Nagler (Breslau) überarbeitete Fassung des Entwurfs zugrunde. Luetgebrune betonte eingangs nochmals, daß Hitler „den Wunsch nach der Schaffung einer SA-Sondergerichtsbarkeit ausdrücklich ausgesprochen“ habe, die für alle strafbaren Handlungen zuständig sein solle. Demgegenüber wies

12 Auch die alte MilitärstrafgerichtsO kannte ein solches Beschwerderecht, damals war das Reichsmilitärgericht zuständig $(§ 247)$.

13 Etwa ähnlich den $\$ \S 89 \mathrm{ff}$. (Strafbare Handlungen gegen die Pflichten der militärischen Unterordnung) des MilStGB v. 16.6. 26 (RGBI. I, S. 275). 
Schlegelberger abermals darauf hin, daß ein entsprechendes Gesetz nicht aufgrund des Reichsgesetzes vom 28. April 1933 erlassen, sondern nur durch das Reichskabinett verabschiedet werden könne. Er und Gürtner hätten „alles Verständnis dafür“, daß eine schlagkräftige Gerichtsbarkeit für die Straftaten von SA-Angehörigen gewährleistet werden müsse, „wenn bei den gegenwärtigen Verhältnissen die bürgerlichen $\mathrm{Ge}$ richte hierzu nicht in der Lage seien“; nur hätten sie Bedenken außenpolitischer Art, die SA-Gerichtsbarkeit vor der Militärjustiz einzuführen: Der „Eindruck der Militärähnlichkeit der SA" müsse unbedingt vermieden werden. Semler erklärte es für unbedingt erforderlich, daß die Militärstrafgerichtsordnung vorher erlassen werde, und forderte die Beseitigung der ,in dem Entwurf enthaltenen Vermischung von Disziplinargerichtsbarkeit und Strafgerichtsbarkeit“. Auch Schlegelberger hob die Unklarheit des Entwurfs in der entscheidenden Frage hervor, ob schlechthin alle oder „nur solche kriminellen Straftaten, die zugleich auch Disziplinarvergehen darstellten“, der SA-Gerichtsbarkeit unterliegen sollten. Er fragte, „ob ein SA-Mann, der in einem Alimentenprozeß einen Meineid leistet, vor ein SA-Gericht oder vor ein bürgerliches Gericht gestellt" werden solle. Luetgebrune bestand auch in diesem Fall auf dem SA-Gericht: alle von SA-Leuten begangenen Straftaten seien gleichzeitig Verstöße gegen die Zucht und Ordnung; der Begriff des Verstoßes gegen Zucht und Ordnung umfasse jedoch darüber hinaus auch Handlungen, die vom StGB nicht mit Strafe bedroht seien. Insofern enthalte der Entwurf „einen Generalstraftatbestand (,Wer ein Schwein ist, wird erschossen') ". Auf Befragen Schlegelbergers legte Luetgebrune dar, leichtere Disziplinarvergehen sollten ,nach der allgemeinen Dienstordnung ${ }^{14}$ behandelt und aus der Zuständigkeit der SA-Gerichte ausgenommen werden. Unter welchen Umständen ,ein leichterer Fall' vorliege, solle dem Ermessen des Gerichtsherrn anheimgestellt sein.“ Auf die Feststellung Böhmes, „daß vom Standpunkte des Reichswehrministeriums es völlig untragbar sei, die Zuständigkeit des Reichsgerichts hinsichtlich der Aburteilung von Landesverratssachen einzuschränken“, erklärte sich Luetgebrune damit einverstanden, daß Hoch- und Landesverratssachen dem Reichsgericht verblieben. Nach weiteren Verhandlungen wurden auch andere Spezialdelikte wie Verstöße gegen Finanzgesetz, Jagdgesetz usw. aus der Zuständigkeit der SA-Gerichtsbarkeit herausgenommen. In den Entwurf war eine Generalklausel eingegangen, die auf den entschiedenen Widerstand aller drei Ministerien stieß: für den Fall der Erklärung des Staatsnotstandes (Belagerungszustand) sollten „durch besondere Verordnung des Reichskanzlers die SA-Gerichte für alle strafbaren Handlungen aller Staatsangehörigen für zuständig erklärt werden“, d.h. die SA-Gerichtsbarkeit an die Stelle der ordentlichen Gerichtsbarkeit treten können. Diese Bestimmung, die die völlige Auslieferung der staatlichen Justiz an die SA und den Todesstoß für alle staatliche Ordnung bedeuten konnte, bezeichnete Schlegelberger als „eine politische Unmöglichkeit“. Gegenüber der geschlossenen Opposition seiner Gesprächspartner mußte Luetgebrune diese Regelung aus dem Entwurf streichen. In die Vorlage war Dohnanyis Vorschlag, das Reichsgericht als Revisionsinstanz einzuschalten, aufgenommen worden; hier mußte sich Luetgebrune der Forderung des Justizministeriums beugen, daß der SA-Rechtsberater nicht anstelle des Reichsanwalts als Anklagevertreter auftreten, sondern lediglich „zur Unterstützung der Reichsanwaltschaft zugezogen werden könne“. Auch die 
Einführung des von Dohnanyi geforderten Beschwerderechts für den Verletzten erkannte Luetgebrune an: als Beschwerdegericht sollte „das Oberste SA-Gericht und, soweit dies in erster Instanz zuständig sei, das Reichsgericht" dienen. Auf Dohnanyis Frage bestätigte Luetgebrune ausdrücklich, „daß das Legalitätsprinzip auf jeden Fall auch im Rahmen der SA-Strafgerichtsordnung uneingeschränkt Geltung besitze“. Ebenso setzten Justiz- und Wehrministerium durch, daß die SA-Richter, aus denen sich - neben den entsprechenden SA-Führern - die Gerichte zusammensetzen sollten, wie an den Kriegsgerichten die Befähigung zum Richteramt haben sollten und einer von ihnen die Verhandlung leiten sollte. Schlegelberger und die Vertreter der Reichswehr forderten, daß der Grundsatz der Öffentlichkeit des Verfahrens unter allen Umständen aufrechterhalten werden müsse. Nun war es gerade ein wesentliches Argument der SA-Führung gegen die Durchführung mancher Prozesse gegen Angehörige ihrer Verbände, daß das Bekanntwerden der ausgebreiteten - für die Verbände meist blamablen - Vorgänge vor der Öffentlichkeit die Interessen des Reiches und der Bewegung gefährde. Man einigte sich, hier die entsprechenden Bestimmungen des Entwurfs einer neuen Militärstrafgerichtsordnung ${ }^{15}$ zu übernehmen, wonach die Öffentlichkeit u.a. wegen Gefährdung der Staatssicherheit ausgeschlossen und die mitwirkenden Personen zur Geheimhaltung verpflichtet werden konnten. An der Kontrolle der Urteile, d.h. dem Bestätigungsrecht des Gerichtsherrn, wollte Luetgebrune unbedingt festhalten, obwohl die Vertreter des Reichswehrministeriums bemerkten, daß die Militärstrafgerichtsordnung eine solche Kontrolle nur im mobilen Verfahren (Feldkriegsgerichtsverfahren) vorsehe.

Aufgrund des Ergebnisses der Besprechung sollte ein Redaktionskomitee, dem neben Luetgebrune je ein Vertreter des Justiz- und des Wehrministeriums angehörte, einen neuen Entwurf ausarbeiten - wenn möglich, schon am nächsten Tag: die Justizleitung hegte ernsthafte Befürchtungen, daß Röhm die Inkraftsetzung des Entwurfs bei Hitler durchsetzen könnte, ohne daß vorher die für erforderlich gehaltenen Rechtsgarantien eingebaut würden. Schlegelberger forderte daher Luetgebrune am Schluß der Besprechung auf, „sich mit allen Mitteln dafür einzusetzen, daß das Gesetz nicht überraschend auf Grund des Reichsgesetzes vom 28. April d.J. erlassen werde. Er müsse nochmals betonen, daß in einem solchen Falle dem Gesetz die Rechtsgrundlage fehlen werde.“ Luetgebrunes Antwort lautete beruhigend: „er halte es für ausgeschlossen, daß der Herr Reichskanzler sich zu einem solchen Schritt entschließen werde“. Hitler „habe im Gegenteil erklärt, das Gesetz solle nur im Einvernehmen mit dem Reichsjustizministerium erlassen werden “ ${ }^{16}$

Die Befürchtungen des Ministeriums waren insofern nicht von der Hand zu weisen, als sich das Problem der Verfolgung von SA-Straftaten fast überall im Reich zugespitzt hatte und dringend einer Entscheidung bedurfte. Röhms Verfügung an seine Verbände vom 19. Juli ${ }^{17}$ - vom gleichen Tage, an dem seine Rechtsberater ersten Kontakt mit dem Reichsjustizministerium aufnahmen -, daß Hitler die SA-Strafgerichtsordnung bereits gebilligt habe und diese nur noch der „formalen Überprüfung“ durch das Justizministerium bedürfe, hatte ihre Wirkung getan. Auf die Verhältnisse in Preußen

15 Vgl. $\S \S 204$ bis 208 der MilStGerO, wie sie später durch das G. v. 4. 11.33 (RGBI. I, S. 921) bekanntgemacht wurde.

${ }_{16}$ Verm. Dohnanyis über die Bespr. v. 4.8.33 (Akten des RJM, Arch. des IfZ, Sign. MA 108).

17 Vgl. Kapitel IV.4.c., S. 400, u. dortige Anm. 87. 
und Bayern ist bereits eingegangen worden ${ }^{18}$; aber auch in den anderen Ländern machten sich die Auswirkungen bemerkbar. Am 25. August fragte z. B. der Württembergische Justizminister beim Reichsjustizministerium an, ob die Einführung der SAGerichtsbarkeit tatsächlich bevorstehe, und bat um eine reichseinheitliche Verhaltensregelung. Seiner Anfrage legte er ein Schreiben des Führers der SA-Brigade Württemberg-Süd an die Staatsanwaltschaft Ulm bei, in dem die verzögerliche Behandlung eines Strafverfahrens gegen zwei SA-Männer „wie auch etwaiger weiter anhängiger oder anhängig werdender Verfahren“" gefordert wurde, da „größtes Interesse [bestehe], daß schon jetzt kein SA-Mann mehr von einem ordentlichen Gericht abgeurteilt wird". ${ }^{19}$ Drei Tage später lief die entsprechende Anfrage des Braunschweigischen Justizministers mit der Bitte um Mitteilung ein, „welches Vorgehen ... bis zum Erlaß [der SAStrafgerichtsordnung] für zweckmäßig gehalten" werde. ${ }^{20}$ Am nächsten Tag folgte die Justizabteilung des ${ }^{\bullet}$ Hessischen Staatsministeriums mit dem beigelegten Bericht eines Justizinspektors an den aufsichtsführenden Richter, daß er den Haftbefehl gegen einen SA-Mann, der seine Geldstrafe wegen Körperverletzung nicht bezahlte, aufheben mußte, da er vom zuständigen SA-Sturmführer in unflätigem Ton und unter Vorlage der Verfügung Röhms vom 19. Juli unter Druck gesetzt worden war. Da den Justizbehörden diese Verfügung völlig unbekannt sei, bat der Inspektor die hessische Justizleitung um klare Richtlinien: „Die Fälle von Zusammenstößen zwischen Gericht und SA-Formationen können sich täglich wiederholen, falls in Bezug auf die Anwendung und die Auslegung der Verfügung des Obersten SA-Führers keine Klarheit geschaffen würde.“21 Die Hessische Justizabteilung wiederholte ihre Bitte mit Schreiben vom 5. September und übersandte einen Bericht des Amtsgerichts Offenbach. Hier war ein wegen fahrlässiger Körperverletzung (Autounfall) angeklagter SS-Mann ,auf ausdrücklichen Befehl seines SS-Führers“ zur Hauptverhandlung nicht erschienen, da - wie sein Verteidiger ausführte - der Unfall auf einer Dienstfahrt geschehen sei und die Aburteilung somit „der Militärgerichtsbarkeit“ unterstehe. Auf Antrag der Staatsanwaltschaft wurde für den neuen Termin Mitte September die Vorführung des Angeklagten angeordnet, bei Erfolglosigkeit Haftbefehl in Aussicht genommen. Das Gericht, das ,in der Wahrung der Staatsautorität eine unserer wesentlichsten Aufgaben“ sah, teilte dem Hessischen Staatsministerium mit, daß es sich zu Verhandlungen mit der SS in dieser Sache nicht für befugt ansehe. ${ }^{22}$

Unter diesen Umständen hielt es Gürtner für angezeigt, die Landesjustizverwaltungen in einem Rundschreiben vom 18. September 1933 darüber zu informieren, daß die Verhandlungen über die Einführung einer besonderen Gerichtsbarkeit für die SA noch nicht abgeschlossen seien und er unverzüglich Näheres mitteilen werde, „sobald in dieser Frage eine Entscheidung gefallen" sei. Er gab jedoch die Weisung, daß vorläufig „selbstverständlich alle Personen, für die die spätere Einführung einer Sondergerichtsbarkeit erwogen wird, der ordentlichen Gerichtsbarkeit“ unterstünden: „An-

18 Vgl. Kapitel IV.2.a., S. 341 ff., u. Kapitel IV.4.c., S. $400 \mathrm{ff}$.

19 Schr. des Württemb.JM an das RJM v. 25.8.33 nebst Schr. der SA-Brigade Württ.Süd an die StAschaft Ulm v. 18.8.33 (Akten des RJM, a.a.O.).

${ }^{20}$ Schr. des Braunschw.JM an das RJM v. 28.8 .33 (a.a.O.).

${ }^{21}$ Schr. des Hess.StMin, Ministerialabt. 1 c, Justiz an das RJM v. 29.8.33 nebst Ber. an das AG Gießen v. 25.8.33 (a.a.O.).

${ }^{22}$ Schr. v. 5.9.33 nebst Bericht des AG Offenbach v. 31.8 .33 (a.a.O.). 
hängige Verfahren sind nach den gesetzlichen Vorschriften fortzuführen; die Einleitung neuer Verfahren hat entsprechend den Gesetzen zu erfolgen." Versuche, die Verfahren von außen her zu verhindern oder zu erschweren, sollten in bedeutsameren Fällen unter Einreichung der Unterlagen an das Ministerium berichtet werden. ${ }^{23}$

Bereits am 15. August hatte Gürtner an den Chef der Reichskanzlei geschrieben, daß es ihm wegen der „Frage der Sondergerichtsbarkeit für die SA ... geboten scheint, den Herrn Reichskanzler durch einen persönlichen Vortrag über den Sachstand zu unterrichten“, und um die Angabe eines Termins ersucht. Eine Woche später telegrafierte Lammers aus Berchtesgaden zurück, Hitler bäte, den „beabsichtigten Vortrag bis nach seiner Rückkehr nach Berlin zu verschieben“ ${ }^{24}{ }^{24}$ Unterdessen verbreitete Röhm als feststehende Tatsache, daß „die Bearbeitung der SA-Strafgerichtsordnung im Einvernehmen mit dem Reichsjustizminister abgeschlossen und sie vom Führer gebilligt“ sei und „in allernächster Zeit in Kraft treten“" werde - so z. B. in einem Schreiben an den bayerischen Ministerpräsidenten Siebert vom 12. September. ${ }^{25}$ Am selben Tag wiederholte Gürtner nach mehreren vergeblichen telefonischen Versuchen gegenüber Lammers schriftlich die „dringende Bitte“, ihm „einen Vortrag beim Herrn Reichskanzler zu vermitteln (Stand der Strafrechtspflege im Reich u. im Zusammenhang damit SA-Gerichtsbarkeit)“. Es handele sich „um Fragen von entscheidender Bedeutung, deren verzögerliche Behandlung nicht zu verantworten wäre“ ${ }^{26}$ Es ist für Hitlers Regierungsstil bezeichnend, daß ein Ressortminister, der nicht wie die Parteifreunde Göring, Goebbels, Heß usw. direkten Zugang zu Hitler hatte, den Regierungschef in einer dringenden Angelegenheit erst nach sechs Wochen zu sprechen bekam: am 19. September kam es endlich zu der von Gürtner gewünschten Unterredung, in der das Problem eine überraschende Wendung nahm. Es stellte sich heraus, daß Hitler den Entwurf einer SA-Strafgerichtsordnung, die die SA-Angehörigen der Zuständigkeit der ordentlichen Justiz entzog, keineswegs "gebilligt" hatte und das fehlinformierte Reichsjustizministerium unter völlig falschen Voraussetzungen an das Problem herangegangen war. Hitler übergab Gürtner den von ihm persönlich unterzeichneten „Entwurf einer Denkschrift über die Errichtung einer Partei- und SA-Gerichtsbarkeit“, die in der Frage der Zuständigkeit gerade das Gegenteil beinhaltete. Zwar erkannte die Denkschrift die Notwendigkeit einer Gerichtsbarkeit für die Partei und deren Sonderorganisationen wie die SA durchaus an; denn für ihren Bestand hätten diese Organisationen besondere Gesetze nötig, deren Einhaltung wiederum durch eine eigene Strafgewalt erzwungen werden müsse. Die entscheidende Frage sei jedoch, welchen sachlichen Umfang diese eigene Gerichtsbarkeit haben solle, und hier wurde klar unterschieden: Alle Vorgänge, die das Gemeinschaftsleben des Gesamtvolkes gefährdeten, fielen „unter die Justiz des nationalsozialistischen Staates“. Dagegen seien „alle Delikte, die die Existenz der politischen Führungsorganisation" - die gegenüber dem Staat „eine besondere, zahlenmäßig begrenzte Stellung“ einnehme - bedrohten, der Gerichtsbarkeit der Partei bzw. ihrer verschiedenen Gliederungen unterworfen.

23 Akten des preuß.JM (GehStArch. Berlin, Sign. Rep. 84 a/12004).

24 Schr. Gürtners an Lammers v. 15.8.33 u. Telegr. Lammers' an Gürtner v. 22.8.33 aus Ramsau b. Berchtesgaden (Akten der Reichskanzlei, BA, Sign. R 43 Il/1553a).

25 Schr. v. 12.9.33 (Akten der bayerStKanzlei, GehStArch. München, Sign. MA 105 483), vgl. Kapitel IV.4.b., Anm. 42.

26 Handschr. Gürtners an Lammers v. 12.9.33 (Akten der Reichskanzlei, a.a.O.). 
„Das heißt also: Es ist die Aufgabe der Justiz der Partei, diejenigen Delikte festzustellen und zu abnden, die in den allgemeinen Strafgesetzen, - weil für den Bestand des Staates unbedroblich - bisber außer Verfolgung standen, für die Existenz der Partei und ibres inneren organischen Lebens aber wichtig sind!

Jede andere Regelung ist unmöglich aus folgenden Gründen:

1. Wenn die Partei ihrer Mission getreu - sei es in ihren Organisationen der Arbeit oder in denen der politisch-männlichen Erziehung, SA, SS usw., zu der Millionenbewegung geworden ist, die sie werden muß, wird es in der Nation verhältnismäßig wenige Männer geben, die nicht von ihr erfaßt sind... Wenn sie nun durch ihre Parteijustiz die an sich von der allgemeinen Gerichtsbarkeit erfaßten Delikte ebenfalls übernimmt, so muß dies zur Schaffung einer zweiten Justizbehörde von geradezu gigantischem Ausmaße führen. Es ist aber nicht die Aufgabe der Partei, sich zu einer monströsen Justizverwaltung auszuwachsen, sondern ausschließlich die politische Erziehung der Nation zu garantieren.

2. Diese Entwicklung führte aber auch sachlich zu unmöglichen Konsequenzen, denn da die Partei nicht jeden Deutschen und jede Deutsche zwingen kann und soll, die Mitgliedschaft zu erwerben, würde jedes Gemeinschaftsdelikt je nach der Zugehörigkeit der Einzelnen zur Partei oder nicht - zu richterlich unmöglichen Verfahren führen.

3. Eine solche Entwicklung würde dann die Partei zwingen, entweder bisherige Richter zu übernehmen, oder sich ihre eigenen Richter zu erziehen. Das erste wäre entweder weltanschaulich unmöglich oder sinnlos, denn dann kann die Partei - wenn sie eine solche Möglichkeit bejaht - ja unmöglich etwas gegen die bisherigen Gerichte haben, das Zweite aber würde ein Menschenalter erfordern...

4. Jeder solche Versuch wäre finanziell untragbar.

5. Der Hinweis, daß auch die Armee ihre eigene Gerichtsbarkeit besitzt, ja diese sogar wiederhergestellt wurde, ist falsch und beweist das Gegenteil. Denn die Armee ist eine eigene gesellschaftliche Organisation, die ihre Angehörigen außerhalb des sonstigen allgemeinen Gemeinschaftslebens vereint. Der Soldat ist nicht nur organisatorisch, sondern tatsächlich dem übrigen Gemeinschaftsleben entzogen. Er ist aus Wohnung und Familie genommen und damit dem allgemeinen Zusammenleben seiner Volksgenossen entrückt. Und nur insoweit dieses zutrifft, steht er unter einer besonderen Gerichtsbarkeit. Denn im Moment, in dem der Soldat trotz seiner noch fortbestehenden Heeresverpflichtungen wieder in die Familie bezw. in sein bürgerliches Leben zurückkehrt, hört seine Unterstellung unter die Militärgerichtsbarkeit auf. Sie wäre in diesem Falle genau so sinnlos, als sie sinnlos ist bei einem Parteigenossen, ganz gleich, in welcher Organisation er sich befindet [!], der aber in der Volksgemeinschaft lebt und in der Partei und ihren Organisationen nur vorübergehenden bezw. begrenzten Dienst tut.

Die Meinung, daß ein Parteigenosse, ein SA- oder SS-Mann, wegen allgemeiner bürgerlicher Delikte, sei es leichter oder schwerer, bestraft werden müßte, spricht nicht für ein eigenes Parteigericht, denn: die leichtere Bestrafung würde dem harten Auslesegedanken der Bewegung zuwiderlaufen, die schwerere Bestrafung braucht nicht durch ein eigenes Gericht vorgenommen werden, sondern kann jederzeit als Erschwerungsgrund, unter Umständen sogar auf Antrag der Partei- bezw. SA-Gerichte, von jedem ordentlichen Gericht berücksichtigt werden.“

Die Denkschrift schloß mit der Forderung, daß für die bezeichneten Aufgaben ein Parteigericht errichtet werden sollte, das sich entsprechend dem organisatorischen Aufbau der Bewegung in eine Anzahl besonderer Senate - Oberstes Parteigericht, SAGericht, Gericht der Arbeitsfront usw. - gliedern sollte. Als nächste Schritte verlangte die Denkschrift, die von diesen Gerichten zu behandelnden Delikte, die Zusammensetzung der Gerichtshöfe, das Verfahren, die Strafen und den Strafvollzug festzulegen. Diesen Katalog ergänzte Gürtner im Entwurf handschriftlich um das Problem der Regelung der Begnadigung und die Frage der Finanzierung, auf die er Hitler auch in der Unterredung aufmerksam gemacht haben dürfte. ${ }^{27}$

27 Das undat. Dok. wurde von Gürtner mit dem handschriftl. Verm. versehen: „Vom Kanzler am 19.9.33 mir übergeben“, und in der Folge von den Reichsministerien als „Denkschrift des Herrn Reichskanzlers“ behandelt (Akten des RJM, Arch. des IfZ, Sign. MA 108). 
Mit dieser Denkschrift, deren Entwurf wahrscheinlich von Fricks Ministerium veranlaßt, vielleicht sogar formuliert worden war $^{28}$ und mit deren Inhalt sich Hitler durch seine Unterschrift identifiziert hatte, besaß das Reichsjustizministerium nunmehr eine Handhabe, den Forderungen der SA entgegenzutreten. Als Luetgebrune am 25. Oktober Gürtner einen neuen Entwurf der SA-Gerichtsordnung überbrachte, der angeblich Hitlers Denkschrift berücksichtigte, konnte ihn der Justizminister nach Prüfung darauf hinweisen, daß die Vorlage und ihre Begründung den Grundlinien der Denkschrift keineswegs entsprachen. Von den kontroversen Punkten seien hier nur die folgenden erwähnt. $^{29}$

Nach diesem Entwurf sollten der Sondergerichtsbarkeit nunmehr alle Handlungen unterliegen, die von SA-Angehörigen „im Dienst“ begangen wurden und schwere Verstöße gegen Zucht und Ordnung ${ }^{30}$ darstellten, „auch wenn sie gleichzeitig als Übertretungen und Vergeben andere gesetzliche Bestimmungen verletzen“.31 Die ordentliche Justiz sollte also - soweit hatte die SA-Führung zurückgesteckt - für alle außerdienstlichen Straftaten und für im Dienst begangene Verbrechen zuständig bleiben. ${ }^{32}$ Als „im Dienst“ sollten SA-Angehörige angesehen werden: „1. alle hauptamtlich beschäftigten SA-Führer ständig, 2. alle übrigen SA-Führer und alle SA-Männer, wenn sie den Dienstanzug tragen“ oder wenn sie Dienst ausübten bzw. auf dem Weg zum oder vom Dienst waren. Der so umrissene sachliche Geltungsbereich erschien dem Justizministerium vor allem durch die Bestimmung zu weit gefaßt, daß „das Tragen des Dienstanzugs schlechthin die SA-Gerichtsbarkeit begründen“ sollte: mit Recht fragte der Justizminister, ob ein SA-Mann, der „im Dienstanzug zu Haus an seinem Schreibtisch Betrugsbriefe“ schreibe, tatsächlich vom SA-Gericht abgeurteilt werden sollte. Auch werde die Zuständigkeitsabgrenzung im konkreten Fall dadurch ungemein erschwert; Beispiel: „ein SA-Mann ist nach Begehung einer Unterschlagung flüchtig gegangen, man weiß nicht, ob er im entscheidenden Zeitpunkt Dienstanzug getragen hat". Andererseits war der vorgesehene Geltungsbereich der Sondergerichtsbarkeit nach Meinung des Justizministeriums wieder zu eng: auch „schwere Verstöße gegen Zucht und Ordnung außer Dienst müssen der SA-Gerichtsbarkeit unterliegen, soweit sie nicht nach den allgemeinen Strafgesetzen strafbar sind“. Die in dem neuen Entwurf vorgesehene Regelung, daß der SA-Gerichtsherr einen Fall, bei dem es sich um Verstöße gegen die allgemeinen Strafgesetze handelt, in toto an die ordentliche Ju-

${ }^{28}$ Frick sandte diesen „vom Führer aufgestellten Entwurf einer Denkschrift“ am 28.9.33 an Heß mit einem Begleitschreiben (BA, Sign. R 43 II/1196), in dem es hieß, das Problem stehe „im Zusammenhange mit der von mir im Auftrag des Führers bereits eingeleiteten Prüfung der Frage, in welcher Form die Partei auch formell in das deutsche Verfassungsrecht einzugliedern sein wird, insbesondere, ob sie als Körperschaft des öffentlichen Rechts zur Trägerin staatsrechtlicher Pflichten und Rechte gemacht werden soll“". Schon drei Tage (22.9.) nach Gürtners Unterredung mit Hitler hatte der zuständige Referent des RMdI telef. im RJM angefragt, wie sich der bislang ausgearbeitete Entw. der SA-GerO „zu der neuen Denkschrift“ verhalte (Verm. v. 25.9.33, Akten des RJM, Arch. des IfZ, Sign. MA 108).

29 Vgl. Verm. v. 4.11.33, Entwurf Luetgebrunes u. Schr. Gürtners an Luetgebrune v. 6.11.33 (a.a.O.). Auf zahlreiche weitere Mãngel, die der Entw. vom Standpunkt des RJM aus aufwies, die aber nicht im Zusammenhang mit der grundsätzlichen Kontroverse stehen, soll hier nicht eingegangen werden.

30 Leichte Verstöße sollten nach der Allgemeinen Dienstordnung der SA (vgl. Anm. 38) geahndet werden.

31 Die Strafen für Übertretungen u. Vergehen waren den entspr. allg. Gesetzen zu entnehmen; als Strafen für schwere disziplin. Verstöße wurden bestimmt: Arrest bis zu 4 Wochen, Degradierung, Entlassung, AusstoBung, Gefängnis bis zu 15 Jahren.

32 Nur während der Zeit eines Staatsnotstandes sollte auch die Aburteilung von Verbrechen „durch Verordnung des Obersten Gerichtsherrn ebenfalls der Zuständigkeit der SA-Gerichte zugeteilt werden“ können. Diese Bestimmung sowie die wieder eingefügte Generalklausel für den Staatsnotstand lehnte das RJM ab. 
stiz überweisen konnte, wenn an ihm neben SA-Angehörigen auch nicht der SA-Gerichtsbarkeit unterstehende Personen beteiligt waren, wurde vom Justizministerium begrüßt - wenn auch von Gürtner mit der kritischen Randbemerkung „Vertrauenssache!" kommentiert. Dagegen lehnte die Justiz die Regelung ab, daß ein SA-Angehöriger - außer auf frischer Tat und bei Fluchtverdacht - nicht durch die ordentlichen Strafverfolgungsbehörden, sondern nur durch den zuständigen SA-Gerichtsherrn verhaftet werden dürfe. ${ }^{33}$

Das Ministerium beanstandete außerdem einige staatsrechtliche Ungereimtheiten. Während nämlich einerseits die Gerichtsgewalt von Hitler als Obersten SA-Führer unmittelbar abgeleitet wurde - an anderer Stelle des Entwurfs wurde die SA-Gerichtsbarkeit allerdings wiederum als ein $Z$ weig der „allgemeinen Parteigerichtsbarkeit“ bezeichnet, die laut der erwähnten Denkschrift von Hitler als dem Führer der Partei ausgehen sollte -, wurde andererseits das Gerichtsverfassungsgesetz als Grundlage der SA-Gerichtsbarkeit angesehen, da die SA-Gerichte „als besondere Gerichte des Reichs ( 14 GVG) zugelassen" werden sollten. Der Stabschef der SA sollte als Stellvertreter Hitlers an der Spitze der SA-Justizverwaltung stehen, dagegen sollten nicht nur er, sondern auch die Führer der Obergruppen und die Führer der Gruppen - d.h. die Gerichtsherren ${ }^{34}$ - die von Hitler ausgehende Strafgewalt als dessen "Stellvertreter" ausüben. Das Reichsjustizministerium, dem es wohl bedenklich schien, die SA-Führer bis herab zum Gruppenführer - wenn auch nur in dieser Hinsicht - zu Stellvertretern Hitlers zu machen, empfahl, allein den Stabschef, „und nur diesen“, zum Stellvertreter zu bestimmen.

In den nächsten Monaten zogen sich die Verhandlungen zwischen Reichsjustizministerium und Oberster SA-Führung hin. Unterdessen wurde am 1. Dezember 1933 das Gesetz zur Sicherung der Einheit von Partei und Staat ${ }^{35}$ erlassen, das federführend durch das Reichsinnenministerium ausgearbeitet worden war. Es hob jenes von der Justizleitung mit Mißtrauen betrachtete Gesetz betr. die Dienststrafgewalt über die Mitglieder der SA und SS vom 28. April 1933 auf und legte Rahmenvorschriften für eine Partei- und SA-Gerichtsbarkeit fest, die die Verletzung jener „erhöhten Pflichten" ahnden sollte, die den Mitgliedern der NSDAP und der SA aus ihrer Mitglied-

33 Durch Röhms Erl. v. 7.10.33 (GehStArch. Berlin, Sign. Rep. 84a/12004) war zunächst in Preußen für die SA eine Art eigener Militärpolizei, das „Feldjägerkorps“, mit 2286 Mann errichtet und bestimmt worden: „Die Festnahme und Vorführung von SA- usw. Führern und -Männern erfolgt auf Ersuchen der zuständigen Polizei- und Justizbehörden allein durch das FJK“; ausgenommen war die „Begehung von Verbrechen im Falle der Ergreifung auf frischer Tat" (sic). Diese Bestimmung führte zur Erschwerung u. sogar Verhinderung der Strafverfolgung (vgl. Ber. des LGPräs. Aachen an den preuß. JM v. 2.8.34, a.a.O.). In Bayern zögerte das Kabinett mit der Errichtung wegen der jährl. Kosten v. 2 Mill. RM, obwohl Innenmin. Wagner das FJK - wohl als Gegengewicht gegen die ihm entgleitende BPP - begrüßte (Prot. der MinRat.Sitzung v. 9.1.34, GehStArch. München, Sign. MA 99 526).

34 Im Gegensatz zum Juli-Entwurf sollten nunmehr „die Gerichte nur von der Gruppe an aufwärts“ gebildet werden, was bei 20 SA-Gruppen, 7 SS-Gruppen, 7 SA-Obergruppen und der OSAF (einschließlich Reichsführung der SS) 35 Gerichte ausmachte. Das Oberste SA-Gericht war zuständig für Anklagen gegen Obergruppen- u. Gruppenf. u. Rechtsmittelgericht für die Entscheidungen der Obergruppengerichte; diese waren zuständig für Anklagen gegen Brigade- u. Oberf. u. entschieden über Berufungen gegen Urteile der Gruppengerichte. Gegen Urteile der Obergruppengerichte als Berufungsgerichte und gegen Urteile des Obersten SA-Gerichts sollte das RG als Revisionsgericht zugelassen werden, soweit es sich um Verstöße gegen die allgem. Strafgesetze handelte. Für Rechtsbeschwerden zur Klageerzwingung war das Oberste SAGericht zustāndig; nur wenn es die Einstellung des Verfahrens verfügt hatte, war das RG als Beschwerdegericht zugelassen.

35 RGBl. I, S. 1016. 
schaft erwuchsen. Obwohl Gürtner in der Kabinettsberatung vorgeschlagen hatte, diese Pflichtverletzungen genauer zu definieren ${ }^{36}$, begnügte sich das Gesetz mit einer Generalklausel: Pflichtverletzung war jede Handlung oder Unterlassung, die den Bestand, die Organisation, die Tätigkeit oder das Ansehen der Partei gefährdete, bei Mitgliedern der SA insbesondere ,jeder Verstoß gegen Zucht und Ordnung“. Außer „den sonst üblichen Dienststrafen“ - wie z. B. Verwarnung, Verweis, Aberkennung der Parteiämter oder des Dienstranges, Ausschluß - sollten auch Haft und Arrest verhängt werden können. Diese Befugnisse mußten vom Staat deshalb ausdrücklich verliehen werden, da diese Maßnahmen sonst möglicherweise den Tatbestand einer strafbaren Freiheitsberaubung verwirklichen konnten. Die Bestimmung bedeutete jedoch nur, daß Haft- und Arreststrafen eingeführt werden konnten, sie bedeutete nicht schon die Ermächtigung zur Anwendung dieser Strafen. ${ }^{37}$ Die notwendigen Durchführungsbestimmungen, insbesondere über Aufbau und Verfahren der Gerichtsbarkeit sowie über den Zeitpunkt ihres Inkrafttretens, sollte Hitler gemäß $\S 8$ des Gesetzes erst noch erlassen. ${ }^{37 a}$ Sie wurden jedoch lediglich in der Form verwirklicht, daß Hitler am 12. Dezember 1933 für die SA eine „Allgemeine Dienstordnung (A.D.O.)“38 genehmigte, die in ihrem Teil „Dienststrafordnung (D.Str.O.)“ von der Möglichkeit Gebrauch machte, daß der unmittelbar vorgesetzte Führer Arreststrafen bis zu einer Höchstdauer von 14 Tagen verhängen konnte. Die für die Parteigerichte der NSDAP ausgearbeiteten innerparteilichen „Richtlinien“, die am 17. Februar 1934 lediglich von Heß als Stellvertreter des Führers genehmigt wurden, verzichteten dagegen auf Haft- und Arreststrafen völlig. ${ }^{39}$ So konnte Reichsinnenminister Frick Ende 1934 mit voller Berechtigung feststellen: „Eine öffentlich-rechtliche Gerichtsbarkeit der Partei und der SA im Sinne des Gesetzes vom 1. Dezember 1933 besteht daher zur Zeit noch nicht. “40

Nach diesem Gesetz konnte es sich bei der vorgesehenen SA-Gerichtsbarkeit nur um eine reine Disziplinargerichtsbarkeit, keinesfalls aber um einen Ersatz für die ordentliche Strafgerichtsbarkeit handeln. Frick, der den letzten Entwurf der Obersten SA-Führung gleichfalls erhalten hatte, sandte am 25. Januar 1934 Ministerialrat Hoche zu Gürtner und ließ im mitteilen, er sei ,nach wie vor der Auffassung, daß nur eine eigene Disziplinarordnung für die SA in Frage kommen könne“. Gürtner nutzte diese Gelegenheit, um Frick über den Stand der Verhandlungen mit der SA-Führung eingehend unterrichten zu lassen. ${ }^{41}$ Schon am nächsten Tag kam es zu einer Unterredung zwischen Hitler, Röhm und Frick, in der Hitler entschied, „daß von einem Reichsge-

36 Vgl. Niederschr. der Ministerbespr. v. 1.12.33, 4.15 Uhr nachm. in der Reichskanzlei (Akten der Reichskanzlei. Die Regierung Hitler, Teil I: 1933/34 [s. Kapitel I, Anm. 3], Band 2, Dok. Nr. 257, S. 984).

37 Vgl. G. Neeße, Das Gesetz zur Sicherung der Einheit von Partei und Staat, Dresden 1934, S. 79.

37a Mit Schr. v. 22.12.33 bat das RMdI das RJM, den Entw. einer DurchfVO zu formulieren, die dem St.d.F. und dem Stabschef der SA vorgelegt werden sollte, und übersandte dafür „Grundsätze für den Ausbau der Partei- und SA-Gerichtsbarkeit“, die mit Hitlers Denkschrift übereinstimmten. Die Angelegenheit wurde jedoch „einstweilen nicht weiter verfolgt“ (Akten der RK, BA, Sign. R 43 II/1196).

38 Sie trat an die Stelle des „Entwurfs der Allgemeinen Dienstordnung (A.D.O.) für die SA“ v. 20.3.32 und hatte folgende Teile: Pflichten des SA-Mannes (A.D.O. I); Besondere Pflichten des SA-Führers (A.D.O. II); Dienststrafordnung (D.Str.O.); Beschwerdeordnung (B.O.) u. Ehrenordnung (E.O.).

39 C. Haidn-F. Fischer, Das Recht der NSDAP, München 1936, S. $695 \mathrm{ff}$.

$40 \mathrm{Vgl}$. W. Frick, Die Gesetze gegen die Neubildung von Parteien und zur Sicherung der Einheit von Partei und Staat (Nationalsozialistisches Handbuch für Recht und Gesetzgebung, herausg. v. H. Frank, München 1934, S. 392).

41 Verm. v. 27.1.34 (Akten des RJM, Arch. des IfZ, Sign. MA 108). 
setz oder auch nur einer Verordnung, die im Reichsgesetzblatt zu veröffentlichen sein würde, abgesehen werden solle. Der aufzustellende Entwurf solle sich auf das beschränken, was im $\S 8$ des Gesetzes vom 1. Dezember 1933 ... vorgesehen sei.“ Allerdings gab Hitler Röhm insofern nach, als er bestimmte, es „müsse Sorge getragen werden, daß auch schwere Disziplinarvergehen eine ausreichende Sühne fänden “ ${ }^{42}$ Aufgrund dieses Ergebnisses hatten Gürtner und Luetgebrune noch am gleichen Tag eine Aussprache, in der Luetgebrune die orakelhafte Absicht äußerte, „eine Disziplinargerichtsbarkeit in ähnlicher Weise aufzubauen, wie das in seinem Entwurf für eine Strafgerichtsbarkeit vorgesehen sei“.43

Der alsbald dem Justizministerium eingereichte „Entwurf einer Ergänzungs- und Ausführungsbestimmung zu dem Gesetz vom 2. [sic] Dezember 1933“" zeigte in der Tat, daß Röhm und Luetgebrune keineswegs gesonnen waren, ihre ursprüngliche Konzeption saufzugeben. In der zugehörigen Begründung hieß es, das Dezember-Gesetz habe „mit Rücksicht auf die Aufgaben ... der Angehörigen der SA ein besonderes Standesrecht festgesetzt“, das „allen anderem Recht vorgeht“. Aus dieser Prämisse zog der Entwurf folgende Schlußfolgerung: „Bei einem Zusammentreffen von Verstößen gegen Zucht und Ordnung der SA-Angehörigen mit gleichzeitigen Verletzungen anderer Gesetzesbestimmungen muß die Verfolgung ... nach dem Standesrecht und durch die Standesgerichte geschehen." Es gehe nicht an, daß ein SA-Mann z. B. wegen eines Hausfriedensbruchs vom SA-Gericht und vom ordentlichen Gericht abgeurteilt werde. „Das Ansehen des Standesgerichts verlangt, daß es nicht gezwungen ist, womöglich auf eine milde Disziplinarstrafe zu erkennen und das ordentliche Gericht nachher in der Lage ist, eine viel empfindlichere Strafe auszusprechen." Vielmehr müsse das SA-Gericht „z. B. den Hausfriedensbruch nicht nur mit einer Arreststrafe, sondern auch mit der nach dem allgemeinen Gesetz vorgesehenen Gefängnisstrafe“ belegen können. „Eine solche Machtbefugnis stärkt das Ansehen des Standesgerichts, verbilligt und vereinfacht die Rechtspflege und übt eine viel nachhaltigere Wirkung auf die Parteigenossen und Standesgenossen aus." Entsprechend dieser in der Begründung ausgesprochenen Zielsetzung unterschied sich der neue Entwurf außer der Präambel und einigen geringfügigen Änderungen durch nichts von dem früher vorgelegten Entwurf eines Gesetzes über die SA-Gerichtsordnung. ${ }^{44}$

Um die Angelegenheit voranzubringen, übergaben Vertreter des Reichsjustizministeriums und des Reichsinnenministeriums auf einer Besprechung am 1. Februar 1934 Luetgebrune den in Fricks Ministerium ausgearbeiteten Entwurf einer Dienststrafordnung für die SA, der sich im Rahmen der Ermächtigung des Gesetzes vom 1. Dezember 1933 hielt. Luetgebrune äußerte ,grundsätzliche Bedenken dagegen, daß die Strafgerichtsordnung als eine Disziplinarordnung, nicht als kriminelle Strafgerichtsordnung ausgestaltet sei. Die sich hieraus ergebende Folge, daß die Zuständigkeit der ordentlichen Gerichte für die von SA-Angehörigen begangenen strafbaren Handlungen unberührt bleibe, sei für die SA untragbar" (!). Die Vertreter des Justizministeriums erwiderten, daß sich die SA-Strafgerichtsordnung nach der Erklärung Hitlers im Rahmen des Dezember-Gesetzes halten müsse und daß dieses Gesetz eben keine „genü-

\footnotetext{
42 Telefon. Mitteil. Hoches an das RJM v. 26.1.34 (a.a.O.).

43 Verm. v. 27.1.34 (a.a.O.).

44 Entw. u. Begründung in den Akten des RJM (a.a.O.).
} 
gende Rechtsgrundlage für einen Eingriff in die Zuständigkeit der allgemeinen Gerichte darstelle“. Falls daher das Reichsjustizministerium an einem Entwurf ,in der von Herrn Reichsminister Röhm gewünschten Form“ mitwirken solle, bedürfe es eines entsprechenden neuen Auftrags an das Ministerium. Es müsse aber Röhm „überlassen bleiben, deswegen die nötigen Schritte zu tun" ${ }^{45}$

Nachdem er bei Röhm Bericht erstattet hatte, reagierte Luetgebrune am 12. Februar mit einem an Gürtner gerichteten Schreiben. Der Entwurf des Innenministeriums komme „für die SA auf keinen Fall in Betracht" und sei „für die SA so unannehmbar, daß die Oberste SA-Führung lieber auf die Einrichtung einer SA-Gerichtsbarkeit überhaupt verzichtet und die Angelegenheit der weiteren Entwicklung überläßt“. Wesentliche Teile dieses Entwurfes seien „gänzlich überflüssig“, da alle darin enthaltenen Vorschriften durch die geltende „Allgemeine Dienstordnung“ der SA bereits zweckentsprechend und endgültig geregelt seien. Es gehe allein noch um eine Dienststrafgerichtsordnung für die Ahndung von schweren Verstößen gegen die Disziplin; hierfür halte die Oberste SA-Führung ihren zuletzt eingereichten Entwurf als „das allein angängige“. Die dort vorgeschlagene Regelung der Fälle von Konkurrenz dieser Art Verstöße mit strafgesetzlichen Übertretungen und Vergehen könne durch eine Verordnung zur Ergänzung des Gesetzes vom 1. Dezember 1933 durchaus verwirklicht werden; auch namhafte Rechtswissenschaftler wie Geheimrat Oetker (Würzburg) und Professor Schoetensack (Tübingen) würden diese Frage bejahen. Sollte aber für die Konkurrenzfälle keine gesetzliche Generalregelung realisiert werden können, „müßte für diese Fälle das Vorrecht bei der SA-Gerichtsbarkeit liegen und der Staatsanwaltschaft durch die Verordnung die generelle Anweisung der Einstellung eines bürgerlichen Strafverfahrens nach $\S 153$ StPO aufgegeben werden". 46

Die Hartnäckigkeit der SA-Führung in dieser Frage - trotz Hitlers grundsätzlicher Entscheidung in der Denkschrift vom September und des präjudizierenden Gesetzes vom Dezember 1933 - ist wohl dadurch zu erklären, daß Hitler, der in jenen Monaten die Dinge in einer Art Schaukelpolitik zwischen der SA und den konservativen Kräften treiben ließ, Röhm persönlich auch in der Frage der SA-Gerichtsbarkeit keine eindeutige Absage erteilte, ihn vielmehr auf einen späteren Zeitpunkt vertröstete. Nur so ist auch der Passus in Röhms Verfügung vom 2. März $1934^{47}$ zu erklären, daß der Entwurf der Dienststrafgerichtsordnung ,aus politischen Gründen“ erst später in Kraft treten könne, so auch seine durch Luetgebrune übermittelte Drohung, daß er lieber „die Angelegenheit der weiteren Entwicklung“ überlassen wolle, als eine für ihn ungenügende Lösung zu akzeptieren.

Daß Hitler eine SA-Strafgerichtsbarkeit im Sinne Röhms nicht wollte, hatte er auch Hans Frank zu verstehen gegeben. Frank erläuterte seinen über diese Frage beunruhigten bayerischen Oberlandesgerichtspräsidenten und Generalstaatsanwälten am 6. April 1934, bei der Einführung der SA-Gerichtsbarkeit hapere es

„an einem wesentlichen Punkte. Der Führer selbst will nicht. Er hat auf meine ihm früher unterbreiteten Vorschläge erklärt, daß er niemals wünschen werde, daß die SA.- oder SS.-Gerichtsbarkeit Delikte zur Aburteilung bekommen solle, die im allgemeinen Strafgesetzbuch enthalten seien. Das ist für uns schon sehr wichtig. Meuterei und dergleichen Sachen soll ruhig die SA.-Ge-

45 Verm. v. 8.2.34 über die Bespr. (a.a.O.).

46 Schr. Luetgebrunes an Gürtner v. 12.2.34 (a.a.O.). Zum §153 StPO vgl. Anm. 54.

47 Akten des RJM (a.a.O.). Zum Inhalt der Verf. v. 2.3.34 vgl. Kapitel IV.4.c., S. 401 f., u. dortige Anm. 92. 
richtsbarkeit bekommen... Es wird also auch in einer irgendwann einmal kommenden SA.-Gerichtsbarkeit dem Willen des Führers entsprechend, niemals eine Einengung der allgemeinen Zuständigkeit der Gerichte kommen. Um diesen Punkt ging lange der Streit. Voraussichtlich wird eine Gerichtsbarkeit zusammengestellt, die den Abschnitt 6 der Militärgerichtsbarkeit [gemeint: des Militärstrafgesetzbuches] auf die SA überträgt. Damit kann sich die Justiz und mithin Reichsjustizminister Gürtner und ich als Reichsjustizkommissar und als Reichsleiter der NSDAP einverstanden erklären." ${ }^{48}$

Gewiß war für die Tatsache, daß die Exemtion der SA-Angehörigen von der ordentlichen Strafjustiz unterblieb, letztlich Hitlers Entscheidung maßgebend. Dennoch ist dafür auch die Gegenwirkung der Ressorts Justiz und Inneres von Bedeutung gewesen. Das Motiv für die Opposition der Justizleitung in dieser Frage darf keineswegs nur im Ressortegoismus - in der bloßen Bewahrung von Zuständigkeit - gesehen werden; den führenden Juristen stand nur zu deutlich vor Augen, was es für den Bestand der Rechtsordnung bedeutet hätte, wenn die aggressiven Energien des braunen Millionenheeres durch die ordentliche Strafgerichtsbarkeit nicht mehr eingedämmt gewesen wären. Dieser Damm war ohnehin nicht mehr undurchlässig: zahlreiche Amnestien und Niederschlagungen, vor allem aber die Obstruktion der verschiedensten Kräfte der Bewegung gegen die Durchführung zahlreicher gerichtlicher Strafverfahren hatten ihn durchlöchert. Nach einer Übersicht, die Luetgebrune Gürtner am 11. Mai 1934 übergab und die aufgrund der Meldungen zusammengestellt worden war, die Röhm in seiner Verfügung vom 2. März von den SA-Gruppen angefordert hatte, lagen gegen Angehörige von Röhms Organisation 4037 „unerledigte“ Strafverfahren vor, davon 3373 gegen SA- und 664 gegen SS-Mitglieder. ${ }^{49}$ Wie sich die SA-Führung die Erledigung dieser Verfahren vorstellte, nachdem sich die Realisierung einer eigenen Gerichtsbarkeit „aus politischen Gründen“ verzögerte, geht aus einem Schreiben Luetgebrunes an Röhm hervor: Eine Wiederaufnahme der Strafsachen durch die ordentlichen Strafverfolgungsbehörden zum Zwecke der Aburteilung verbiete sich grundsätzlich; andernfalls würde plötzlich eine solche Fülle von Prozessen gegen SA-Angehörige anfallen, daß zwangsläufig „ein Prestige-Verlust der SA als der Gewaltträgerin des neuen Staates" eintreten müsse. Darüber hinaus seien auch Anzeichen dafür vorhanden, daß in der Mehrzahl der Fälle eine Verhandlung vor den Strafgerichten durch SA-Angehörige „mit Gewalt verhindert" werden und damit „der Rechtspflege des neuen Staates" Abbruch getan würde. Deshalb seien zunächst die Strafsachen, in denen das Hauptverfahren noch nicht eröffnet sei, daraufhin zu prüfen, ob sie „nicht mangels Beweises oder nicht mangels des Bewußtseins der Rechtswidrigkeit einfach eingestellt werden“ könnten. Sei das Hauptverfahren schon eröffnet, müsse geprüft

48 Bespr. der bayer. Justizverwaltung mit den OLGPräs. u. GStAen am 5./6.4.34 (Akten des bayer. JM, BayHStArch. Abt. II, MJu 16 997). Zu „Abschnitt 6“ des MilStGB vgl. Anm. 13. Auch der bayer. Reichsstatthalter v. Epp lehnte als Verfechter der Staatsautorität eine SA-Strafgerichtsbarkeit ab: „Der Gedanke einer Sondergerichtsbarkeit für bestimmte Volksteile widerspricht dem nationalsozialistischen Grundsatz der Volksgemeinschaft. Er bedeutet auch eine Vertrauensminderung für die Tätigkeit der ordentlichen Gerichte. Die Mitgliederlabilität einer so großen Organisation wie es die SA ist wird der Feststellung, wer diesen Sondergerichten zu einem bestimmten Zeitpunkt untersteht, häufig Schwierigkeiten machen. Die Schaffung einer Sondergerichtsbarkeit der SA und SS wird auch ... erhebliche finanzielle Aufwendungen notwendig machen“ (undat. Notiz für die Ministerratsbespr., nach dem 9.4.34, GehStArch. München, Sign. Reichsstatthalter 446).

49 Statistik in den Akten des RJM (Arch. des IfZ, Sign. MA 108). An der Spitze lag die SA-Gruppe Niederrhein mit 732, bei der SS die Gruppe West (Düsseldorf) mit 124 Verfahren. 
werden, ob die Strafsache „nicht etwa gemäß $§ 153$ StPO wegen Geringfügigkeit der Sache und der zu erwartenden Strafe auf Anregung der Staatsanwaltschaft oder mit ihrer Zustimmung durch Gerichtsbeschluß “ einzustellen sei. „Die dann noch übriggebliebenen Strafsachen" sollten hinsichtlich der Möglichkeit einer Niederschlagung überprüft werden. Um die Niederschlagung durch die zuständigen Stellen zu erreichen, sei allerdings notwendig, daß „die SA-Angehörigen, die nach dem Sachverhalt in diesen Fällen strafwürdig sind, von der SA auf dem Dienstwege zuvor bestraft" würden. Auch ohne eine besondere Ergänzungs- oder Ausführungsverordnung für die SA biete hierzu das Reichsgesetz vom 1. Dezember 1933 die Rechtsgrundlage: nach ihm könne „im Dienstzuchtwege der SA-Angehörige mit Arrest von unbeschränkter Dauer (Konzentrationslager) bestraft werden“. ${ }^{50}$ Mit dieser Auslegung des DezemberGesetzes maßte sich die SA-Führung - sozusagen durch die Hintertür - wiederum eine eigene Verfolgung strafbarer Handlungen ihrer Angehörigen an und brachte überdies eine gefährliche Vermengung von Straf- und Schutzhaft ins Spiel.

War die Einführung der SA-Sondergerichtsbarkeit bis zum Frühjahr 1934 auch verhindert worden, so hielt die Justiz diese Gefahr für noch keineswegs endgültig gebannt, solange Röhm und die SA im NS-Herrschaftssystem einen Machtfaktor darstellten. In der erwähnten Besprechung mit den Chefs der bayerischen Justizbehörden hatte Frank die Absicht geäußert, vom Reichsjustizminister über die Einführung oder Nichteinführung der SA-Gerichtsbarkeit nunmehr eine ,autoritäre [wohl: autoritative] Stellungnahme zu verlangen“, damit die - durch diese Unsicherheit verursachte „stark spürbare Hemmung des autoritären staatsanwaltschaftlichen Vorgehens beseitigt" werde. ${ }^{51}$ Im Entwurf der Richtlinien an alle Landesjustizverwaltungen, den Gürtner daraufhin im Mai für die Behandlung der Strafsachen gegen SA-Angehörige ausarbeiten und auch Frick vorlegen ließ, hieß es jedoch darüber bemerkenswert vorsichtig: das Justizministerium halte das Ruhen dieser Verfahren mit einer geordneten Rechtspflege nicht für vereinbar, „da eine SA-Strafgerichtsbarkeit bisher nicht eingerichtet und auch nicht abzusehen ist, ob oder wann [?] sie geschaffen werden wird“" ${ }^{52} \mathrm{Mag}$ diese vorsichtige Formulierung mit darauf zurückzuführen sein, daß der Entwurf auch Röhm zur Prüfung zuging, so zeigt sie doch deutlich die Unsicherheit, die das Reichsjustizministerium in dieser Frage beherrschte. Ende Mai suchte Gürtner den Chef der Reichskanzlei auf und bat ihn, erneut Hitlers Auffassung zu dieser Angelegenheit zu erforschen. Nach Lammers' Vortrag sprach sich der abwartende Hitler dahingehend aus, „daß er die Frage vorerst nicht näher behandelt zu wissen wünsche“, aber seinen früheren, Gürtner gegenüber geäußerten „Standpunkt über Art und Umfang der SAGerichtsbarkeit nicht geändert habe“. ${ }^{52 a}$ Die Unsicherheit des Reichsjustizministeriums war mit der Ausschaltung Röhms am 30. Juni 1934 sofort beseitigt: als die Richtlinien in der Fassung der Allgemeinverfügung vom 20. Juli 1934 im Amtsblatt der Justiz veröffentlicht wurden, lautete der entsprechende Satz nunmehr eindeutig:

50 Schr. Luetgebrunes an Röhm v. 21.2.34 (DC Berlin, Sign. Sammlung Schumacher 406).

51 Vgl. Anm. 48.

s2 Entw. u. Begleitschr. v. Gürtner am 16.5.34 paraphiert, von Frick am 17.5.34 abgezeichnet; hervorgehobene Worte handschriftl. eingefügt (Akten des RJM, a.a.O.).

52a Verm. Lammers' v. 31.5.34 in den Akten der RK (BA, Sign. R 43 II/1505); dort auch das Schr. Gürtners v. 25.5.34 mit der Bitte um eine Unterredung mit Lammers, die am 29. 5. stattfand. 
„Eine SA-Strafgerichtsbarkeit besteht nicht und ist auch nicht in Aussicht genommen." ${ }^{\text {"S3 }}$

Auch die Bestimmungen in dieser Allgemeinverfügung, die die Behandlung der Strafverfahren gegen SA-Angehörige nunmehr reichseinheitlich regelten und durch deren Anwendung jener seit Monaten anstehende Berg von Verfahren abgetragen werden sollte, hatten nach dem 30. Juni einige Änderungen erfahren. Die Vorschriften besagten, daß jene Verfahren - besonders wenn es sich „um Vorkommnisse aus einer weiter zurückliegenden Zeit" handelte - eingestellt werden sollten, in denen sich keine tatsächlichen Anhaltspunkte für eine gerichtlich verfolgbare Handlung mehr ergäben oder „die Beweisführung scheitern“ werde. Die Staatsanwaltschaft sollte auch $\S 153 \mathrm{StPO}^{54}$ in „sachgemäßer Auslegung“ anwenden. In diesem Zusammenhang war ein auf den Vorschlag Luetgebrunes zurückgehender ${ }^{55}$ Passus des ursprünglichen Entwurfs weggefallen, daß die Schuld des Täters im Sinne dieses Paragraphen dann als gering anzusehen sei, wenn ,der Täter von den zuständigen SA-Stellen wegen der Tat bereits im Wege der Dienstzucht ... eine erhebliche Bestrafung erfahren“ habe. Gegen diese Bestimmung hatte auch schon Staatssekretär Pfundtner im Namen des Reichsinnenministeriums opponiert, da sie „politisch nicht unbedenklich“ sei und eine derartige Ausweitung des $\S 153$ StPO „die Abdankung einer geordneten Strafrechtspflege “ bedeute. ${ }^{56}$ Die Allgemeinverfügung folgte seinem Vorschlag, daß derartige Fälle, in denen „das Sühnebedürfnis der Volksgemeinschaft ein weiteres Einschreiten nicht mehr erfordert", durch Niederschlagung zu erledigen seien. Eine Niederschlagung sollte die Staatsanwaltschaft bei der zuständigen Landesjustizverwaltung auch in Fällen anregen, in denen die Voraussetzungen für eine Einstellung zwar nicht vorlägen, die Durchführung des Verfahrens - ,insbesondere bei Vorkommnissen aus den

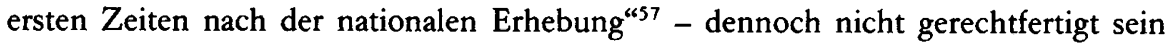
würde. Sei dagegen eine Einstellung oder Niederschlagung nicht zu verantworten, so sei „zur Wahrung der Rechtsordnung des Staates wie des Ansehens der SA. in der Volksgemeinschaft geboten, die Verfahren mit Nachdruck und Beschleunigung durchzuführen“. Im ursprünglichen Entwurf hatte es hier zusätzlich: „zur Erhaltung der Manneszucht in der SA“ geheißen - wohl als Hinweis an die SA-Führung, daß durchaus auch die Tätigkeit der ordentlichen Gerichte zur Aufrechterhaltung der Disziplin innerhalb dieser Organisation dienen konnte und sollte. In der Allgemeinverfügung wurde weiter vorgeschrieben, in allen einschlägigen Strafverfahren frühzeitig festzustellen, welcher Standarte oder sonstigen Gliederung der Beschuldigte angehörte. War die Verhaftung eines SA-Angehörigen erfolgt oder mit einer Freiheitsstrafe zu rechnen, hatte die Staatsanwaltschaft mit dem zuständigen SA-Führer Fühlung zu nehmen. In der vor der Röhm-Affäre konzipierten Fassung war diese Regelung noch mit "der Bedeutung der SA als eines Grundpfeilers des nationalsozialistischen Staates“ begründet worden. Dort war außerdem vorgesehen gewesen, daß „dem Rechtsberater der SA-Standarte des Beschuldigten von der Einleitung des Strafverfahrens Mittei-

53 AV des RJM betr. Strafverfahren gegen SA-Angehörige v. 20.7.34 (DJ 1934, S. 926).

$54 \$ 153$ StPO betraf die Nichtverfolgung bzw. Einstellung des Verfahrens bei Übertretungen bzw. Vergehen, "wenn die Schuld des Täters gering ist und die Folgen der Tat unbedeutend sind“.

ss Vgl. Anm. 46.

${ }_{56}$ Schr. des RMdI (I.V. Pfundtner) an das RJM v. 30.5.34 (Akten des RJM, Arch. des IfZ, Sign. MA 108).

57 Im Entwurf vor dem 30. Juni 1934: „der nationalen Revolution“. 
lung“ zu machen und „erbetene weitere Nachrichten über den Gang des Verfahrens“ zu geben seien. An die Stelle dieser Anordnung, die den SA-Stellen eine größere Einwirkungsmöglichkeit in den jeweiligen Stadien des Verfahrens gegeben hätte, war nunmehr die Bestimmung getreten, daß nur noch die Eröffnung der Hauptverhandlung und das rechtskräftige Urteil mitzuteilen waren - und zwar ausschließlich dem jeweiligen Gruppenführer und der zuständigen Gaurechtsstelle, d.h. der Rechtsstelle bei der Gauleitung der NSDAP.

Wie empfindlich das Reichsjustizministerium in diesen Fragen auf jede Regung Hitlers reagierte, zeigt ein Ereignis, das sich unmittelbar nach dem Erlaß der Verfügung abspielte. Während der Bayreuther Festspiele 1934 beschwerte sich der neue Stabschef der SA Lutze bei Hitler, daß die Justiz gegen einige alte Kämpfer in der SA Strafverfahren durchführe, darunter auch gegen solche, die er ,in der SA zu behalten wünsche“. Hitler ließ am 28. Juli aus Bayreuth durch Lammers im Reichsjustizministerium anrufen und mitteilen, daß ihm dieses Vorgehen nicht erwünscht sei und daß „wegen Vorkommnissen, die vor dem 15. Juli 1934 lägen, tunlichst von einem Verfahren abgesehen werden möchte“. Da eine allgemeine Amnestie nicht beabsichtigt sei, solle sich das Ministerium ,überlegen, wie den Wünschen Rechnung getragen werden könne“. Der dienstälteste Ministerialdirektor Richter, der seine auf Sommerurlaub befindlichen Vorgesetzten Gürtner und Schlegelberger vertrat, und Ministerialrat Mettgenberg wiesen Lammers auf die Richtlinien hin, die bereits durch die Allgemeinverfügung vom 20. Juli herausgegeben worden seien. Als sich herausstellte, daß diese Verfügung in Bayreuth nicht bekannt war, und Mettgenberg Lammers deren Inhalt erläuterte, meinte der Chef der Reichskanzlei, daß sich Hitlers und Lutzes Wünsche mit der Verfügung ,sehr wohl würden vereinbaren lassen“. Im Ministerium wurde daraufhin beschlossen, „die sämtlichen schwebenden Verfahren gegen SA-Angehörige im Reichsjustizministerium einer Durchprüfung und Sichtung zu unterwerfen“; die dafür erforderlichen Hilfskräfte sollten vom Ministerium einberufen werden. Der in Feldberg im Schwarzwald weilende Schlegelberger gab telefonisch sein Einverständnis und bat, daß Ministerpräsident Göring und Staatssekretär Freisler im preußischen Justizministerium davon unterrichtet werden sollten. Freisler, der sich zum Urlaub in Sylt aufhielt, äußerte jedoch den Wunsch, daß die preußischen Fälle in seinem Ministerium gesichtet würden, und begründete das damit, daß sein Haus „bereits über den erforderlichen Beamtenstab verfüge" ${ }^{58}$ Am 29. Juli sandte Richter den Entwurf eines an die Landesjustizverwaltungen gerichteten Rundschreibens nach Bayreuth, wonach die Staatsanwaltschaften „unverzüglich ohne Rücksicht auf den Stand des Verfahrens die Akten über alle schwebenden Strafsachen gegen SA- und SS-Angehörige der Landesjustizverwaltung vorlegen" sollten, soweit nicht eine Einstellung des Verfahrens erwogen werde. Die Landesjustizverwaltungen wiederum sollten die Akten schnellstens an das Reichsjustizministerium schicken, damit dort alle Fälle, in denen die Durchführung oder die Niederschlagung des Verfahrens beabsichtigt sei, geprüft werden könnten, „um eine einheitliche und sachgemäße Behandlung“ zu erreichen. Nur für PreuBen wurde eine Regelung vorbehalten, auf welche Weise eine Prüfung der im preußischen Justizministerium gesammelten Akten erfolgen sollte. Wie Richter in seinem Begleitschreiben an Lammers erläuterte, gäbe „die Zusammenziehung der Sachen in

s8 Verm. v. 28.7.34 in den Akten des RJM (a.a.O.). 
Berlin die Möglichkeit, die Fälle mit den beteiligten SA- und SS-Stellen zu erörtern, gegebenenfalls sie auch dem Führer selbst vorzutragen“.59 Am Abend des 1. August meldete sich Lammers abermals telefonisch; er habe Lutze den Entwurf übermittelt, und dieser werde demnächst Gegenvorschläge vorlegen. Mit einemmal war die Angelegenheit nicht mehr brandeilig: es stellte sich heraus, daß es Lutze mit seiner Intervention bei Hitler vordringlich um die Freilassung und Außerverfolgungsetzung des inhaftierten SA-Gruppenführers Freiherr von Schorlemer gegangen war, den in Bremen ein Gerichtsverfahren erwartete. ${ }^{60} \mathrm{Ob}$ die in Richters überstürzt verfaßtem Entwurf vorgesehenen Maßnahmen jemals verwirklicht wurden, geht aus den Akten nicht hervor. Wahrscheinlich sind sie durch die nach Hindenburgs Tod erlassene Amnestie vom 7. August 1934 überflüssig geworden. ${ }^{61}$

59 Schr. Richters an Lammers v. 29.7.34 nebst Entwurf eines RdSchr. an die LandesJVerw. (a.a.O.).

${ }^{60}$ Verm. v. 2.8.34 (a.a.O.). Gürtner lud die Leiter der Bremer JVerw. für den 3.8.34 ins RJM ein, um die Angelegenheit v. Schorlemer zu erörtern. Schorlemer wurde zunächst gegen Sicherheiten aus der Haft entlassen (Diensttageb. des RJM, Bd. 5, Eintr. v. 14.9.35, BA, Sign. R 22/1088).

61 Seit der im Zuge der Verreichlichung erlassenen AV des RJM betr. Vereinheitlichung der StAschaft v. 18.12.34 (DJ, S. 1608) hatten die Vorstände der StAschaften im Reich dem RJM sowieso alle für die Staatsführung wichtige oder weitere Kreise beschäftigende oder „zur Erteilung von Weisungen Anlaß“ bietende Strafsachen zu berichten. 